\title{
FAN IDENTITY AND IDENTIFICATION DRIVERS - STOKING THE FLAMES OF THE PHOENIX
}

By

Markus Rühl

A thesis submitted to the Victoria University of Wellington in partial fulfilment of the requirements for the degree of Master of Management Studies

Victoria University of Wellington

2010 


\begin{abstract}
Fans are of highest importance for the financial success of sports clubs (van Leeuwen, Quick, \& Daniel, 2002). However, the nature of fandom and the meaning that fans place upon their relationship with a sports club varies and different degrees of fandom exist (Wann \& Branscombe, 1990). Whilst much research has been done on the assessment of fan identification, little work has contributed to its practical application. For example, for sport marketers to actively strengthen their fan base, more than a mere assessment of the identification level of their fans is necessary.

It is suggested that knowledge about the underlying identification drivers of fans with different identification levels is needed to inform any managerial action.

This research aims to enhance understanding about the relationship between the level of fan identification and the drivers of identification, and it does so, via a study of New Zealand's only professional football club Wellington Phoenix FC.

A cross-sectional convenience sample of 517 Wellington Phoenix fans was surveyed using both online and researcher administered/respondent completed questionnaires. The Sports Spectator Identification Scale (Wann \& Branscombe, 1993) was used to measure fan identification, and participants were categorized into five identification levels.
\end{abstract}

Findings show that ten of 16 identification drivers are correlated with the identification level. Of particular interest are findings that indicate a mediating impact of the identification level on specific relationships. For instance, lowly identified fans place a higher relevance on the success of the team, whilst for highly identified fans, success is of lesser relevance. In contrast to that, the sense of belonging created by fellow fans is more important to those who are highly identified. Other drivers such as the general interest in football possess a nearly constant relevance throughout different identification levels.

A multivariate factor analysis revealed patterns among identification drivers that suggest fans can be categorized according functional, symbolic and interpersonal constructs that can be described as a live experience factor, an admiration factor and a social network factor. 
Based on these results, fan profiling was undertaken and various marketing implications were discussed. The insights attained allow researchers and marketing practitioners to better understand the relevance of different drivers on the development of fan identification, and to better understand how marketing strategies may promote such higher levels of identification. 


\section{ACKNOWLEDGEMENTS}

I would like to acknowledge all people involved in the creation of this thesis.

Special thanks go to Professor John Davies and Professor John Brocklesby who supported me with their proficient knowledge, enthusiasm, and time in this research. More importantly, both John Davies and John Brocklesby always expressed a high level of interest and care for this project.

I would also like to thank all participants for contributing their time and thoughts.

Lastly, I would like to thank the administrative team at Victoria Management School, particularly Sophia Lum and Megan Key, for their great support and guidance. 


\section{TABLE OF CONTENTS}

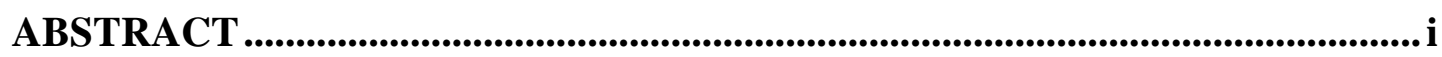

ACKNOWLEDGEMENTS.....................................................................................iii

TABLE OF CONTENTS................................................................................................. iv

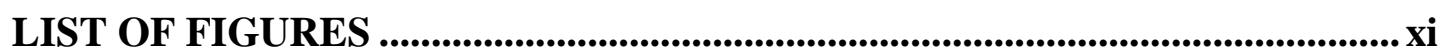

LIST OF TABLES

CHAPTER 1: INTRODUCTION.................................................................................. 1

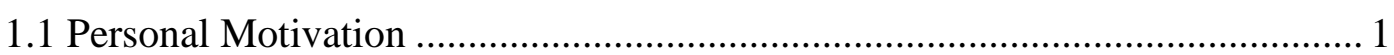

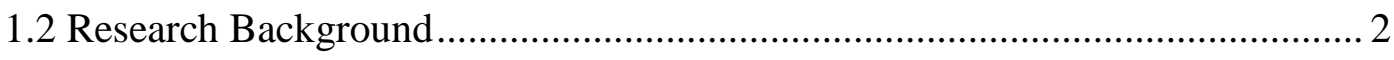

1.3 Research Objectives ................................................................................ 4

1.4 Research Scope

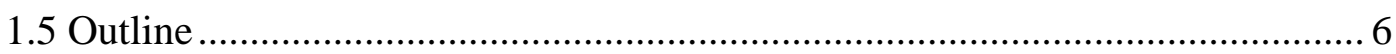

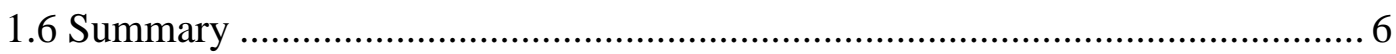

CHAPTER 2: LITERATURE REVIEW ............................................................ 7

2.1 The A-League and Wellington Phoenix FC ....................................................

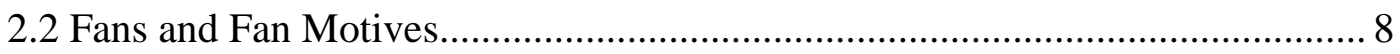

2.2.1 Motives of Attending Sports Events .................................................................. 8

2.2.2 Degrees of Fandom................................................................................. 10

2.2.3 Development of Fan Loyalty................................................................................ 11

2.2.4 Fan Loyalty in the Context of Franchise Teams................................................ 12

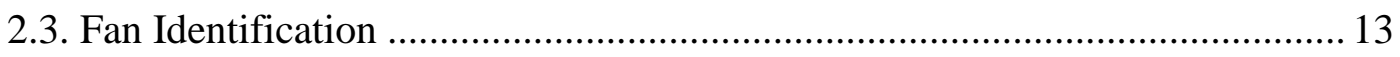

2.3.1 Personal Identity in Sports .................................................................................. 13

2.3.2 Social Identity in Sports............................................................................. 14

2.3.3 Image Management of Fans ………………………………………………… 16

2.3.4 Fan Identification Drivers …………………………………………….... 18

2.4. Fan Identification from a Sports Marketing Perspective.................................. 20 
2.4.1 The Value of Fan Identification for Sports Organizations .................................. 20

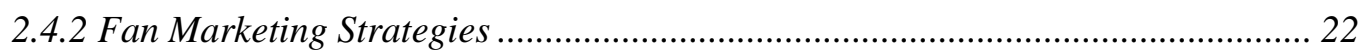

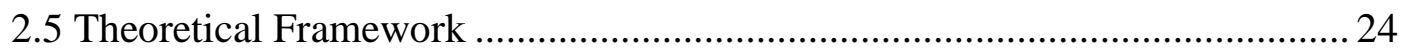

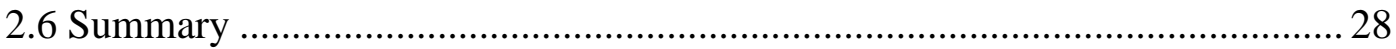

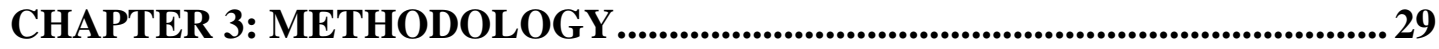

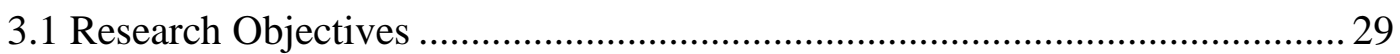

3.1.1 Overview of Sample Characteristics.................................................................... 29

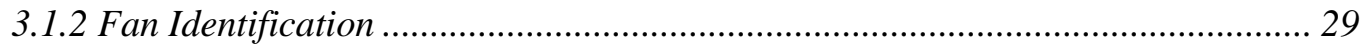

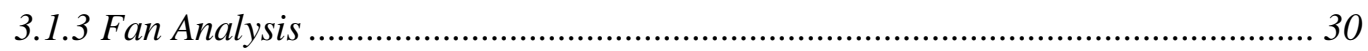

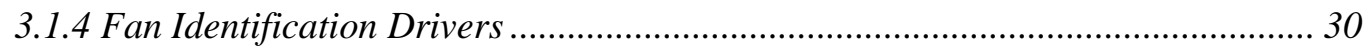

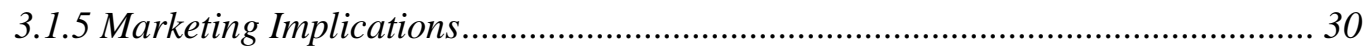

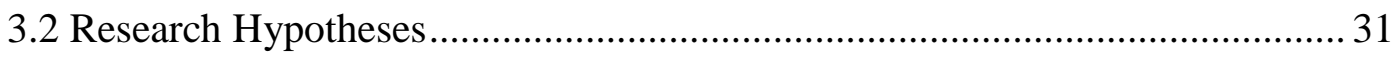

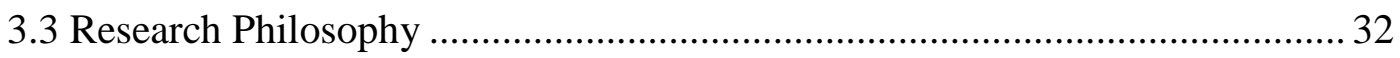

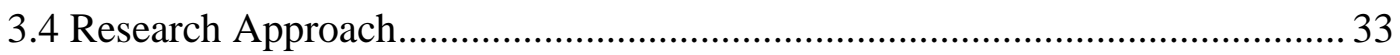

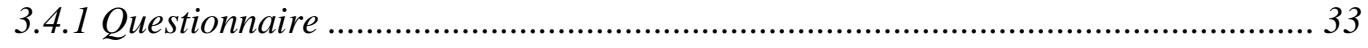

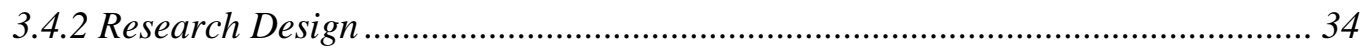

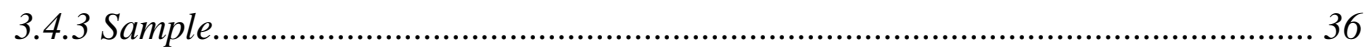

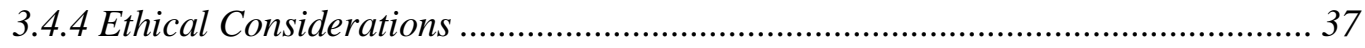

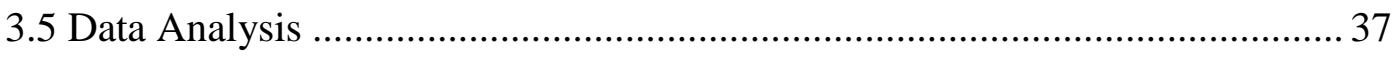

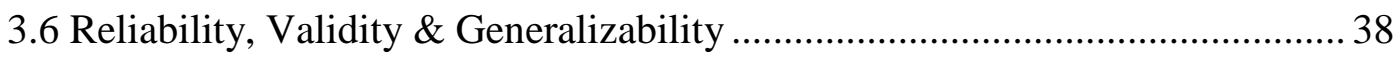

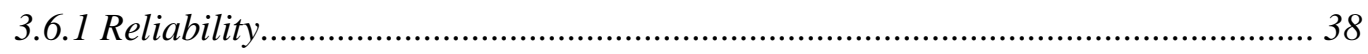

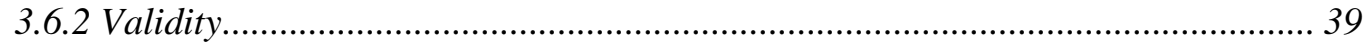

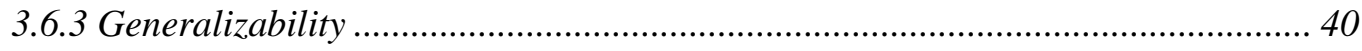

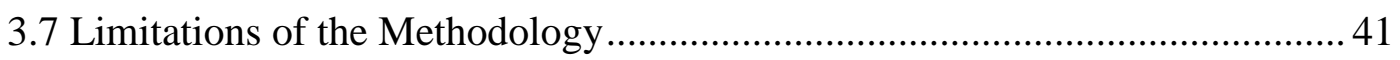

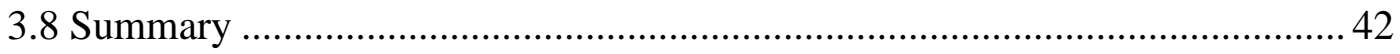

CHAPTER 4: DATA ANALYSIS AND RESULTS .................................................. 43

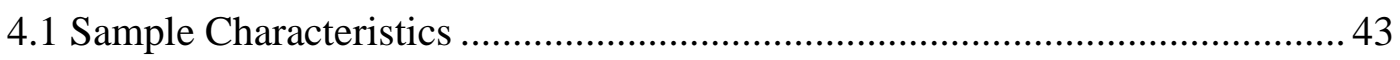

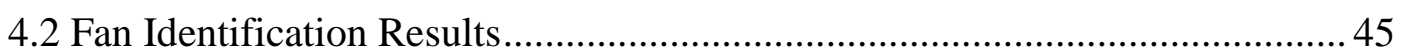




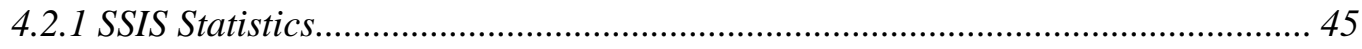

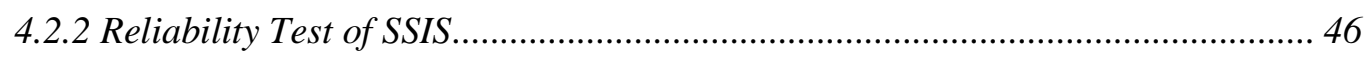

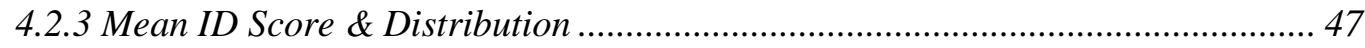

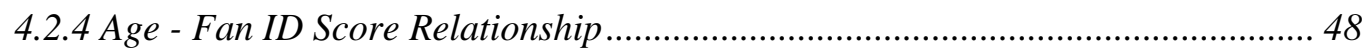

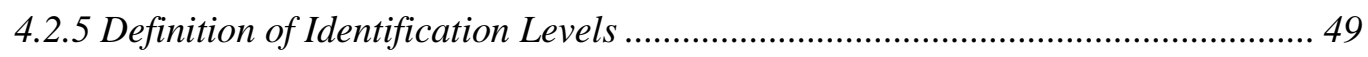

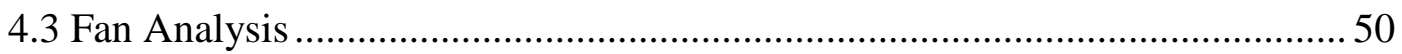

4.3.1 Gender - Fan ID Level Relationship.................................................................. 50

4.3.2 Age - Fan ID Level Relationship ................................................................... 51

4.3.3 Marital Status - Fan ID Level Relationship......................................................... 51

4.3.4 Fan Duration - Fan ID Level Relationship....................................................... 52

4.3.5 Spectator Type - Fan ID Level Relationship...................................................... 52

4.3.6 Preferred Spectator Medium - Fan ID Level Relationship.................................. 56

4.3.7 Form of Attendance - Fan ID Level Relationship.............................................. 56

4.3.8 Public Display of Allegiance - Fan ID Level Relationship.................................. 58

4.4 Analysis of Fan Identification Drivers .........................................................5

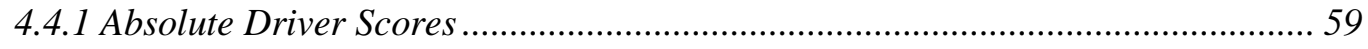

4.4.2 Structural Patterns of Identification Drivers..................................................... 61

4.4.3 Reliability Test of Driver Constructs ................................................................. 63

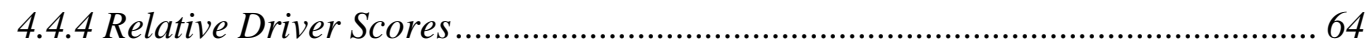

4.5 Relationship between Identification Drivers and Fan Identification................ 65

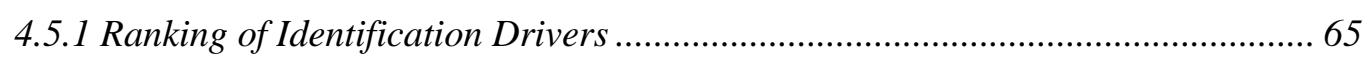

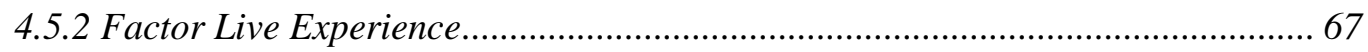

4.5.2.1 Driver Relationships with Fan ID Level.................................................. 67

4.5.2.2 Mean Relative Scores by Fan ID Levels................................................. 67

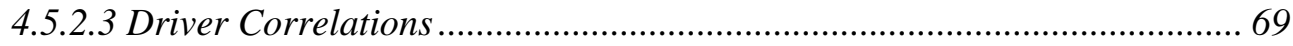

4.5.2.4 Regression Analysis for Factor Live Experience........................................ 70

4.5.2.5 Driver - Fan ID Matrix......................................................................... 71

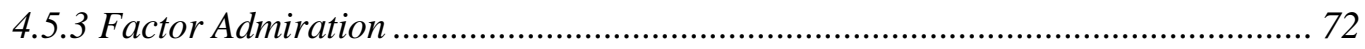

4.5.3.1 Driver Relationships with Fan ID Level..................................................... 73

4.5.3.2 Mean Relative Scores by Fan ID Levels..................................................... 73 


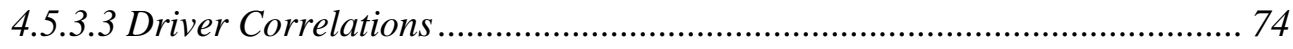

4.5.3.4 Regression Analysis for Factor Admiration ............................................... 75

4.5.3.5 Driver - Fan ID Matrix....................................................................... 75

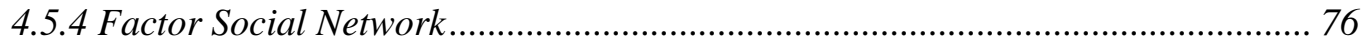

4.5.4.1 Driver Relationships with Fan ID Level.................................................... 76

4.5.4.2 Mean Relative Scores by Fan ID Levels.................................................... 77

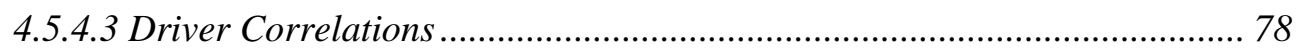

4.5.4.4 Regression Analysis for Factor Social Network .......................................... 79

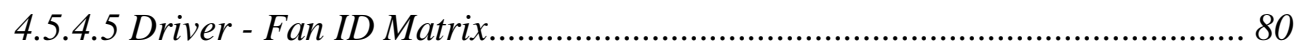

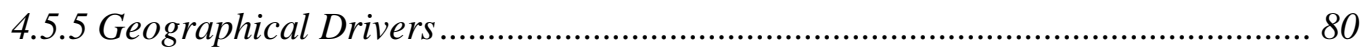

4.5.5.1 Driver Relationships with Fan ID Level............................................... 81

4.5.5.2 Mean Relative Scores by Fan ID Levels.................................................. 81

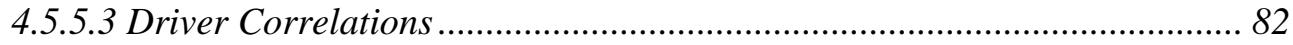

4.5.5.4 Regression Analysis for Geographical Drivers ......................................... 83

4.5.5.5 Driver - Fan ID Matrix........................................................................ 83

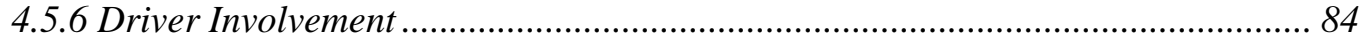

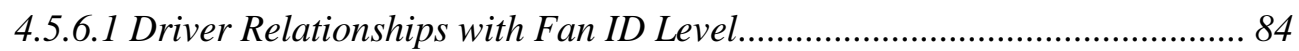

4.5.6.2 Mean Relative Scores by Fan ID Levels.................................................... 85

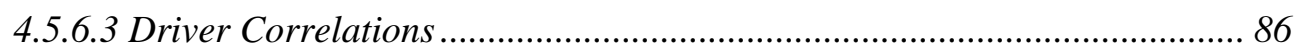

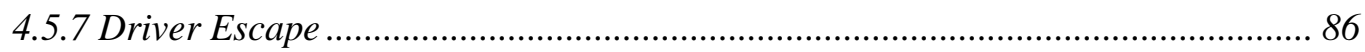

4.5.7.1 Driver Relationships with Fan ID Level.................................................. 86

4.5.7.2 Mean Relative Scores by Fan ID Levels................................................. 86

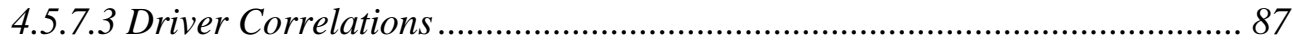

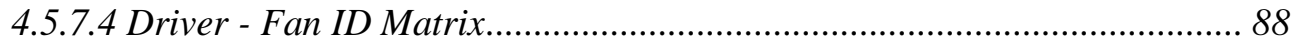

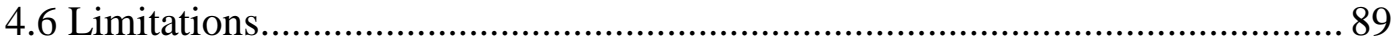

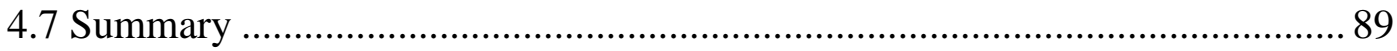

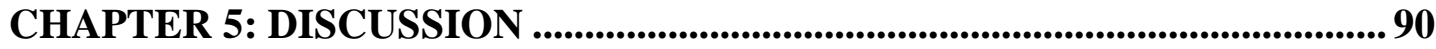

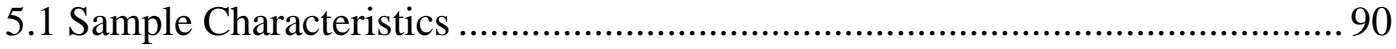

5.2 Fan Identification with Wellington Phoenix FC ........................................... 91

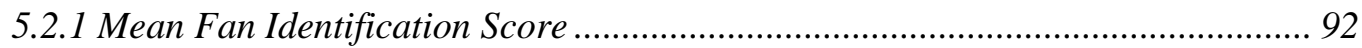

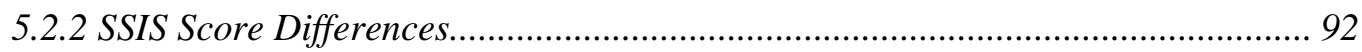

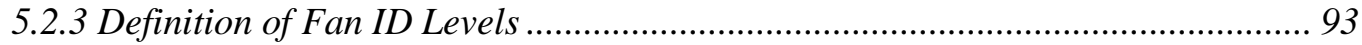

5.2.4 Demographic Characteristics and Fan Identification ......................................... 93 
5.3 Identification Drivers of Wellington Phoenix Fans ........................................ 94

5.3.1 Structural Patterns of Identification Drivers ..................................................... 94

5.3.2 Relative Importance of Identification Drivers .................................................. 97

5.4 Relationship between Identification Drivers and Fan Identification................ 99

5.4.1 Drivers of the Factor Social Network................................................................. 100

5.4.2 Drivers of the Factor Live Experience .............................................................. 101

5.4.3 Drivers of the Factor Admiration ...................................................................... 102

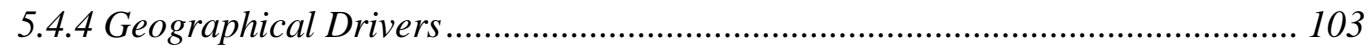

5.4.5 Drivers Involvement \& Escape ………….................................................... 104

5.4.6 Meaning of the Driver - Fan ID Matrix........................................................... 105

5.5 Marketing Implications for Wellington Phoenix FC................................... 106

5.5.1 Value of Fan Identification for Wellington Phoenix FC ..................................... 107

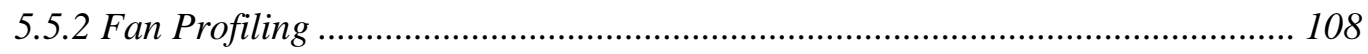

5.5.3 Implications for Fan Marketing ...................................................................... 109

5.5.3.1 Fan Marketing for Non-Fans ............................................................... 110

5.5.3.2 Fan Marketing for Lowly and Moderately Identified Fans ..................... 111

5.5.3.3 Fan Marketing for all Fans ................................................................. 112

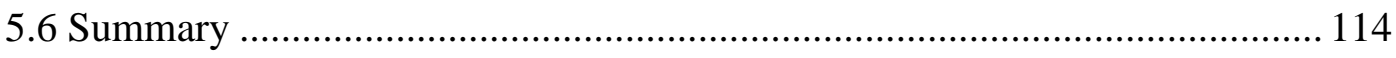

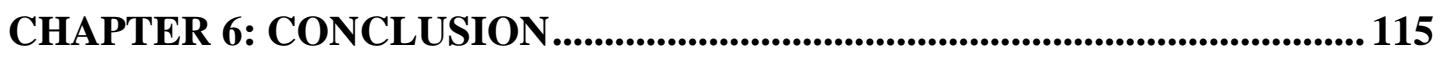

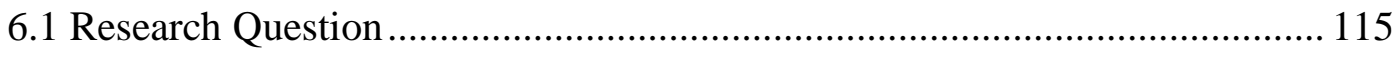

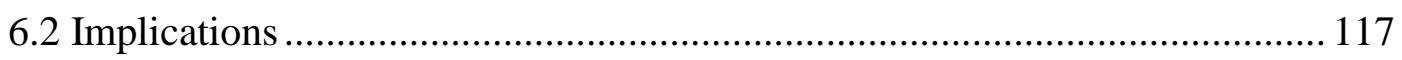

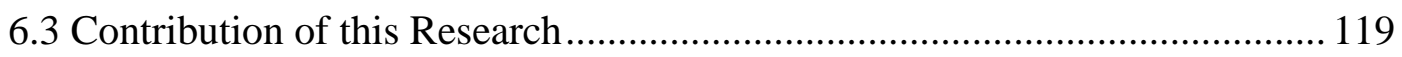

6.4 Opportunities for Further Research ...................................................... 119

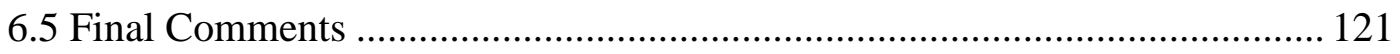

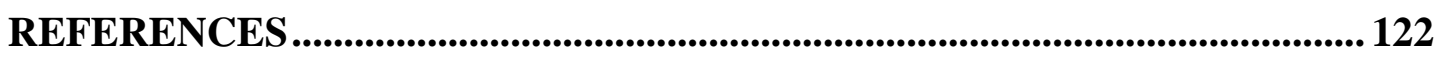

APPENDIX A: RESEARCH TOOLS................................................................... 129

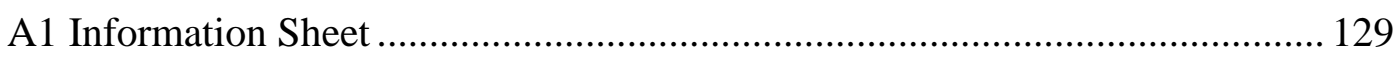

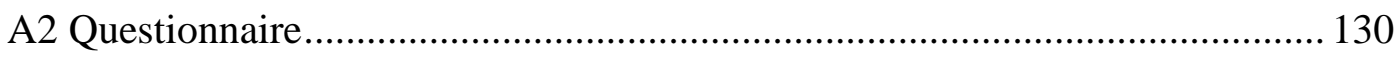




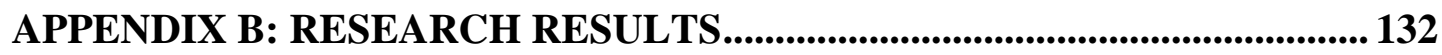

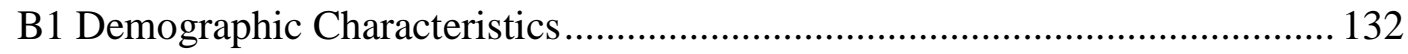

B1.1 Gender, Age, and Marital Status of the Participants ........................................ 132

B1.2 Active Engagement in Football ..................................................................... 132

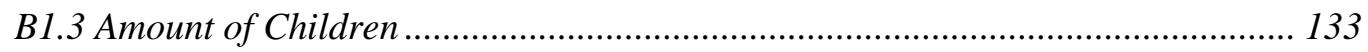

B1.4 Amount of Children that play football............................................................... 133

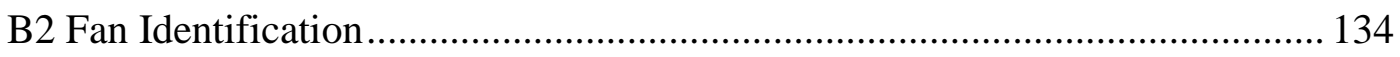

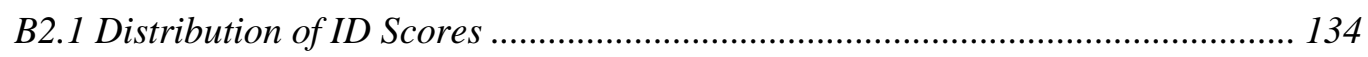

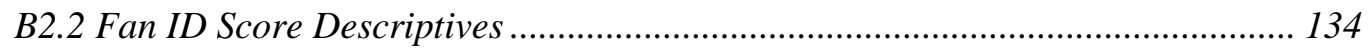

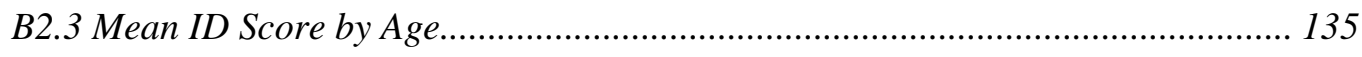

B2.4 Age * Fan ID Level Cross-tabulation ….......................................................... 135

B2.5 Gender * Fan ID Level Cross-tabulation....................................................... 136

B2.6 Marital Status * Fan ID Level Cross-tabulation........................................... 136

Chi-Square Tests (Marital Status - Fan ID Level)...................................................... 137

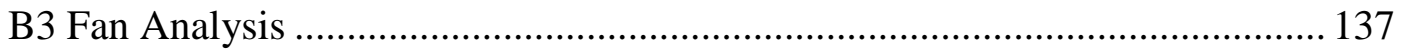

B3.1 Spectator Type * Fan ID Level Cross-tabulation........................................... 137

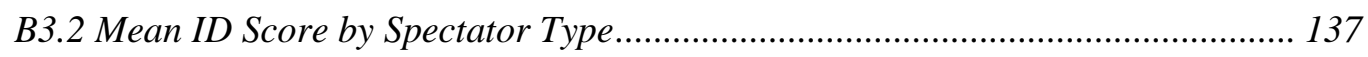

B3.3 Fan Duration * Fan ID Level Cross-tabulation.............................................. 138

B3.4a Number of Attendances by Spectator Type ...................................................... 138

B3.4b Number of Attendances by Fan ID Level ..................................................... 139

B3.5 Preferred Spectator Medium * Fan ID Level Cross-tabulation......................... 139

B3.6 Preferred Group Size * Fan ID Level Cross-tabulation ................................... 140

B3.7 Preferred Group Type * Fan ID Level Cross-tabulation.................................. 140

B3.8 Merchandise at Games * Fan ID Level Cross-tabulation................................. 141

B3.9 Merchandise outside of Games * Fan ID Level Cross-tabulation ...................... 141

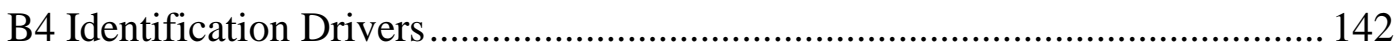

B4.1 Factor Analysis - Communalities ................................................................... 142

B4.2 Factor Analysis - Rotated Factor Matrix ……............................................... 143

B4.3 Factor Analysis - Total Variance Explained .................................................... 143 
B5 Relationship between Drivers and Fan ID .................................................. 144

B5.1 Mean Relative Driver Scores by Fan ID Level .............................................. 144

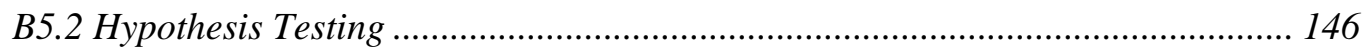

B5.3 Pearson Correlation Analyses.................................................................... 148

B5.4 Spearman's Rank Correlation Analyses............................................................ 151

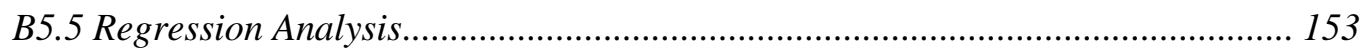




\section{LIST OF FIGURES}

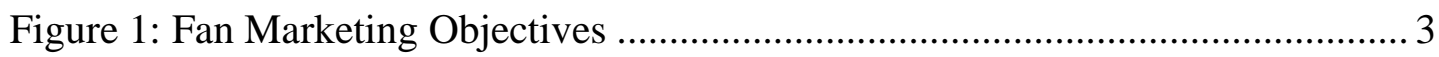

Figure 2: Conceptual Model of Fisher and Wakefield (1998) .................................. 24

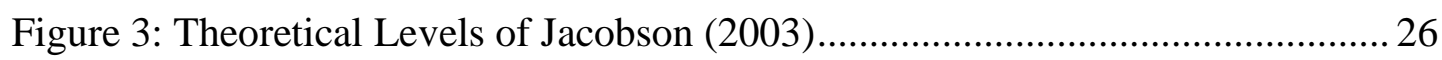

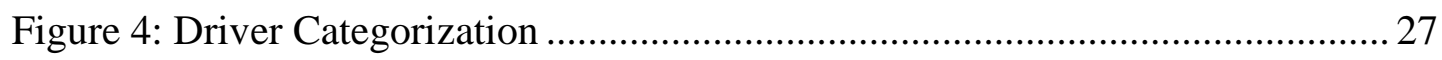

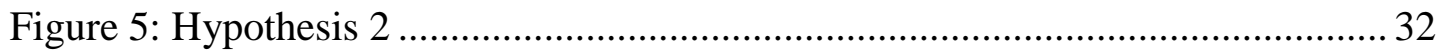

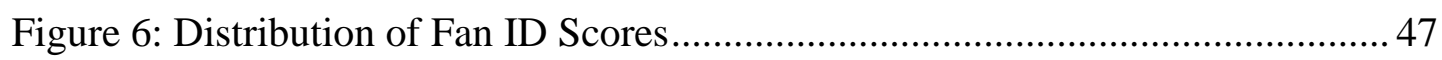

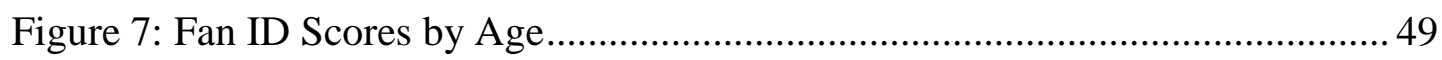

Figure 8: Fan ID Level Distribution by Gender ................................................. 51

Figure 9: Fan ID Scores by Spectator Type …..................................................... 54

Figure 10: Fan ID Level Ratio by Spectator Type .............................................. 55

Figure 11: Factor Live Experience: Mean Relative Driver Scores ........................... 68

Figure 12: Factor Live Experience: Driver - Fan ID Matrix ................................... 72

Figure 13: Factor Admiration: Mean Relative Driver Scores ................................. 73

Figure 14: Factor Admiration: Driver - Fan ID Matrix ........................................... 76

Figure 15: Factor Social Network: Mean Relative Driver Scores.............................. 77

Figure 16: Factor Social Network: Driver - Fan ID Matrix................................... 80

Figure 17: Geographical Drivers: Mean Relative Driver Scores ............................. 81

Figure 18: Geographical Drivers: Driver - Fan ID Matrix ..................................... 84

Figure 19: Driver Involvement: Mean Relative Driver Scores ............................... 85

Figure 20: Driver Escape: Mean Relative Driver Scores ....................................... 87

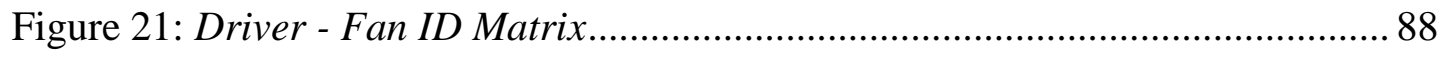


Figure 22: Structural Patterns of Identification Drivers........................................... 95

Figure 23: Discussion: Driver - Fan ID Matrix ................................................. 105

Figure 24: Implications for Fan Marketing ..................................................... 110

Figure 25: Conclusion: Driver - Fan ID Matrix ................................................ 116 


\section{LIST OF TABLES}

Table 1: Sport Spectator Motives of SFMS, MSC and MSSC ............................... 9

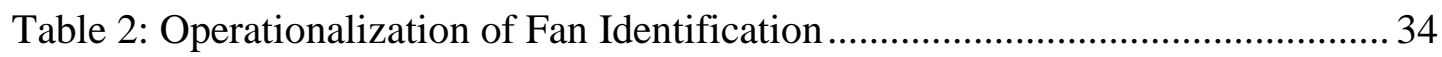

Table 3: Operationalization of Identification Drivers ................................................. 35

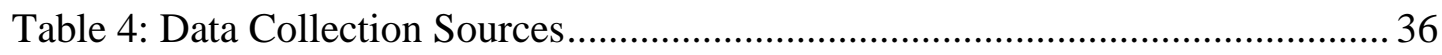

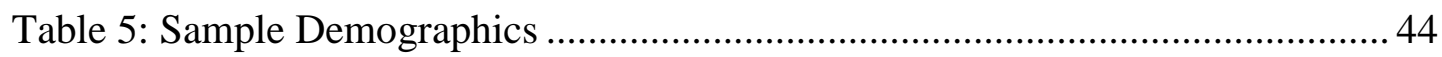

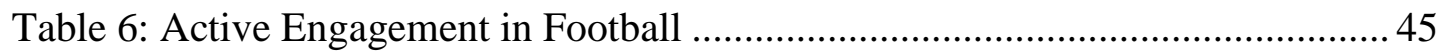

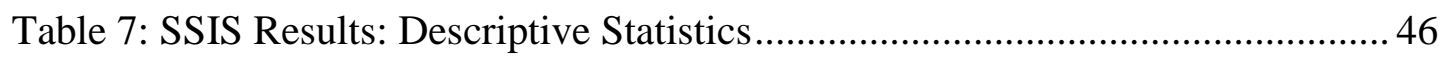

Table 8: Construct Fan Identification: Reliability Statistics ................................ 47

Table 9: Definition of Fan ID Levels ................................................................... 50

Table 10: Fan Duration * Fan ID Level Cross-tabulation ................................... 52

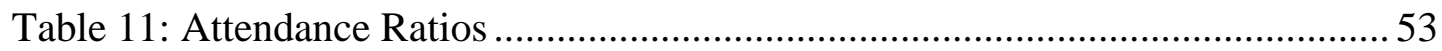

Table 12: Mean Attendances by Fan ID Level ...................................................... 55

Table 13: Preferred Spectator Medium * Fan ID Level Cross-tabulation ................. 56

Table 14: Preferred Group Size * Fan ID Level Cross-tabulation............................. 57

Table 15: Preferred Group Type * Fan ID Level Cross-tabulation ..........................5 57

Table 16: Merchandise at Games * Fan ID Level Cross-tabulation ......................... 58

Table 17: Merchandise outside of Games * Fan ID Level Cross-tabulation ..............59

Table 18: Mean Driver Scores: Descriptive Statistics ..............................................6 60

Table 19: Identification Drivers: KMO and Bartlett's Test of Sphericity .................61 61

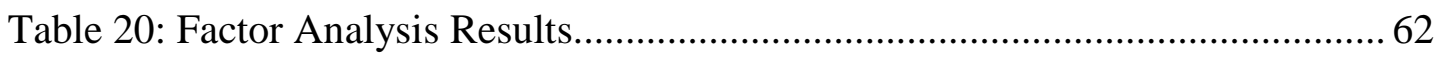

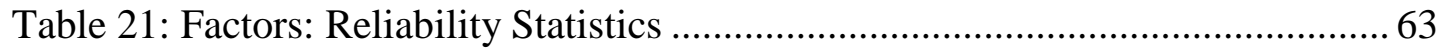

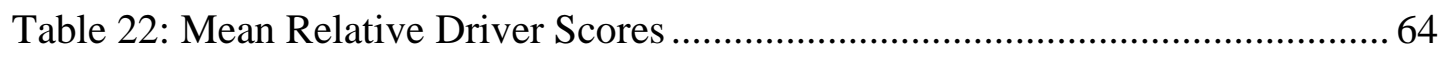




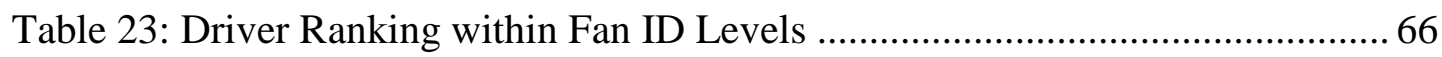

Table 24: Factor Live Experience: Pearson Correlation ......................................... 70

Table 25: Factor Live Experience: Regression Model Summary ............................ 71

Table 26: Factor Admiration: Pearson Correlation.................................................. 74

Table 27: Factor Admiration: Regression Model Summary ….............................. 75

Table 28: Factor Social Network: Pearson Correlation........................................... 78

Table 29: Factor Social Network: Regression Model Summary................................ 79

Table 30: Geographical Drivers: Pearson Correlation .......................................... 82

Table 31: Geographical Drivers: Regression Model Summary ............................... 83

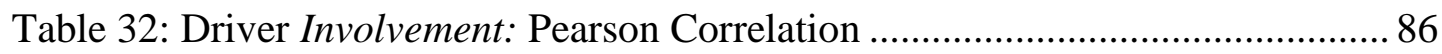

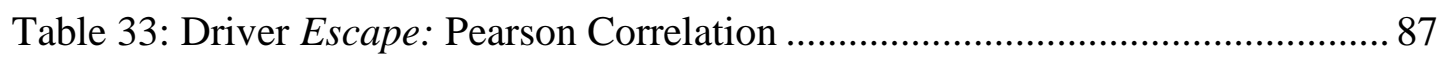

Table 34: Comparison between Sample and Census Data...................................... 91 


\section{CHAPTER 1: INTRODUCTION}

Chapter 1 provides an introduction to the topic of this thesis. It starts with the personal motivation of the author. A brief research background of the topic is then presented. Following that, the practical and scientific relevance is discussed. Subsequently, research objectives are illustrated and the research question is shown. Chapter 1 closes by presenting scope and outline.

\subsection{Personal Motivation}

The decision to write my Master's thesis about the relationship between sport and identity was, to a great extent, influenced by my personal interests. Since early childhood I have been actively participating in various sports disciplines. Beyond my active participation, following sports from a fan's perspective has always played an important role within my recreational activities. In this context, it has become apparent that I support sports teams for different reasons. The reasons for my support of German football club Werder Bremen is my admiration for the tradition and culture that has developed in this club over a long period of time. This includes the preference for young talented players over high-profile stars as well as the loyalty towards coach and management in difficult times. In European football contests such as the Champions League, I support German clubs due to my national background. The reasons for my support of ice hockey club Frankfurt Lions however, is the atmosphere and excitement I experience during the games. For more than 3 years, I supported a local basketball club. The active involvement of one of my friends offered a place in which my circle of friends could regularly come together. These examples illustrate that a wide spectrum of possible motives to support a sports team exist. It may explain why fan communities are highly heterogeneous in terms of their motives. It is of great interest to me how supporting a sports team is related to an individual's personal identity. I started placing an emphasis on this topic in the first year of the Master's degree by selecting this topic for a research project. Hence, focusing on this topic in the context of my Master's thesis can be seen as a natural progression of interests and ideas.

Furthermore, the importance of football in New Zealand has risen due to the participation of Wellington Phoenix in the Australian A-League and the recent 
success of the All-Whites in the world cup 2010. This offers a very interesting environment for studies about fan identification.

\subsection{Research Background}

Sport is an integral part of our society. Within society, sport forms a social subsystem which supports social recognition and identity reinforcement (Weiss, 2001). Identity reinforcement can be achieved through an active engagement in sports or through passive engagement in form of sport fandom. Within sport fandom, football (soccer) fandom plays a significant role as football is widely recognized to be the most popular sports discipline in the world (Shobe, 2008a). In contrast to other forms of leisure activity, football fandom can create high levels of identification and emotional attachment (Sutton, McDonald, Milne, \& Cimperman, 1997) which often leads to a strong loyalty that individuals feel towards football teams (James, 2001). For this reason, an application of Stebbins' (1992) profit hypothesis on football fandom is limited. According to the profit hypothesis, individuals only continue participating in leisure activities in which the rewards such as self-gratification or self-actualization outweigh the costs, such as anxiety or embarrassment. In football fandom however, many fans maintain their commitment despite constant disappointment and embarrassment (Jones, 2000). The strong emotional commitment that football fandom can create explains why in South America, many fans refer to their supported clubs as mothers, to themselves as sons and to the playing ground as home (Giulianotti, 2002). Furthermore, football and football fandom can be defined as a cultural institution that is inextricably wrapped up in political and economic processes which shape places and societies worldwide. An example for this is the significant role that Football Club Barcelona played in the social construction and reproduction of the Catalan identity between 1899 and 1975 (Shobe, 2008a). Hence, football fandom cannot adequately be understood by merely treating it as another leisure activity.

For professional sports organizations, fans are of highest importance. Consumer research literature considers brand loyalty as one of the greatest assets for marketers and a key determinant for brand equity (Funk \& Pastore, 2000). Therefore, it is in the interest of professional sports organization to create and maintain a large fan base. Such a fan base secures financial viability by positively impacting upon attendance, 
merchandising sales, and television ratings (Funk \& Pastore, 2000). However, a football team is not equally important to all its fans as the meaning that fans place upon their relationship with their team varies (Wann \& Branscombe, 1990). In heterogeneous groups of fans with different levels of identification, highly identified fans are more valuable to a sports organization than lowly identified fans. This can be explained by three main reasons: Firstly, highly identified fans generate higher profits for sports clubs, especially with regards to merchandising sales (Summers, Johnson Morgan, \& Kanoyangwa, 2007). One of the reasons for this is a reduced price sensitivity of fans with a strong emotional attachment (Sutton et al., 1997). Secondly, the attendance of highly identified fans is less dependent on the actual success of the team (Wann \& Branscombe, 1990). Therefore, highly identified fans less likely cause attendance fluctuation which contributes to more stable profits. Finally, fans with a strong connection towards a team more likely develop a longterm affiliation (Sloan, 1979) which leads to a higher sustainability of profits.

The formation of fan identification can be described as a process (James, 2001). No individual develops high fan identification towards a sports club in an instant. Moreover, different levels of fan identification exist. In order to positively influence fan identification, sports organizations need to find ways to bring fans to the next higher identification level (see figure 1).

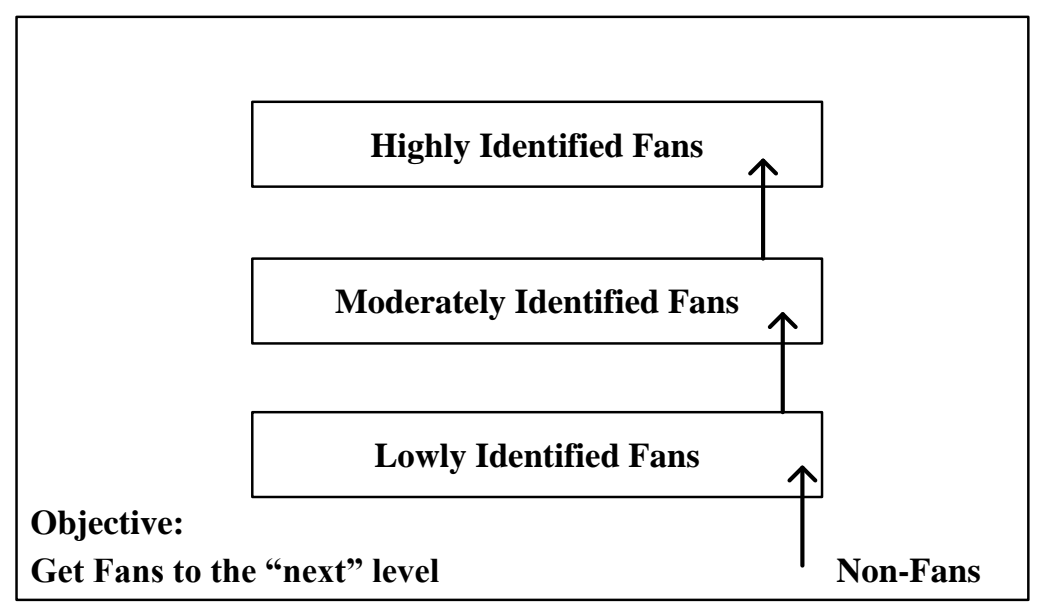

Figure 1: Fan Marketing Objectives

To achieve this, sports organizations need a deep understanding of their fans, especially regarding their current level of fan identification, fan characteristics, and underlying motivational drivers. This understanding may then inform marketing strategies that seek to target fan groups according to their level of fan identification. 


\subsection{Research Objectives}

Much research on fan identification focuses on characterizing sports fans by correlating their level of fan identification with socio-demographic characteristics. Other studies within sports management research concentrate on motives for fans to attend games and support specific sports teams. According to Wann, Schrader, and Wilson (1999) there is a lack of research regarding the relationship between the level of fan identification and the underlying drivers to become a fan. To the current day, this research gap has not adequately been filled.

This research aims at contributing to fill this gap by exploring how a set of identification drivers is related to the level of fan identification. This is undertaken using the case of New Zealand's only professional football club Wellington Phoenix FC, which is currently competing in the Australian A-League. Additionally, a second shortcoming in research literature is addressed by this thesis. There is little evidence on fan identification towards new sports teams (Lock, Darcy, \& Taylor, 2009). To date, the analysis of the psychological attachment of fans to the Major-League Baseball franchise club Cleveland Browns by James, Kolbe, and Trail (2002) and the analysis of member identification with the Australian football club Sydney FC by Lock et al. (2009) have been the only attempts to fill this gap. As Wellington Phoenix FC has only been competing in the A-League since the start of the season 2007/2008, the results of this research contribute evidence on fan identification with new sports teams.

Enhancing knowledge about fan identification is furthermore of high practical relevance. Within sports organizations, this knowledge can inform strategic decisions to positively impact the relationship between fans and the team, for example via tailored marketing events (Lock et al., 2009). With profound knowledge of how fan identification develops, specific fan groups can be approached more precisely.

Overall, this research pursues the following five main objectives:

1. Development of a questionnaire which enables researchers to assess the level of fan identification as well as the relevance of a set of fan identification drivers

2. Application of this questionnaire on a large number of fans and spectators of New Zealand's professional football club Wellington Phoenix FC 
3. Analysis of fan identification with reference to demographic characteristics and fan behaviour

4. Identification of structural patterns among fan identification drivers and analysis of relationships between identification drivers and the level of fan identification

5. Discussion of potential marketing implications based on the findings

In order to achieve these objectives, the following research question is tested:

\section{How are specific identification drivers related to the level of fan identification?}

\subsection{Research Scope}

The nature and level of sports fan identification can vary across different dimensions, ranging from a general identification with a sports discipline to an identification with particular players, teams, clubs or fellow fans (van Leeuwen et al., 2002). These different forms and levels of identification have different conceptual structures. Club identification represents a multidimensional construct of which fan identification and team identification are but two factors (van Leeuwen et al., 2002, p.110). An individual can be a football fan without supporting a particular team. Likewise, an individual may support a university sports team without being interested in the sports itself (Branscombe \& Wann, 1991). This research focuses on team identification. Team identification describes the psychological attachment of a fan to a team (Wann, Royalty, \& Roberts, 2000). For team identification to be present, an active connection between an individual and the team must exist (Foster \& Hyatt, 2007). An individual who never follows a team can therefore not be considered a fan. This thesis focuses on fans who possess at least a minimal level of team identification with Wellington Phoenix. Across this thesis, the terms, fan identification and team identification, are used interchangeably. 


\subsection{Outline}

This research consists of six chapters. In chapter 1, an introduction to the topic is provided and research objectives are presented. Chapter 2 offers a more detailed overview of previous work in the areas relevant to this research. Based on the findings in chapter 2, the theoretical framework of this research is developed. Chapter 3 describes the research methodology. It starts by setting out the objectives, hypotheses, and philosophical assumptions underpinning the research approach. Subsequently, research design and instrument are presented. Chapter 3 then describes how the data is analyzed, and comments on ethical considerations, credibility and generalizability and limitations. Chapter 4 presents the results of the data analysis. It begins by illustrating demographic characteristics of the sample. Then, results of the assessment of fan identification are presented; fan characteristics such as attendance behaviour or attitude towards merchandise products are reported. Lastly, this section focuses on the results regarding the identification drivers. In chapter 5, the findings are discussed and interpreted in relation to the findings of the literature review. The interpretation of the findings aims to provide new insights with regards to the research gaps discussed. Findings are then used to discuss marketing implications. Chapter 6 concludes the research by presenting key findings in a manner seeking to answer the research question. Furthermore, limitations of this research are mentioned and suggestions for future research are given.

\subsection{Summary}

In chapter 1, the personal motivation of the author was presented and an overview of the research background including the rationale for this work was provided. Following a discussion of the research objectives, the research question was formulated. The chapter finished by illustrating scope and outline of this research. 


\section{CHAPTER 2: LITERATURE REVIEW}

The literature review in chapter 2 seeks to present the main findings of previous work on the areas addressed by this research. The chapter starts by providing a historic overview of the Australian A-League as well as the club Wellington Phoenix FC. The following section concentrates on fans and fan motives. Then, chapter 2 focuses on fan identification and fan identification drivers. Lastly, fan identification is discussed from a sports marketing perspective and the theoretical framework of this research is developed.

\subsection{The A-League and Wellington Phoenix FC}

In Australia, strong ties between football and ethnic communities have developed as a result of the role of football in the acculturation of migrants arriving since the 1940s (Lock et al., 2009). Football teams had mainly identified with Greek, formerYugoslavian, and Italian communities (Rapley \& McHoul, 2002). However, these ethnic ties had prevented football from a wider acceptance in the highly saturated sports market in Australia as the teams faced problems in attracting fans outside these cultural groups (Lock et al., 2009). In 2003, a report called The Structure, Governance and Management of Soccer in Australia (Independent Soccer Review and Committee, 2003) suggested radical changes to the governance and management structure of Australian football including a one-club-per-city policy. Subsequent to this report, the National Soccer League (NSL) was replaced by the A-League in 2005 in an attempt to separate football from dysfunctional ethnic ties (Lock et al., 2009). In 2005, the A-League started with 8 franchise teams including the New Zealand Knights as the only New Zealand based team (Football Federation Australia, 2008). In 2007, after the second season of the new league, Wellington Phoenix FC took over the A-League license of the New Zealand Knights. Prior to the start of season 2009/2010, the A-League expanded to 10 teams with North Queensland Fury and Gold Coast United joining (Football Federation Australia, 2008). To date, Wellington Phoenix FC is still the only New Zealand based team in the Australian ALeague. 
Recent research shows that the transformation from the NSL to the A-League has led to an opening of Australian Football towards a much wider spectator base. According to Lock (2009), the re-developed A-League has managed to attract a more mainstream audience than the previous NSL. In 27 years, the NSL had never reached an average attendance of 6,000 . In the first year of the A-League the average leaguewide attendance was 10,955 (Lock et al., 2009). While this demonstrates the success of the regulatory changes undertaken, there is perceived to be a significant discrepancy between active and passive interest in football. For example, whilst since 2003, football has overtaken cricket as the sport that is most played in Australia (Hallinan, Hughson, \& Burke., 2007), it is far from being the most mediated and supported sport discipline.

\subsection{Fans and Fan Motives}

This section covers previous research findings on sports fans and fan motives. It emphasizes motives for attending sports events, different degrees of fandom, development of fan loyalty, and fan loyalty in the context of franchise teams.

\subsubsection{Motives of Attending Sports Events}

Sports events provide an environment which spectators feel part of, without requiring special skills or knowledge of particular institutional values (Branscombe \& Wann, 1991). Gantz (1981) highlights the pleasurable experience of sport events, particularly when the supported player or team performs well. Additionally, attendance at sport events is a practical leisure activity for families to maintain a sense of unity, and can therefore contribute to a higher quality of life (Branscombe \& Wann, 1991). Many scales have been developed to assess the underlying motives for sports consumption. Well renowned examples are the Sport Fan Motivation Scale (SFMS) by Wann (1995), the Motivations of Sport Consumers scale (MSC) by Milne and McDonald (1999) or the Motivation Scale for Sport Consumption (MSSC) by Trail and James (2001). These scales mainly focus on functional motives for the attendance of sports events as the following table indicates: 


\begin{tabular}{|lll|}
$\begin{array}{l}\text { SFMS } \\
\text { (Wann, 1995) }\end{array}$ & $\begin{array}{l}\text { MSC } \\
\text { (Milne \& McDonald, 1999) }\end{array}$ & $\begin{array}{l}\text { MSSC } \\
\text { (Trail \& James, 2001) }\end{array}$ \\
\hline Aesthetics & Aesthetics & Achievement \\
\hline Drama & Achievement & Acquisition of knowledge \\
\hline Economics & Affiliation & Aesthetics \\
\hline Entertainment & Aggression & Drama \\
\hline Escape & Competition & Escape \\
\hline Family & Risk taking & Family \\
\hline Group Affiliation & Self-actualization & Physical Attraction \\
\hline Self-Esteem & Self-esteem & Physical Skill \\
\hline & Skill mastery & Social interaction \\
\hline & Social facilitation & \\
\hline
\end{tabular}

Table 1: Sport Spectator Motives of SFMS, MSC and MSSC

The attendance of sports events differentiates from other recreation activities due to the unique nature of athletic competition. Unlike other forms of leisure behavior, sports events offer a sense of drama while having unpredictable outcomes (Madrigal, 1995). In their study about causes for brand loyalty in professional football, Parker and Stuart (1997) compare the performance expectations between fans of the clubs Manchester United and Manchester City. Although the expectations of Manchester United fans are higher than the expectations of Manchester City fans prior to a game, there is no guarantee for a victory. It is often argued that this uncertainty is affected by the degree of competitive balance within a sporting league (Owen, Ryan, \& Weatherston, 2006). According to Fort and Quirk (1995), sports leagues are in the business of selling competition on the playing field (Fort \& Quirk, 1995, p.1265). Parker and Stuart (1997) ascribe the uncertainty that results from competitive balance to be an essential reason for the maintenance of fan commitment. This view accords with Wann and Branscombe (1990) who state that although the uncertain outcome seems to make an identification with a sports team risky, research shows that this form of euphoric stress (Wann \& Branscombe, 1990, p.112) is attractive and one of the reasons why people attend sport events. Additionally to this uncertainty, Gantz (1981) highlights the reality of sports as a reason for differing sets of viewing 
motivations. The following section describes different degrees of fandom in the sports context.

\subsubsection{Degrees of Fandom}

Different degrees of fandom and spectatorship exist (Jacobson, 2003). Therefore, and particularly when exploring drivers for fan identification, an explanation of the terms fan and spectator is necessary. Krohn, Clarke, Preston, McDonald, and Preston (1998) describe the main difference between fans and spectators by their emotional commitment during sport events. While spectators merely enjoy viewing a sport event without getting caught up in what Madrigal (1995) calls the logistics or aesthetics of it, fans believe in the ritual and demonstrate a high degree of enthusiasm. The author furthermore comments that in contrast to spectators, fans perceive themselves as members of an existing fan community with which they form an alliance. In their study about the measurement of sport involvement, Shank and Beasley (1998) used the definition of the psychological construct of involvement by Zaichkowsky (1985) and applied it on sports fans. Involvement, as a person's perceived relevance of the object based on inherent needs, values, and interests, is higher among fans than spectators. Beisser (1967) defines a sports fan as someone who feels part of the game and who experiences similar feelings as the players, including pre-game symptoms such as nervousness (Krohn et al., 1998). In South America, many fans refer to their supported clubs as mothers, to themselves as sons and to the playing ground as home (Giulianotti, 2002).

Other authors define fan groups based on the degree of involvement of their group members. Wann \& Branscombe (1990) refer to those fans, to which the identification with a particular team is highly relevant to their personal identity, as die-hard fans. Those fans persevere with their team, even if success is lacking. Fair-weather fans on the other hand only participate when the team is performing well, but stay away in unsuccessful times. To Wann and Branscombe (1990), fair-weather fans are responsible for attendance fluctuation, especially after very successful or very unsuccessful seasons. Giulianotti (2002) differentiates between supporters, followers, fans and flâneurs, depending on an individual's identification and solidarity as well as on the duration of and personal investment to the relationship with a sports team. The indicators mentioned above can be used to distinguish between different forms of fandom. 
These indicators are reflected by the definition of team identification as the personal commitment and emotional involvement that customers have with a sport organization (Sutton et al., 1997, p.15). Therefore, the level of fan identification with a respective sport organization can be seen as the key difference between fans and mere spectators.

\subsubsection{Development of Fan Loyalty}

Fans are highly important as they impact revenues from ticket sales, sales of merchandising products and, indirectly sponsorship (van Leeuwen et al., 2002). However, professional football clubs cannot simply rely on the fact that fans will always be loyal. Moreover, fanaticism may be reduced by different factors such as rule changes, trading of players, hyper-commercialization, increasing ticket prizes, perceptions of exorbitant player salaries, or in the case of franchise teams, relocations or mergers of teams (van Leeuwen et al., 2002). In order to achieve sustainable financial success, football clubs need to maintain and enhance the level of loyalty of their fans. The risk of a decrease of fan loyalty can be addressed by incorporating marketing techniques from other sectors (Parker \& Stuart, 1997). In this context, a necessary step for sports marketers is to enhance understanding of the loyalty formation processes that lead to an emotional attachment between fans and their teams.

Fan loyalty does not develop overnight. James (2001) suggests that it can be seen as the result of a cognitive development process in which psychological connections are formed. In this process, teams are actively compared and evaluated, and attachments are formed. However, the development of psychological connections can be influenced by different factors such as the availability of games that are viewed, or the acceptability of teams by relevant socializing agents such as family or friends. The first examination of such connections and the cognitive development of team loyalty was undertaken by James (2001). His results show that preferences for and commitment to sports teams can start developing at the age of 5. At this age, the socializing agent with the highest influence for the introduction to a sports team is the father. Parker and Stuart (1997) call this form of parental influence indoctrination. However, various socializing agents appear to have a differential influence on individuals' preferences at certain points and situations in their life. For 
adults, by example, community associations and peers have a greater influence on shaping team loyalty (Kolbe \& James, 2000).

In their study, Parker and Stuart (1997) compare the loyalty of football fans with the loyalty of customers of other product sectors. The authors point out that in contrast to other sectors, football fans show a phenomenal brand loyalty as they tend to stick to their club despite the fact that other football clubs might be more successful. The bond between a fan and his or her supported team can be seen as a positive affected bond (Foster \& Hyatt, 2007, p.196). As a corollary, the affected bond with rivals of the supported team may be of negative nature. Previous research indicates that fan loyalty can evolve in the context of new sports teams. On the example of US NHL team San Jose Sharks, Gladden and Funk (2001) provide an example that shows that fan loyalty can evolve even in the absence of a long lasting history. The following section focuses on fan loyalty in the context of franchise teams.

\subsubsection{Fan Loyalty in the Context of Franchise Teams}

Sport fandom in the context of franchise teams differs from fandom in the traditional context and can be seen as a highly complex phenomenon (Foster \& Hyatt, 2007). In the case of American NFL teams, relocation or intended relocation of franchise teams have triggered significant reactions within fan bases. On the example of the relocation of the Cleveland Browns to Baltimore in 1995, Sutton et al. (1997) shows how fan movements can become political, social and judicial forces. Foster and Hyatt (2007) analyzed the implications of the transformation of the NHL franchise team Hartfort Whalers into the Carolina Hurricanes on Whalers fans that had strong and emotional identifications prior to their team's relocation. They found out that fans' emotional reaction is much more complex than a simple civic or symbolic allegiance (Lewis, 2001) with fans either sticking to their home city or to the relocated team. The authors illustrate five different ways of how left-behind fans reacted. These are: continued identification, disidentification, schizo-identification, neutral identification, and non-identification. Remarkably, only 3 out of 23 interviewed participants reported a continued identification after the franchise relocation. In 1997, Sutton et al. compared the effects of a relocation announcement of two franchise teams of the American National Football League (NFL). Despite the similar environment of the two teams, their fan bases reacted differently. This indicates that the development of fan identification may not be uniform or 
predictable. Hence, the influence of various external factors in the context of franchise teams makes it very difficult to predict the future development of fan identification. The following section emphasizes the formation of fan identification.

\subsection{Fan Identification}

Researchers predominantly look at fan identification processes from a social identity theory perspective (Tajfel \& Turner, 1979). According to Turner (1982), the self concept of an individual consists of two separate identities: the individual's personal identity and the individual's social identity. Whereas the personal identity is formed by feelings about oneself such as intelligence, attractiveness, or competence, an individual's social identity is constituted by the group affiliations with which one identifies (van Leeuwen et al., 2002). This section starts by elaborating on aspects around personal and social identity in sports. It then addresses the topic of image management through sports fandom. Lastly, this section presents findings of previous research on fan identification drivers.

\subsubsection{Personal Identity in Sports}

Recreation activities provide a medium for self-development and personal enhancement (Kuentzel, 2000) by contributing to the process in which individuals seek to create and maintain self-awareness in relation to the world around them (Haggard \& Williams, 1992). Kuentzel (2000) describes how identity literature discusses the role of leisure behavior with regards to individuals' personal identities. He refers to Mead's (1934) symbolic interactionism, which defines the individual's self as driven by goals, intentions, values, beliefs, and attitudes and formulated through social interaction. This allows two different explanations about the role of leisure activities in the creation of an individual's self. The first explanation is that individuals commit to certain self-images and then seek to find leisure activities that allow behavior which confirms this self-image. The second explanation asserts that the self-identity of an individual is subject to constant change. In this case, leisure activities are seen as means to work on the development of a desired self-identity (Kuentzel, 2000).

In their study about the motivation to participate in leisure activities, Haggard and Williams (1992) found that different leisure activities symbolize different sets of 
identity images to their participants and therefore function differently in the selfaffirmation process. The identity image of a kayaker could therefore represent character traits such as adventurous, sociable or outdoorsy. Haggard and Williams (1992) concluded that identity images serve as an essential motivation for leisure activities. Hence, the choice of being a kayaker indirectly reflects the desire to be perceived as adventurous, sociable, and/or outdoorsy. More general, the selection of leisure activities by individuals is highly influenced by the activities' ability to affirm valued aspects of their identity. Hence, the freedom of selecting leisure activities implies that people choose those activities that enhance, or add to their self-definition (Kuentzel, 2000).

From a symbolic interactionist view (Stryker, 1968), an individual's self is defined as a set of internalized roles or identities (Hirt, Zillmann, Erickson, \& Kennedy, 1992, p.725). Therefore, being a sports fan can be seen as an internalized role which makes it a part of a fan's self. However, the importance of being a fan to an individual's sense of self, depends on the degree of identification. For highly identified individuals, the fan role is central to their self-identity. For lowly identified fans on the other side, this role is only a peripheral part of their self-identity (Wann et al., 2000). Any form of personal identity formation or enhancement including processes such as self-recognition and self-evaluation can only be done in a surrounding society or social group (Weiss, 2001). For that reason, the individual's social identity needs to be taken into consideration in order to understand why, and in which way, sport fan identification forms, and how this identification relates to an individual's self-concept (van Leeuwen et al., 2002).

\subsubsection{Social Identity in Sports}

Social identity theory (Tajfel \& Turner, 1979) describes the implications of group memberships on the way, individuals see themselves and are seen by others. A social group is a set of individuals who understand themselves as members of the same social category (Stets \& Burke, 2000). Membership in a social group can positively or negatively influence this self-image. As individuals strive to achieve and maintain a positive self-image, they tend to seek group memberships which contribute to a positive social identity (Tajfel, 1981). In this context, merely belonging to the favourable group is enough to provide positive consequences to its members. Direct social interaction or personal relationships with fellow group members are not 
necessary (Tajfel, 1970). Sports fans can be seen as group members of particular fan communities. Applying Tajfel's (1970) notion to the sports domain illustrates that fan communities provide positive consequences to their members even if fans do not directly interact with other fans. A deeper look at the benefits of sport fandom shows why Madrigal (1995) refers to sport fandom as a form of social identity from which individuals can derive emotional significance.

Through an identification with a local sport team, individuals become attached to a larger social network (Wann, 2006). These social networks help maintaining the psychological health of sport fans by creating a sense of belonging (Gantz, 1981) and reducing anxiety, loneliness and isolation (Wann, 2006). Furthermore, the affiliation with a football club serves as a powerful topic of conversation and sometimes is the only unifying subject between colleagues and workmates (Parker \& Stuart, 1997). Therefore, it is not surprising that Wann (2006) identified a positive correlation between the level of identification with a local sport team and a fan's psychological well-being. According to Melnick (1993), the stadium or sports arena is of particular interest as it represents a place that satisfies a variety of interpersonal desires. That is because the stadium atmosphere creates a social experience consisting of a strong sense of community and an illusion of intimacy. Hence, stadium atmosphere serves casual sociability which is one of the main psychosocial motives to attend sports events (Melnick, 1993). In this environment, shared experiences of highly identified fans lead to a creation of a strong sense of bonding with other fans (Branscombe \& Wann, 1991). This sense of bonding eventually leads to an identification of fans with the fan community. The importance of the place in the creation of a sense of community explains why identification with a distant team does not have a positive effect on the psychological well-being of a fan (Wann, 2006).

By identifying with a fan community, individuals perceive themselves as members of this particular group. According to Turner (1985), group memberships represent a form of social categorization. His self-categorization theory is an extension of social identity theory and focuses on the motivations for and implications of group memberships. Through this process of self-categorization individuals form an identity (Stets \& Burke, 2000). Furthermore, social categorization can be interpreted as a form of depersonalization as group behaviours, attitudes and feelings are 
assimilated by its group members. For this reason, it assists in reducing the subjective uncertainty of individual group members (Hogg, 2000).

Through social comparison processes, other individuals that show similarities to the own self are categorized and labelled as the in-group. Likewise, individuals who differ from the self are perceived to represent out-groups (Stets \& Burke, 2000). A social group can only work in favour of the social identity of its members if it maintains a distinction that is positive in relation to other existing groups (Tajfel, 1981). The existence of out-groups is therefore useful as it provides a way to express the differences that lead to the reasons for the membership with the in-group (Foster \& Hyatt, 2007). Only in an environment in which other groups exist, can a meaning be placed upon the attributes and positive effects that a group membership provides to the social identity of that group (Tajfel, 1981). Often, the term we is used to refer to the in-group represented by the own fan community and the term them to the outgroup represented by the fan community of the opponent. In order to maintain a positive social identity (Tajfel \& Turner, 1979), fans often convince themselves that the in-group is superior to the out-group (Wann \& Dolan, 1994a) by perceiving fellow fans of the own team more favourable than fans of other teams. The following section explains common image management behaviour by sports fans that can be explained by the impact of fandom on individuals' identity.

\subsubsection{Image Management of Fans}

Hirt et al. (1992) illustrates that mood and self-esteem of identified fans are affected by game outcomes of their supported teams. Fans tend to perceive team success as personal success and team failure as personal failure. Due to its significance on an individual's self-evaluation, team identification can be defined as the extent to which individuals perceive themselves as fans of the team, are concerned with the team's performance, and view the team as a representation of themselves (Branscombe \& Wann, 1992, p.1017).

Social psychology research has identified three mechanisms that, when used by individuals, help maintain their positive social identity (Wann, 1993). The first mechanism is commonly referred to as basking in reflected glory (Cialdini, Borden, Thorne, Walker, Freeman, \& Sloan, 1976). BIRGing refers to the tendency of people to share in the glory of a successful other with whom they are in some way 
associated (Cialdini et al., 1976, p.366). In the football context, the successful other can be a team as well as single players or the coach. Cialdini et al. (1976) draw upon Heider's (1958) balance theory to explain the BIRGing process. If an observer evaluates a successful unit positively, and perceives a relationship between that successful unit and a person, the observer automatically evaluates the person positively in order to keep his cognitive system in balance. For individuals that seek to bask in reflected glory, an affiliation or membership is necessary to be able to publicly display the existing relationship. Affiliations can, for example, be ethnic or religious similarities, or simply the fact that the person was born, lives or lived in the same area as the successful unit. When no such connection exist, sport fans tend to proclaim their affiliation by displaying symbols such as badges, buttons, stickers or jerseys. Cialdini et al. (1976) tested the existence of the BIRGing phenomenon by assessing the behavior of university students after attending games of their university teams. They found out that students used the term we more often to describe the supported team after victories, and the term they when the team failed. Furthermore, more students wore specific clothing to signalize their affiliation to the university when the team was successful. According to Madrigal (1995), BIRGing can be described as an affective state. He states that together with the enjoyment factor of watching a game, BIRGing directly contributes to customer satisfaction.

For individuals who strongly identify with a football team the spectator role is likely to be central to their identity. In this case, both success and failure of the supported team have a strong impact on the feeling of self-worth of those individuals (Wann \& Dolan, 1994b). When an individual's self-esteem depends upon his or her group memberships, any form of devaluation of that group is seen as a threat to this person's identity (Wann \& Branscombe, 1990). The second technique to maintain positive social identity is known as cutting off reflected failure (CORF). CORFing describes an active distancing from unsuccessful others in order to avoid any kind of negative association (Snyder, Lassegard, \& Ford, 1986). Snyder et al. (1986) tested the tendency to BIRG and to CORF by US college students. Both distancing processes, BIRGing and CORFing, occurred to equal extents after victories and losses. Therefore, the authors concluded that the participants truly identified with the relative sense of success or failure of their respective groups, and that it was the strong identification that caused participant's distancing behaviours. The possibility 
to share success in order to boost satisfaction and self-worth, and to reduce the emotional association in unsuccessful periods, means that fans are exposed to relatively low risk (Gantz, 1981). The BIRGing process can therefore be referred to as an image-enhancement strategy, whereas the CORFing process can be identified as an image-protection strategy (Snyder et al., 1986).

Madrigal (1995) illustrates that of the three determinants: expectancy disconfirmation, team identification, and quality of opponent, the determinant team identification has the dominant influence on BIRGing. This accords with Wann and Branscombe's (1990) results that show that higher team identification results in a greater tendency to BIRG. However, higher team identification appears to prevent fans from an ability to CORF as they maintain their association to a team even when faced with defeat. The inability of highly identified fans to distance from failure leads to unavoidable costs and consequences of fandom such as the negative association and suffering (Hirt et al., 1992). In some cases, this inability leads to a third mechanism called blasting or derogation. In situations in which self-esteem is lowered, some fans tend to use hostile attitudes and behaviours towards oppositional fans to regain their damaged social identity. For those fans, derogation creates the psychological perception that the own fan community is better than the opposite fan community, which then leads to an increase of self-esteem (Wann, 1993). The next section discusses fan identification drivers.

\subsubsection{Fan Identification Drivers}

James (2001) identifies social interaction and leisure socialization to have strong influence on leisure choices. The term socialization is defined as a process in which individuals learn values, traits, attitudes, norms, knowledge, and skills to perform social roles (Krohn et al., 1998). Within the sports domain, socialization describes social and psychological influences on someone's initial attraction to sport. Applied to team identification, socialization involves learning and internalizing values, knowledge, attitudes, and behaviours necessary to becoming a team fan. Hence, besides personal characteristics, interpersonal factors and the social environment have a strong effect on team identification (Kolbe \& James, 2000). Family and friends, so called norm reference groups (James, 2001, p.235), provide an environment in which team identification and loyalty is created through both socialization and social interaction. During childhood, family structures are the 
primary influence on behavior patterns and recreation participation. Later, this social environment is often augmented by the school community and friends (James, 2001).

According to Shobe (2008a), further drivers for team identification have been addressed by researchers within social sciences, including geography, sociology and anthropology, who consider the role of sport in the construction of collective identities. Shobe (2008a), for example, highlights the influence of football in the social construction and reproduction of cultural, political, and national identities by looking at the role of Football Club Barcelona in the development of a Catalan identity between 1899 and 1975. His main finding is that sport, and football in particular, is more than a mere reflection of place-based identity, it actively supports its construction. Therefore, football clubs can provide a medium for collective identification with a place. However, when a football club is involved in the social construction of a collective identity, forms of exclusion can occur. Shobe (2008b) analyzed the role of FC Barcelona in the development and use of the Catalan language in the years 1975 and 2005. He emphasizes that the use of Catalan as a means of reinforcing the connection to Catalonia also creates an exclusionary atmosphere with regards to the opening of the club towards a global brand with international fans and members. Halberstadt, O’Shea, and Forgas (2006) examined the effects of cultural differences on the rivalry between New Zealand and Australian sports teams. The authors highlight an asymmetric relationship between the two countries, with New Zealand fans showing a stronger in-group identification and outgroup rivalry towards Australian teams than vice versa.

Beyond its contribution to the expression of national identities, football and football clubs can represent cities, towns or suburbs, and therefore support the creation of what Anderson (1991) calls imagined communities (Shobe, 2008a). Within a local community, sport connects people, provides unifying symbols, promotes communication, and creates environments for solidarity (Sutton et al., 1997). Shobe (2008a) refers to Hague and Mercer (1998) who elaborate on the role of the Scottish football club Raith Rovers in the creation and reproduction of social memories with regards to the collective experiences of the residents. Pratt and Salter (1984) state that for some fans, the place or city represented is more important than the representation of the sports team. An example of fans to which the regional connection with the supported team is of highest importance can be seen in the 
English Premier League, where fans of other teams vilify Manchester United for having a majority of fans outside the region of Manchester (King, 2000).

A confrontation of a city or region with another city or region represents the medium in which identities and solidarities can be expressed (King, 2000). Strong rivalries between football clubs can develop when clubs and their supporter groups represent conflicting political, cultural or religious identities. A dramatic example of such a rivalry between two football clubs and their respective identities is the one between FC Barcelona and Real Madrid (Shobe, 2008a). These two clubs symbolize Catalan (FC Barcelona) and Castilian (Real Madrid) national identities which adds cultural and political aspects to the pre-existing athletic rivalry. Another example of a strong 'we against them' dynamic is the one between Glasgow Celtic and Glasgow Rangers where oppositional cultural, religious and political identities clash (Shobe, 2008a).

In such circumstances, it may be no surprise that identity is not static but dependent on time and situation (Weiss, 2001). As a consequence, the construction of regional identity is an ongoing process as communities are constantly re-imagined and reinvented through new developments (King, 2000). Football teams do not just mirror dynamics of the city or region in which they are located but rather are actively drawn upon to advance ideas about places (Shobe, 2008b, p.103). Implications of the various underlying motivational drivers on sports marketing is addressed in the following section.

\subsection{Fan Identification from a Sports Marketing Perspective}

This section starts by illustrating the value of fan identification for professional sports organizations. It then looks at specific fan marketing strategies to positively impact fan identification.

\subsubsection{The Value of Fan Identification for Sports Organizations}

Fan identification is highly beneficial to football clubs. According to Madrigal (1995), the level of identification is positively correlated to the personal joy when the team is successful. It furthermore leads to a stronger tendency to BIRG which directly contributes to customer satisfaction (Madrigal, 1995). From a managerial perspective, a stronger tendency to BIRG by highly identified fans is beneficial as it leads to an increase of merchandising sales (Summers et al., 2007). High fan 
identification also results in reduced price sensitivity (Sutton et al., 1997). Interestingly, highly identified fans even demonstrate a higher loyalty towards mediocre teams (Madrigal, 1995). The higher the fan identification, the lower is the tendency of supporters to increase the distance between themselves and the team (CORF) in unsuccessful periods (Wann \& Branscombe, 1990). Therefore, high fan identification minimizes the impact of team performance and athletic success on the financial success of a football club (Sutton et al., 1997). An explanation of the BIRGing and CORFing behaviour of highly identified fans can be developed by looking at the way that individuals judge, assess or react to game outcomes and direct experiences. For example, highly identified fans tend to highlight internal causes such as players' efforts or fan support following successful games, and external causes such as fate or referee decisions following unsuccessful games (Wann \& Dolan, 1994b). The authors call this behavior attributional bias, and link it with the aim of highly identified fans to boost self-esteem.

The importance of identification is also emphasized by the Sport Spectator Satisfaction Model (SSSM) of van Leeuwen et al. (2002). The SSSM is a modified version of the Disconfirmation of Expectations Model (DEM), which has been developed to understand the drivers for customer satisfaction. The DEM describes how the interplay of both customer expectations and the perceived performance of a service or product affects customer satisfaction. Positive disconfirmation would occur if the perceived performance exceeds customer expectations. Alternatively, negative disconfirmation would occur if customer expectations exceed the perceived performance. Positive or negative disconfirmation would then directly impact customer satisfaction. In order to make it applicable to the sports domain, the authors added factors such as club identification and the win/lose phenomenon to the extant DEM model. According to their findings, club identification has a positive relationship with both expectations and perceived performance. Furthermore, higher club identification leads to a more positive disconfirmation. Van Leeuwen et al. (2002) explain this by the notion that, according to social identity theory, individuals tend to positively evaluate products or services with which they identify, in order to maintain their level of social identity. 


\subsubsection{Fan Marketing Strategies}

No managerial action can directly influence a team's success on the field. However, managerial action can affect levels of fan identification. Therefore, according to Sutton et al. (1997), sport marketers should place a high emphasis on the concept of fan identification. The authors identify four characteristics that managerial action can address in order to increase fan identification with franchise clubs: team characteristics, organizational characteristics, affiliation characteristics, and activity characteristics. The factor team characteristics mainly addresses the perceived quality of the team. Organizational characteristics represent the reputation of a franchise club and the league in which it is participating. An example for a prestigious franchise club with a high level of fan identification is the professional baseball team New York Yankees (Sutton et al., 1997). Affiliation characteristics describe the connection or bond that a fan exhibits with regards to a team. In this respect, a sports team serves as a gateway to a larger group of people with similar interests. As a consequence, the authors identify this factor as the one with the strongest long-term effects. Activity characteristics refer to the exposure of the sports team via additional channels such as electronic and print media. According to Sutton et al. (1997), multiple source coverage may lower information barriers and may enable individual fans to obtain the degree of identification that is intended.

However, not all managerial activities seem to focus on matters relating to fan identification. In the UK, for example, various developments have led to a substitution of established, highly identified fans by wealthier new spectators. This has been especially so, given the creation of high-priced seating in smaller capacity stadia at the expense of low price, high capacity stadia catering for traditional fans (Giulianotti, 2002). It is thought that the strengthening of club ties with corporations, and the emergence of pay-per-view television, have contributed to such developments. Sutton et al. (1997) formulates four management-derived strategies that seek to increase fan identification. The first seeks to increase of the player/team accessibility to fans. Autograph sessions, player appearances and diverse grassroots events can lead to an enhancement of the attraction of the team. A second strategy describes activities to enhance community links and increase the community involvement of the football club. Social projects and charity events, for instance, improve the credibility and reputation of the club by demonstrating shared goals with 
the community. As a team's positive reputation also reflects positively on its fans, fan identification with such a team becomes more attractive. One example is the nonprofit charity foundation founded by the NBA team Orlando Magic (Sutton et al., 1997). A third strategy emphasizes the sense of belonging for fans by reinforcing a club's history and tradition, through activities such as the creation of a Hall of Fame, or a selection of the All-time team. The last strategy refers to the relationship between fans and the club. By establishing fan clubs, organizing trips to away matches or newsletters, sports clubs actively promote the feeling that the fans are part of the team (Sutton et al., 1997, p.21). Furthermore, the pro-active creation of a link between the team and the city in which it is located can provide a powerful source of identification. Such a link may help the attribution of positive characteristics to both the city and team, in a manner that strong feelings about each entity are then mutually reinforced (Kolbe \& James, 2000).

However, managers of sport organizations also need to consider the characteristics of different customer segments and their emergence as fans. Summers et al. (2007) examined sports consumption by Australian teenagers. An important finding was that teenagers are mainly driven by the atmosphere and entertainment offered. As such, given the lack of serious involvement and identification, teenagers consider their sport attendance decision on the same basis as any other recreational activity such as going to the cinema. Sport managers therefore need to focus on what may be regarded as the periphery of pre- and post-game entertainment to attract this group. Furthermore, Summers et al. (2007) suggests that sport managers need to focus on ways to increase involvement and identification of this customer segment.

Sports organizations may project to the public in several ways. According to Foster and Hyatt (2007), inconsistencies or conflicts in the perception of a sports organization may also lead to identification-related conflicts amongst fans. Such inconsistencies lead to what Elsbach's (1999) refers to as schizo-identification, a state in which fans not only identify with ideas and values of some parts, but also disidentify with other parts of a sport organization (Foster \& Hyatt, 2007). Organizational disidentification refers to the behaviour of active separation between one's identity and the identity of the organization (Elsbach \& Bhattacharya, 2001). However, disidentification is not the opposite of identification. It is the process of disassociation of one's social identity from negative aspects of an organization or 
group (Foster \& Hyatt, 2007). As such, disidentification can have negative consequences as it creates the risk of counter-organizational action and of negative public statements (Foster \& Hyatt, 2007, p.198). Therefore, it is important that the component parts of a sports organization such as single players, the team, the coach and the management convey, project and represent similar ideas and values through their actions. Based on the previous discussion, a theoretical framework for this research is developed and presented in the following section.

\subsection{Theoretical Framework}

Based on the literature review, a set of 16 identification drivers were surfaced as relevant to this research. A conceptual model by Fisher and Wakefield (1998) is used as a starting point for the development of the theoretical framework. This model highlights and assesses the influence of an initial set of three drivers. These drivers are domain involvement, perceived group performance and group member attractiveness on sports team identification. Domain involvement reflects an individual's intention to both actively and passively participate in a particular sport discipline (Hill \& Green, 2000). Whilst perceived group performance describes the performance of the sports team as perceived by the individual supporter, group member attractiveness comprises an individual's admiration for the team, individual players or the coach (Jacobson, 2003).

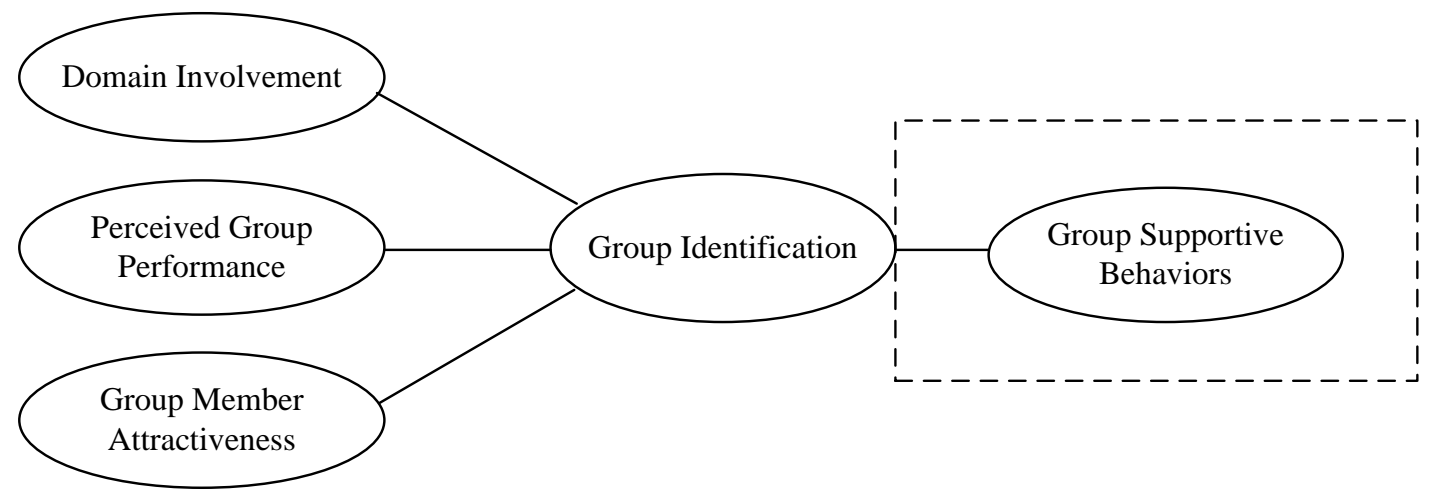

Figure 2: Conceptual Model of Fisher and Wakefield (1998)

However, since this model was primarily developed to demonstrate the influence of fan identification drivers on group identification and tested between successful and unsuccessful teams, the sole use of Fisher \& Wakefield's (1998) set of drivers is limited for the purposes of this research. In contrast to Fisher \& Wakefield's (1998) study, this research solely focuses on one sports team. Therefore, it needs to consider 
a wider range of drivers than merely those which are linked to the team's success. Furthermore, the element Group Supportive Behaviors describes how group identification impacts fan behaviour. As this thesis does not focus on group behaviour influenced by fan identification, the element Group Supportive Behaviors is not taken into consideration.

In order to modify Fisher and Wakefield's (1998) model, a look at the work of Jacobson (2003) is beneficial. Jacobson (2003) examines fan identification from an identity theory perspective. He describes two distinct conceptual levels: the Interpersonal/Network Level of Identity and the Symbolic Level of Identity. The Interpersonal/Network Level reflects the degree of involvement that an individual has towards a particular sports discipline (Jacobson, 2003). Besides the domain involvement, the Interpersonal/Network Level emphasizes the concept of socialization. Drivers in this category include socializing agents such as family, friends and colleagues. Finally, this level encompasses the concept of collective identities, represented by the sense of belonging that individuals develop within the fan community. This level therefore covers the domain involvement and the group member attractiveness from Fisher and Wakefield's (1998) model.

The Symbolic Level represents drivers that reflect the desire to be part of the environment created by a winning team (Jacobson, 2003, p.8). This addresses the perceived group performance, included in the model of Fisher and Wakefield (1998). Jacobson (2003) manifests a strong connection between drivers within the symbolic level and the desire to bask in reflected glory. The symbolic level encompasses both the perceived performance of the supported team and the symbolic attractiveness of the team, individual players, and the coach (Jacobson, 2003). The following diagram shows the main groups of drivers belonging to the Interpersonal/Network and the Symbolic Levels of Identity: 

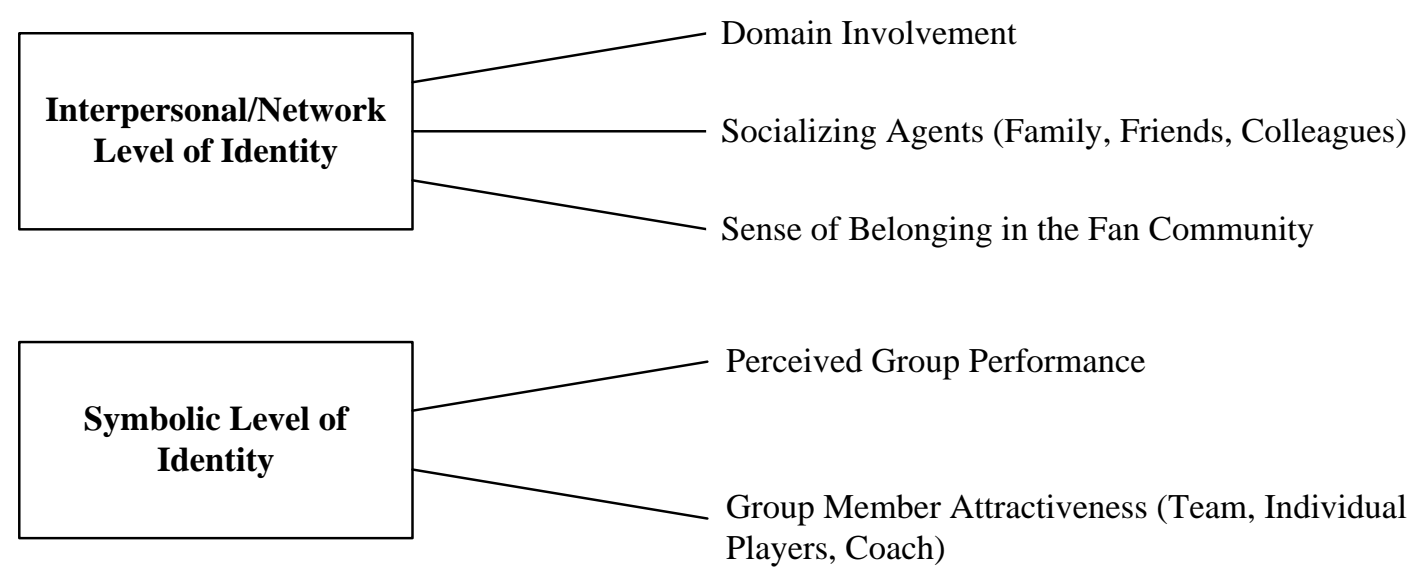

Figure 3: Theoretical Levels of Jacobson (2003)

In addition to the drivers of the interpersonal/network and symbolic level, two further categories of drivers are considered in this thesis. Research indicates that regional affiliations can play a significant role in the identity formation process (i.e. Shobe, 2008a; Pratt \& Salter, 1984). Therefore, a geographical category is included in the conceptual model. This construct contains the drivers: city, country and stadium. The drivers, city and country, for example, may be used to assess in which way the representation of the city of Wellington, or the country of New Zealand, influences fan identification with Wellington Phoenix. In this context, it is necessary to mention that at the time of this research, Wellington Phoenix is the only New Zealand football club in the Australian A-League. The driver stadium refers to the Westpac Stadium as the place where the crowd congregates, to support their team.

According to Funk and Pastore (2000), direct experiences of fans are considered to be effective predictors of loyalty towards a sports team. This view accords with that of Giulianotti (2002), who has referred to team support as a lived experience, rooted in a grounded identity that is reflected in an affectionate relationship to the ground that is regularly revisited (Giulianotti, 2002, p.33). Thus, in order to address the importance of experiences, a fourth set of drivers is added to the existing set. Drawing on motivation variables found in the fan motivation scales of Wann (1995), Milne and McDonald (1999), and Trail and James (2001), it consists of the motives excitement, enjoyment, stadium atmosphere and escape from daily routines. This is also a consequence of prior findings that point out that particular fan segments primarily attend games for, so called, functional reasons (Summers et al., 2007). A total of 16 identification drivers is therefore selected to be assessed in this research. 
Figure 4 shows the 16 identification drivers and the categories in which they are grouped:

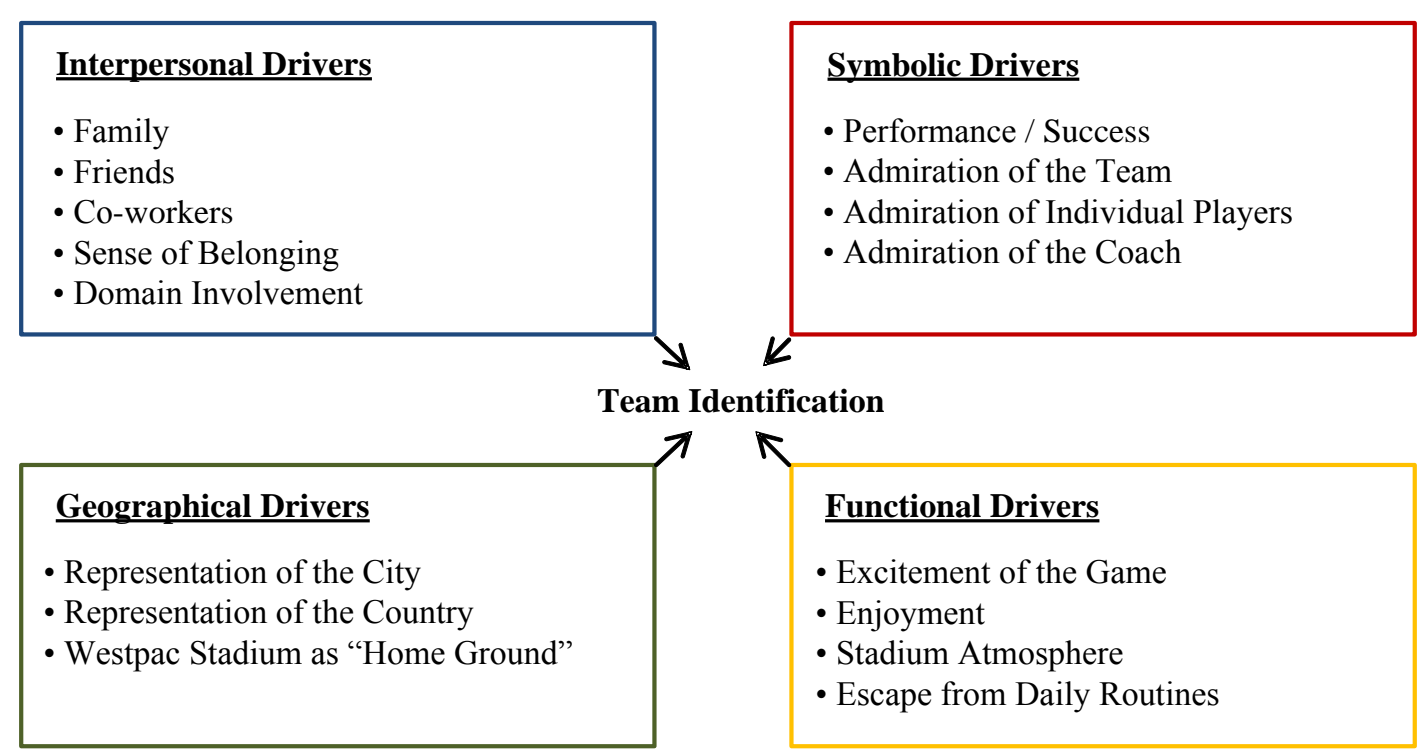

Figure 4: Driver Categorization

It may be noted that the categorization of 16 drivers in four sets, is similar to the clusters developed by Wann, Tucker, and Schrader (1996) in their analysis of the reasons for individuals to form and maintain their identification with sports teams. Wann et al. (1996) clustered relevant drivers into the three groups: success of the team, geographical location, and the influence of friends/peers. A similar categorization was undertaken by Kolbe and James (2000), who assessed the motives of 518 long-term season ticket holders for identification with the professional American Football League (NFL) team Cleveland Browns. For this, the authors used similar categories describing the influence of family and friends, attraction to specific players or the coach, the connection of the club to the fans' hometown, stadium atmosphere, tradition of the club, and the identification with other Cleveland Brown fans.

In addition to the assessment of the importance of identification drivers, an assessment of the fan identification level is necessary. Identification with a sports team is not a monolithic concept and there are different ways of assessing fan identification (Foster \& Hyatt, 2007), including unidimensional and multidimensional methods. In this research, the Sports Spectator Identification Scale (SSIS) by Wann \& Branscombe (1993) is used to assess fan identification. With the SSIS, fan identification is evaluated as a unidimensional construct. Attempts to 
create scales that incorporate multidimensional constructs have been undertaken. One example is the TEAM*ID scale of Heere and James (2007) which considers the six dimensions: public evaluation, private evaluation, interconnection of self, sense of interdependence, behavioural involvement, and cognitive awareness. However, the development of multidimensional scales has not reached the stage of being an acceptable operational construct that is also both reliable and valid (Heere \& James, 2007).

\subsection{Summary}

The literature review sought to build a basic understanding of previous work on the area addressed in this research. It provided insights into sport fandom, fan motives, formation of fan identities and fan identification drivers. The elaboration of fan identity formation was underpinned by a social identity theory perspective. Furthermore, the value of fan identification for sports marketers and various strategies to positively influence fan identification were discussed. Lastly, the literature review allowed for a development of a theoretical framework including the selection of 16 identification drivers to be assessed in this research. 


\section{CHAPTER 3: METHODOLOGY}

Chapter 3 describes the research methodology. It starts by outlining research objectives, hypotheses, and underlying philosophical assumptions. It then describes the research approach and data analysis. Following that, aspects around reliability, validity, and generalizability are discussed. Lastly, limitations that arise from the methodology are named.

\subsection{Research Objectives}

Four main objectives of this research are outlined in this section. Subordinate aims are listed below each objective.

\subsubsection{Overview of Sample Characteristics}

The first objective is to provide an overview of the nature and representativeness of the sample.

Objective 1: Description of sample characteristics

Aim 1: Provide of an overview of the sample structure

Aim 2: Compare sample characteristics with latest New Zealand census data

\subsubsection{Fan Identification}

The second objective is to present the results of the SSIS analysis to show and describe the level of fan identification of the participants. The distribution of fan ID scores (SSIS scores) is then used to define distinct fan identification levels (fan ID levels) which serve for further analyses.

Objective 2: Assessment of the participants' fan identification

Aim 1: Provide descriptive statistics on mean ID scores

Aim 2: Illustrate distribution of ID scores throughout the sample

Aim 3: Present descriptive statistics for each of the seven SSIS questions

Aim 4: Create fan ID levels based on distribution of ID scores 


\subsubsection{Fan Analysis}

The third objective is to undertake a fan characterization. This allows for an examination to link fan characteristics to fan ID levels, which provides more detailed insights about Wellington Phoenix' fan structure.

Objective 3: Identification of participants' fan characteristics and their relationship with fan ID levels

Aim 1: Provide insights about participants' fan characteristics

Aim 3: Identify differences in fan characteristics associated with fan ID levels

\subsubsection{Fan Identification Drivers}

The fourth objective focuses on the fan identification drivers. Descriptive statistics are presented and an analysis of structural patterns among the drivers is undertaken. Subsequently, the relationships between the identification drivers and the fan ID levels are analysed. The findings are used to test the research hypotheses.

Objective 4: Analysis of fan identification drivers

Aim 1: Provide descriptive statistics of identification drivers in consideration of demographic and fan characteristics

Aim 2: Identify structural patterns among the 16 identification drivers

Aim 3: Analyze relationships between identification drivers and fan ID levels

Aim 4: Test hypotheses

\subsubsection{Marketing Implications}

The last objective is to discuss potential marketing implications according to the findings of the data analysis.

Objective 5: Discussion of marketing implications

Aim 1: Undertake fan profiling based on fan ID levels and relationship with identification drivers

Aim 2: Discuss potential marketing strategies to increase fan identification among fans 
An overview of the data analysis and the methods used to achieve these objectives is presented in section 3.5. The following section illustrates the hypotheses of this research.

\subsection{Research Hypotheses}

This research is exploratory in nature. The lack of previous research on the relationship between the level of fan identification and the underlying drivers to become a fan, has not been adequately filled since it was mentioned by Wann et al. (1999). Nevertheless, the literature review supports the formulation of two hypotheses.

Hypothesis 1 focuses on structural patterns among the identification drivers. Based on prior research findings, a categorization according interpersonal, symbolic, geographical, and functional characteristics was undertaken. Hypothesis 1 states that structural patterns among the drivers will be identified that reflect this categorization.

H1: Factor groups derived from a factor analysis show structural similarities to the initial categorization of identification drivers capturing interpersonal, symbolic, geographical, and functional characteristics. These patterns are manifest in terms of within-groups correlations being stronger than inter-group correlations.

Due to the exploratory nature of this research, literature has not provided much evidence on the relationship between individual identification drivers and the level of fan identification. One exception, in which evidence of the relationship between an identification driver and the level of fan identification has been provided, is the driver success. According to Wann and Branscombe (1990), the attendance of highly identified fans is less dependent on the actual success of the team than would be the attendance of lowly identified fans. It is suggested that, despite the young age of Wellington Phoenix, this relationship can be confirmed in the current research. Hence, the importance of the driver success is expected to be lower, the higher the level of fan identification is.

H2: There is a statistically significant relationship between the driver success and the level of fan identification. This relationship reflects that success becomes less important, the higher the level of fan identification is. 
Figure 5 illustrates the kind of relationship that is expected between the driver success and the level of fan identification. However, no assumptions are made on the steepness of the graph.

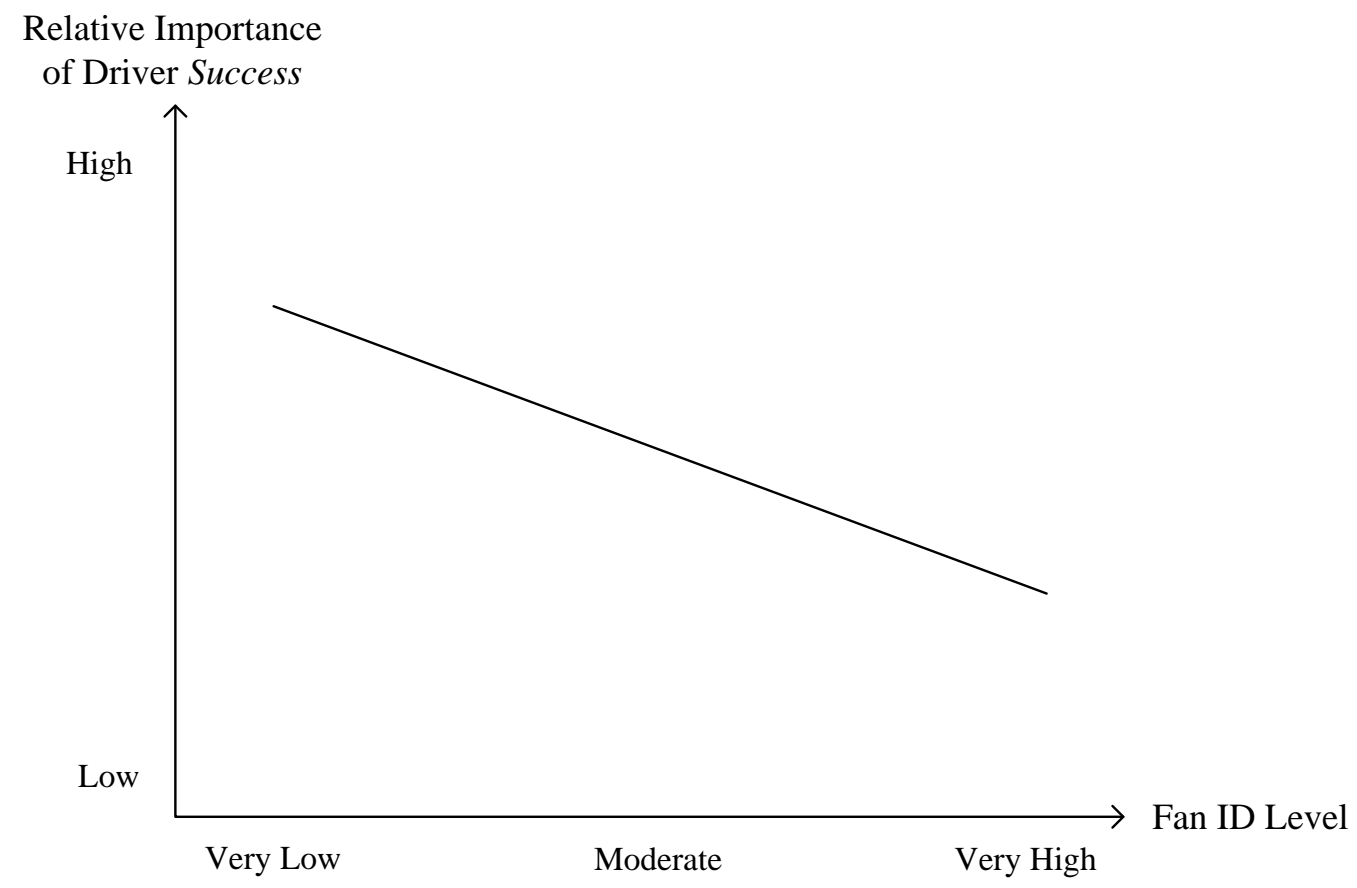

Figure 5: Hypothesis 2

As mentioned earlier, research literature has not provided much evidence on the relationship between identification drivers and the level of fan identification, other than for the driver success. Therefore, no further hypotheses are developed. However, as a primary objective of this research is to explore possible relationships, analyses are performed on all 16 fan identification drivers. These analyses seek to reveal statistically significant relationships between the drivers and the level of fan identification as well as to describe these relationships. The following sections cover methodological aspects that explain the measures used for testing the hypotheses and to achieve the objectives of this research. It starts by describing the philosophical assumptions underpinning this research.

\subsection{Research Philosophy}

This research was conducted from a positivist perspective. The key assumption of positivism is that reality is external and objective and that its properties can be measured using objective methods (Easterby-Smith, Thorpe, \& Jackson, 2008). The purpose of positivist research is to produce knowledge that is not biased by the 
beliefs or desires of the researcher (O'Leary, 2004). This research aims at enhancing knowledge about the relationship between fan identification and identification drivers. It does so by seeking to provide measures of fan identification and identification drivers, and then seeking to quantify relationships between them. Furthermore, the philosophical assumptions of positivism support the use of hypotheses and underpin the importance of generalization (Easterby-Smith et al., 2008). To allow for generalizability, positivist approaches are often associated with cross-sectional analyses with large sample sizes. This research is empirical and hypothesis-driven. A structured questionnaire was chosen as the instrument to collect the data, and administered to a cross-sectional convenience sample of more than 500 participants, providing opportunity to determine the statistical significance of results. The issues of validity, reliability, and generalizability are addressed in greater detail in sub-section 3.6.

\subsection{Research Approach}

This section describes the research approach, starting with the research instrument and design. It then provides information about the sample and mentions ethical considerations.

\subsubsection{Questionnaire}

A structured questionnaire was chosen as the instrument to collect the data. The questionnaire contained a total of 38 questions in four sections. A pilot study was conducted to assess the ease of use and understanding of the questionnaire. In this pilot study, 15 participants tested the questionnaire and provided constructive feedback on the clarity of the questions as well as on design and style related issues. The feedback provided was then used to modify and improve the questionnaire. Subsequent to the development of the final questionnaire, a web version was created using Qualtrics Survey Software. The additional web-based instrument had various advantages. Firstly, the data collection via the web survey did not generate any costs. Secondly, the Qualtrics software offered a feature to force answers to particular questions. As a result, missing values were avoided. Finally, the web-based survey facilitated participation of people that could not be directed in person or who were not accessible to interview. Therefore, further channels and ways of approaching participants became possible. 


\subsubsection{Research Design}

In positivist research, concepts need to be operationalized so that facts can be measured quantitatively (Easterby-Smith et al., 2008). The two main concepts of this research are fan identification and identification drivers. This section describes how the two main concepts are operationalized and shows the structure of the questionnaire. The questionnaire consisted of four sections. Section A contained questions about the participant's fan characteristics such as questions about the type of spectator (season ticket holder, regular visitor, occasional visitor, non-visitor), the season in which the support commenced and the number of games attended in the previous season. Furthermore, fan behaviour related questions were included. These questions focused on the way, games are usually attended (alone, in groups of 2-3 people, in groups of 4-6 people, with 7 people or more); and who the games are normally attended with (family members, friends, co-workers, other). Finally, section A asked for the preferred medium to follow games (Westpac Stadium, television, newspaper, internet, radio) and how often merchandise is worn during and outside of games. Section B addressed the concept of fan identification. To assess fan identification, the seven SSIS question items of Wann and Branscombe (1993) were customized to accommodate Wellington Phoenix and to fit the current research (table 2). An 8-point Likert scale was used to assess the scores for each of the seven questions. The sum of the scores represents the Fan ID Score, which consequently can range between 7 and 56 .

\section{Seven SSIS Question items to measure fan identification:}

1. How important is it to you that Wellington Phoenix wins?

2. How strongly do you see yourself as a fan of Wellington Phoenix?

3. How strongly do your friends see you as a fan of Wellington Phoenix?

4. During the season, how closely do you follow the Phoenix via any of the following: in person, television, radio, internet, or newspaper?

5. How important is being a fan of Wellington Phoenix to you?

6. How much do you dislike the Wellington Phoenix' greatest rivals?

7. How often do you display the Wellington Phoenix name or insignia at your place of work, where you live, or on your clothing? 
Section $\mathrm{C}$ focused on the assessment of the identification drivers. As mentioned in the theoretical framework, a set of 16 drivers was developed based on the findings of the literature review. In order to assess the importance of these drivers to the participants, 16 statements were formulated (table 3). An 8-point Likert scale was used to assess the relevance of each driver.

\begin{tabular}{|c|c|c|}
\hline Question: I support Wellington Phoenix... & Identification Drivers & Level \\
\hline ...because of my personal interest in football & Domain Involvement & Interpersonal \\
\hline $\begin{array}{l}\text {...because the Phoenix represent Wellington and } \\
\text { the surrounding regions }\end{array}$ & Representation of the City & Geographical \\
\hline ...due to the team's performance/success & Performance / Success & Symbolic \\
\hline ...because family members also support them & Family & Interpersonal \\
\hline ...due to my admiration for the team & Admiration for the Team & Symbolic \\
\hline $\begin{array}{l}\text {...because I enjoy the stadium atmosphere (e.g. } \\
\text { crowd antics, chanting etc.) }\end{array}$ & Stadium Atmosphere & Functional \\
\hline ...because it offers an escape from daily routines & $\begin{array}{l}\text { Escape from Daily } \\
\text { Routines }\end{array}$ & Functional \\
\hline ...because my friends are fans too & Friends & Interpersonal \\
\hline ...due to my admiration for the coach & Admiration for the Coach & Symbolic \\
\hline $\begin{array}{l}\text {...because Wellington Phoenix represents the } \\
\text { only New Zealand team in the A-League }\end{array}$ & $\begin{array}{l}\text { Representation of the } \\
\text { Country }\end{array}$ & Geographical \\
\hline ...for leisure/enjoyment & Enjoyment & Functional \\
\hline ...because I feel a sense of belonging in the crowd & Sense of Belonging & Interpersonal \\
\hline ...due to my admiration for individual players & $\begin{array}{l}\text { Admiration for Individual } \\
\text { Players }\end{array}$ & Symbolic \\
\hline ...because of the excitement of the game & Excitement of the Game & Functional \\
\hline ...because my co-workers are fans too & Co-workers & Interpersonal \\
\hline $\begin{array}{l}\text {...because the Westpac Stadium is our "home } \\
\text { ground" }\end{array}$ & $\begin{array}{l}\text { Westpac Stadium as } \\
\text { "Home Ground" }\end{array}$ & Geographical \\
\hline
\end{tabular}

Table 3: Operationalization of Identification Drivers

Across the following sections, the 16 identification drivers will be addressed by the following terms: involvement, city, success, family, team, atmosphere, escape, friends, coach, country, enjoyment, belonging, players, excitement, co-workers, and stadium. 
Lastly, section D was included to obtain personal data such as gender, age, marital status and number of children. Furthermore, this section asked for information about both the participants' and the children's active engagement in football.

\subsubsection{Sample}

Data collection was undertaken in July and the first half of August 2010. It was planned to finish data collection before the start of the season 2010/2011 in order to avoid any kind of influence by recent game outcomes on the responses. To achieve a representative sample in terms of demographic characteristics and spectator type, different channels and events were used to approach participants. Firstly, representatives of various local football clubs were contacted and asked to support this research by sending the web-link of the online questionnaire to active and passive members of the clubs. In many cases, team captains and coaches were approached. A variety of types of teams regarding age groups and gender were addressed based on the assumption that the approach of people with an active interest in football would lead to a high response rate. Furthermore, the coverage of different types of teams provided for a representative sample regarding gender and age. Secondly, different university settings such as the library or resident halls were selected to approach young female and male fans. Thirdly, two postings were made on the internet forum of the Wellington Phoenix supporter club Yellow Fever at different times. As this community is known to have a strong commitment towards the club, it was expected to gain a number of regular visitors and season ticket holders through this channel. Finally, the All-Whites/Wellington Phoenix street parade was used to personally approach participants. This event was expected to attract people from a wide range of demographic characteristics. Table 4 shows the number of responses from each channel/event and the intended target group:

\begin{tabular}{lcccc} 
Target & Football Clubs & University & Yellow Fever & Street Parade \\
\hline Gender & male/ female & male/ female & male/ female & male / female \\
\hline Age & $13-65$ & $16-30$ & all & all \\
$\begin{array}{l}\text { Spectator } \\
\text { Type }\end{array}$ & all & $\begin{array}{c}\text { occasional/ } \\
\text { regular }\end{array}$ & $\begin{array}{c}\text { regular/ season } \\
\text { ticket }\end{array}$ & all \\
Responses & 150 & 70 & 200 & 100 \\
\hline
\end{tabular}

Table 4: Data Collection Sources 
A total of 517 people participated in this research. Around 350 participants made use of the online questionnaire and around 170 used the printed questionnaire. During the All-Whites/Wellington Phoenix street parade, 3 Master's students assisted in approaching participants. This was done to ensure a large number of responses from the 2-hour event. Participants who were approached in person were offered a chocolate bar after completion of the questionnaire.

\subsubsection{Ethical Considerations}

Human Ethics Committee approval was granted by Victoria University of Wellington prior to the commencement of the data collection. Data collection was undertaken via an anonymous questionnaire. Participants could at no time be identified based on the answers given. Furthermore, none of the questions asked for sensitive information. As a result of that, no complaints about the questionnaire or individual questions have been reported. Through an information sheet, participants were informed that participation is voluntary and anonymous. Additionally, it was communicated that all data will be reported in aggregate form. Finally, participants were informed that access to the research data is restricted to the researcher and his supervisors and will be destroyed at the end of the research.

\subsection{Data Analysis}

Data analysis is necessary to make sense of the collected data. Results and findings of the data analysis can then be used to achieve the research objectives and to test the hypotheses. This section describes the statistical approaches used in this research.

Descriptive statistics were used to examine participants' demographic data and fan characteristics as well as for the assessment of fan identification. The descriptive statistics included univariate as well as multivariate analyses such as crosstabulations. A multivariate factor analysis was performed to explore the structure and potential patterns among the 16 identification drivers. The factor analysis identified groupings of variables, as factors, and as factor scores, that account for the variability inherent in the data. The factors are ranked in order of the variability that they account for; and the variables within a factor are ranked according to their correlation with the factor score. Pattern and meaning is then sought for the major factors, by 
assessing the coherence and communality shared by the major variables in any factor. Results of this factor analysis were used to test hypothesis 1 .

For the analysis of the relationship between fan identification and identification drivers, five different fan ID levels were defined and the sample was categorized according to these fan ID levels. In a second step, the identification driver scores were normalised relative to the individuals' mean scores across all drivers. For each of the five different fan ID levels, mean relative scores were then built. These means reflect the relative importance of each identification driver in each of the fan ID levels. This approach allowed to rank the drivers for each fan ID level based on their relative importance. Subsequently, relationships between identification drivers and fan ID levels were identified using one-way analysis-of-variance (ANOVA) tests. Relationships that show statistical significance were then explored further and described using correlation and regression analyses.

The two software programs used to support the data analysis are Microsoft Excel and SPSS. The descriptive univariate analysis of the 16 identification drivers was done using Excel spreadsheets. For further descriptive statistics of the participant's demographic and fan characteristics as well as for the multivariate factor analysis, correlation and regression analyses, SPSS was used. For analyses that were undertaken with Microsoft Excel, results were rounded to 2 decimals points.

\subsection{Reliability, Validity \& Generalizability}

This section comments on issues related to reliability, validity, and generalizability of the results.

\subsubsection{Reliability}

Reliability represents the extent to which an instrument, measure or procedure provides the same results when repeated several times (O'Leary, 2004). There are different ways to test reliability. One possibility is to administer a questionnaire a second time to the same participants. As the data collection in this research was undertaken anonymously, this was not possible. A further possibility to test reliability is using constructs that are measured by multiple question items. This was done in the case of fan identification which was assessed via seven SSIS question items (Wann \& Branscombe, 1993). Further constructs were identified through the 
factor analysis. Reliability tests were performed on both the construct of fan identification and the constructs identified by the factor analysis. The measurement of reliability in this research is based on internal consistency and is done with the Cronbach's $\alpha$ method. This research is of exploratory nature. According to Straub, Boudreau, and Gefen (2004), values of .70 for confirmatory research and .60 for exploratory research are considered acceptable.

\subsubsection{Validity}

Validity seeks to confirm the accuracy of the gained data and findings in relation to the situation that is being studied (O'Leary, 2004). It therefore indicates that the methods used in a study warrant the conclusions that are drawn. In positivist research, it is of particular importance that results accurately reflect reality.

Different types of validity are discussed in the literature. The three types of validity that are elaborated in this section are internal validity, construct validity and external validity. Internal validity relates to systematic factors of bias and means that alternative explanations for the observations and results can be eliminated (EasterbySmith et al., 2008). For this study, internal validity is addressed through an extensive literature review. All variables used in the questionnaire were developed in alignment with the findings of this literature review. Furthermore, a pilot study with feedback sessions was included to test the comprehension of all questions. This ensured that the research instrument is more likely to accurately reflect the situation that is being studied. Construct validity refers to the operationalization of the constructs used. The emphasis is on how well instrument items fit together in order to capture the essence of a construct (Straub et al., 2004, p.388). The only construct that was initially used in this research was fan identification. For the assessment of fan identification, the Sports Spectator Identification Scale (SSIS) of Wann and Branscombe (1993) was chosen. This construct, consisting of seven questions, has since been used by many researchers to measure fan identification (e.g. Wann et al., 2000; Lock et al., 2009 etc.). Further constructs were identified through a multivariate factor analysis. External validity relates to the generalizability of the findings (Easterby-Smith et al., 2008) and will be discussed in the following section. 


\subsubsection{Generalizability}

Generalizability means that findings gained and conclusions made based on a specific sample or setting are directly applicable to a wider population or a different setting (O'Leary, 2004). To be able to generalize research findings, samples of sufficient size need to be taken (Easterby-Smith et al., 2008). The objective is to acquire a sample set from which inferences can be drawn about the population. According to O'Leary (2004), an appropriate sampling strategy is necessary to ensure a broad and adequate representation of the population. In this research, a large sample size of 517 participants was achieved. Furthermore, different channels and events were used to make sure that participants with different demographic characteristics could be targeted and approached. At the beginning of chapter 4 , an overview of the sample characteristics is provided. Later, the sample set is compared to the latest census data for New Zealand.

With regards to the setting, generalizability appears to be difficult to achieve, and sometimes, may not be appropriate, either within the fan community of Wellington Phoenix or in terms of other football clubs. Data collection mainly focused on fans within the Wellington region. It cannot be assumed that fans who live outside of Wellington support the team for the same reasons. For example, Wellington based fans might have a stronger tendency to support the team as they represent their home town. Generalizability in the sense of other football clubs is not sought. The reason for that is that many factors have a potential influence on aspects of identification. Such factors include the history, tradition or the location of a football team or the general standing of football in the society. As these factors vary from club to club, generalization of findings and conclusions towards other football clubs is not possible. Furthermore, generalizability in the sense of other sport disciplines is not appropriate. Wenner and Gantz (1989) argue that different motivational patterns exist for different sport disciplines. For example, the motive excitement of the game has proven to be much more relevant to fans of basketball teams than to fans of baseball teams (Wann et al., 1999). These motivational patterns must therefore be considered when applying the developed framework to fans within different sports disciplines. The following section mentions limitations that arise from this methodology. 


\subsection{Limitations of the Methodology}

The first limitation refers to the sample structure. Funk and James (2006) mention that team identification is more apparent in men than in women. Furthermore, age and cultural backgrounds may lead to differences with regards to the functional, emotional and symbolic attachment to a sports team. Although targets regarding demographic characteristics of participants were set, it is questionable whether the sample precisely matched the actual fan structure. However, this risk is accepted, as the main objective of this research is to explore fan identification and its relationship with identification drivers. For this objective to be achieved, it is argued to not be essential to precisely match the demographic characteristics of the fan structure.

The second limitation stems from a general weakness associated with questionnaire survey instruments. As the survey instrument was self-administered, questions carry the risk of being misunderstood, and without researcher intervention, may remain misunderstood. However, the risk of ambiguity within the questionnaire was reduced by running a pilot study with feedback sessions.

Lastly, a limitation exists regarding the geographical location of the participants. The fan base of Wellington Phoenix is certainly not limited to the Wellington region. However, the questionnaire included various drivers that address the attendance of live games (enjoyment, excitement, escape, belonging, atmosphere) or otherwise assume the Wellington region to be home of the participants (city, stadium). Therefore, the ratings of these drivers are likely to be affected by participants that live outside the Wellington region. Three out of four channels and events used to collect data (local football clubs, Victoria University and the street parade) took place in Wellington. There is no data relating to the geographical base of the 200 participants recruited through the Yellow Fever online forum. However, results show that $96.0 \%$ of Yellow Fever participants declared to attend games occasionally, regularly or with a season ticket. We may therefore presume that most of these participants live in the Wellington region, within travel distance of the Westpac Stadium home ground. 


\subsection{Summary}

The methodology chapter has sought to clarify research objectives, hypotheses, underlying philosophical assumptions, and the research approach, including an operationalization of the concept fan identification and the 16 fan identification drivers. Subsequently, the data analysis process was described. Finally, reliability, validity, and generalizability as well as limitations of this research were discussed. The findings of the data analysis are presented in chapter 4. 


\section{CHAPTER 4: DATA ANALYSIS AND RESULTS}

In chapter 4, an overview of the data analysis and results is provided. Firstly, research sample characteristics are presented. Following that, results of the measurement and analysis of participants' fan identification are shown. Based on those results, a definition of five distinct fan identification levels is developed and described. In an extended fan analysis, these fan identification levels are then used to explore the relationship between specific fan characteristics and fan identification. Subsequently, the results of an analysis of the fan identification drivers are presented. Structural patterns among the drivers, identified with a multivariate factor analysis, are then shown, manifested as factor groups. The factors, so determined, are used to group the drivers for further analyses. An analysis of the relationship between fan identification and identification drivers is then performed by connecting relative driver scores with the five fan ID levels. This analysis encompasses one-way ANOVA tests, correlation and regression analyses and a meta-analysis presented in the form of a driver - fan ID matrix. This chapter closes by elaborating on possible limitations of the data analysis. Tables to all statistical data illustrated in this chapter can be found in the appendix.

\subsection{Sample Characteristics}

Among the 517 participants, $77.6 \%$ (401) were male and $22.4 \%$ (116) female. The distribution based on age shows that respondents spanned the defined age classes with participants in the age group of 21-25 years representing the largest group. Due to low numbers of participants in the age groups $\leq 15$ years, 61-65 years, and $\geq 66$ years, tests of statistical significance were not appropriate for these groups. Therefore, it was decided to merge the age groups $\leq 15$ years and $16-20$ years to be a new age group $\leq 20$ years. Likewise, the age groups $56-60$ years, $61-65$ years and $\geq 66$ years were merged towards a new age group $\geq 56$ years.

In table 5, the distribution of participants regarding gender, age, and marital status is illustrated, and shows that major groupings include those of single marital status $(58 \%)$, and married status (38\%). 


\begin{tabular}{|c|c|c|c|c|c|}
\hline \multicolumn{2}{|c|}{ Gender } & Frequency & Percent & Valid & Cumulative \\
\hline \multirow[t]{3}{*}{ Valid } & Male & 401 & 77.6 & 77.6 & 77.6 \\
\hline & Female & 116 & 22.4 & 22.4 & 100.0 \\
\hline & Total & 517 & 100.0 & 100.0 & \\
\hline \multicolumn{2}{|c|}{ Age } & Frequency & Percent & $\begin{array}{c}\text { Valid } \\
\text { Percent }\end{array}$ & $\begin{array}{c}\text { Cumulative } \\
\text { Percent }\end{array}$ \\
\hline \multirow[t]{10}{*}{ Valid } & $\leq 20$ years & 101 & 19.5 & 19.5 & 19.5 \\
\hline & $21-25$ years & 104 & 20.1 & 20.1 & 39.7 \\
\hline & 26-30 years & 58 & 11.2 & 11.2 & 50.9 \\
\hline & $31-35$ years & 53 & 10.3 & 10.3 & 61.1 \\
\hline & $36-40$ years & 56 & 10.8 & 10.8 & 72.0 \\
\hline & 41-45 years & 42 & 8.1 & 8.1 & 80.1 \\
\hline & $46-50$ years & 48 & 9.3 & 9.3 & 89.4 \\
\hline & $51-55$ years & 33 & 6.4 & 6.4 & 95.7 \\
\hline & $\geq 56$ years & 22 & 4.3 & 4.3 & 100.0 \\
\hline & Total & 517 & 100.0 & 100.0 & \\
\hline \multicolumn{2}{|c|}{ Marital Status } & Frequency & Percent & $\begin{array}{c}\text { Valid } \\
\text { Percent }\end{array}$ & $\begin{array}{c}\text { Cumulative } \\
\text { Percent }\end{array}$ \\
\hline \multirow[t]{5}{*}{ Valid } & Single & 302 & 58.4 & 58.4 & 58.4 \\
\hline & Married & 198 & 38.3 & 38.3 & 96.7 \\
\hline & Divorced & 11 & 2.1 & 2.1 & 98.8 \\
\hline & Widowed & 6 & 1.2 & 1.2 & 100.0 \\
\hline & Total & 517 & 100.0 & 100.0 & \\
\hline
\end{tabular}

Table 5: Sample Demographics

Given that $58 \%$ of respondents were single marital status, it is not surprising that almost two-thirds $(64.4 \%)$ of the participants indicated that they did not have children. This group is followed by participants with two children (16.4\%), one child (9.1\%), and three children (7.2\%). The maximum amount of children in the current sample was seven.

Results show that more than three in four participants (77.8\%) can be described as actively engaged in football. Four in ten $(39.5 \%)$ of participants indicated they had played at least 10 seasons in an organized team, league or competition. $15.9 \%$ of the participants played for 1-3 seasons, $12.8 \%$ for 4-6 seasons, and 9.7\% for 7-9 seasons. The remaining participants $(22.2 \%)$ have never played football. In table 6 , the active engagement in football of the participants is shown. 


\begin{tabular}{|ll|r|r|r|r|}
\hline & Frequency & Percent & Valid Percent & $\begin{array}{c}\text { Cumulative } \\
\text { Percent }\end{array}$ \\
\hline Valid & Never played & 115 & 22.2 & 22.2 & 22.2 \\
& 1-3 Seasons & 82 & 15.9 & 15.9 & 38.1 \\
4-6 Seasons & 66 & 12.8 & 12.8 & 50.9 \\
7-9 Seasons & 50 & 9.7 & 9.7 & 60.5 \\
10+ Seasons & 204 & 39.5 & 39.5 & 100.0 \\
Total & 517 & 100.0 & 100.0 & \\
\hline
\end{tabular}

Table 6: Active Engagement in Football

Active engagement in football was also assessed for the children of participants. Almost half $(42.4 \%)$ of the children were actively involved in football. Following a description of the sample characteristics, the next section focuses on the assessment of the participants' level of fan identification.

\subsection{Fan Identification Results}

This section starts by presenting the results and findings from the seven question items making up the SSIS construct. Subsequently, participants' fan identification levels are shown using the mean identification score (ID score). Furthermore, the distribution of ID scores throughout the sample of 517 participants is presented. The mean ID score is then broken down by different age groups. In sub-section 4.2.2, reliability is tested for the construct of fan identification, measured by the seven SSIS question items. Lastly, in subsection 4.2.4, the distribution of ID scores is used to define five distinct fan identification levels.

\subsubsection{SSIS Statistics}

The construct of fan identification can be expressed by the fan ID score. This score represents the cumulated scores assessed by seven SSIS question items. Therefore, it is possible to determine a fan ID score for each participant, as well as a mean fan ID score for the entire sample. Responses to the seven SSIS question items were given by all participants $(\mathrm{n}=517)$. In table 7 , descriptive statistics are provided for each of the seven SSIS question items, ordered by their individual mean scores. 


\begin{tabular}{|c|c|c|c|}
\hline Variable & Mean & Std. Deviation & $\mathbf{N}$ \\
\hline $\begin{array}{l}\text { During the season, how closely do you follow the Phoenix } \\
\text { via any of the following: in person, television, radio, } \\
\text { internet, or newspaper? }\end{array}$ & 6.46 & 1.701 & 517 \\
\hline $\begin{array}{l}\text { How strongly do you see yourself as a fan of Wellington } \\
\text { Phoenix? }\end{array}$ & 6.41 & 1.722 & 517 \\
\hline How important is it to you that Wellington Phoenix wins? & 6.23 & 1.671 & 517 \\
\hline $\begin{array}{l}\text { How important is being a fan of Wellington Phoenix to } \\
\text { you? }\end{array}$ & 5.97 & 1.962 & 517 \\
\hline $\begin{array}{l}\text { How strongly do your friends see you as a fan of } \\
\text { Wellington Phoenix? }\end{array}$ & 5.92 & 2.006 & 517 \\
\hline $\begin{array}{l}\text { How often do you display the Wellington Phoenix name or } \\
\text { insignia at your place of work, where you live, or on your } \\
\text { clothing? }\end{array}$ & 4.01 & 2.491 & 517 \\
\hline $\begin{array}{l}\text { How much do you dislike the Wellington Phoenix' greatest } \\
\text { rivals? }\end{array}$ & 3.44 & 2.188 & 517 \\
\hline
\end{tabular}

Table 7: SSIS Results: Descriptive Statistics

The seven SSIS question items show major differences regarding their individual mean scores. Whilst some items, such as those relating to the frequency of following Wellington Phoenix, the own self-perception of being a fan, and the importance of winning, show mean scores above 6 , two other items demonstrate significantly lower mean scores. These two items are concerned with the intensity to which Wellington Phoenix' greatest rivals are disliked and the name or insignia of Wellington Phoenix is displayed. The difference between the highest (6.46) and the lowest (3.44) mean score is highly statistically significant. Furthermore, it is interesting that the two SSIS items with the lowest mean score also show the greatest variability among all seven items. In the following section, reliability is tested for the overall construct of fan identification.

\subsubsection{Reliability Test of SSIS}

One possibility to test reliability is to use constructs that are measured by multiple items. Fan identification can be viewed as such a construct, as it is measured by seven SSIS items. A reliability test for these items was performed using the Cronbach's $\alpha$ method. The result of this test is an alpha value of .885 (table 8). This 
value clearly exceeds the value of .60 which is considered acceptable for exploratory studies (Straub et al., 2004).

\begin{tabular}{|c|c|c|c|}
\hline \multicolumn{4}{|c|}{ Reliability Statistics } \\
\hline Construct & $\begin{array}{c}\text { Cronbach's } \\
\text { Alpha }\end{array}$ & $\begin{array}{c}\text { Cronbach's Alpha Based } \\
\text { on Standardized Items }\end{array}$ & $\begin{array}{c}\text { N of } \\
\text { Items }\end{array}$ \\
\hline Fan Identification & $\mathbf{. 8 5}$ & $\mathbf{. 8 9 3}$ & $\mathbf{7}$ \\
\hline
\end{tabular}

Table 8: Construct Fan Identification: Reliability Statistics

\subsubsection{Mean ID Score \& Distribution}

Fan identification with Wellington Phoenix can be expressed by the fan ID score. The fan ID score of each participant represents the sum of the scores of the seven SSIS items (Wann \& Branscombe, 1993). Given the range of scores between 1 and 8 for each of the seven items, the total ID score can range between 7 and 56. The sample of 517 participants in this study shows a mean fan ID score of 38.4. The following histogram illustrates the distribution of fan ID scores across the sample.

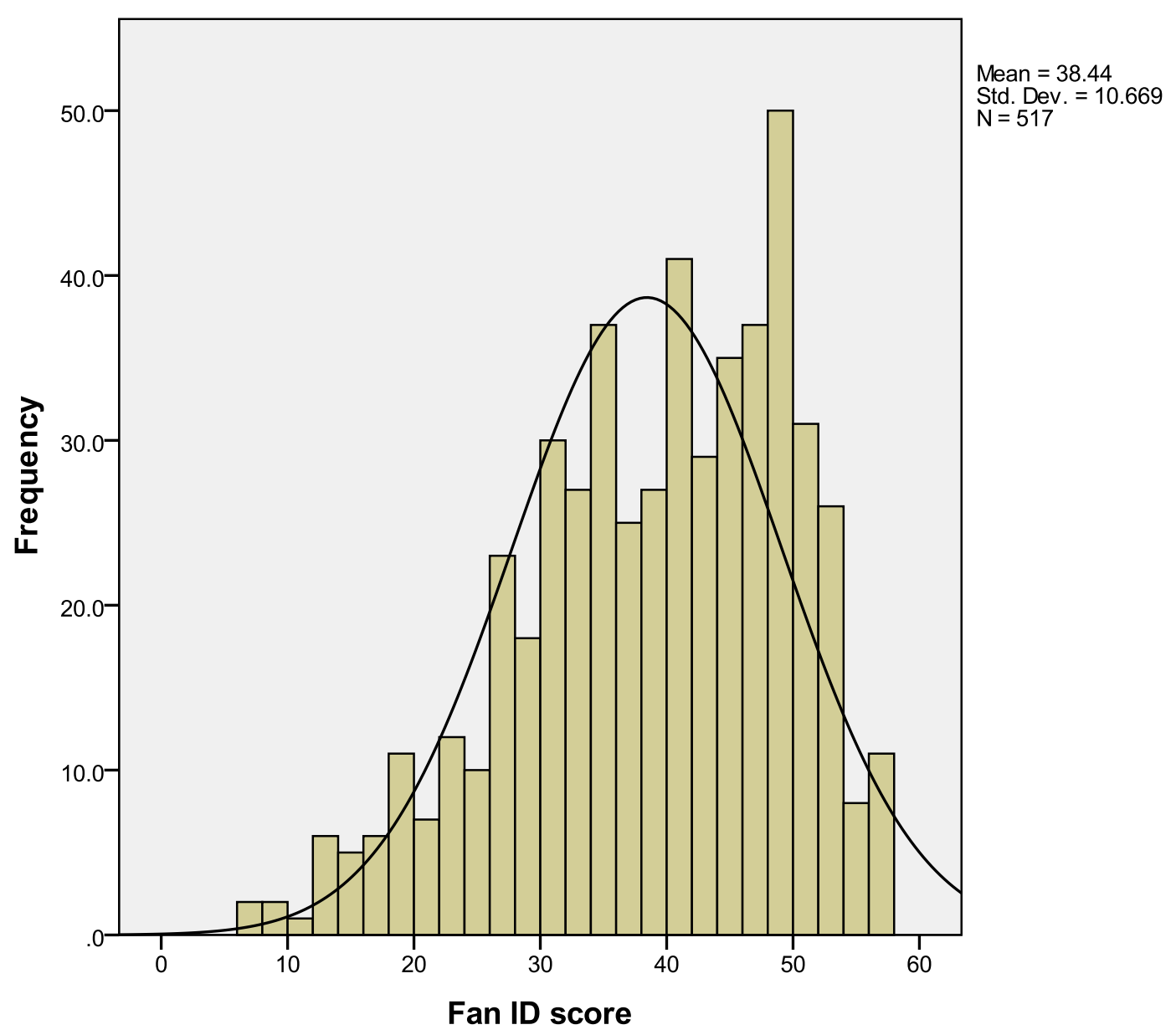

Figure 6: Distribution of Fan ID Scores 
The histogram shows that scores span the entire range of possible fan ID scores, and approximate a bell-shaped curve. The modal fan ID score is 49 . One possible way of testing normality of a distribution is through skewness and kurtosis values. The distribution of fan ID scores in this study shows low values of skewness (-.580) and kurtosis (-.259) (see appendix B2.2). This indicates that the distribution of fan ID scores is close to a normal distribution. Hence, statistical findings regarding the mean fan ID score and the standard deviation possess a high degree of reliability.

\subsubsection{Age - Fan ID Score Relationship}

In order to test whether fan identification is related to the age of the participants, a one-way analysis-of-variance (ANOVA) test was performed. The null hypothesis $H_{0}$ of this ANOVA test stated that different age groups have no effect on the mean fan ID score:

$H_{0}: \mu_{1}=\mu_{2}=\mu_{3}=\mu_{4}=\mu_{5}=\mu_{6}=\mu_{7}=\mu_{8}=\mu_{9}$

$1=$ age group $\leq 20$ years; $2=$ age group $21-25$ years etc.

Consequently, the alternative research hypothesis $H_{1}$ stated that the mean of at least one age group differs from the mean of another age group. The ANOVA test revealed a p-value of .092 (appendix B2.3). As the p-value is higher than .05, the null hypothesis, which states that the mean fan ID score is the same in all age groups, cannot be rejected. Statistically, there is no significant difference in mean fan ID scores between different age groups. However, the graph in figure 7 highlights that the lowest mean fan ID scores occur in the age groups 21-25 years and 26-30 years, whereas the highest mean ID scores can be found at the age group $\geq 56$ years. 


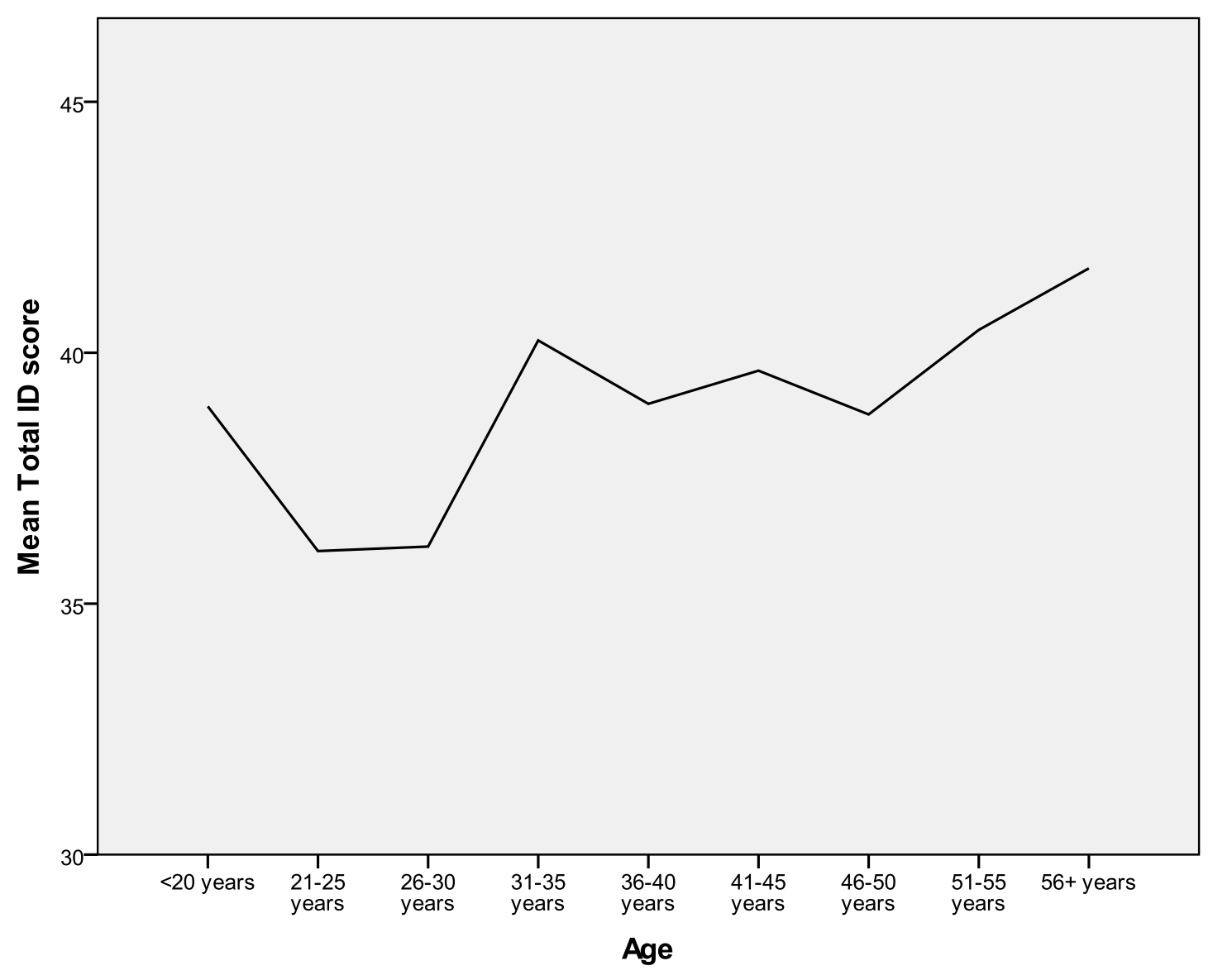

Figure 7: Fan ID Scores by Age

The relationship between age and fan identification was tested using the fan ID scores of participants. In section 4.3, a second test analysis is performed to test the relationship between age and fan identification, using the fan ID level that is defined in the following section.

\subsubsection{Definition of Identification Levels}

In order to explore the relationship between fan identification and identification drivers, participants were then classified according their fan ID scores. Sutton et al. (1997) defined the three discernable levels low identification (social fans), medium identification (focused fans), and high identification (vested fans). Given the purpose of this research, however, it was decided that a definition of five distinct levels of fan identification could more adequately serve to examine the nature and relationship between identification drivers and fan identification. It was furthermore decided to determine these five distinct fan ID levels based on the distribution of fan ID scores across the sample. The fan ID score of 39 was taken as a central point as it is arranged between the mean fan ID score in this research (38.4) and the mean fan ID 
score of 39.3 that was determined as a mean ID score for sports teams by Wann and Branscombe (1993). Table 9 presents the five fan ID levels, each capturing approximately one fifth of the sample respondents, that were defined for this research and the number of participants that are represented by each level.

\begin{tabular}{|lccc|}
\hline Name & $\begin{array}{c}\text { ID Score } \\
\text { Range }\end{array}$ & $\begin{array}{c}\text { Amount of } \\
\text { Participants }\end{array}$ & $\begin{array}{c}\text { Participants } \\
\text { in \% }\end{array}$ \\
\hline very low identification & $\mathbf{7 - 2 8}$ & 96 & 18.6 \\
\hline low identification & $\mathbf{2 9 - 3 5}$ & $\mathbf{1 0 1}$ & $\mathbf{1 9 . 5}$ \\
\hline moderate identification & $\mathbf{3 6 - 4 2}$ & $\mathbf{1 0 5}$ & $\mathbf{2 0 . 3}$ \\
\hline high identification & $\mathbf{4 3 - 4 8}$ & $\mathbf{1 1 3}$ & $\mathbf{2 1 . 9}$ \\
\hline very high identification & $\mathbf{4 9 - 5 6}$ & $\mathbf{1 0 2}$ & $\mathbf{1 9 . 7}$ \\
\hline Total & & & $\mathbf{1 0 0 . 0}$ \\
\hline
\end{tabular}

Table 9: Definition of Fan ID Levels

These fan ID levels are used for further analyses throughout this research. The following section connects the fan ID levels with various fan characteristics.

\subsection{Fan Analysis}

This section starts by analyzing the relationship between the fan ID level as defined above and the participants' age. Following that, the relationship between other fan characteristics such as fan duration, spectator type, preferred spectator medium, form of attendance, and public display of allegiance, with the fan ID level are analyzed.

\subsubsection{Gender - Fan ID Level Relationship}

In order to test whether there is a statistical relationship between the gender of participants and the fan ID level, a chi-square test was performed. The Pearson chisquare statistic revealed a p-value of .000 (appendix B2.5). Therefore, the null hypothesis $H_{0}$, which states that no relationship exists between the gender of participants and the fan ID level, can be rejected. Statistically, there is also a significant difference of fan identification between male and female participants. In fact, figure 8 shows that male participants are more uniformly distributed across all 
fan ID levels than females, but with a tendency towards high (24.2\%) and very high (22.4\%) fan ID levels. This makes almost half of the male participants (46.6\%) very highly or highly identified with Wellington Phoenix. By contrast, less than one in four female participants $(24.1 \%)$ is very highly or highly identified. Furthermore, more than one third of female participants $(34.5 \%)$ however demonstrate a very low fan ID level.

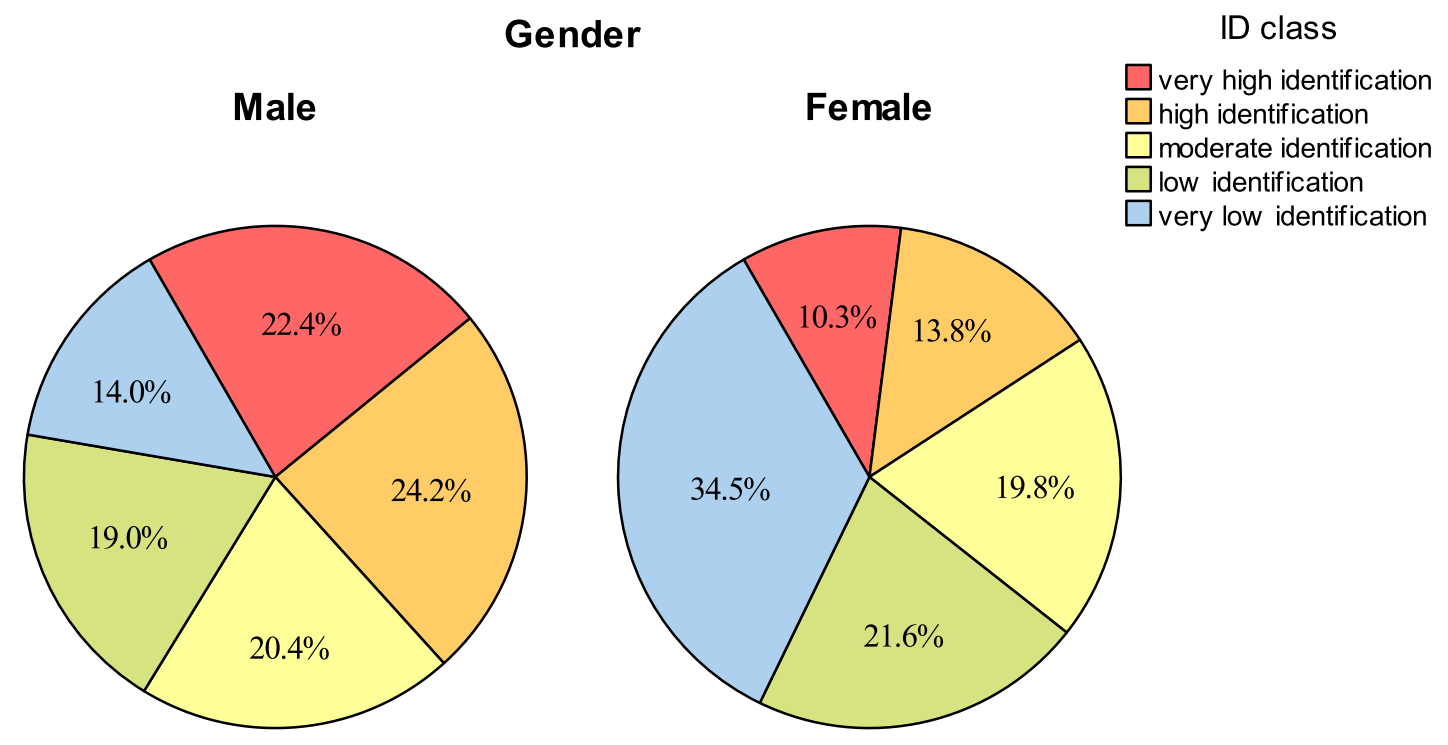

Figure 8: Fan ID Level Distribution by Gender

Similarly, a chi-square test was performed to test whether there is a statistical relationship between the age of participants and the fan ID level.

\subsubsection{Age - Fan ID Level Relationship}

The Pearson chi-square statistic shows a p-value of .682 (appendix B2.4). Therefore, the null hypothesis $\mathrm{H} 0$ which states that no relationship exists between the age of participants and the fan ID level, cannot be rejected. Thus, in contrast to the gender, there is no statistically significant difference of fan ID levels between participants of different age groups. In the following sections, relationships between the fan ID level and other fan characteristics are explored.

\subsubsection{Marital Status - Fan ID Level Relationship}

As with participants' age, marital status does not show a statistically significant relationship with fan ID level. The Pearson chi-square statistic shows a p-value of .435 (appendix B2.6). 


\subsubsection{Fan Duration - Fan ID Level Relationship}

Around two thirds $(66.0 \%)$ of the participants declared to have started supporting Wellington Phoenix in their first season in $2007 / 2008$. One sixth $(17.8 \%)$ had been supporting the club since their second season in 2008/2009, and one in seven (14.1\%) since their third season in 2009/2010. The remaining $2.1 \%$ indicated to have started supporting Wellington Phoenix in the current season 2010/2011. A chi-square test was performed to identify a possible relationship between the fan duration and the fan ID level. A p-value of .000 (Pearson chi-square) indicates that there is a significant statistical relationship between fan duration and the fan ID level (appendix B3.3). In fact, results indicate that higher fan ID levels are associated with higher percentages of individuals who started their fan commitment in the first season in 2007/2008. Almost 9 out of 10 (87.3\%) highly identified participants have been supporting Wellington Phoenix since the club's first season, compared to three quarters $(75.2 \%)$ of moderately identified fans and one third (36.5\%) of very lowly identified fans (table 10).

\begin{tabular}{|l|l|c|c|c|c|c|c|}
\hline \multicolumn{2}{|c|}{} & \multicolumn{7}{|c|}{ Fan Duration * Fan ID Level Cross-tabulation } \\
\cline { 3 - 8 } \multicolumn{2}{|c|}{} & $\begin{array}{c}\text { very low } \\
\text { identification }\end{array}$ & $\begin{array}{c}\text { low } \\
\text { identification }\end{array}$ & $\begin{array}{c}\text { moderate } \\
\text { identification }\end{array}$ & $\begin{array}{c}\text { high } \\
\text { identification }\end{array}$ & $\begin{array}{c}\text { very high } \\
\text { identification }\end{array}$ & Total \\
\hline $\mathbf{2 0 0 7 / 2 0 0 8}$ & in \% & $36.5 \%$ & $43.6 \%$ & $75.2 \%$ & $83.2 \%$ & $87.3 \%$ & $66.0 \%$ \\
\hline $\mathbf{2 0 0 8 / 2 0 0 9}$ & in \% & $21.9 \%$ & $29.7 \%$ & $15.2 \%$ & $14.2 \%$ & $8.8 \%$ & $17.8 \%$ \\
\hline $\mathbf{2 0 0 9 / 2 0 1 0}$ & in \% & $32.3 \%$ & $25.7 \%$ & $9.5 \%$ & $1.8 \%$ & $3.9 \%$ & $14.1 \%$ \\
\hline $\mathbf{2 0 1 0 / 2 0 1 1}$ & in \% & $9.4 \%$ & $1.0 \%$ & $.0 \%$ & $.9 \%$ & $.0 \%$ & $2.1 \%$ \\
\hline Total & in \% & $100.0 \%$ & $100.0 \%$ & $100.0 \%$ & $100.0 \%$ & $100.0 \%$ & $100 \%$ \\
\hline
\end{tabular}

Table 10: Fan Duration * Fan ID Level Cross-tabulation

The next section focuses on the relationship between fan ID level and spectator type.

\subsubsection{Spectator Type - Fan ID Level Relationship}

Approximately one third of the participants (33.8\%) declared to be season ticket holders. Almost one quarter (23.6\%) consider themselves as regular visitors without a season ticket and just over one third (37.1\%) as occasional visitors. The remaining $5.4 \%$ of the participants had never attended a game at the time of survey. On average, participants attended approximately 6.9 games in the previous season 2009/2010. Season ticket holders account for an average of just over 12 games a season, regular visitors 8 games and occasional visitors 2.45 games. Overall, this 
equals an attendance ratio of 3 to 1 for regular to occasional visitors and 5 to 1 for season ticket holders to occasional visitors (see table 11).

\begin{tabular}{|lcc|}
$\begin{array}{l}\text { Spectator Type by } \\
\text { frequency of attendance }\end{array}$ & $\begin{array}{c}\text { Mean } \\
\text { Attendances }\end{array}$ & Ratio \\
\hline Occasional Visitors & $\mathbf{2 . 4 5}$ & $\mathbf{1}$ \\
\hline Regular Visitors & $\mathbf{7 . 9 2}$ & $\mathbf{3}$ \\
\hline Season Ticket Holders & $\mathbf{1 2 . 1 4}$ & $\mathbf{5}$ \\
\hline
\end{tabular}

\section{Table 11: Attendance Ratios}

The stronger emotional commitment of season ticket holders compared to respondents identified as other spectator types is furthermore reflected by differences in the mean fan ID scores. The results of a one-way ANOVA test (p-value: .000) reveals a statistically significant relationship between the spectator type, by frequency of attendance, and the fan ID score (see appendix B3.2). Not surprisingly, season ticket holders show the highest mean fan ID score (45.62) of all spectator types. This group is followed by regular visitors (39.60), occasional visitors (32.32) and individuals who have never attended a game of Wellington Phoenix (30.36) as illustrated in figure 9. 


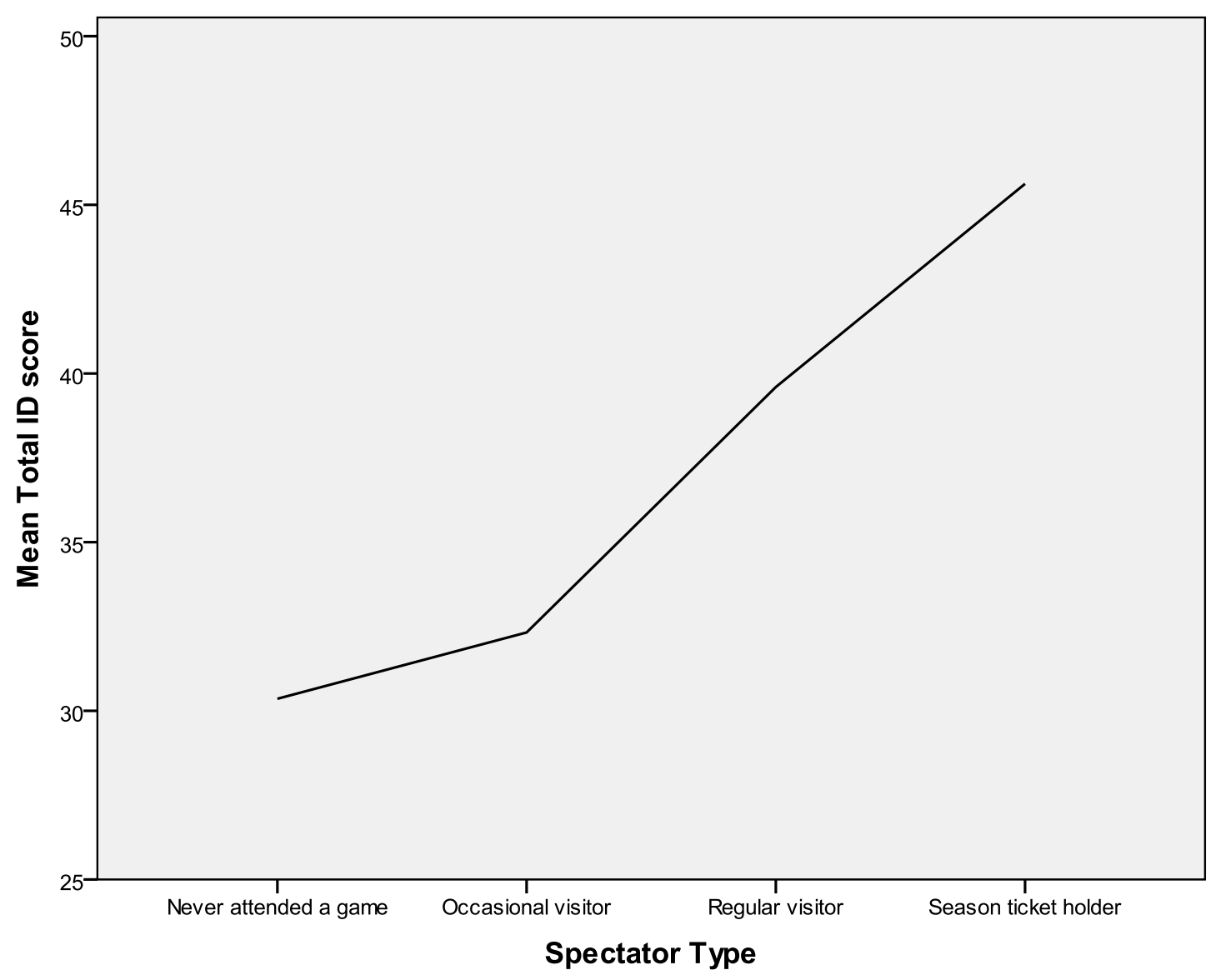

Figure 9: Fan ID Scores by Spectator Type

Figure 10 illustrates the relative distribution of participants of different spectator attendance types into each of the five fan ID levels. The largest percentage of season ticket holders belong to the group of very highly identified fans. Approximately three in four season ticket holders show a high or very high fan identification. Remarkably, the largest grouping (29.5\%) of regular visitors possess low fan identification. More than one third of occasional visitors $(36.5 \%)$ shows very low fan identification and almost two thirds $(62.0 \%)$ are very lowly or lowly identified. Participants who have never attended a game show a similar distribution with almost a half (46.4\%) being very lowly identified and two thirds (64.3\%) showing very low or low fan identification. 


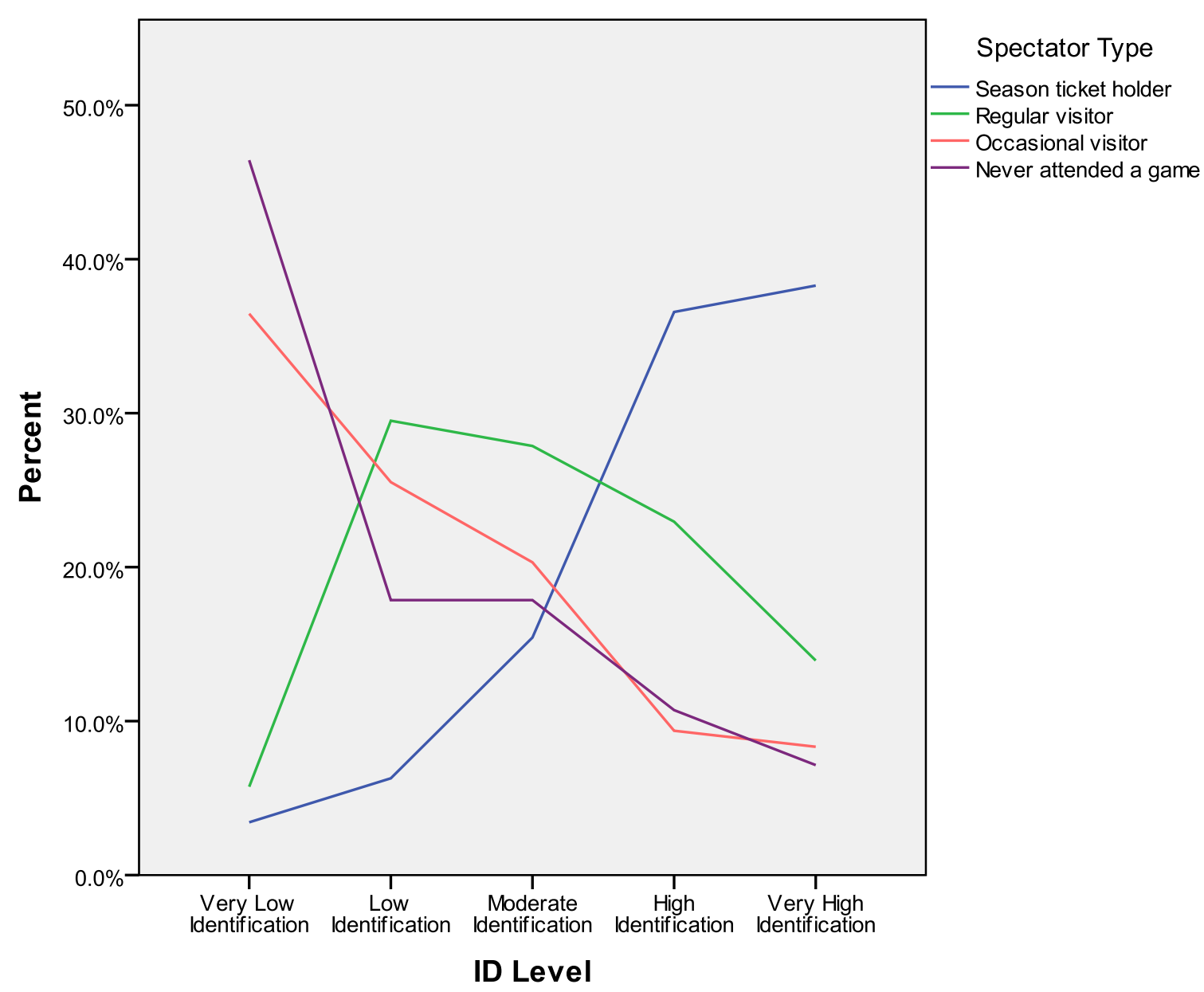

Figure 10: Fan ID Level Ratio by Spectator Type

The results of a one-way ANOVA test (p-value: .000) indicate a statistically significant relationship between the fan ID score and attendance patterns in the season 2009/2010 (see appendix B3.4b). As shown in table 12, the average number of attendances steadily increases with the level of fan identification.

\begin{tabular}{lcc} 
Fan ID Level & N & Mean Attendances \\
\hline very low identification & $\mathbf{9 6}$ & $\mathbf{2 . 5 7}$ \\
\hline low identification & $\mathbf{1 0 1}$ & $\mathbf{5 . 0 9}$ \\
\hline moderate identification & $\mathbf{1 0 5}$ & $\mathbf{6 . 5 2}$ \\
\hline high identification & $\mathbf{1 1 3}$ & $\mathbf{9 . 3 8}$ \\
\hline very high identification & $\mathbf{1 0 2}$ & $\mathbf{1 0 . 3 9}$ \\
\hline Total & $\mathbf{5 1 7}$ & $\mathbf{6 . 9 0}$ \\
\hline
\end{tabular}

Table 12: Mean Attendances by Fan ID Level

The following section focuses on the relationship between fan ID level and preferred spectator medium. 


\subsubsection{Preferred Spectator Medium - Fan ID Level Relationship}

The preferred medium to follow games of Wellington Phoenix is through live attendance at Westpac Stadium (76.6\%). A further one in six (15.9\%) favour television, $5.0 \%$ internet, $1.9 \%$ newspaper and $.6 \%$ most often follow the games on the radio (see table 13). A chi-square test was performed to identify a possible relationship between preferred spectator medium and fan ID level. A p-value of .000 (Pearson chi-square) indicates that a statistically significant relationship exists (appendix B3.5). Indeed, the percentage of participants who prefer to attend games at Westpac Stadium is greater at higher fan ID levels. Whereas less than two thirds $(58.3 \%)$ of very lowly identified fans prefer the Westpac Stadium, more than three quarters $(78.1 \%)$ of moderately identified fans and nine in ten $(90.2 \%)$ of very highly identified fans prefer the live attendance. However, the medium television follows a mirror-image negative pattern, being preferred by only $3.9 \%$ of very highly identified fans, but by $12.4 \%$ of moderately identified fans and by $30.2 \%$ of very lowly identified fans.

\begin{tabular}{|l|l|c|c|c|c|c|c|}
\hline \multicolumn{2}{|c|}{} & \multicolumn{6}{|c|}{ Preferred Spectator Medium * Fan ID Level Cross-tabulation } \\
\cline { 3 - 8 } & & $\begin{array}{c}\text { very low } \\
\text { identification }\end{array}$ & $\begin{array}{c}\text { low } \\
\text { identification }\end{array}$ & $\begin{array}{c}\text { moderate } \\
\text { identification }\end{array}$ & $\begin{array}{c}\text { high } \\
\text { identification }\end{array}$ & $\begin{array}{c}\text { very high } \\
\text { identification }\end{array}$ & Total \\
\hline $\begin{array}{l}\text { Westpac } \\
\text { Stadium }\end{array}$ & in \% & $58.3 \%$ & $71.3 \%$ & $78.1 \%$ & $83.2 \%$ & $90.2 \%$ & $76.6 \%$ \\
\hline Television & in \% & $30.2 \%$ & $23.8 \%$ & $12.4 \%$ & $10.6 \%$ & $3.9 \%$ & $15.9 \%$ \\
\hline Newspaper & in \% & $3.1 \%$ & $2.0 \%$ & $2.9 \%$ & $.9 \%$ & $1.0 \%$ & $1.9 \%$ \\
\hline Internet & in \% & $7.3 \%$ & $3.0 \%$ & $5.7 \%$ & $4.4 \%$ & $4.9 \%$ & $5.0 \%$ \\
\hline Radio & in \% & $1.0 \%$ & $.0 \%$ & $1.0 \%$ & $.9 \%$ & $.0 \%$ & $.6 \%$ \\
\hline Total & in \% & $100.0 \%$ & $100.0 \%$ & $100.0 \%$ & $100.0 \%$ & $100.0 \%$ & $100 \%$ \\
\hline
\end{tabular}

Table 13: Preferred Spectator Medium * Fan ID Level Cross-tabulation

Subsequently to the preferred spectator medium, the usual form of attendance is analyzed starting with the group size when attending games.

\subsubsection{Form of Attendance - Fan ID Level Relationship}

The most common way that participants attend games, is as a part of a group. Few $(6.8 \%)$ of the participants attend games by themselves. Almost half of all participants (47.0\%) most commonly visit the stadium in a group of 2-3 people. More than a third (36.8\%) indicated being part of a group of 4-6, and 9.3\% a group size of 7 people or more. A chi-square test revealed a p-value of .783 (Pearson chi-square). Hence, there 
is no statistically significant relationship between the preferred group size and the fan ID level (see appendix B3.6). Indeed, there is a similar distribution of participants in all group sizes across fan ID levels. Table 14 presents the distribution of participants regarding the preferred group size at games.

\begin{tabular}{|l|c|c|c|c|c|c|c|}
\hline \multirow{2}{*}{} & \multicolumn{5}{|c|}{ Preferred Group Size * Fan ID Level Cross-tabulation } \\
\cline { 2 - 8 } & $\begin{array}{c}\text { very low } \\
\text { identification }\end{array}$ & $\begin{array}{c}\text { low } \\
\text { identification }\end{array}$ & $\begin{array}{c}\text { moderate } \\
\text { identification }\end{array}$ & $\begin{array}{c}\text { high } \\
\text { identification }\end{array}$ & $\begin{array}{c}\text { very high } \\
\text { identification }\end{array}$ & Total \\
\hline By Myself & in \% & $7.3 \%$ & $4.0 \%$ & $4.8 \%$ & $10.6 \%$ & $6.9 \%$ & $6.8 \%$ \\
\hline $\begin{array}{l}\text { Group of } \\
\text { 2-3 People }\end{array}$ & in \% & $50.0 \%$ & $45.0 \%$ & $49.5 \%$ & $43.4 \%$ & $48.0 \%$ & $47.1 \%$ \\
\hline $\begin{array}{l}\text { Group of } \\
\text { 4-6 People }\end{array}$ & in \% & $33.3 \%$ & $42.0 \%$ & $39.0 \%$ & $36.3 \%$ & $33.3 \%$ & $36.8 \%$ \\
\hline $\begin{array}{l}\text { 7 People } \\
\text { or more }\end{array}$ & in \% & $9.4 \%$ & $9.0 \%$ & $6.7 \%$ & $9.7 \%$ & $11.8 \%$ & $9.3 \%$ \\
\hline Total & in \% & $100.0 \%$ & $100.0 \%$ & $100.0 \%$ & $100.0 \%$ & $100.0 \%$ & $100 \%$ \\
\hline
\end{tabular}

Table 14: Preferred Group Size * Fan ID Level Cross-tabulation

In addition to the question about the preferred group size, participants were asked to indicate the type of company or group, with whom they usually attend games. Responses are available for 488 participants who attended with other parties. Almost two thirds $(62.7 \%)$ of the 488 participants indicated to prefer to attend games with friends, followed by nearly one third (29.5\%) who are usually accompanied by family members and $2.9 \%$ who prefer to attend games with co-workers. A Pearson chi-square test shows a p-value of .565 (appendix B3.7), which indicates that there is no statistically significant relationship between the preferred group type and the fan ID level (table 15).

\begin{tabular}{|l|c|c|c|c|c|c|c|}
\hline \multicolumn{2}{|c|}{} & \multicolumn{5}{|c|}{ Preferred Group Type * Fan ID Level Cross-tabulation } \\
\cline { 2 - 8 } & $\begin{array}{c}\text { very low } \\
\text { identification }\end{array}$ & $\begin{array}{c}\text { low } \\
\text { identification }\end{array}$ & $\begin{array}{c}\text { moderate } \\
\text { identification }\end{array}$ & $\begin{array}{c}\text { high } \\
\text { identification }\end{array}$ & $\begin{array}{c}\text { very high } \\
\text { identification }\end{array}$ & Total \\
\hline $\begin{array}{l}\text { Family } \\
\text { members }\end{array}$ & in \% & $27.8 \%$ & $28.3 \%$ & $29.7 \%$ & $33.0 \%$ & $28.4 \%$ & $29.5 \%$ \\
\hline Friends & in \% & $70.0 \%$ & $64.6 \%$ & $64.4 \%$ & $62.1 \%$ & $71.6 \%$ & $66.4 \%$ \\
\hline $\begin{array}{l}\text { Colleagues / } \\
\text { Co-workers }\end{array}$ & in \% & $1.1 \%$ & $5.1 \%$ & $5.0 \%$ & $2.9 \%$ & $.0 \%$ & $2.9 \%$ \\
\hline Other & in \% & $1.1 \%$ & $2.0 \%$ & $1.0 \%$ & $1.9 \%$ & $.0 \%$ & $1.2 \%$ \\
\hline Total & in \% & $100.0 \%$ & $100.0 \%$ & $100.0 \%$ & $100.0 \%$ & $100.0 \%$ & $100 \%$ \\
\hline
\end{tabular}

Table 15: Preferred Group Type * Fan ID Level Cross-tabulation 
The 6 participants, who selected the option other, indicated they usually attended games with family \& friends (3), football team (1), partner (1), and random yellow fever fans (1). The final section concentrates on the relationship between fan ID level and the tendency to publicly display fan allegiance both during and outside of games.

\subsubsection{Public Display of Allegiance - Fan ID Level Relationship}

Overall, almost half of the participants (44.7\%) stated they wear merchandise products such as scarves, jackets, t-shirts or jerseys while attending games. Just one quarter $(28.4 \%)$ indicated they never wear merchandise to games. A Pearson chisquare test (p-value: .000) indicated, there is a statistically significant relationship between the fan ID level and the tendency to wear merchandise during games (appendix B3.8). Indeed, results indicate that higher fan identification leads to a stronger tendency to publicly display fan allegiance by wearing merchandise. This is supported by the fact that $87.3 \%$ of individuals with very high fan identification always wear merchandise at games. For lower fan ID levels, 69.9\% were highly identified, $39.0 \%$ were moderately identified, $17.8 \%$ were lowly identified and only $4.2 \%$ were very lowly identified participants. The obverse may be noted where fan allegiance is never expressed by wearing merchandise at games. Whereas more than three quarters of those with very low fan identification (77.1\%) never wears merchandise at games, this applies to less than a quarter $(24.8 \%)$ of moderately identified fans and only $2.0 \%$ of very highly identified fans (see table 16 ).

\begin{tabular}{|l|l|c|c|c|c|c|c|}
\hline \multirow{2}{*}{\multicolumn{2}{|c|}{}} & \multicolumn{6}{|c|}{ Merchandise at Games * Fan ID Level Cross-tabulation } \\
\cline { 3 - 8 } & $\begin{array}{c}\text { very low } \\
\text { identification }\end{array}$ & $\begin{array}{c}\text { low } \\
\text { identification }\end{array}$ & $\begin{array}{c}\text { moderate } \\
\text { identification }\end{array}$ & $\begin{array}{c}\text { high } \\
\text { identification }\end{array}$ & $\begin{array}{c}\text { very high } \\
\text { identification }\end{array}$ & Total \\
\hline Always & in \% & $4.2 \%$ & $17.8 \%$ & $39.0 \%$ & $69.9 \%$ & $87.3 \%$ & $44.7 \%$ \\
\hline Often & in \% & $6.2 \%$ & $14.9 \%$ & $8.6 \%$ & $8.8 \%$ & $4.9 \%$ & $8.7 \%$ \\
\hline Sometimes & in \% & $5.2 \%$ & $12.9 \%$ & $12.4 \%$ & $13.3 \%$ & $5.9 \%$ & $10.1 \%$ \\
\hline Rarely & in \% & $7.3 \%$ & $16.8 \%$ & $15.2 \%$ & $1.8 \%$ & $.0 \%$ & $8.1 \%$ \\
\hline Never & in \% & $77.1 \%$ & $37.6 \%$ & $24.8 \%$ & $6.2 \%$ & $2.0 \%$ & $28.4 \%$ \\
\hline Total & in \% & $100.0 \%$ & $100.0 \%$ & $100.0 \%$ & $100.0 \%$ & $100.0 \%$ & $100 \%$ \\
\hline
\end{tabular}

Table 16: Merchandise at Games * Fan ID Level Cross-tabulation

The view that higher fan identification leads to a stronger tendency to publicly display fan allegiance by wearing merchandise can also be seen outside of games. A p-value of .000 (Pearson chi-square) indicates that there is also a statistically significant relationship between the fan ID level and the tendency to wear 
merchandise outside of games (appendix B3.9). However, the overall tendency to wear merchandise outside of games is lower. Only $2.3 \%$ of all participants reported to always wear merchandise outside of games. A large majority (83.4\%) of participants with very high fan identification often or sometimes wear merchandise outside of games. Moderately identified fans have a lesser tendency to wear merchandise outside of games, with only one in six $(17.1 \%)$ often wearing team merchandise, one third (33.3\%) sometimes, just over one in five (21.9\%) rarely, and one in four (26.7\%) never. Not surprisingly, most individuals (81.2\%) with very low fan identification never wear merchandise outside of games (see table 17).

\begin{tabular}{|l|c|c|c|c|c|c|c|}
\hline \multirow{2}{*}{\multicolumn{2}{|c|}{}} & \multicolumn{6}{|c|}{ Merchandise outside of Games * Fan ID Level Cross-tabulation } \\
\cline { 3 - 8 } & $\begin{array}{c}\text { very low } \\
\text { identification }\end{array}$ & $\begin{array}{c}\text { low } \\
\text { identification }\end{array}$ & $\begin{array}{c}\text { moderate } \\
\text { identification }\end{array}$ & $\begin{array}{c}\text { high } \\
\text { identification }\end{array}$ & $\begin{array}{c}\text { very high } \\
\text { identification }\end{array}$ & Total \\
\hline Always & in \% & $.0 \%$ & $.0 \%$ & $1.0 \%$ & $2.7 \%$ & $7.8 \%$ & $2.3 \%$ \\
\hline Often & in \% & $.0 \%$ & $3.0 \%$ & $17.1 \%$ & $32.7 \%$ & $51.0 \%$ & $21.3 \%$ \\
\hline Sometimes & in \% & $5.2 \%$ & $14.9 \%$ & $33.3 \%$ & $35.4 \%$ & $32.4 \%$ & $24.8 \%$ \\
\hline Rarely & in \% & $13.5 \%$ & $25.7 \%$ & $21.9 \%$ & $19.5 \%$ & $6.9 \%$ & $17.6 \%$ \\
\hline Never & in \% & $81.2 \%$ & $56.4 \%$ & $26.7 \%$ & $9.7 \%$ & $2.0 \%$ & $34.0 \%$ \\
\hline Total & in \% & $100.0 \%$ & $100.0 \%$ & $100.0 \%$ & $100.0 \%$ & $100.0 \%$ & $100 \%$ \\
\hline
\end{tabular}

Table 17: Merchandise outside of Games * Fan ID Level Cross-tabulation

The next section presents the results of analyses around the fan identification drivers.

\subsection{Analysis of Fan Identification Drivers}

This section starts by presenting descriptive statistics for 16 identification drivers. Results of a multivariate factor analysis are then shown and reliability is tested for the constructs identified. Lastly, relative scores for all drivers are calculated and shown. In addition to the findings of the factor analysis, these relative scores are used in section 4.5 to analyze the relationship between the drivers and fan ID levels.

\subsubsection{Absolute Driver Scores}

Table 18 provides an overview of descriptive statistics of the assessment of 16 identification drivers ranked by their mean driver scores. 


\begin{tabular}{|c|c|c|c|c|}
\hline Variables (Drivers D1-D16) & Mean & $\begin{array}{c}\text { Std. } \\
\text { Deviation }\end{array}$ & $\begin{array}{l}\text { Coefficient } \\
\text { of Variation }\end{array}$ & $\mathbf{N}$ \\
\hline D1: Involvement & 6.64 & 1.750 & .264 & 517 \\
\hline D11: Enjoyment & 6.29 & 1.557 & .248 & 517 \\
\hline D14: Excitement & 6.11 & 1.714 & .281 & 517 \\
\hline D2: City & 5.94 & 1.940 & .327 & 517 \\
\hline D6: Atmosphere & 5.91 & 2.013 & .341 & 517 \\
\hline D10: Country & 5.80 & 2.217 & .382 & 517 \\
\hline D5: Team & 5.09 & 2.089 & .410 & 517 \\
\hline D12: Belonging & 4.74 & 2.272 & .479 & 517 \\
\hline D16: Stadium & 4.50 & 2.427 & .539 & 517 \\
\hline D13: Players & 4.38 & 2.132 & .487 & 517 \\
\hline D9: Coach & 4.10 & 2.219 & .541 & 517 \\
\hline D3: Success & 4.07 & 2.132 & .524 & 517 \\
\hline D8: Friends & 3.83 & 2.168 & .566 & 517 \\
\hline D7: Escape & 3.79 & 2.356 & .622 & 517 \\
\hline D4: Family & 2.66 & 2.122 & .798 & 517 \\
\hline D15: Co-workers & 2.38 & 1.779 & .747 & 517 \\
\hline
\end{tabular}

Table 18: Mean Driver Scores: Descriptive Statistics

The table shows that the mean scores vary to a great extent. Whilst the drivers involvement (6.64), enjoyment (6.29) and excitement (6.11) show relatively high mean scores, the drivers family (2.66) and co-workers (2.38) show low scores. This represents a ratio of approximately 2.8:1 between the highest (6.64) and the lowest (2.38) mean driver score. In addition to the mean driver score, values of standard deviation and coefficient of variation are presented. The coefficient of variation represents the standard deviation divided by the mean. Therefore, it provides an indication of the relative size of variability. The range of standard deviations is relatively small with values from 1.557 (enjoyment) to 2.427 (stadium) and significantly smaller than the range of means. It is interesting to note that the coefficient of variation tends to be low for drivers with high mean scores and high for drivers with low mean scores. For those drivers, having high mean scores and 
low coefficients of variation, correlation with fan ID level may not be expected. Given that the coefficients of variation of all identification drivers are below 1, drivers are generally not anticipated to be highly correlated with fan ID level.

\subsubsection{Structural Patterns of Identification Drivers}

It is suggested that an integral part of the analysis of fan identification drivers is the identification of structural patterns among the drivers. Factor analysis is regarded to be suitable to describe the internal structure of large sets of variables by identifying patterns of variance and correlations within the data (Lawley \& Maxwell, 1962). Therefore, a multivariate factor analysis was conducted to provide insights about the structure within the set of identification drivers. In the first step, initial and extraction communalities for all 16 identification drivers were determined (see appendix B4.1). The two drivers involvement and country showed significantly lower communality scores than all other drivers. As low communality values indicate that variables do not fit well in the factor solution, the drivers involvement and country were excluded from the factor analysis. In order to test if a factor analysis is useful for the reduced set of variables, a Kaiser-Meyer-Olkin Measure of Sampling Adequacy (KMO) test and Bartlett's Test of Sphericity was undertaken (see table 19).

\begin{tabular}{|l|l|l|}
\hline \multicolumn{3}{|c|}{ KMO and Bartlett's Test } \\
\hline Kaiser-Meyer-Olkin Measure of Sampling Adequacy & .863 \\
\hline \multirow{3}{*}{ Bartlett's Test of Sphericity } & Approx. Chi-Square & 2475.114 \\
\cline { 2 - 3 } & df & 91 \\
\cline { 2 - 3 } & Sig. & .000 \\
\hline
\end{tabular}

Table 19: Identification Drivers: KMO and Bartlett's Test of Sphericity

According to Coakes, Steed \& Ong (2009), KMO values larger than .6 and significance values smaller than .05 are acceptable. A KMO value of .866 and a significance level of .000 therefore indicate that the factor analysis is useful for the remaining set of variables. Table 20 shows the results of the factor analysis. Drivers are grouped based on their belonging to the resulting factors. Within the factors, drivers are ordered according their factor loadings. Factor loadings above .5 are determined to be significant. Variables with factor loadings below .5 were not included in the factors. 


\begin{tabular}{|c|c|c|c|}
\hline Variables & $\begin{array}{c}\text { D_FAC1 } \\
\text { Live Experience }\end{array}$ & $\begin{array}{c}\text { D_FAC2 } \\
\text { Admiration }\end{array}$ & $\begin{array}{c}\text { D_FAC3 } \\
\text { Social Network }\end{array}$ \\
\hline D11: Enjoyment & .678 & .206 & -.036 \\
\hline D12: Belonging & .628 & .291 & .211 \\
\hline D6: Atmosphere & .599 & .278 & .198 \\
\hline D14: Excitement & .502 & .446 & .095 \\
\hline D5: Team & .228 & .795 & .129 \\
\hline D13: Players & .347 & .666 & .251 \\
\hline D9: Coach & .243 & .656 & .253 \\
\hline D15: Co-workers & .090 & .162 & .613 \\
\hline D3: Success & .065 & .180 & .612 \\
\hline D4: Family & -.010 & .189 & .598 \\
\hline D8: Friends & .303 & -.014 & .561 \\
\hline D7: Escape & .497 & .099 & .290 \\
\hline D16: Stadium & .393 & .246 & .407 \\
\hline D2: City & .198 & .046 & .313 \\
\hline
\end{tabular}

(Extraction Method: Principal Axis Factoring, Rotation Method: Varimax with Kaiser Normalization, Rotated Factor Matrix - Rotation converged in 4 iterations)

\section{Table 20: Factor Analysis Results}

The results of the factor analysis show a grouping of identification drivers into three main constructs (factors). The three factors account for $45.2 \%$ of variability in the data. Factor 1 consists of the drivers enjoyment, belonging, atmosphere, and excitement. This factor includes three drivers of the functional level as categorized in the theoretical framework of this research as well as the driver belonging. As all drivers of this factor are strongly related to live experiences during the games, this factor was called live experience. The second factor contains the three drivers team, players and coach. These drivers represent three out of four drivers of the symbolic level as categorized in the theoretical framework. Due to the fact that all drivers in this factor describe an admiration for different representatives of the football team, this factor was called admiration. The third factor includes the drivers co-workers, 
success, family, and friends. Predominantly, this factor is influenced by social drivers and, to a high degree, represents the interpersonal level as categorized in the theoretical framework. Therefore, this factor was called social network. The drivers escape, stadium and city show factor loadings below .5. Therefore, these drivers were not included in one of the three factors. Due to low communality scores, the drivers involvement and country were not included in the factor analysis. This results in 5 of the 16 drivers not being included in any of the constructs developed. Interestingly, all drivers of the geographical level (country, city, and stadium), as defined in the theoretical framework, are among the drivers that do not belong to one of the three factors. The following section describes the results of a reliability test of the driver constructs identified by the factor analysis.

\subsubsection{Reliability Test of Driver Constructs}

Although the factor analysis was not undertaken solely to reduce the number of variables, reliability for the 3 constructs was nevertheless assessed. In order to measure the internal consistency of the driver constructs live experience, admiration and social network, Cronbach's alpha test was applied. As shown in table 21, alpha values of all constructs were above .70 . As values above .60 indicate acceptable values for exploratory research (Straub et al., 2004), internal consistency is given for the three driver constructs.

\begin{tabular}{|c|c|c|c|}
\hline \multicolumn{4}{|c|}{ Reliability Statistics } \\
\hline Construct & $\begin{array}{c}\text { Cronbach's } \\
\text { Alpha }\end{array}$ & $\begin{array}{c}\text { Cronbach's Alpha Based } \\
\text { on Standardized Items }\end{array}$ & $\begin{array}{c}\text { N of } \\
\text { Items }\end{array}$ \\
\hline Live Experience & $\mathbf{. 7 7 5}$ & $\mathbf{. 7 8 5}$ & $\mathbf{5}$ \\
Admiration & $\mathbf{. 8 3 0}$ & $\mathbf{. 8 3 0}$ & $\mathbf{3}$ \\
Social Network & $\mathbf{. 7 1 0}$ & $\mathbf{. 7 1 3}$ & $\mathbf{4}$ \\
\hline
\end{tabular}

Table 21: Factors: Reliability Statistics

As mentioned earlier, the results of the factor analysis were not intended to be used to reduce the number of variables. However, it is noteworthy that the results highlight the areas, in which a categorization based on practical evidence differs from the groupings suggested by the literature review. Additionally, the three factors live experience, admiration and social network will be used for further analyses. 


\subsubsection{Relative Driver Scores}

For each of the 16 identification drivers, participants could place scores between 1 and 8. Although such driver scores indicate an overall level of importance, they are considered limited in expressing how important a driver is compared to other drivers for that individual. It is therefore suggested to use relative driver scores as they may provide a more appropriate picture of the importance of each driver. Therefore, relative driver scores were calculated for each driver and participant. This was done by generating an average driver score for each participant. Then, each of the 16 individual driver scores was divided by the average driver score, to create a relative score of each driver and for each participant. Table 22 presents such mean relative scores of each driver for the whole sample. Drivers with a mean relative score above 1 reflect a higher relative importance amongst sample respondents compared to average. Likewise, drivers with a score below 1 show a lower relative importance than the average.

\begin{tabular}{|llc|}
\hline Rank & Driver & Mean Relative Score \\
\hline $\mathbf{1}$ & D1: Involvement & $\mathbf{1 . 4 5}$ \\
\hline $\mathbf{2}$ & D11: Enjoyment & $\mathbf{1 . 3 6}$ \\
$\mathbf{3}$ & D14: Excitement & $\mathbf{1 . 3 0}$ \\
\hline $\mathbf{4}$ & D2: City & $\mathbf{1 . 2 9}$ \\
\hline $\mathbf{5}$ & D6: Atmosphere & $\mathbf{1 . 2 5}$ \\
\hline $\mathbf{6}$ & D10: Country & $\mathbf{1 . 2 4}$ \\
\hline $\mathbf{7}$ & D5: Team & $\mathbf{1 . 0 6}$ \\
\hline $\mathbf{8}$ & D12: Belonging & $\mathbf{. 9 7}$ \\
\hline $\mathbf{9}$ & D16: Stadium & $\mathbf{. 9 2}$ \\
\hline $\mathbf{1 0}$ & D13: Players & $\mathbf{. 8 9}$ \\
\hline $\mathbf{1 1}$ & D3: Success & $\mathbf{. 8 5}$ \\
\hline $\mathbf{1 2}$ & D9: Coach & $\mathbf{. 8 3}$ \\
\hline $\mathbf{1 3}$ & D8: Friends & $\mathbf{. 8 0}$ \\
\hline $\mathbf{1 4}$ & D7: Escape & $\mathbf{. 7 8}$ \\
\hline $\mathbf{1 5}$ & D4: Family & $\mathbf{. 5 4}$ \\
\hline $\mathbf{1 6}$ & D15: Co-workers & $\mathbf{. 4 8}$ \\
\hline
\end{tabular}

Scores are rounded to 2 digits after the decimal point

Table 22: Mean Relative Driver Scores 
The driver involvement possesses the highest mean relative score among all identification drivers. Hence, an active interest in football has the greatest effect on the decision to support Wellington Phoenix. Furthermore, it is interesting that all four drivers of the factor live experience rank among the first eight positions. This underlines the strong importance, that experiences related to the live attendance of games appear to have for fans. The three drivers of the factor admiration, however, appear to be of medium importance with the driver team ranking on $7^{\text {th }}$, players on $10^{\text {th }}$, and coach on $12^{\text {th }}$ position. Drivers of the factor social network are of low importance to the participants. In particular, the drivers friends $\left(13^{\text {th }}\right)$, family $\left(15^{\text {th }}\right)$, and co-workers $\left(16^{\text {th }}\right)$ show low relative mean scores. By contrast, geographical drivers possess an above-average importance. Wellington Phoenix' representational role in relation to the city $\left(4^{\text {th }}\right)$ and country $\left(6^{\text {th }}\right)$ appear to significantly contribute to being a fan. The total range of all mean relative scores is considerably large, with a ratio of approximately 3:1 between the mean relative score of the driver involvement (1.45) and the driver co-workers (.48). The relative driver scores are used for a detailed analysis of the relationship between the identification drivers and fan identification in the following section.

\subsection{Relationship between Identification Drivers and Fan Identification}

In order to explore the relationship between identification drivers and fan identification, participants were clustered into five distinct fan ID levels. This allows for a comparison of the relative driver scores for each of the five ID levels. In this section, means of the relative driver scores are shown for each fan ID level. Within each level, drivers are then ranked according to their relative importance. Subsequently, graphs are presented that show the mean relative scores of the drivers of the three factors live experience, admiration and social network, and for the remaining drivers that were not clustered in one of the factors.

\subsubsection{Ranking of Identification Drivers}

Table 23 presents a driver ranking for each of the five fan ID levels according to the mean relative driver scores. 


\begin{tabular}{lccccc}
\hline Rank & $\begin{array}{c}\text { Very Low } \\
\text { Identification }\end{array}$ & $\begin{array}{c}\text { Low } \\
\text { Identification }\end{array}$ & $\begin{array}{c}\text { Moderate } \\
\text { Identification }\end{array}$ & $\begin{array}{c}\text { High } \\
\text { Identification }\end{array}$ & $\begin{array}{c}\text { Very High } \\
\text { Identification }\end{array}$ \\
\hline $\mathbf{1}$ & Enjoyment & Involvement & Involvement & Involvement & Involvement \\
$\mathbf{2}$ & City & City & Excitement & Enjoyment & Enjoyment \\
$\mathbf{3}$ & Involvement & Enjoyment & Enjoyment & Excitement & Atmosphere \\
$\mathbf{4}$ & Country & Excitement & City & Atmosphere & Excitement \\
$\mathbf{5}$ & Excitement & Country & Country & Team & Team \\
\hline $\mathbf{6}$ & Atmosphere & Atmosphere & Atmosphere & City & City \\
$\mathbf{7}$ & Success & Success & Team & Country & Country \\
$\mathbf{8}$ & Friends & Team & Stadium & Belonging & Belonging \\
$\mathbf{9}$ & Stadium & Stadium & Belonging & Players & Players \\
$\mathbf{1 0}$ & Team & Friends & Players & Coach & Coach \\
\hline $\mathbf{1 1}$ & Escape & Belonging & Success & Stadium & Stadium \\
\hline $\mathbf{1 2}$ & Belonging & Players & Coach & Escape & Escape \\
$\mathbf{1 3}$ & Players & Coach & Friends & Success & Success \\
$\mathbf{1 4}$ & Coach & Escape & Escape & Friends & Friends \\
$\mathbf{1 5}$ & Family & Family & Family & Family & Family \\
$\mathbf{1 6}$ & Co-workers & Co-workers & Co-workers & Co-workers & Co-workers \\
\hline
\end{tabular}

For mean relative scores of all drivers see appendix B5.1.

Table 23: Driver Ranking within Fan ID Levels

The table reveals that ranking of some drivers does not vary across the five fan ID levels, for example, some drivers are highly or lowly ranked, regardless of fan ID level. Other drivers show variability in their relative position from the very low to the very high fan ID level. Drivers that do not significantly change in their relative position are involvement, enjoyment, excitement, atmosphere (constant high ranking), stadium (constant moderate ranking), and family, co-workers, and escape (constant low ranking). Drivers that steadily increase their relative position in the ranking with an increasing fan ID level are team, belonging, players, and coach. Drivers that steadily decrease their relative position in the ranking with an increasing fan ID level are city, country, success, and friends.

In order to test possible relationships between drivers and fan ID level, one-way ANOVA tests were conducted for each of the 16 identification drivers. In five cases, the ANOVA test revealed p-values of larger than .050 (see appendix B4.4). In the remaining 11 cases, p-values were below .050. Hence, only five of the 16 identification drivers do not show a statistically significant relationship to the fan ID level, whereas 11 drivers demonstrate a statistically significant relationship. In the following sections, charts are presented for a more detailed analysis of the 
relationship between the identification drivers and the fan ID level. These charts show the relative importance of the drivers for the five fan ID levels. Drivers of the factors live experience, admiration and social network are discussed as a set. Subsequently, the remaining drivers are analyzed, starting with the geographical drivers city, country and stadium and followed by the drivers involvement and escape.

\subsubsection{Factor Live Experience}

The factor live experience contains the drivers atmosphere, enjoyment, belonging and excitement. This section starts by presenting the results of the one-way ANOVA tests. Subsequently, a chart is presented which shows the mean relative scores of the four drivers for each of the five fan ID levels. Following that, a correlation and regression analysis is undertaken to identify and analyze possible correlations between the identification drivers and the fan ID level. The results of these analyses are then used to place the drivers of the factor live experience in a matrix that shows both the relative importance and the correlation with the fan ID level. Subsequently, further drivers will be added to this matrix after being analyzed.

\subsubsection{Driver Relationships with Fan ID Level}

In order to test whether the drivers of the factor live experience are related to the fan ID level, a one-way ANOVA test was conducted. This and all subsequent ANOVA tests are based on the relative driver scores. The results for the factor live experience indicate significant differences among the four drivers. The drivers excitement $(\mathrm{p}=.638)$ and atmosphere $(\mathrm{p}=.471)$, show $\mathrm{p}$-values of above .05 . Therefore, there is no statistically significant relationship between those drivers and the fan ID level. The drivers enjoyment $(\mathrm{p}=.013)$ and belonging $(\mathrm{p}=.000)$, however, show $\mathrm{p}$-values of below .05, which means that these two drivers are related to the fan ID level.

\subsubsection{Mean Relative Scores by Fan ID Levels}

In the following chart, graphs illustrate the mean relative scores of each of the drivers atmosphere, enjoyment, belonging and excitement for each of the five fan ID levels. 


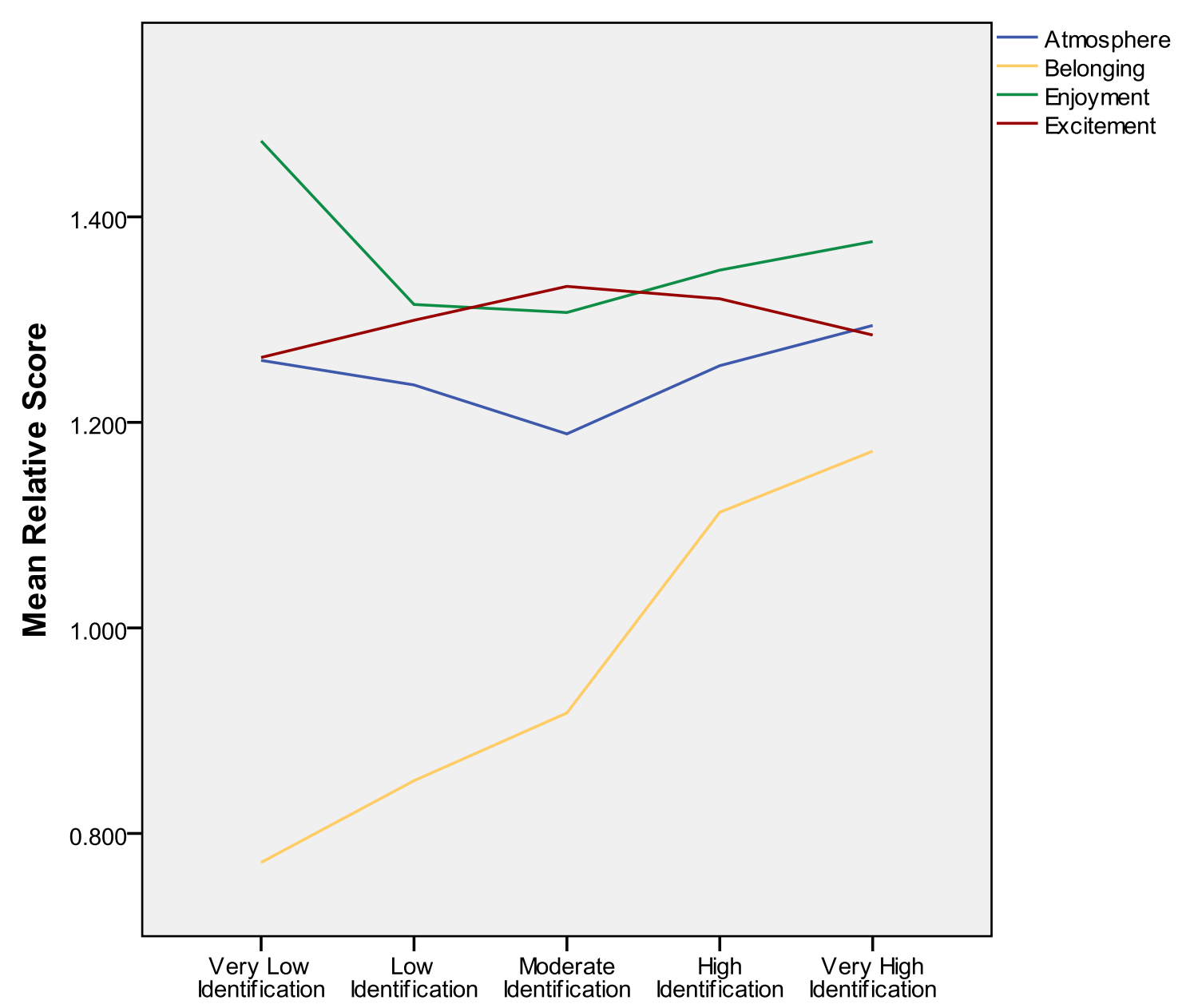

Fan ID Level

Figure 11: Factor Live Experience: Mean Relative Driver Scores

The chart reveals a difference between the graph of the driver belonging and the graphs of the drivers enjoyment, excitement and atmosphere. The graphs of the drivers enjoyment, excitement and atmosphere are drawn at constant high levels with mean relative scores ranging from 1.2 and 1.5 across all fan ID levels. The graphs of the drivers excitement and atmosphere are drawn within a relatively small mean score range. None of the three drivers enjoyment, excitement, and atmosphere shows a steady increase or decrease over the five fan ID levels. According to the ANOVA test, there is no statistically significant relationship between the two drivers excitement and atmosphere and the fan ID level. This is not surprising as the graphs of these two drivers show no visible association with the fan ID level.

The drivers enjoyment and atmosphere have the lowest relative driver score occurring at a moderate fan ID level. The relative scores of the driver atmosphere are similarly high for the very low (1.26) and very high (1.29) fan ID levels. In contrast, 
the driver enjoyment shows a higher relative score in the group of very lowly identified individuals. An opposite pattern can be seen for the driver excitement, as the highest relative driver score occurs at the moderate fan ID level and the lowest scores for the fan ID levels very low (1.26) and very high (1.28).

The fourth driver in this chart, belonging, differs significantly from the three drivers described above. In contrast to them, the relative driver score of belonging steadily increases from the lowest to the highest fan ID level. Therefore, the driver appears to be strongly associated with the fan ID level. Furthermore, the difference between the driver score of .77 at the fan ID level very low and 1.17 at the fan ID level very high reflects a wide range of scores throughout the five fan ID levels. However, the scores for the fan ID levels high and very high still remain lower than the lowest scores for the three drivers enjoyment, excitement and atmosphere. The relative importance of the driver belonging for participants in the ID levels very low, low, and moderate has a value lower than 1 . That means that the scores that respondents with these fan ID levels placed on the importance of the driver belonging are below the average scores for all 16 drivers. In comparison, respondents with high and very high fan ID levels rate the importance of the driver belonging as being above the overall average driver importance.

\subsubsection{Driver Correlations}

Two types of correlation analyses, Pearson and Spearman's Rank Correlations, were performed to identify correlations between the fan ID level and the drivers of the factor live experience as well as possible correlations among the drivers. To determine the Pearson coefficient, the total fan ID score from the SSIS instrument and the relative driver scores were used. Spearman's Rank Correlation was undertaken using the fan ID levels together with the relative driver scores. Throughout the following sections, the term fan ID level continues to be used to describe the level of fan identification, even when it refers to the total fan ID score as in the case of the Pearson coefficient. The Pearson coefficients, illustrated in table 24 provide an indication of the strength of the correlations. In this research, coefficients between 0 and .3 are considered weak, between .3 and .7 moderate, and between .7 and 1 strong correlations. 


\begin{tabular}{|c|c|c|c|c|c|}
\hline & Fan ID Score & Atmosphere & Belonging & Enjoyment & Excitement \\
\hline Fan ID Score & 1 & & & & \\
\hline Atmosphere & .014 & 1 & & & \\
\hline Belonging & $.364 * *$ & $.147 * *$ & 1 & & \\
\hline Enjoyment & $-.111 *$ & .076 & 0.20 & 1 & \\
\hline Excitement & .060 & .050 & .012 & $.302 * *$ & 1 \\
\hline
\end{tabular}

**. Correlation is significant at the .01 level (2-tailed).

*. Correlation is significant at the .05 level (2-tailed).

Table 24: Factor Live Experience: Pearson Correlation

Not surprisingly, given prior literature, the drivers excitement and atmosphere show no significant correlation with the fan ID score. This result also conforms with the results of Spearman's Rank Correlation (see appendix B5.4). In the case of the driver enjoyment, results differ for Pearson and Spearman's Rank Correlation statistics. Whereas Pearson coefficient indicates a weak negative correlation between the driver enjoyment and the fan ID level, which is significant at the $p=.05$ level, the correlation coefficient of Spearman's Rank Correlation shows no significant correlation. For the driver belonging, both correlation coefficients indicate a moderate positive correlation with fan ID level.

Among the identification drivers of the factor live experience, a moderate positive correlation exists between the drivers excitement and enjoyment and a weak positive correlation between the drivers belonging and atmosphere. Spearman's Rank Correlation additionally shows weak positive correlations between the drivers enjoyment and atmosphere and excitement and atmosphere.

\subsubsection{Regression Analysis for Factor Live Experience}

Separate stepwise linear regression analyses, with the dependent variable being the fan ID score, were conducted using individual drivers of the factors live experience, admiration and social network, as well as the geographical drivers as the independent variables. Subsequently, a linear regression analysis was conducted using the composite driver scores for each of the factor groups. The drivers involvement and escape were not taken into consideration as they showed no statistically significant correlation with the fan ID level. Table 25 presents the fan ID regression model 
summary with independent variables being the individual drivers of the factor live experience, as well as for the composite driver score of the factor. The complete regression analysis model summaries and coefficients can be found in the appendix (B5.5).

\begin{tabular}{|c|c|c|c|c|}
\hline & $\mathrm{R}$ & R Square & $\begin{array}{l}\text { Adjusted } \\
\text { R Square }\end{array}$ & $\begin{array}{l}\text { Std. Error of } \\
\text { the Estimate }\end{array}$ \\
\hline Atmosphere* & .014 & .000 & -.002 & 10.678 \\
\hline Enjoyment* & .111 & .012 & .010 & 10.613 \\
\hline Excitement* & .060 & .004 & .002 & 10.660 \\
\hline Belonging* & .364 & .132 & .131 & 9.947 \\
\hline Factor Live Experience $* *$ & .396 & .157 & .150 & 9.835 \\
\hline
\end{tabular}

*. Individually tested

**. Conjointly tested

Table 25: Factor Live Experience: Regression Model Summary

Of particular interest are the r-square values of the driver that shows a possibly meaningful and statistically significant correlation with the fan ID level, belonging, as well as the factor live experience that represents the grouping of the drivers atmosphere, belonging, enjoyment and excitement. A r-square value of .132 means that the driver belonging explains $13.2 \%$ of the variation of the fan ID score. The driver enjoyment, with a r-square of .012, only explains $1.2 \%$ of the variation, and can therefore be disregarded as an explanatory variable. The whole factor live experience explains $15.7 \%$ of the variation of the fan ID score.

\subsubsection{Driver - Fan ID Matrix}

Following the analysis of the mean relative driver scores for the total sample (table 23) and a correlation analysis of all 16 drivers, the driver - fan ID matrix was developed. This matrix combines the relative importance of drivers with the type and strength of correlation with the fan ID level. The matrix is a plot of the mean relative importance scores for individual drivers within each factor group and the Pearson correlation scores linking relative importance of drivers to fan ID level. The matrix plot is inclusive of all correlation scores, regardless of the statistical significance of 
the correlations. Figure 12 highlights the positions of the drivers of the factor live experience in the driver - fan ID matrix.

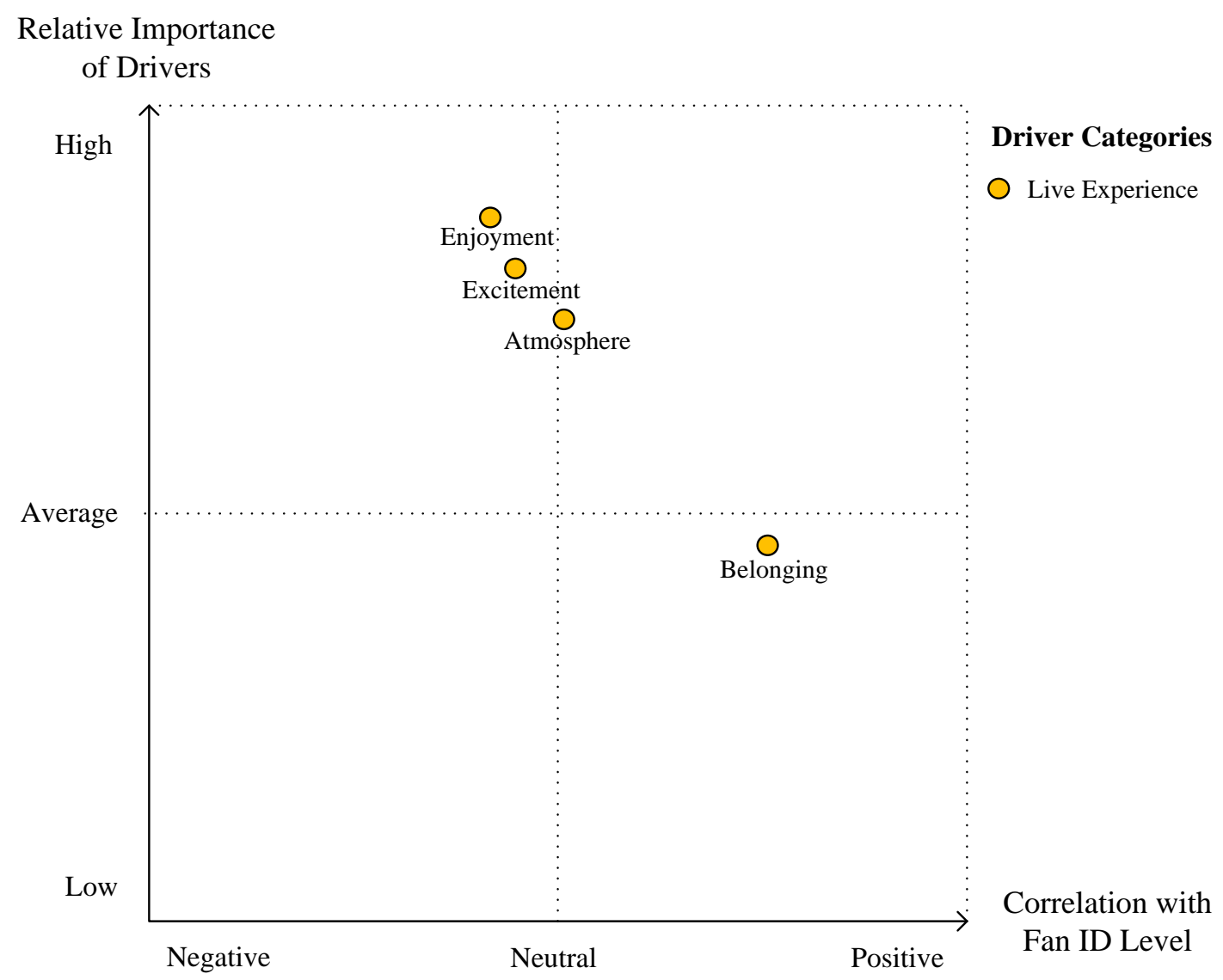

Figure 12: Factor Live Experience: Driver - Fan ID Matrix

The matrix visually highlights the difference between the driver belonging and other drivers atmosphere, enjoyment and excitement. Whereas the driver belonging shows a mean relative importance slightly below average and a moderate positive correlation with the fan ID level, the drivers atmosphere, enjoyment and excitement show a high mean relative importance and correlations around the neutral point, accentuating the need to consider both dimensions of the matrix in interpreting the different statistics.

\subsubsection{Factor Admiration}

The factor admiration contains the drivers team, coach, and players. Similar to the analysis of the factor live experience, this section starts by testing possible relationships between the drivers and the fan ID level. Following that, the mean relative scores of the drivers are shown for each of the five fan ID levels. Correlations between the drivers and the fan ID level are then analyzed and a 
regression analysis is performed. Finally, the drivers of the factor admiration are added to the driver - fan ID matrix.

\subsubsection{Driver Relationships with Fan ID Level}

A one-way ANOVA test was conducted to identify relationships between the drivers of the factor admiration and the fan ID level. The test revealed p-values of .000 for each of the drivers team, coach, and players. Hence, the relative importance of all three drivers of the factor admiration is significantly related to the fan ID level.

\subsubsection{Mean Relative Scores by Fan ID Levels}

Figure 13 shows the mean relative scores of the drivers team, coach, and players for each of the five fan ID levels.

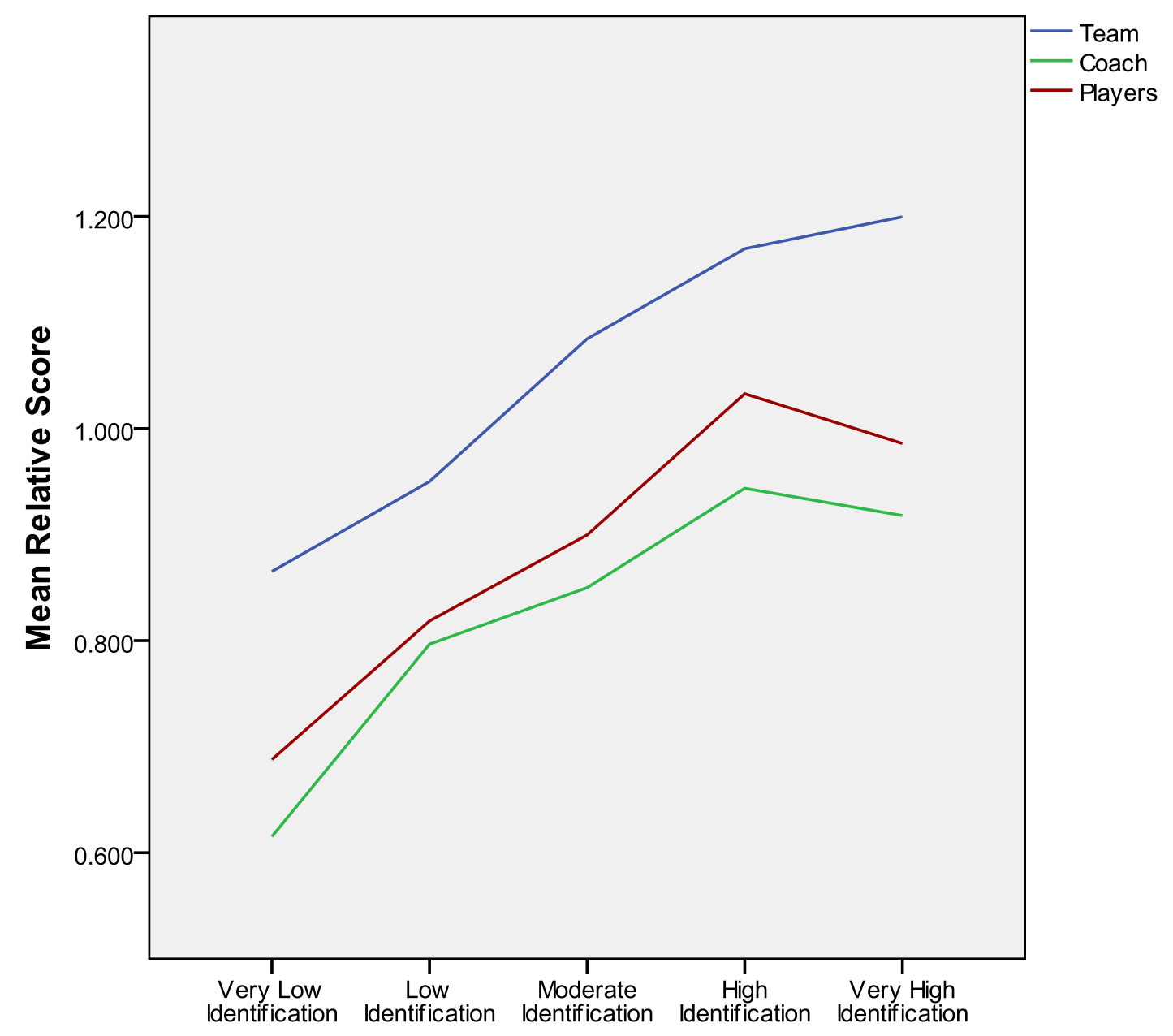

Fan ID Level

Figure 13: Factor Admiration: Mean Relative Driver Scores 
The three drivers of the factor admiration, team, coach and, players, follow a similar structural pattern throughout the five fan ID levels. The lowest mean relative scores of all three drivers occur on the lowest fan ID level. From very low to high fan ID level, the mean relative scores of all drivers steadily increase. However, for high to very high fan ID level, the mean relative scores develop differently. Whereas the score of the driver team increases monotonically, scores of the drivers coach and players are not constantly monotonic. Of all three drivers in this factor, the driver team scores highest for all fan ID levels. For participants who are moderately (1.08), highly (1.17) or very highly (1.20) identified with Wellington Phoenix, the admiration for the team has a higher relative importance than the average of all drivers. The mean relative score of the driver players ranges from .69 (very low fan ID level) to 1.03 (high fan ID level). In contrast, the mean relative scores of the driver coach are below 1, for all fan ID levels, with a range from .62 (very low fan ID level) to .94 (high fan ID level). The graph clearly illustrates the similar type of relationship for each driver, such that, in general, the higher the fan ID levels, the higher is the relative importance of the drivers within the factor admiration.

\subsubsection{Driver Correlations}

Pearson and Spearman's Rank Correlations were performed to reveal correlations between the drivers of the factor admiration and fan ID level as well as correlations between the drivers. Table 26 presents the Pearson coefficients for the factor admiration.

\begin{tabular}{|c|c|c|c|c|}
\hline & Fan ID Score & Team & Coach & Players \\
\hline Fan ID Score & 1 & & & \\
\hline Team & $.338 * *$ & 1 & & \\
\hline Coach & $.277 * *$ & $.308 * *$ & 1 & \\
\hline Players & $.325^{* *}$ & $.212 * *$ & $.340 * *$ & 1 \\
\hline
\end{tabular}

**. Correlation is significant at the .01 level (2-tailed).

\section{Table 26: Factor Admiration: Pearson Correlation}

The results of both Pearson and Spearman's Rank Correlation (B5.4) show positive correlations between the drivers team, coach and, players and fan ID level as well as positive correlations among these drivers. The Pearson coefficient of the driver 
coach (.277) is below .3 and the correlation is therefore considered weak. In contrast, the correlations of the drivers team and players with the fan ID level are viewed as moderately strong. The highest correlation (.340) exists between the drivers coach and players. Such statistics reflect the relationships apparent in the graphs, which show a strong association towards each other (figure 13). Overall, results show that the drivers of the factor admiration possess moderate positive correlations with the fan ID level as well as with each other.

\subsubsection{Regression Analysis for Factor Admiration}

A stepwise linear regression analysis, with the dependent variable being the fan ID score, was conducted using individual drivers of the factor admiration. Following that, a regression analysis was performed on the composite driver score for the factor admiration. Table 27 presents the regression model summary for the individual drivers of the factor admiration, as well as for the composite driver score of the factor.

\begin{tabular}{|c|c|c|c|c|}
\hline & $\mathrm{R}$ & R Square & $\begin{array}{l}\text { Adjusted } \\
\text { R Square }\end{array}$ & $\begin{array}{l}\text { Std. Error of } \\
\text { the Estimate }\end{array}$ \\
\hline Team* & .338 & .114 & .112 & 10.052 \\
\hline Coach* & .277 & .077 & .075 & 10.260 \\
\hline Players* & .325 & .106 & .104 & 10.098 \\
\hline Factor Admiration ${ }^{* *}$ & .440 & .193 & .189 & 9.609 \\
\hline
\end{tabular}

*. Individually tested; **. Conjointly tested

Table 27: Factor Admiration: Regression Model Summary

The correlation coefficients of both Pearson and Spearman's Rank Correlation indicate all drivers of the factor admiration are (positively) correlated to the fan ID level. The driver team has the highest r-square value within the factor admiration and explains $11.4 \%$ of the variation of the fan ID score. Together, the composite factor admiration explains $19.3 \%$ of the variation of the fan ID score.

\subsubsection{Driver - Fan ID Matrix}

Subsequent to the correlation and regression analysis of the factor admiration, the drivers team, coach and players can be added to the driver - fan ID matrix. Figure 14 shows the plots of the relevant driver scores within the matrix. 


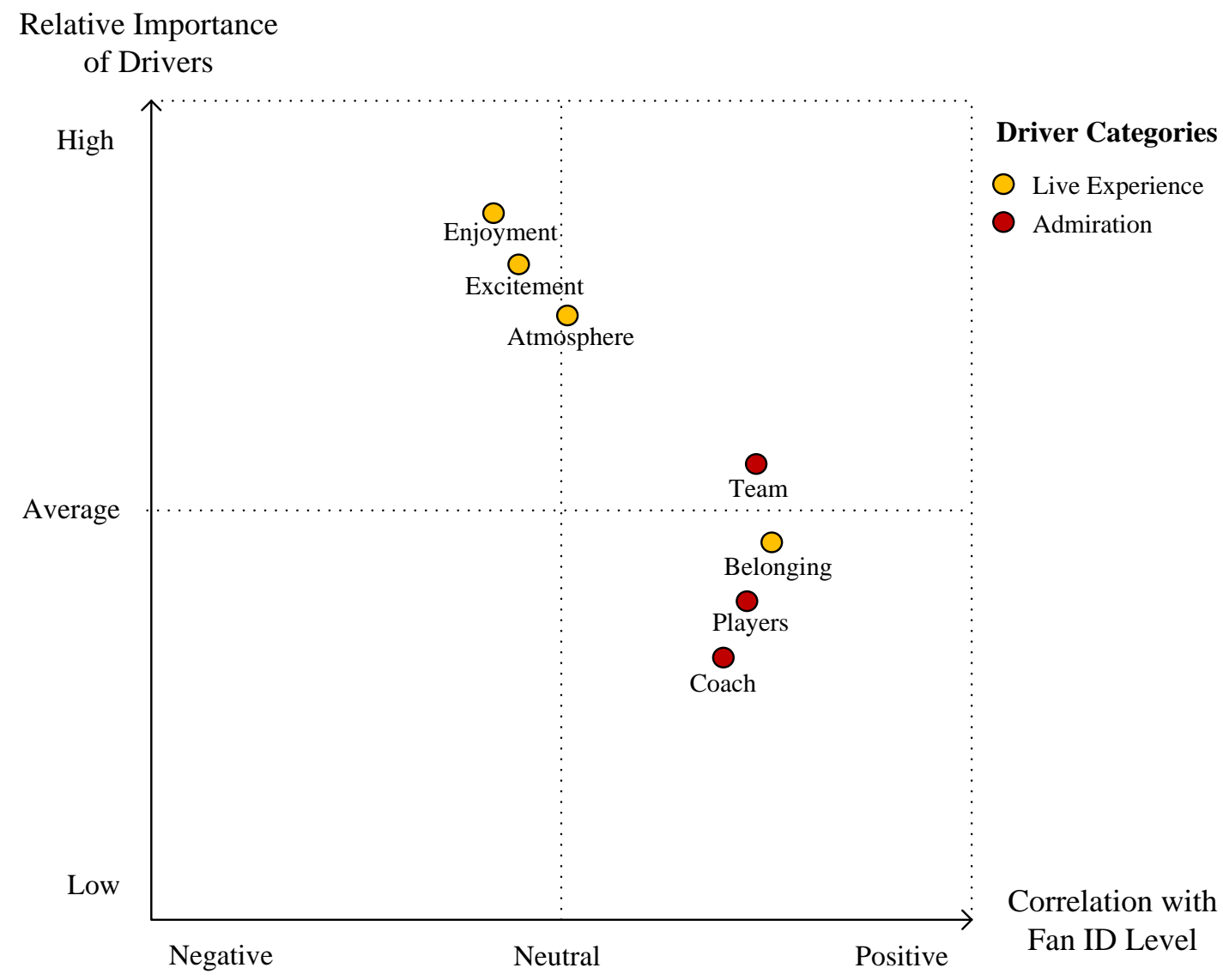

Figure 14: Factor Admiration: Driver - Fan ID Matrix

The three drivers of the factor admiration are reasonably clustered together on the driver - fan ID matrix. Due to a moderate positive correlation with the fan ID level, they are also located near the driver belonging. The driver team is placed within the upper right quadrant as its mean relative score is above average. In contrast, the drivers coach and players are close, but located on the lower right quadrant due to mean relative scores below average.

\subsubsection{Factor Social Network}

The factor social network contains the drivers family, friends, co-workers, and success. In this section, relationships and correlations between these drivers and the fan ID level are analyzed and described, and the drivers are added to the driver - fan ID matrix.

\subsubsection{Driver Relationships with Fan ID Level}

One-way ANOVA tests revealed p-values of .000 for the drivers success and friends and p-values of .001 for the drivers family and co-workers. Therefore, the relative 
importance of all four drivers of the factor social network bears a significant statistical relationship to fan ID levels.

\subsubsection{Mean Relative Scores by Fan ID Levels}

Figure 15 shows the mean relative scores of the drivers family, friends, co-workers, and success for each of the five fan ID levels.

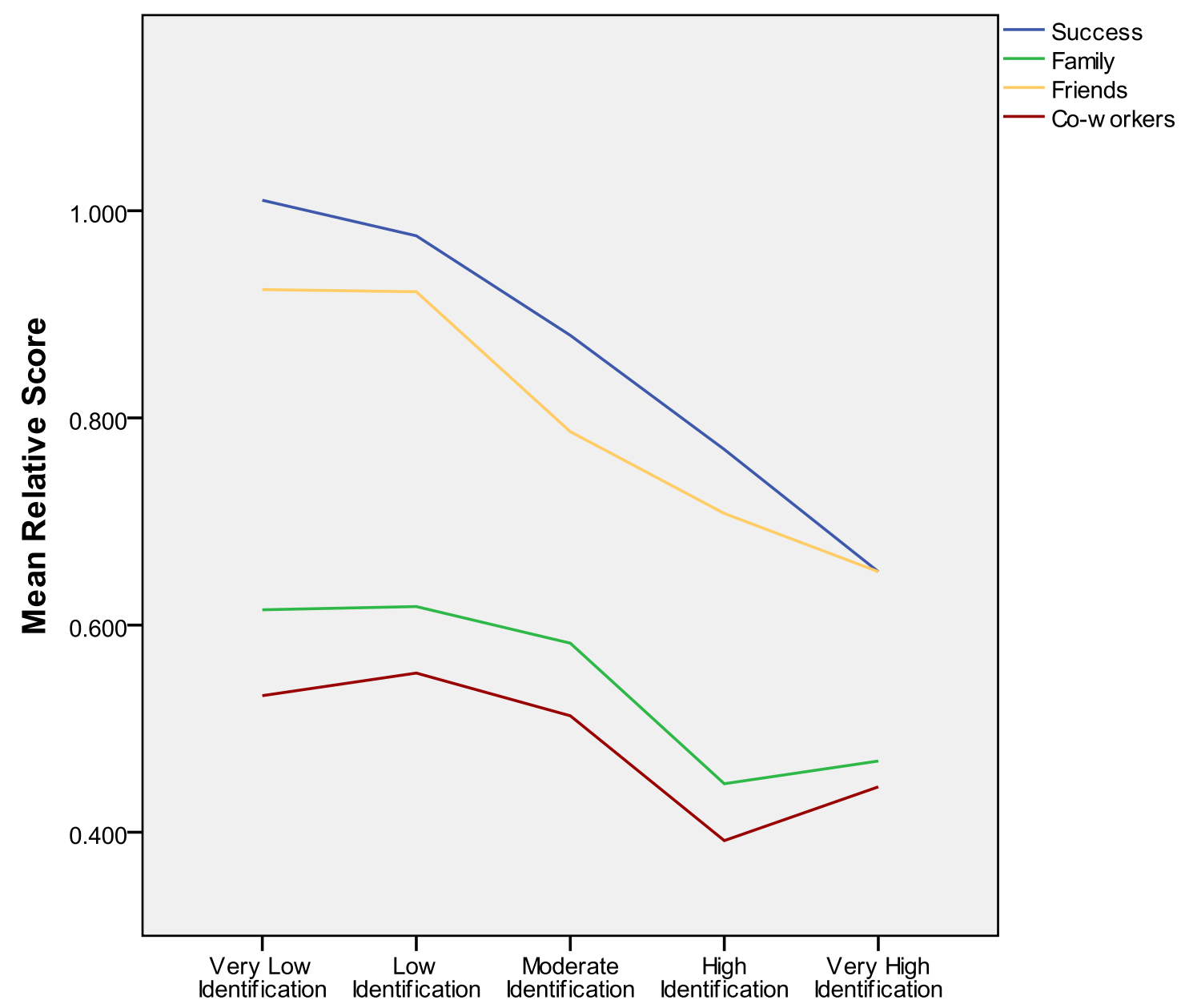

Fan ID Level

Figure 15: Factor Social Network: Mean Relative Driver Scores

The drivers family, friends, co-workers, and success show similar structural patterns in relationship to the five fan ID levels. Whereas the mean relative scores of the drivers success and friends show a monotonic relationship, the scores of the drivers family and co-workers are not consistently monotonic, and slightly increase for the higher fan ID level. The drivers family and co-workers share a similar structural pattern. However, the mean relative scores of these two drivers range at a very low level from .62 to .45 (family) and .55 to .39 (co-workers). Hence, the relative 
importance of both drivers is significantly lower than the average for all drivers. In comparison, the driver friends ranges at a considerably higher level between .92 (very low fan ID level) and .65 (very high fan ID level). This suggests that, of all socializing agents, friends have a greater effect on team support. In general, the mean relative scores of the drivers family, friends and co-workers show the tendency to decrease from very low to very high fan ID levels. Hence, it may be inferred that the higher the fan ID levels, the lower is the relative importance of the drivers of the factor social network. This contrasts with finding and tendency shown by the drivers of the factor admiration.

\subsubsection{Driver Correlations}

Pearson and Spearman's Rank Correlations were performed to reveal correlations between the drivers of the factor social network and the fan ID level as well as correlations among the drivers. Table 28 presents the Pearson coefficients for the factor social network.

\begin{tabular}{|c|c|c|c|c|c|}
\hline & Fan ID Score & Success & Family & Friends & Co-workers \\
\hline Fan ID Score & 1 & & & & \\
\hline Success & $-.290 * *$ & 1 & & & \\
\hline Family & $-.133 * *$ & $.282 * *$ & 1 & & \\
\hline Friends & $-.273 * *$ & $.112 *$ & .067 & 1 & \\
\hline Co-workers & $-.145^{* *}$ & $.108 *$ & $.202 * *$ & $.235^{* *}$ & 1 \\
\hline
\end{tabular}

Table 28: Factor Social Network: Pearson Correlation

According to the ANOVA test which was performed earlier, statistically significant relationships exist between the drivers success, family, friends, and co-workers and the fan ID level. The graphs in figure 15 further highlighted that the relative driver scores of all four drivers tend to decrease with increasing fan ID levels. Therefore, it is not surprising that both Pearson and Spearman's Rank Correlation show negative correlations between all drivers and the fan ID level. However, none of the coefficients exceeds the threshold value of .3 below which these correlations are considered weak. The strongest correlation to the fan ID level is detected for the 
driver success. This is conforming to the chart (figure 15) in which the driver success shows the steadiest decrease from the very low to the very high fan ID level.

Among the drivers of the factor social network, further correlations exist. At one point, results slightly differ between the Pearson and Spearman's Rank Correlation. Whereas the Pearson coefficient indicates a weak positive correlation between the drivers co-workers and family, the correlation coefficient of Spearman's Rank Correlation shows a moderate positive correlation. Overall, results show that the drivers of the factor social network demonstrate weak negative correlations with the fan ID level and weak positive correlations towards each other.

\subsubsection{Regression Analysis for Factor Social Network}

A stepwise linear regression analysis, with the dependent variable being the fan ID score, was conducted using individual drivers of the factor social network and followed by a regression analysis for the composite driver score of the factor. Table 29 shows the regression model summary for both the individual drivers of the factor social network, as well as for the composite driver score of the factor.

\begin{tabular}{|c|c|c|c|c|}
\hline & $\mathrm{R}$ & R Square & $\begin{array}{l}\text { Adjusted } \\
\text { R Square }\end{array}$ & $\begin{array}{l}\text { Std. Error of } \\
\text { the Estimate }\end{array}$ \\
\hline Success* & .290 & .084 & .082 & 10.221 \\
\hline Family* & .133 & .018 & .016 & 10.584 \\
\hline Friends* & .273 & .075 & .073 & 10.272 \\
\hline Co-workers* & .145 & .021 & .019 & 10.566 \\
\hline Factor Social Network** & .384 & .148 & .141 & 9.888 \\
\hline
\end{tabular}

*. Individually tested; **. Conjointly tested

Table 29: Factor Social Network: Regression Model Summary

According to the correlation coefficients of both Pearson and Spearman's Rank Correlation, all drivers of the factor social network are (negatively) correlated to the fan ID level. The driver success has the highest r-square value within the factor social network and yet only explains $8.4 \%$ of the variation of the fan ID score. The factor social network conjointly explains $14.8 \%$ of the variation of the fan ID score and, of all other composite factor variables has the least explanatory power. 


\subsubsection{Driver - Fan ID Matrix}

Following the correlation and regression analysis of the factor social network, the drivers success, friends, family and co-workers can be added to the driver - fan ID matrix. Figure 16 shows how these drivers are positioned in the matrix compared to the drivers of the previous factors.

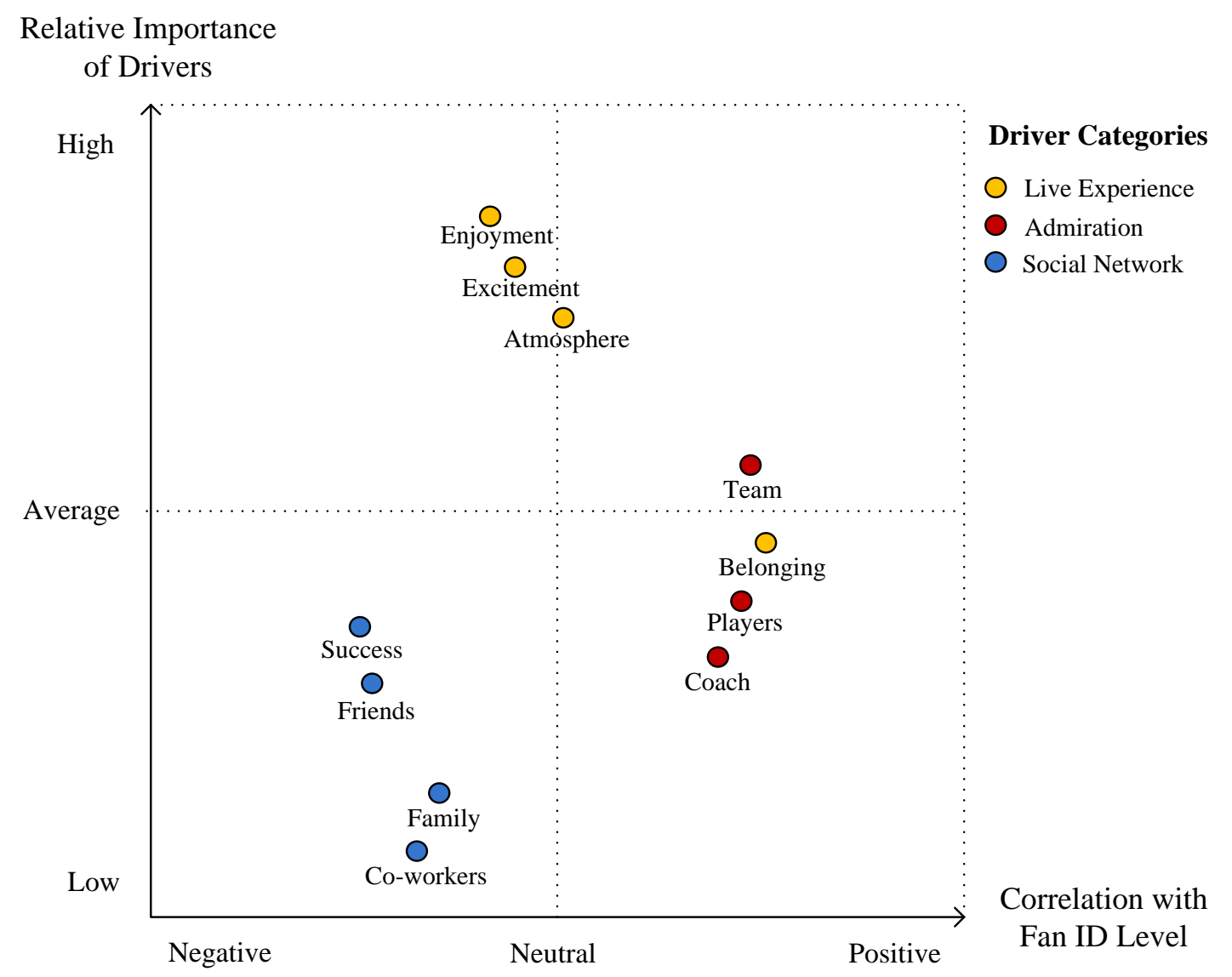

Figure 16: Factor Social Network: Driver - Fan ID Matrix

The four drivers of the factor social network are clustered at the lower left quadrant of the driver - fan ID matrix. They share the characteristic of possessing mean relative scores below average and being negatively correlated with the fan ID level. Within the lower left quadrant, the drivers family and co-workers show significantly lower mean relative scores than the drivers success and friends.

\subsubsection{Geographical Drivers}

Although not part of the same factor, the geographical drivers country, city, and stadium are conjointly analyzed and described as they share similar characteristics. 


\subsubsection{Driver Relationships with Fan ID Level}

The results of the one-way ANOVA test reveals major differences between the geographical drivers. Whereas low p-values of the drivers country (.009) and city (.000) indicate that these two drivers possess a statistically significant relationship with the fan ID level, a p-value of .946 shows that no relationship exists between the driver stadium and the fan ID level.

\subsubsection{Mean Relative Scores by Fan ID Levels}

Figure 17 shows the mean relative scores of the three geographical drivers country, city, and stadium for each of the five fan ID levels.

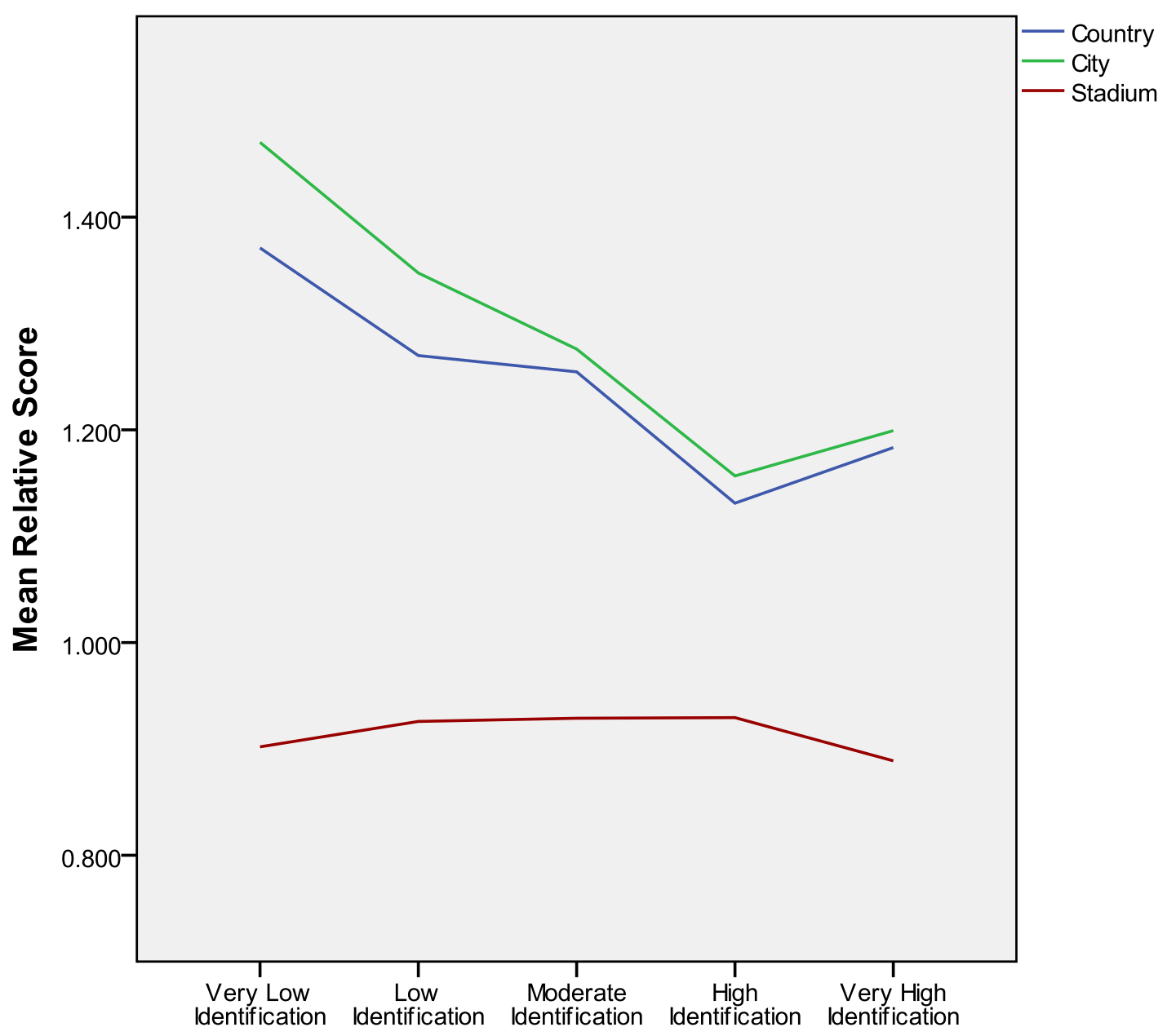

Fan ID Level

Figure 17: Geographical Drivers: Mean Relative Driver Scores

Given the results of the ANOVA test, the shape of these graphs confirm the dissimilarity between the two drivers country and city and the driver stadium. In general, the former drivers show a steady decrease of mean relative scores as fan ID 
levels increase from very low to high. In contrast, the mean relative scores of the driver stadium only show minor variation for different fan ID levels. In addition to differences in the nature of relationships, the drivers country and city are placed on significantly higher score levels than the driver stadium. Across all fan ID levels, participants ascribe an importance to the drivers country and city that is above the average for all other drivers. The importance placed on the driver stadium, however, is below the average across all fan ID levels. Overall, there is a tendency for the mean relative scores of the drivers country and city to decrease from lower to higher fan ID levels, whereas the driver stadium shows no sign of association with the fan ID level.

\subsubsection{Driver Correlations}

In order to identify and describe correlations between the geographical drivers and the fan ID level, as well as correlations among the drivers, Pearson and Spearman's Rank Correlations were performed. Table 30 presents the Pearson coefficients for the geographical drivers.

\begin{tabular}{|c|c|c|c|c|}
\hline & Fan ID Score & Country & City & Stadium \\
\hline Fan ID Score & 1 & & & \\
\hline Country & $-.160 * *$ & 1 & & \\
\hline City & $-.211 * *$ & -.026 & 1 & \\
\hline Stadium & .008 & -.073 & .070 & 1 \\
\hline
\end{tabular}

**. Correlation is significant at the .01 level (2-tailed).

Table 30: Geographical Drivers: Pearson Correlation

As expected, the results of the correlation analysis show no correlation between the driver stadium and the fan ID level, and weak negative correlations between the drivers country and city and the fan ID level. Indeed, the coefficients of both Pearson and Spearman's Rank Correlation only indicate weak correlations. Furthermore, the results indicate that no correlations exist between the geographical drivers. This is surprising in the case of the drivers country and city as their graphs (figure 17) show similar patterns. 


\subsubsection{Regression Analysis for Geographical Drivers}

A stepwise linear regression analysis, with the dependent variable being the fan ID score, was conducted using the set of geographical drivers. Table 29 shows the regression model summary for both the individual geographical drivers, as well as for the composite driver score. The regression model summary is presented in Table 31.

\begin{tabular}{|c|c|c|c|c|}
\hline & $\mathrm{R}$ & R Square & $\begin{array}{l}\text { Adjusted } \\
\text { R Square }\end{array}$ & $\begin{array}{l}\text { Std. Error of } \\
\text { the Estimate }\end{array}$ \\
\hline Country * & .160 & .026 & .024 & 10.542 \\
\hline City * & .211 & .045 & .043 & 10.438 \\
\hline Stadium * & .008 & .000 & -.002 & 10.679 \\
\hline Geographical Drivers** & .269 & .072 & .067 & 10.307 \\
\hline
\end{tabular}

*. Individually tested; **. Conjointly tested

Table 31: Geographical Drivers: Regression Model Summary

The geographical drivers country and city show weak (negative) correlations to the fan ID level. The stepwise linear regression analysis reveals r-square values of .045 for the driver city, .026 for the driver country, and .000 for the driver stadium. Therefore, the driver city explains $4.5 \%$ and the driver country $2.6 \%$ of the variation of the fan ID score. Not surprisingly, the uncorrelated driver stadium does not explain any of the variation. The three geographical drivers conjointly explain $7.2 \%$ of the variation of the fan ID score, and have little value in predicting fan ID levels.

\subsubsection{Driver - Fan ID Matrix}

Subsequent to this analysis of type and strength of correlations between the geographical drivers and the fan ID level, the drivers country, city and stadium can be added to the driver - fan ID matrix. Figure 18 highlights the positions of the geographical drivers in this matrix. 


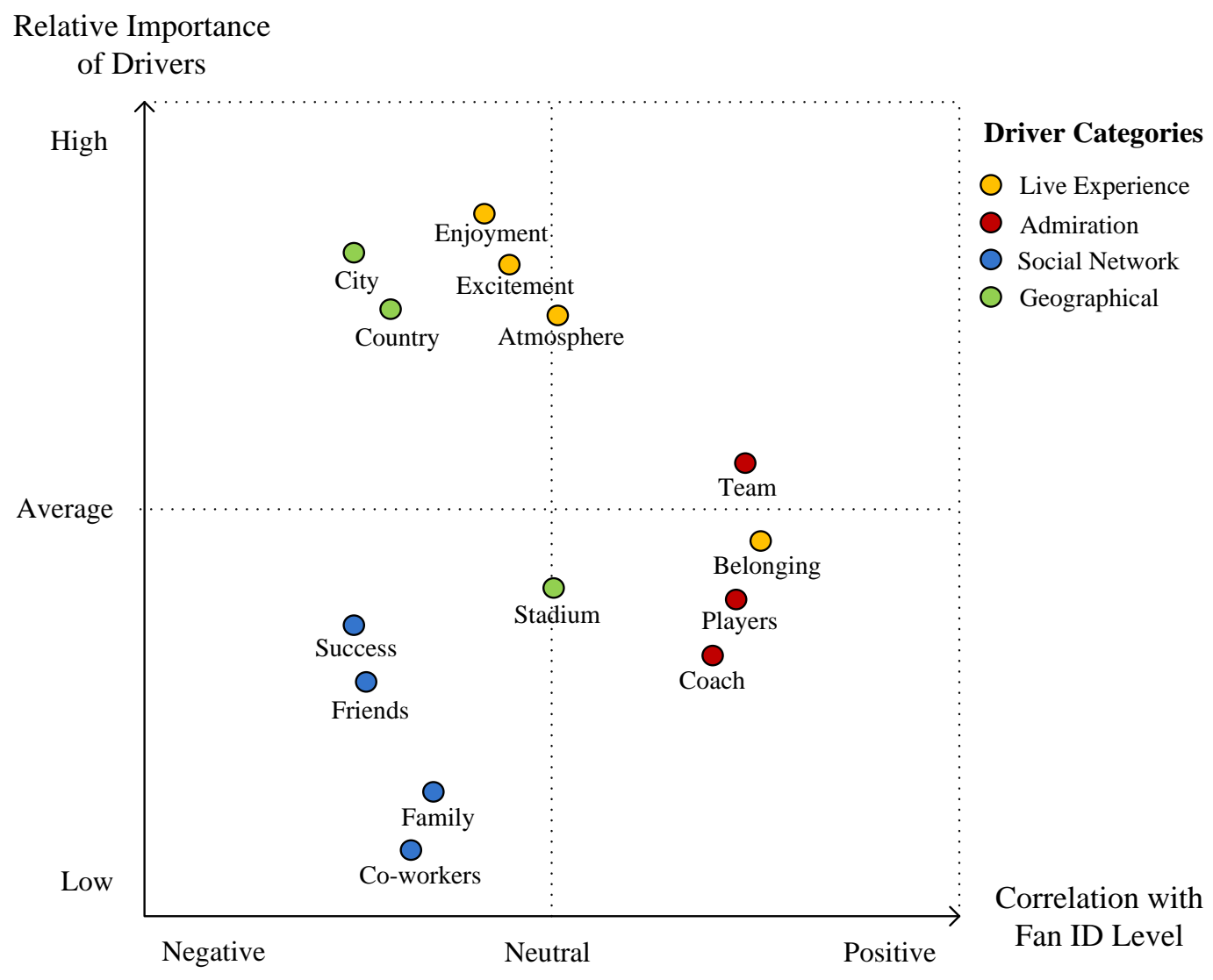

Figure 18: Geographical Drivers: Driver - Fan ID Matrix

Not surprisingly, the differences between the drivers country and city and the driver stadium that were identified in the prior analyses are also reflected in the spatial differences in the driver - fan ID matrix. Whereas the drivers country and city are clustered at the upper left quadrant (close to the drivers enjoyment, excitement and atmosphere), the driver stadium is placed at a relatively neutral position in the lower half of the matrix.

\subsubsection{Driver Involvement}

In this section, the relationship and correlation between the driver involvement and the fan ID level is analyzed and described.

\subsubsection{Driver Relationships with Fan ID Level}

A one-way ANOVA test revealed a p-value of .634 for the driver involvement and its relationship to fan ID level. This shows that the driver involvement, which represents the general interest in the sports discipline, shows no statistically significant relationship with the fan ID level. 


\subsubsection{Mean Relative Scores by Fan ID Levels}

Figure 19 shows the mean relative score of the driver involvement for each of the five fan ID levels.

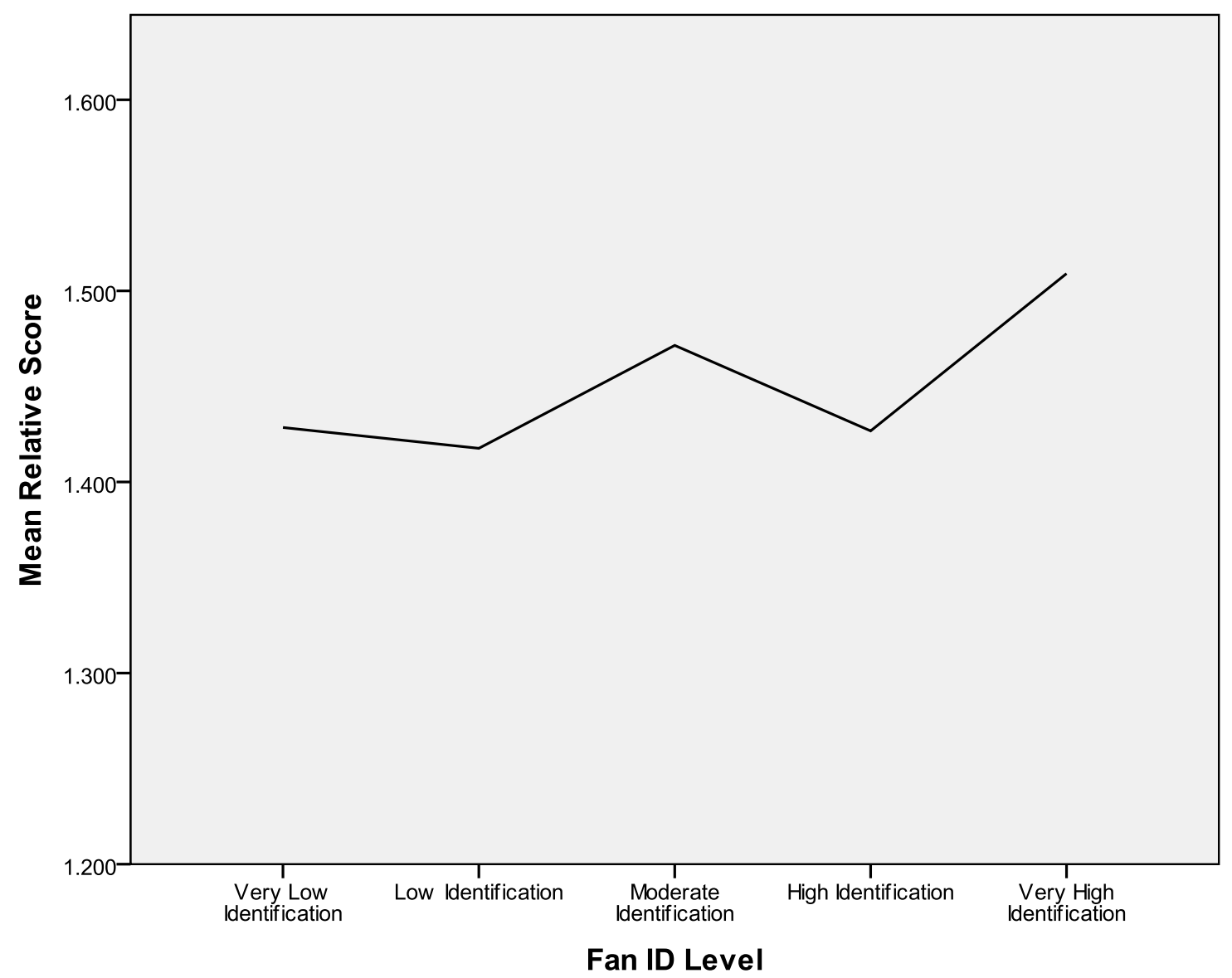

Figure 19: Driver Involvement: Mean Relative Driver Scores

Across all fan ID levels, the mean relative scores of the driver involvement range at a very high level. The highest mean relative score occurs at the very high fan ID level (1.51). No other identification driver shows a higher mean relative score in any of the five fan ID levels. However, the graph illustrates no meaningful pattern or association between mean relative importance scores and fan ID levels. However, if the mean relative scores for the driver involvement have a low variability or coefficient of variation across fan ID levels, then it would not be expected to observe strong correlation. Nevertheless, the high mean relative scores signal that the driver involvement is important for all fan ID levels, because it does not vary across ID levels. 


\subsubsection{Driver Correlations}

Pearson and Spearman's Rank Correlations were performed to assess a possible correlation between the driver involvement and the fan ID level. Table 32 presents the Pearson coefficients for the driver involvement.

\begin{tabular}{|l|l|l|}
\hline & Fan ID Score & Involvement \\
\hline Fan ID Score & 1 & \\
\hline Involvement & .057 & 1 \\
\hline
\end{tabular}

Table 32: Driver Involvement: Pearson Correlation

The results of the correlation analysis confirm the results of the ANOVA test and the interpretation of the graph (figure 19) that there is no statistically significant correlation between the driver involvement and the fan ID level. For this reason, a regression analysis was not performed.

\subsubsection{Driver Escape}

In this section, the relationship and correlation between the driver escape and the fan ID level is analyzed and described. Finally, the drivers involvement and escape are added to the driver - fan ID matrix.

\subsubsection{Driver Relationships with Fan ID Level}

A one-way ANOVA test revealed a p-value of .079 for the driver escape. Therefore, there is no significant relationship between the driver escape and the fan ID level.

\subsubsection{Mean Relative Scores by Fan ID Levels}

Figure 20 shows the mean relative score of the driver escape for each of the five fan ID levels. 


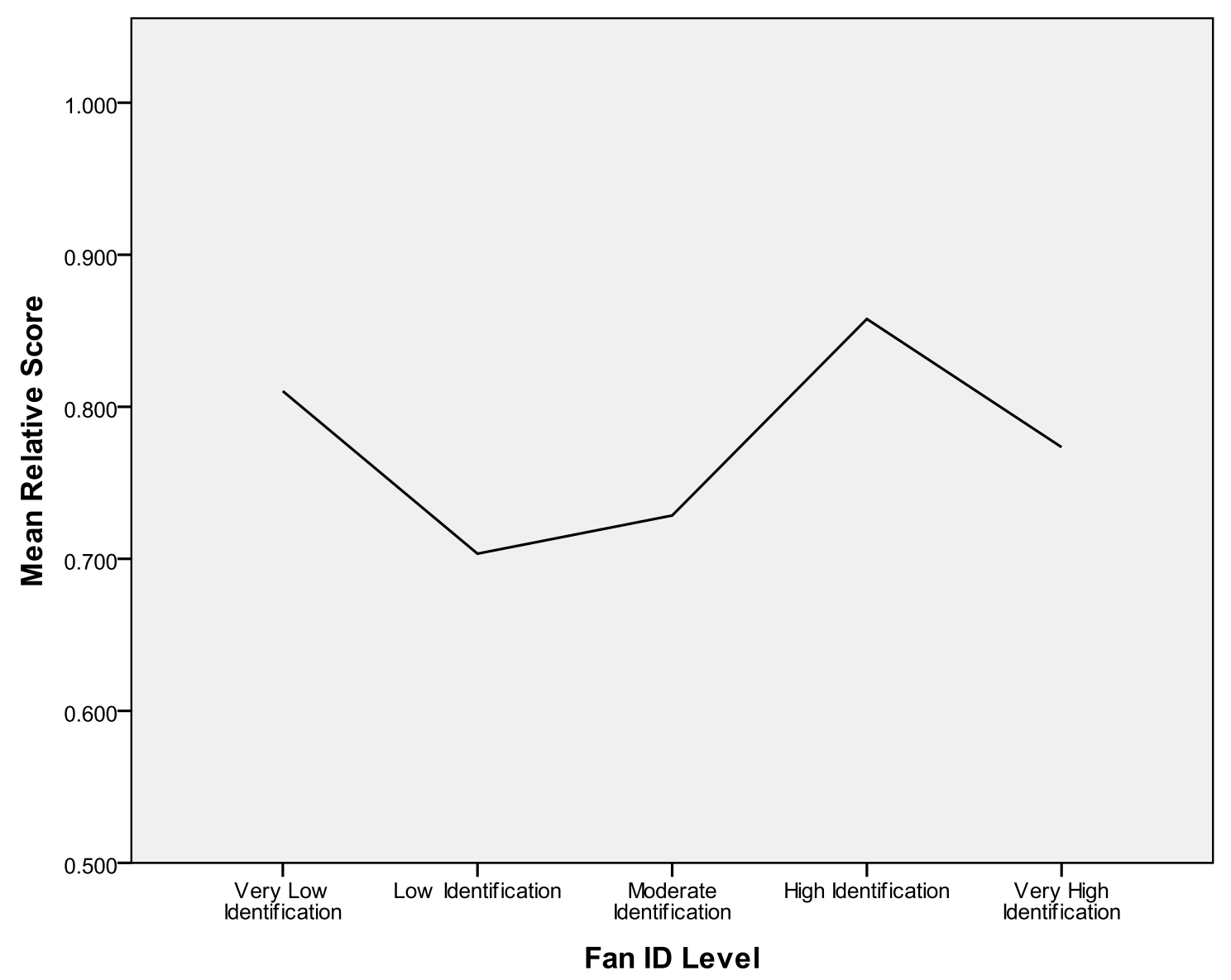

Figure 20: Driver Escape: Mean Relative Driver Scores

Similar to the driver involvement, the relative importance scores for the driver escape shows no clear pattern of association with fan ID level. Its highest mean relative scores occur at the fan ID levels very low (.81) and high (.86). Hence, across all five ID levels, the relative importance that participants place on the driver escape is below average.

\subsubsection{Driver Correlations}

Pearson and Spearman's Rank Correlations were performed to reveal a possible correlation between the driver escape and the fan ID level. Table 33 presents the Pearson coefficients for the driver escape.

\begin{tabular}{|l|l|l|}
\hline & Fan ID Score & Escape \\
\hline Fan ID Score & 1 & \\
\hline Escape & -.004 & 1 \\
\hline
\end{tabular}

Table 33: Driver Escape: Pearson Correlation 
Both Pearson coefficient and Spearman's Rank Correlation show that no statistically significant correlation exists between the driver escape and the fan ID level. Therefore, a regression analysis was not performed.

\subsubsection{Driver - Fan ID Matrix}

Finally, the two individual drivers involvement and escape are added to the driver fan ID matrix. Figure 21 displays the completed matrix including all 16 identification drivers.

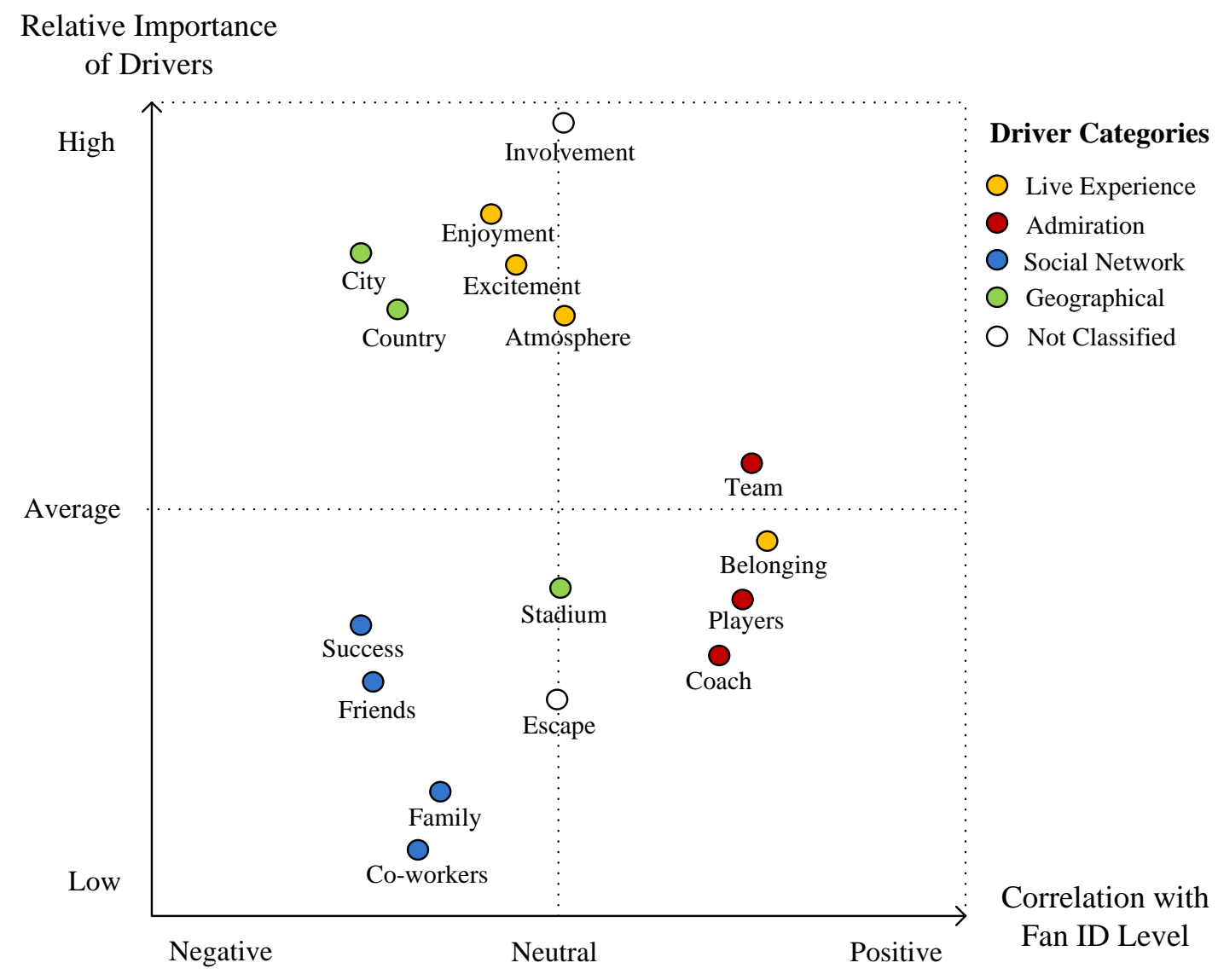

Figure 21: Driver - Fan ID Matrix

Following the analyses of the two individual drivers involvement and escape, the driver - fan ID matrix is finalized. The drivers involvement and escape show no statistically significant correlations with fan ID level, as they possess Pearson coefficient values close to .000 . However, there is a difference between the two drivers as the mean relative score of the driver involvement is significantly higher than the mean relative score of the driver escape. Nevertheless, even the driver involvement, despite having high relative importance to fans, is not correlated to fan ID level. Whilst this result may appear surprising, it may be inferred that if there is 
little variability in the relative importance scores for involvement, it may not be expected to see fan ID levels varying with relative importance scores that are uniformly high.

\subsection{Limitations}

In order to develop distinct fan ID levels for the purpose of analysis, an ID score of 39 was taken as the central point, around which the five ID levels were defined, capturing approximately one fifth $(20 \%)$ of sample respondents. It is noted that a different form of categorization into fan ID levels would have been possible, and that such a different categorization could have affected the findings of this analysis. However, the main purpose of categorizing participants into more separate identification groups, than previously used in the literature, was to refine the analysis of how the relative importance of the 16 identification drivers may be related to the fan ID level. Therefore, a classification into the groups very low identification, low identification, moderate identification, high identification and very high identification was chosen to create more distinct fan ID levels.

\subsection{Summary}

In chapter 4, results of the data analysis were presented. First, a description of participants' demographic characteristics was provided, followed by an analysis of participants' fan identification. A definition of five distinct fan identification levels then allowed for an extended fan analysis, in which the fan ID levels were related to specific fan characteristics. Subsequently, the driver characteristics were analyzed starting with an identification of structural patterns among the drivers. An analysis of the relationship between fan identification and identification drivers was then performed using relative driver scores and the defined fan ID levels. One-way ANOVA tests, as well as correlation and regression analyses were conducted, to examine the relationship between fan ID levels and the relative importance scores of drivers, identified within their separate factor groups. The results of these analyses then allowed for a creation of the driver - fan ID matrix. Lastly, limitations of the data analysis were mentioned. In the following chapter, the findings are discussed and compared to findings of previous research. 


\section{CHAPTER 5: DISCUSSION}

In chapter 5, results and findings of this research are discussed and compared to previous literature findings. Firstly, the demographic characteristics of the sample are compared to the latest census data of New Zealand. Subsequently, fan identification results are compared to results of previous fan identification research. The discussion then focuses on the assessment of identification drivers. This comprises their relative importance as well as structural patterns that were revealed among the drivers. In a subsequent section, the relationship between identification drivers and fan ID level is discussed and an answer to the research question is provided. Lastly, findings are used to profile fans according their fan ID levels and driver preferences and potential marketing implications for Wellington Phoenix are elaborated.

\subsection{Sample Characteristics}

In this section, a comparison of the demographic characteristics, gender and age between the sample of this research and the latest New Zealand census data from the year 2006 (Census Data New Zealand, 2006) is conducted. It becomes apparent that the demographic characteristics of the sample differs from the demographic characteristics as shown in the census data regarding gender and age. The gender distribution in the sample of Phoenix fans is disproportionate to the New Zealand population with more than three out of four participants being male $(77.6 \%)$ and only $22.4 \%$ being female as opposed to an almost equal distribution between male (48.8\%) and female $(51.2 \%)$ in the census data. A direct comparison of the distribution of age groups in the research sample and the census data cannot be undertaken precisely as the definitions regarding age groups slightly differ. However, the research sample shows significantly higher percentages than the census data for age groups between $20(21)$ and $39(40)$ years. In the age groups $\leq 20(\leq 19)$ years and $\geq 56(\geq 55)$ years, the research sample shows significantly lower percentages than the census data. The difference for the age group $\leq 20(\leq 19)$ years is not surprising as the census data includes people between the age 0 and 19 whereas a certain maturity, a de facto minimum age criterion, was necessary to be considered for taking part in this research. Table 34 illustrates the distribution regarding gender and age of both the research sample and the New Zealand census data of 2006. 


\begin{tabular}{|c|c|c|c|c|c|}
\hline \multicolumn{6}{|c|}{ Gender } \\
\hline \multicolumn{3}{|c|}{ Research Sample } & \multicolumn{3}{|c|}{ Census Data New Zealand 2006} \\
\hline Gender & Total & in \% & Gender & Total & in $\%$ \\
\hline Male & 401 & 77.6 & Male & $1.965,621$ & $\sim 48.8$ \\
\hline Female & 116 & 22.4 & Female & $2.062,329$ & $\sim 51.2$ \\
\hline Total & 517 & 100.0 & Total & $4.027,947$ & 100.0 \\
\hline \multicolumn{6}{|c|}{ Age } \\
\hline \multicolumn{3}{|c|}{ Research Sample } & \multicolumn{3}{|c|}{ Census Data New Zealand 2006} \\
\hline Age Group & Total & in \% & Age Group & Total & in $\%$ \\
\hline$\leq 20$ years & 101 & 19.5 & $\leq 19$ years & $1.167,774$ & $\sim 29.0$ \\
\hline $21-25$ years & 104 & 20.1 & 20-24 years & 270,978 & $\sim 6.7$ \\
\hline $26-30$ years & 58 & 11.2 & 25-29 years & 242,442 & $\sim 6.0$ \\
\hline $31-35$ years & 53 & 10.3 & $30-34$ years & 276,561 & $\sim 6.9$ \\
\hline $36-40$ years & 56 & 10.8 & 35-39 years & 301,554 & $\sim 7.5$ \\
\hline $41-45$ years & 42 & 8.1 & 40-44 years & 313,695 & $\sim 7.8$ \\
\hline $46-50$ years & 48 & 9.3 & 45-49 years & 293,424 & $\sim 7.3$ \\
\hline $51-55$ years & 33 & 6.4 & $50-54$ years & 252,729 & $\sim 6.3$ \\
\hline$\geq 56$ years & 22 & 4.3 & $\geq 55$ years & 908,790 & $\sim 22.5$ \\
\hline Total & 517 & 100.0 & Total & $4.027,947$ & 100.0 \\
\hline
\end{tabular}

Table 34: Comparison between Sample and Census Data

Previous research has provided evidence that the demographic characteristics of football fans significantly differ from the demographic characteristics of a society. The target group of Football Federation Australia is mainly represented by people between the ages of 21 and 35 (Lock et al., 2009). 40.6\% of the participants in this research fall into this category. Furthermore, football spectating in Australia is predominantly pursued by males (Summers et al., 2007). The disproportionate gender distribution in this research is therefore not surprising and appears to be a common phenomenon in research on sports fans (e.g. James et al., 2002; Hill \& Green, 2000; Gladden \& Funk, 2001).

\subsection{Fan Identification with Wellington Phoenix FC}

This section discusses the results of the assessment of fan identification as well as the categorization of fans into five fan ID levels. 


\subsubsection{Mean Fan Identification Score}

The sample of 517 participants in this research showed a mean fan ID score of $\underline{38.4}$. This is slightly lower than the fan ID score of 39.3 that was determined by Wann and Branscombe (1993) as a mean ID score for established sports teams. Taking consideration of the young age of Wellington Phoenix, it appears appropriate to compare these results with the results of studies on other new sports teams. A recent study by Lock et al. (2009) measured fan identification with Sydney FC, another new franchise team that competes in the A-League. The assessment of fan identification of 510 Sydney FC fans using the SSIS revealed a mean ID score of 42.94 which is higher than both the mean ID score of this research and the mean ID score determined by Wann and Branscombe (1993). The difference in mean ID scores might be explained by the fact that only members of Sydney FC were included in the study as opposed to an equal distribution of Wellington Phoenix fans in terms of membership or spectator type. It is suggested that club members demonstrate a form of financial commitment which may indicate stronger ties to a sports club. Remarkably, the fan identification scores of these new sports teams were found to be similar (for Wellington Phoenix FC) or even higher (for Sydney FC) than the mean score for established teams determined by Wann and Branscombe (1993). While this finding supports the conclusion of Lock et al. (2009) that fan identification can develop quickly in a new team context, evidence on the robustness of such identification scores needs to be provided.

\subsubsection{SSIS Score Differences}

The analysis of the individual SSIS item scores revealed significant differences between SSIS items. The questions regarding the intensity to which Wellington Phoenix' greatest rivals are disliked and the frequency, with which the name or insignia of Wellington Phoenix is displayed, showed significantly lower mean scores than all other SSIS items, conforming to the findings of Lock et al. (2009). It is suggested that the lack of perceived rivalries can be explained by two reasons. Firstly, Wellington Phoenix has been the only New Zealand based club since the start of the A-League. Rivalries that evolve as a consequence of regional proximity are therefore not possible. Secondly, the young age of Wellington Phoenix does not allow for rivalries that evolve due to a history of athletic clashes. The second SSIS item in which significantly lower scores occurred relates to the public expression of 
fan commitment. Similar to the findings of Lock et al. (2009), Wellington Phoenix fans do not express their affiliation with the club outside the stadium the same way as fans of established clubs. This is supported by the results of the question item about the BIRGing behaviour manifest in public display of merchandise outside of games. These results revealed that more than half of all participants rarely or never wear merchandise outside of games.

\subsubsection{Definition of Fan ID Levels}

In this research, participants were categorized based on their fan ID score. Following examination of the distribution of fan ID scores, it was decided to define five distinct levels of fan identification around a central fan ID score of 39. Previous research has predominantly worked with three discernable levels of fan identification such as low identification (social fans), medium identification (focused fans), and high identification (vested fans) defined by Sutton et al. (1997) or the segmentation into high-, moderate-, and low-loyalty groups by Funk and Pastore (2000). However, not all researchers define distinct fan groups by the fan ID score. Giulianotti's (2002) differentiation between supporters, followers, fans, and flâneurs, depending on an individual's identification and solidarity as well as on the duration of and personal investment to the relationship with a sports team, is one example for a different segmentation. In order to answer the research question for this study, a definition of fan ID levels based on the fan ID score was considered necessary. Furthermore it was considered that a definition of five ID levels would more precisely support the examination of the relationship between identification drivers and fan identification than three ID levels.

\subsubsection{Demographic Characteristics and Fan Identification}

Previous research on fan identity with new sports teams discusses whether fan identification is influenced by demographic characteristics or not. Sports researchers have provided different answers to this question. Whilst the findings of James et al. (2002) suggest that fan identification is unrelated to demographic characteristics such as gender, age, education level, or income level, the results of Lock et al. (2009) indicate that identity strength shows a significant relationship with age and income, but no relationship with gender or current employment. While testing the Sport Fan 
Motivation Scale (SFMS), Wann et al. (1999) found no significant relationship between identity strength and age.

In this research, the influence of three demographic characteristics age, gender, and marital status on fan identification was tested. Findings revealed a significant relationship between gender and fan ID level but no significant between-group differences for age and marital status. These findings partly differentiate from the findings of James et al. (2002) and Lock et al. (2009). However, differences regarding the sample types need to be taken into consideration. Whilst James et al. (2002) concentrated on season ticket holders of a new sports team prior to the beginning of the first season, Lock et al. (2009) examined members of a new sports team. Wann et al. (1999) solely included students with ages ranging from 18 years to 49 years. In this research, no selection was undertaken based on membership status or spectator type. Further research is therefore necessary to enhance understanding of the influence of demographic characteristics on fan identification.

\subsection{Identification Drivers of Wellington Phoenix Fans}

This section provides a discussion about the structural patterns among the drivers that were identified through a factor analysis. The findings of this factor analysis are then compared to the categorization of drivers undertaken in chapter 2. Lastly, the relative importance of both individual drivers and factors identified are discussed.

\subsubsection{Structural Patterns of Identification Drivers}

A multivariate factor analysis, undertaken to identify structural patterns among the driver variables, revealed three main factors that account for $45.2 \%$ of variability in the data. Due to the driver characteristics, the factors were called live experience, admiration, and social network. These factors show similarities to the driver categorization developed in the theoretical framework of this research. In particular, similarities exist between the factor live experience and the functional level, the factor admiration and the symbolic level and the factor social network and the interpersonal level as the following figure (figure 22) shows: 


\section{Categorization}

\section{Functional}

- Excitement

- Enjoyment

- Atmosphere

- Escape

\begin{tabular}{|l|}
\hline Symbolic \\
- Success \\
- Team \\
- Players \\
- Coach \\
\hline
\end{tabular}

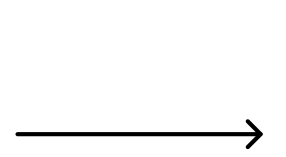

Interpersonal

- Family

- Friends

- Co-workers

- Belonging

- Involvement

\begin{tabular}{l} 
Geographical \\
- City \\
- Country \\
- Stadium \\
\hline
\end{tabular}

\section{Factor Analysis}

\section{Live Experience}

- Excitement

- Enjoyment

- Atmosphere

- Belonging ?

\begin{tabular}{|ll|}
\hline \multicolumn{2}{|c|}{ Admiration } \\
- Team & \\
- Players & $\checkmark$ \\
- Coach & $\checkmark$ \\
\hline
\end{tabular}

Social Network

- Family

- Friends

- Co-workers

- Success ?

\section{Unspecified \\ - City ? \\ - Country ? \\ - Stadium ? \\ - Involvement ? \\ - Escape ?}

Figure 22: Structural Patterns of Identification Drivers

As illustrated, the factor live experience contains the three drivers excitement, enjoyment, and atmosphere which had previously been categorized as functional drivers. The driver escape which had also been categorized as a functional driver was not included in any of the three factors due to its low factor loading.

Furthermore, the factor analysis indicated a high correlation between the driver belonging and the factor live experience. The driver belonging represents the sense of belonging that fans develop within the fan community. According to Gantz (1981), a sense of belonging is created by social networks and helps maintain the psychological health of sport fans. For this reason, it was anticipated that the driver belonging could well be included in a group of interpersonal drivers. However, the findings suggest that belonging is also tied up with the feelings and emotions that evolve during the live attendance. Tajfel's (1970) notion that fan communities 
provide positive consequences to their members, even if fans do not directly interact with other fans, helps in imagining that a sense of belonging can evolve within a crowd. Hence, the driver belonging appears to be connected with collectively experiencing excitement, enjoyment and the stadium atmosphere, rather than being merely created by the group of people with whom a fan may attend a game.

The factor admiration contains the three drivers team, players and coach. All three drivers had previously been categorized within the group of symbolic drivers. However, the driver success, which had also been categorized as a symbolic driver, is not included in the factor admiration.

The third factor, social network, consists of the four drivers, family, friends, coworkers, and success. The first three drivers, family, friends, co-workers had been categorized into the group of interpersonal drivers. The fourth driver, success, had been categorized as a symbolic driver. Therefore, its placement within the factor social network is surprising. It is suggested that this may be explained by the role of social drivers for Wellington Phoenix fans. For example, due to the young age of the club, indoctrination by family members, friends, or co-workers is considered to be limited. However, the cognitive development of team loyalty is strongly influenced by these socialising agents (Parker \& Stuart, 1997; Kolbe \& James, 2000; James, 2001).

It is therefore suggested that the role of the social network differs between the context of new sports teams and established teams. Previous studies have shown that people within the social network do not only serve as socialising agents, but also as company for the attendance of games. Jones (2000) found out that $90 \%$ of fans of the English football club Luton Town, attend games as part of a group. In this research, 93.2\%. of fans were found to visit games as part of a group. With the indoctrination role being limited in the case of Wellington Phoenix, people within the social network are therefore primarily seen to have an accompanying role for the attendance of games. The success of the team may have a direct link to this role as it significantly influences the perceived quality of the time that is shared with people from the social network. Madrigal (1995) highlights the personal joy fans attain when the team is successful. It is suggested that this joy is achieved by both individual fans, and also fans who attend games as part of a group. 
Lastly, the interpersonal drivers belonging and involvement are not included in the factor social network. As mentioned earlier, the driver belonging was found to belong to the factor live experience. According to the factor analysis, the driver involvement is not specified as part of any of the factors identified. Together with the driver escape and the three geographical drivers city, country, and stadium, it belongs to a group of five identification drivers that are unspecified.

The comparison between the categorization developed within the theoretical framework, and the findings of the factor analysis, allows for a test of hypothesis 1 :

H1: Factor groups derived from a factor analysis show structural similarities to the initial categorization of identification drivers capturing interpersonal, symbolic, geographical, and functional characteristics. These patterns are manifest in terms of within-groups correlations being stronger than inter-group correlations.

Nine out of eleven drivers that were allocated to factor groups through the factor analysis had been previously categorized into the respective corresponding groups. An attempt was made to explain the allocation of the drivers belonging and success into different groups. Five drivers including the three geographical drivers were not linked to a distinct factor. Nevertheless, the high ratio of drivers that were grouped in a similar matter as suggested in the theoretical framework supports hypothesis 1 .

\subsubsection{Relative Importance of Identification Drivers}

Of all identification drivers tested, involvement showed the highest relative importance to Wellington Phoenix fans. Hence, it may be inferred that an active interest in football has the greatest effect on the decision to support Wellington Phoenix. This also supports the findings of Hill and Green (2000). In their study, involvement with the sport of rugby was identified a significant predictor for future attendance motivation. Furthermore, research has provided evidence that individuals who are actively engaged in a specific sports discipline are also likely to be actively involved as fans (Wann et al., 1999). In this research, more than three quarters (77.8\%) of all participants indicated a current or past active engagement in football. It is therefore not surprising to find the driver involvement as foremost of all 16 drivers regarding the relative importance for Wellington Phoenix fans. 
All drivers within the factor live experience rank between $2^{\text {nd }}$ and $7^{\text {th }}$ position based on their relative importance. The high importance that Wellington Phoenix fans placed on drivers associated with the live experience at games is not surprising. In their study on predictors of loyalty towards a professional sports team, Funk and Pastore (2000) tested eight attitude properties. Their results indicated that the attitude measures direct experience and importance are most effective in predicting loyalty towards a professional team. However, the authors define direct experience in a wider context, including any form of prior participation or contact that individuals have had to team-related activities. Nevertheless, despite embracing more dimensions than the construct live experience, used in this research, the attitude measure direct experience is argued to be relevant and applicable as experiences during live games represent an essential part of the overall direct experience.

The three drivers captured in the factor admiration appear to be of medium importance, with the driver team ranking $7^{\text {th }}$, players as $10^{\text {th }}$, and coach in the $12^{\text {th }}$ position. Interestingly, the driver team possesses a higher relative importance than the driver players. It is suggested that the reason for this is the lack of star players in Wellington Phoenix' team. Therefore, fans appear to connect with the Wellington Phoenix team as an entity rather than with individual players. The low position of the driver coach is somehow surprising. Despite the fact that the coach was not found to be a significant predictor of loyalty towards a football club in the study of Gladden and Funk (2001), the authors indicate that the main visible attributes of the coach are a track record for success and/or significant charisma (Gladden \& Funk, 2001, p.73). The head coach of Wellington Phoenix, Ricky Herbert, undoubtedly possesses these attributes, due to his successful engagement as the head coach of the national team, and his playing record with the New Zealand All Whites national team.

Drivers within the factor social network appear to be of low importance to the participants. In particular, the drivers friends $\left(13^{\text {th }}\right)$, family $\left(15^{\text {th }}\right)$, and co-workers $\left(16^{\text {th }}\right)$ show low relative mean scores. The driver success also ranks in the lower half of the ranking $\left(11^{\text {th }}\right)$. These results are interesting as they significantly differ from findings in previous research. In the context of well established football teams, social indoctrination has a very strong effect on the emotional commitment that individuals can develop towards a football team (Parker \& Stuart, 1997). In the study of Parker and Stuart (1997), 54\% of the participants who indicated that their parents supported 
a particular team also developed an allegiance towards the same team. It is therefore suggested that a reason for the low relative importance of social network drivers relates to the young age of Wellington Phoenix. The extent to which social indoctrination and particularly family indoctrination can affect the emotional commitment towards Wellington Phoenix, is suggested to be little. In the case of the driver success, the results are less surprising. According to Gladden and Funk (2001), the success of a team is not a significant predictor of long-term loyalty towards a football club, and only 9\% of 781 participants in the study of Parker and Stuart (1997) indicated that success was the reason for them to support a team.

By contrast, geographical drivers were found to be of high importance. In particular, Wellington Phoenix' role in representing the city $\left(4^{\text {th }}\right)$ and country $\left(6^{\text {th }}\right)$ ranked high in the list of the 16 drivers. This conforms to the findings of Kolbe and James (2000). In their study on the American NFL team Cleveland Browns, the statements Browns as my hometown team and Browns as a Cleveland institution ranked top with regards to their influence on becoming a Browns fan. In their study, geographical drivers even ranked slightly higher than live experience drivers such as stadium atmosphere. The driver stadium $\left(9^{\text {th }}\right)$ appeared to be of average importance for Wellington Phoenix fans. It is argued that the lower rank can be explained by the lack of memories which fans can connect with their home ground due to the young age of the club.

Lastly, the low ranking of the driver escape $\left(14^{\text {th }}\right)$ supports the findings of Wann et al. (1999). In their measurement of eight different motives of sport fans, the motive escape scored relatively low $\left(6^{\text {th }}\right)$. The following section focuses on the relationship between the drivers and the five distinct fan ID levels.

\subsection{Relationship between Identification Drivers and Fan Identification}

In this section, findings regarding the relationship between identification drivers and the fan ID level are discussed and compared to findings of previous work. As mentioned earlier, research literature has not provided much evidence in this area except for the driver success. As such, only one hypothesis was formulated. However, due to the exploratory nature of this research, the discussion addresses further relationships between drivers and the fan ID level which have emerged. In order to address hypothesis 2 first, this section starts with a discussion of the factor 
social network. Subsequently, the remaining factors and driver groupings are discussed. Lastly, an attempt is made to interpret the driver - fan ID matrix.

\subsubsection{Drivers of the Factor Social Network}

The discussion of the relationship between various drivers and fan ID level begins with an exploration and testing of hypothesis 2. Based on the findings of Wann and Branscombe (1990) that the attendance of highly identified fans is less dependent on the actual success of a sports team than is the attendance of lowly identified fans, the following hypothesis is tested:

H2: There is a statistically significant relationship between the driver success and the level of fan identification. This relationship reflects that success becomes less important, the higher the level of fan identification is.

Results revealed a statistically significant relationship between the driver success and the fan ID level ( $\mathrm{p}=.000)$. Indeed, both Pearson and Spearman's Rank Correlation showed a negative correlation between the driver success and the fan ID level. The driver also exhibited the strongest correlation of all drivers within the factor social network. Therefore, hypothesis 2 can be confirmed. It is important to mention that hypothesis 2 was based on evidence that focused on established sports teams. This indicates that the findings of Wann and Branscombe (1990) may be applicable in the context of new sports teams.

The remaining drivers of the factor social network - family, friends, and co-workers, also show statistically significant relationships and negative correlations with the fan ID level. Hence, all social network drivers follow the same correlation and structural pattern. Whilst the drivers are of higher importance for lowly identified fans, they are of lower importance for highly identified fans. Findings of previous research show that the driver family is used in at least two different ways. Parker and Stuart (1997) used the construct to test the influence of family indoctrination on the development of fan commitment towards a football team. Their results indicated that family has a very strong effect on this development and hence it can be assumed that higher scores for the driver family are associated with higher fan ID levels. Wann et al. (1999) interpreted the motive family differently. For them, it represents the time that a sports fan can spend with family members during sports games. Their findings indicate that high ratings for family are associated with low fan ID levels as such 
individuals typically pursue different goals than highly identified fans, namely, to spend time with their family. Therefore, the findings of this research indicate that Wellington Phoenix fans interpret family as time that can be spend with family members in the same way as explained by Wann et al. (1999). Considering opportunities for family indoctrination being limited due to the young age of the club, this is not surprising.

Findings for the drivers friends and co-workers align with the findings of Gladden and Funk (2001). According to them, peer group acceptance is negatively correlated with team loyalty. It is therefore argued that highly identified Wellington Phoenix fans are not primarily attending home games to spend time with friends or coworkers. Rather, as highlighted by Gladden and Funk (2001), the acceptance by peer groups is important to individuals who possess a low level of fan identification. Similarly for the driver family, it is inferred that participants interpreted the drivers friends and co-workers in the context of spending time during games rather than as agents of social indoctrination.

\subsubsection{Drivers of the Factor Live Experience}

With regards to the relationship between drivers of the factor live experience and the fan ID level, results revealed a significant difference between the driver belonging and the drivers enjoyment, excitement and atmosphere. Whilst the driver belonging showed a significant positive correlation with the fan ID level $(p=.000)$, no significant correlation with fan ID level could be identified for the drivers enjoyment, excitement and atmosphere.

The positive correlation of the driver belonging with fan ID level, found in this research, also aligns with the findings of Wann et al. (1999). Of eight different motives for sports fans that were tested in their study, group affiliation was found to be positively correlated with degree of fandom. Wann et al. (1999) defined group affiliation as a means to share experiences with fellow fans of the same team and therefore as a means to address a fan's need for belongingness. Hence, it is argued that individuals who are motivated by gaining a feeling of belonging among fellow fans, tend to develop stronger fan identification. It is furthermore suggested that the relationship between belonging and the fan ID level is not dependent on location and history of a football team. 
For the remaining drivers enjoyment, excitement and atmosphere no statistical relationship was found with the fan ID level. A comparison to findings of prior research appears difficult as the definition of the concept experience with regards to sport game attendance varies. When Funk and Pastore (2000) stated that attitude measures of direct experience are very effective predictors of loyalty toward a professional team (p.182) they were mainly referring to pre- and post-game experiences rather than experiences during games. By stating that there is no data suggesting that stadium factors are more important to fans of the home team than for other fans, Hill \& Green (2000) referred to service elements offered by the stadium.

Wann et al. (1999) connects the driver entertainment with fans who perceive sport spectating as a pastime similar to watching movies or television or listening to music (Wann et al., 1999, p.115). Their results showed that entertainment has a positive correlation with the degree of fandom. These results are supported by findings of Gladden and Funk (2001) who identified a positive correlation between team loyalty and the construct of product delivery of which entertainment was an element. The findings of this research differ from these findings. Whilst the high importance of live experience drivers across all fan ID levels supports the notion that sport consumers showed a great need to be entertained (Gladden \& Funk, 2001), none of the drivers enjoyment, excitement and atmosphere showed a significant correlation with the fan ID level. It is therefore argued that fans' need to be entertained, as mentioned by Gladden and Funk (2001), applies to fans across all fan ID levels. Furthermore, it is suggested that whilst fans who are driven by stadium atmosphere, excitement of the game, or entertainment, satisfy this need by attending home games, these drivers do not lead to an increasing identification with the club.

\subsubsection{Drivers of the Factor Admiration}

Results showed positive correlations between the drivers of the factor admiration and the fan ID level. Hence, whilst the drivers team, coach, and players are of little importance for lowly identified fans, their relative importance increases at higher fan ID levels. These results are in contrast to previous research findings. Gladden and Funk (2001) identified a significant negative correlation between the admiration for star players and team loyalty. They argue that for highly committed fans, the presence of a star player may only have little impact. Furthermore, according to their findings, the head coach was not found to be a significant predictor of loyalty 
towards a football club. Both of these findings differ from the findings in this research.

It is suggested that lowly identified fans of teams in economically strong leagues, such as the English Premier League, are more likely to know individual players, the coach or even the whole team than lowly identified fans of teams in economically weaker leagues, such as the A-League. This notion is further supported by the lack of star players in A-League teams. In the case of Wellington Phoenix, it is therefore argued that lowly identified fans are less likely to know individual players, team or coach. For that reason, these drivers are assumed to be of less relevance for those fans and of higher relevance for highly identified fans who tend proactively to follow the news about the club and its representatives.

\subsubsection{Geographical Drivers}

With regards to the relationship with the fan ID level, the geographical drivers country and city differ from the driver stadium. Results indicated a significant negative correlation between the fan ID level and the drivers country and city. Hence, whilst lowly identified fans placed a high importance on these two drivers, importance decreased for fans on higher fan ID levels. For the driver stadium no correlation with the fan ID level was found.

According to findings of Kolbe and James (2000), the factor place is of significant importance for fans of sports teams. In the case of Wellington Phoenix, it is necessary to mention that the club represents the only professional football team in New Zealand within the A-League. The representation of both the Wellington region and the country explains the high overall importance of these drivers. It is argued that this importance is high for lowly identified fans as it provides a possibility to proclaim an affiliation to the club that does not exist otherwise. According to Cialdini et al. (1976), to be born, be living or have lived in the same region, are examples of reasons for such an affiliation. For highly identified fans however, stronger affiliation to team, players, coach or fellow fans, seem to replace the importance of the regional representational role of the club.

With regards to the driver stadium, the finding that no correlation exists between it and the fan ID level are similar to findings of Gladden and Funk (2001). According to them, the stadium that may well serve as an attribute to attract fans was not found 
to be a significant predictor of team loyalty among highly identified fans, and, indeed, no positive correlation was found. However, Gladden and Funk (2001) pointed out that a stadium may serve as a stronger attraction to non-committed fans. As such, this statement indicates a possible negative correlation between the driver stadium and the fan ID level. As indicated earlier, there is a lack of memories that fans can connect with the home ground of a new sports team. It is therefore argued that Wellington Phoenix' home ground, Westpac Stadium, as a driver of fan identification, has a similar effect on both lowly and highly identified fans.

\subsubsection{Drivers Involvement \& Escape}

Findings showed no statistically significant relationships between the fan ID level and the drivers involvement and escape. As mentioned earlier, there is evidence that individuals who are actively engaged in a specific sports discipline are more likely to be actively involved as fans (Wann et al., 1999). This was supported by the findings of this research, as more than three quarters of all participants indicated a current or past active engagement in football and the driver involvement showed the highest overall relevance of all 16 drivers. However, the conclusion of Fisher and Wakefield (1998) that identification with a professional sports team is likely to be higher if a fan is highly involved with the sport cannot be confirmed. Moreover, findings indicate that whilst involvement has a high relevance in the context of new sports teams, it does not influence the level of fan identification. Due to the high relevance associated with involvement across all fan ID levels, it is furthermore argued that it can indeed serve as a significant predictor for future attendance motivation, as stated by Hill and Green (2000).

In their study about the Sport Fan Motivation Scale (SFMS), Wann et al. (1999) tested the relationship between SFMS scores and the degree to which an individual is a sport fan. In this test, a positive correlation between the motive escape and the degree of fandom was identified. In addition to that, Gladden and Funk (2001) identified escape to be a significant predictor of team loyalty. The results of this research however indicated that no relationship between the driver escape and the fan ID level exists. The interpretation that the sport team's ability to provide an escape is an important part of the committed fan's everyday life (Gladden \& Funk, 2001, p.85) leads to the suggestion that Wellington Phoenix' ability of providing an escape is not significantly more important to highly identified fans than to lowly 
identified fans. Further research is necessary to test factors that might influence the relationship between escape and fan ID level. In the following section, the driver fan ID matrix is discussed. This discussion aims to provide a basis for fan profiling which is then used to develop potential marketing strategies for Wellington Phoenix.

\subsubsection{Meaning of the Driver - Fan ID Matrix}

Following the discussion of individual identification drivers, a more holistic view is presented in this section. This holistic view is achieved by discussing patterns on the driver - fan ID matrix. Of particular interest are driver clusters that indicate shared characteristics. The objective of this analysis and discussion is to form a basis for identifying various marketing initiatives and implications. Figure 23 shows the driver - fan ID matrix.

Relative Importance of Drivers

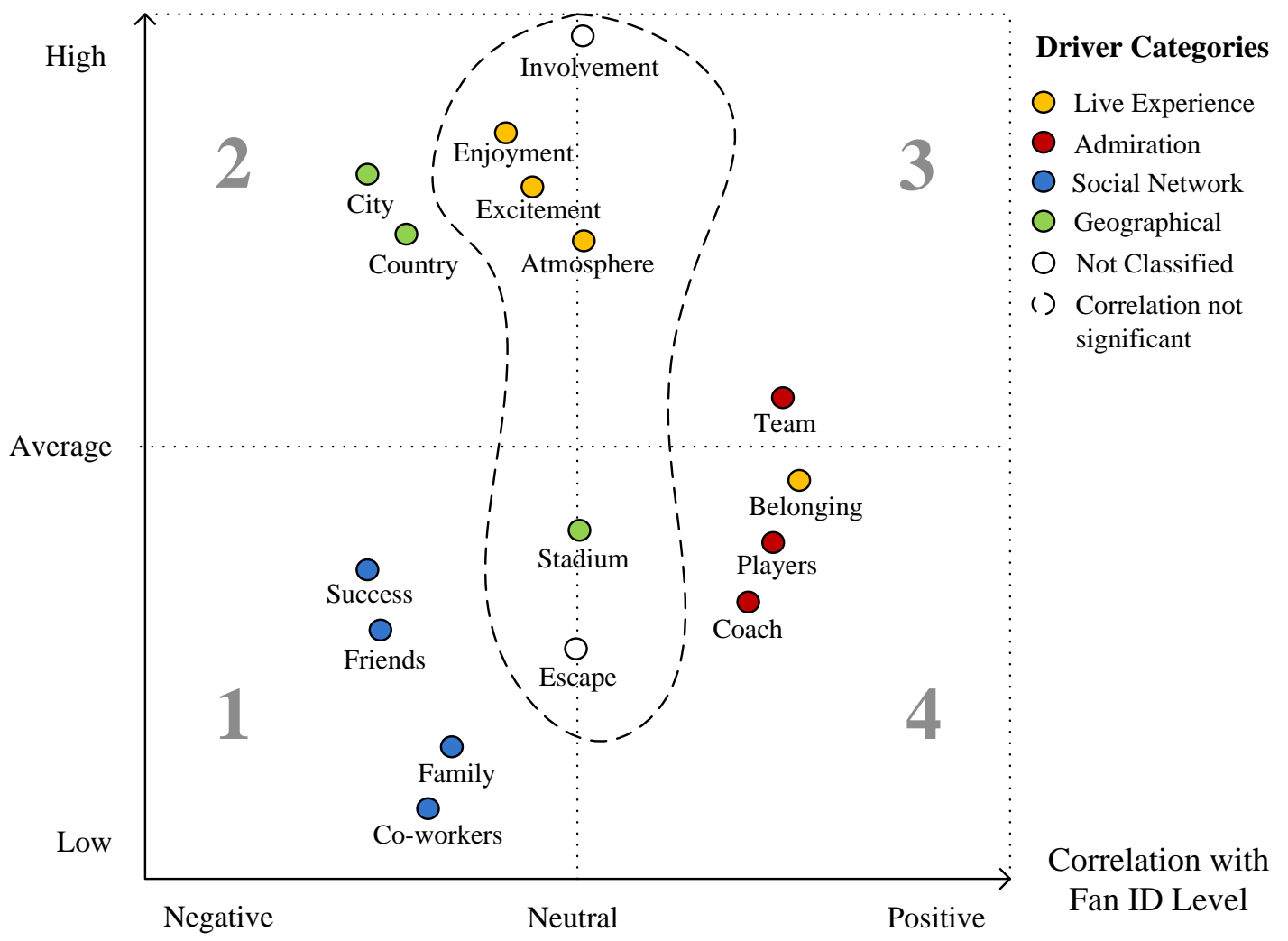

Figure 23: Discussion: Driver - Fan ID Matrix

The matrix combines the relative importance of drivers (y-axis) with the direction and strength of correlations with the fan ID level (x-axis). The left half of the matrix consists of drivers that showed a negative correlation with the fan ID level. This side contains the quadrants negative correlation - low importance (1) and negative 
correlation - high importance (2). The right half of the matrix consists of drivers that showed a positive correlation with the fan ID level. This side contains the quadrants positive correlation - high importance (3) and positive correlation - low importance (4). Drivers within the dashed line were not found to be significant at the .01 level.

All drivers located on the left half of the matrix share the characteristic of being more important to fans with low identification than to fans with high identification. This applies to the four social network drivers as well as to the two geographical drivers city and country. The vertical position indicates the relevance level of the drivers. Hence, the social network drivers on quadrant 1 indicate a similar relationship towards the fan ID level as the geographical drivers city and country on quadrant 2, but find themselves on a lower importance level with respect to their relationship with fan ID level.

As a result of their positive correlation with the fan ID level, the drivers located on the right half of the matrix are more important to fans with high identification than to fans with low identification. All three admiration drivers, team, players, and coach, as well as the live experience driver belonging are placed on this side of the matrix. Due to its above average relevance, team is the only driver located in quadrant 3. Within quadrant 4 , the driver belonging is highest in relevance and bordering on quadrant 3.

The drivers located within the dashed curve are not significantly correlated with the fan ID level. However, the driver involvement as well as the three live experience drivers enjoyment, excitement, and atmosphere possess a higher importance than the drivers stadium and escape. In the following sections, the driver locations in this matrix are taken into consideration for a formulation of specific marketing implications.

\subsection{Marketing Implications for Wellington Phoenix FC}

The previous discussion mainly focused on addressing the research question about the relationship between specific drivers and the level of fan identification. In doing so, this research sought to contribute evidence to fill the gap identified by Wann et al. (1999), and to enhance understanding about fan identification towards new sports teams. However, enhancing knowledge about fan identification is also of high 
practical relevance as it enables sports marketers to better address specific fan groups for customized marketing activities. This section aims to start a discussion on how findings of this research can be used to inform marketing strategies.

\subsubsection{Value of Fan Identification for Wellington Phoenix FC}

According to Madrigal (1995), there is a positive correlation between the level of fan identification and the tendency for fans to BIRG. The results of this research confirm this by revealing a statistically significant relationship between the level of fan identification and the BIRGing behaviour, both during and outside of games. Highly identified fans of Wellington Phoenix show their affiliation to the club by wearing merchandise in higher frequencies than lowly identified fans. An explanation for this is given by Wann et al. (2000) who found that the level of fan identification, together with the level of self-esteem, is related to an individual's decision to strategically self-present his or herself as a fan of a specific team (Wann et al., 2000, p.203).

The findings of Summers et al. (2007) that BIRGing leads to increased merchandise sales as well as Wann and Branscombe's (1993) notion that highly identified fans have stronger purchase intentions for licensed products imply that highly identified fans may contribute more to the financial success of Wellington Phoenix than lowly identified fans. Further evidence on the positive effects of fan identification on the financial success of football clubs can be found in literature on consumer satisfaction. According to Fisher and Wakefield (1998), there is a relationship between club identification and customer satisfaction. The authors demonstrated that fans' team support behaviours are associated with their level of fan identification. For example, it was found that highly identified fans attended more games and spent more money on licensed products than lowly identified fans. This statement is supported by the findings of this research. In addition to the statistically significant relationship between the level of fan identification and the tendency to BIRG it was found that the level of fan identification also shows a statistically significant relationship to frequency of attendance.

Lastly, high fan identification may contribute to the financial stability of a football club. The findings of this research revealed a negative correlation between the level of fan identification and the perceived importance of success. Hence, the attendance of highly identified fans is less dependent on current success than the attendance of 
lowly identified fans as highly identified fans demonstrate a higher loyalty towards their supported team, even in unsuccessful times (Madrigal, 1995). The following sections elaborate potential marketing implications for Wellington Phoenix to actively promote the development of fan identification.

\subsubsection{Fan Profiling}

In order to maximize the positive outcomes of high fan identification, sports marketers need to develop marketing activities that aim to strengthen fan identification across the spectrum of identification levels. It is suggested that the first step of developing specific marketing activities is to profile different fan groups. Such profiling, often referred to as microsegmentation, is a growing trend in consumer research (Funk \& Pastore, 2000). The findings of Mahony, Madrigal and Howard (1999), that team loyalty in the American NFL could be largely determined through knowledge of an individual's personality characteristics (Kolbe \& James, 2000) indicate that profiling is possible in the context of sports fans. Whilst a thorough fan profiling would exceed the scope of this research, findings of this research are incorporated in an attempt to further stimulate debate on sports fan profiling. This attempt to illustrate the profiling of Wellington Phoenix fans chooses to focus on the distinction between lowly and highly identified fans.

Lowly identified fans of Wellington Phoenix appear to be driven by four different motivations. Firstly, Wellington Phoenix' city and country representational role in the A-League is important to this fan group. Furthermore, lowly identified fans value social aspects connected to the attendance of home games, particularly the ability to spend time with family and friends. Additionally, in-game experiences such as excitement, entertainment, and stadium atmosphere are important drivers for this fan group. Lastly, an active participation in football significantly increases the likelihood of them to attend home games. Lowly identified fans do not feel a close connection to the team, individual players or other club representatives. Information about the club is not actively gathered. Games are attended on an occasional basis as lowly identified fans perceive attendance as just another leisure activity, comparable to going to the theatre. As individuals that are low in group identification are primarily concerned with their own needs (van Leeuwen et al., 2002), current success has a major impact on their future attendance intention. 
In contrast, highly identified fans of Wellington Phoenix appear to be primarily motivated by a perceived connection with the team, individual players and other representatives of the club. Knowledge about the club is actively gathered. Furthermore, highly identified fans value the sense of belonging they feel during home games. This sense of belonging is mainly created by the crowd and the crowd atmosphere. The shared interest between the crowd and highly identified fans is enough to generate a sense of belonging, and makes direct interaction unnecessary (Tajfel, 1970). Similarly, lowly identified fans as a fan group are motivated by ingame experiences, and an active participation in football is often linked with an active interest in spectating. For highly identified fans, game attendance is more than just another leisure activity. It becomes part of their social identity from which they can derive emotional significance (Madrigal, 1995). As individuals high in group identification are motivated to ensure the wellbeing of the group rather than primarily being concerned with their own needs (van Leeuwen et al., 2002), success is of little importance. The following section focuses on marketing activities which incorporate these preliminary profiles.

\subsubsection{Implications for Fan Marketing}

Marketing strategies can only be successful if augmented by a thorough understanding of the role that sports teams play in a fan's life as well as the benefits the sports team can provide to its fans (Gladden \& Funk, 2001). Preliminary profiling can be seen as a first step in achieving such an understanding. In the following, such profiles are discussed in the context of previous literature findings, and propositions for marketing strategies targeting fans according to their fan ID level are formulated. The formation of fan identification is considered to be a process (James, 2001). Therefore, the discussion is orientated towards the objective to bring fans to the next higher identification level as explained in section 1.2 and illustrated by figure 24 . 


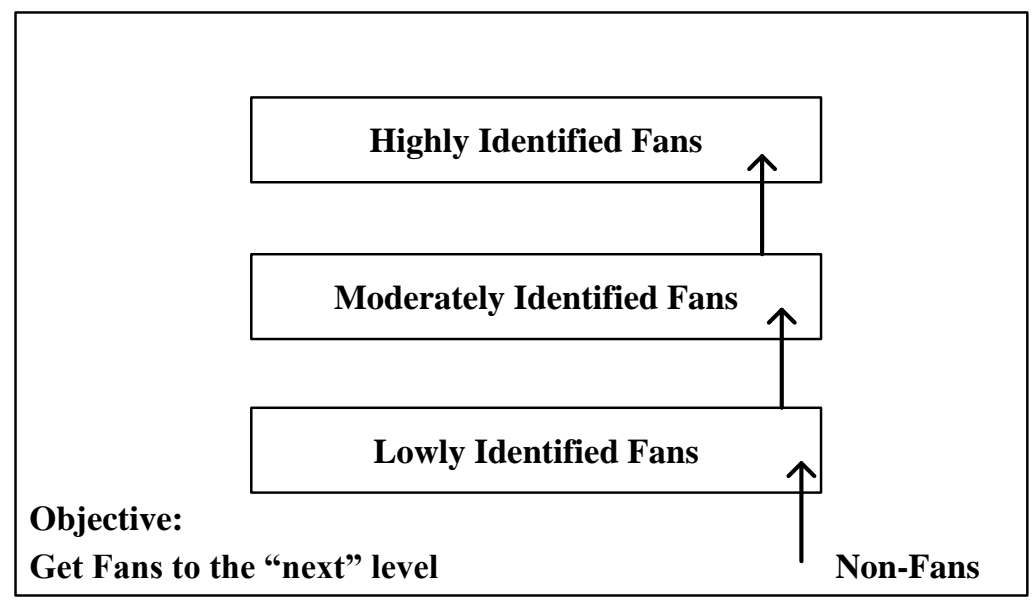

Figure 24: Implications for Fan Marketing

The following section focuses on implications for fan marketing aiming to turn nonfans into lowly identified fans.

\subsubsection{Fan Marketing for Non-Fans}

Sport spectatorship is a social activity. Previous studies have shown that the majority of fans visit games in groups. Jones (2000) found out that $90 \%$ of fans of English football club, Luton Town, attend games as part of a group. An even higher percentage (93.2\%) was revealed in this research. Fan profiling has revealed that social aspects are particularly important for lowly identified fans. Therefore, it is suggested that marketing strategies that aim to turn non-fans into lowly identified fans should focus on highlighting game attendances as an appropriate way to spend time with family, friends, or co-workers. This could be achieved by altering communication on advertisements or offering special deals in the form of ticket bundles for families, friend groups, or co-workers. Depending on the success of such special deals offerings, ticket bundles could be offered to local companies, schools, universities, or clubs on a regular basis. Another strategy that could be tested focuses on what Melnick (1993) calls promoting connections between spectators (Melnick, 1993, p.57). In this strategy, specific seating areas within the stadium could be reserved for fans who share specific characteristics such as age or neighbourhoods.

For the long-term development of a strong fan base, it may be considered advisable to implement marketing strategies that actively promote family, and in particular, parental indoctrination. The findings of Parker and Stuart (1997) showed how powerful parental indoctrination can be in the context of football fandom. Given the often strong influence of the father in the cognitive development of team preferences 
and loyalty of children, the sports marketers of Wellington Phoenix may emphasize events that allow fathers to spend time with their children at team-related activities. Such connection is perceived to be a powerful tool in shaping team loyalty at an early stage (Kolbe \& James, 2000).

Furthermore, the profiling undertaken earlier has shown that lowly identified fans are motivated by the representational role of Wellington Phoenix with respect to their home city and country. Therefore, it is suggested that marketing activities that target non-fans should highlight the link between Wellington Phoenix and both the city of Wellington and New Zealand. The findings of Kolbe and James (2000) revealed that a pro-active creation of a link between the team and the city in which it is located can provide a powerful source of identification. Community involvement such as an involvement in social projects or charity events could improve the credibility and reputation of the club by demonstrating shared goals with the community (Sutton et al., 1997).

Lastly, the effect that success has on attendance numbers is often highlighted. Indeed, findings indicate that success is perceived important by lowly identified fans. Merchandise sales for NBA team Houston Rockets increased by almost $400 \%$ after the 1994 Championship season (Sutton et al., 1997). Nevertheless, it is suggested not to develop marketing strategies solely around success as it would create the risk that support may be lost when performance fades (Fisher \& Wakefield, 1998). According to Hill and Green (2000), the recognition that success alone does not guarantee a full stadium has led to marketing strategies shifting from a product orientation with a focus on providing quality sport, to a service orientation with a focus on providing entertainment experience. The following section focuses on marketing strategies directed towards lowly and moderately identified fans.

\subsubsection{Fan Marketing for Lowly and Moderately Identified Fans}

In order to target fan groups with low or moderate fan ID levels it is suggested that marketing strategies incorporate those drivers that are positively correlated to the fan ID level and therefore of particular importance for highly identified fans. The driver belonging, as well as drivers within the admiration factor, match these criteria.

It is suggested that an emphasis on admiration drivers can serve as an effective means to address lowly identified fans. Building on the finding that this fan group 
lacks in-depth knowledge about team, players, and other representatives, it is suggested to actively support these fans in acquiring additional knowledge. This could be done via free booklets to spectators in which team, individual players, opponent, or the coach is presented. Another idea is to show short clips on the screen prior to a game. Such clips could present individual players, augmented by their personal statistics for the current season, or special moments such as goals scored. Lastly, the importance of direct contact between fans and players is often pointed out in research literature. According to Sutton et al. (1997), accessibility of the team can serve as an effective means to increase the attraction for the team and individual players among fans. The authors highlight examples such as grassroots events, autograph sessions or fan festivals. This accords with the views of Gladden and Funk (2001) who suggest special chat rooms for direct communication between players or other representatives and members of fan clubs as one of many ideas to make fans feel like a part of the team (Gladden \& Funk, 2001, p.85).

Moderately identified fans are assumed to already have solid knowledge of team and players. It is argued that this target group can best be addressed by an emphasis on the sense of belonging which can evolve from fan commitment. By facilitating fans' involvement in particular fan rituals or chants, they may more likely to feel a part of the fan community. Further ways to strengthen the sense of belonging of fans were pointed out by Sutton et al. (1997) who stressed the importance of newsletters and also establishing fan clubs. Lastly, the creation of an official Wellington Phoenix song that is played prior to games could serve as a means for further bonding between the club and its fans. A prime example of how songs can lead to chants unique to certain teams is the song you'll never walk alone that football fans around the world associate with Football Club Liverpool. The following section focuses on general marketing implications for all fan ID levels.

\subsubsection{Fan Marketing for all Fans}

Due to the high importance of live experience factors across all fan ID levels, it is advised that Wellington Phoenix focuses on providing what Gladden and Funk (2001) call an entertaining experience before, during and after home games. In welldeveloped football leagues, there is a trend to build new stadia that enhance the entertainment experience for fans (Hill \& Green, 2000). These stadia often contain elements such as video cubes for replays, luxury boxes, improved seating, and offer 
pre-game, halftime, and post-game entertainment. In the case of Wellington Phoenix, however, it may be advisable to emphasis ways to exploit the potential of the home arena. This is especially so, when a full stadium can add atmosphere and excitement to the experience of the sport event as it provides fans with the chance of obtaining an unmediated experience of team and game (Hill \& Green, 2000). Therefore, it is suggested to promote attendance numbers by offering subsidised ticket bundles. In order to address the importance of the driver involvement, these ticket bundles could be offered to local sports clubs as members of these clubs are more likely to be actively interested in football. Pre season games could for example be used to invite whole football teams free of charge to create an impressive stadium atmosphere. Referring to the findings of Summers et al. (2007) that teenagers are mainly driven by atmosphere and entertainment, subsidised offers to youth clubs could furthermore help to attract the fans of tomorrow. The importance of the home ground is furthermore addressed by Westerbeek and Shilbury (1999) who state that emphasis within the marketing mix should be placed on the sport facility as it represents the place in which product and services are experienced (Hill \& Green, 2000). Findings of this research indicate that the perceived importance of Westpac Stadium is relatively low. Therefore, sport marketers are advised to increase the effort in promoting Westpac Stadium as the home ground of team and fans and therefore create an emotional connection between fans and the sport facility.

A further issue that warrants attention is the importance of rivalries for sports teams. According to Sutton et al. (1997), fans define a team based upon their competitors if well-developed rivalries exists. However, findings in this research indicate that special rivalries have not yet developed for Wellington Phoenix. In the current situation, with only one New Zealand team competing in the A-League, this would appear to be a challenge for Wellington Phoenix, as geographical proximity is assumed to play a significant role in the evolution of rivalries. Nevertheless, pointing out historical victories or defeats against certain competitors prior to a game might, to an extent, create a tradition of rivalry. 


\subsection{Summary}

A total of 16 identification drivers were analyzed regarding structure, relative importance and relationship with the fan ID level. In chapter 5, the findings of various analyses were discussed and compared to findings of previous research. Following that, possible implications for Wellington Phoenix were discussed. In particular, various sport marketing strategies were highlighted to positively influence fan identification on all fan ID levels.

Main findings will be explored and discussed in chapter 6 . This includes highlighting important drivers impacting on fan ID levels, the use of the driver - fan ID matrix in profiling fans, and the development of marketing initiatives. 


\section{CHAPTER 6: CONCLUSION}

In this final chapter, the key findings are summarized and the research question is answered. Implications of these findings are highlighted. Subsequently, the contribution of this research is elaborated and limitations are acknowledged. Finally, opportunities for future research are formulated.

\subsection{Research Question}

There is a great variety of work on the characterization of sports fans and their underlying motives. However, not much evidence has been provided on the relationship between the level of fan identification and the underlying drivers to become a fan (Wann et al., 1999). This research addresses this gap by first reviewing the literature on fan motives, fan identification processes, and management implications. Based on this literature review, a set of 16 fan drivers were identified. A questionnaire survey instrument was then designed and administered to a total of 517 Wellington Phoenix fans to assess the importance of these drivers as well as the level of fan identification. The findings of various data analyses provided answers to the research question formulated in chapter 1 :

\section{How are specific identification drivers related to the level of fan identification?}

Firstly, a multivariate factor analysis was performed to identify structural patterns among the set of 16 drivers. Findings suggest fans can be categorized according functional, symbolic and interpersonal constructs that can be described as a live experience factor, an admiration factor and a social network factor. To analyze the relationship between the drivers and the level of fan identification, relative driver scores were calculated for each participant and one-way ANOVA tests, correlationand regression analyses were performed.

Findings revealed that the live experience drivers, enjoyment, excitement, and atmosphere, are of high importance but uncorrelated with the fan ID level. A separate live experience driver belonging as well as the admiration drivers team, players, and coach were found to be of average importance and positively correlated with the fan ID level. The social network drivers, friends, family, co-workers, and success, were identified low in importance and negatively correlated with the fan ID 
level. Two geographical drivers, city and country, showed a high relative importance and negative correlation with the fan ID level. A stadium driver was found to be of below-average importance and uncorrelated with the fan ID level. Lastly, the drivers involvement (high importance) and escape (low importance) were also found to be uncorrelated with the fan ID level. A driver - fan ID matrix was provided to illustrate a holistic view of both the relative importance and the correlation of the 16 identification drivers with fan ID level (figure 25).

Relative Importance

of Drivers

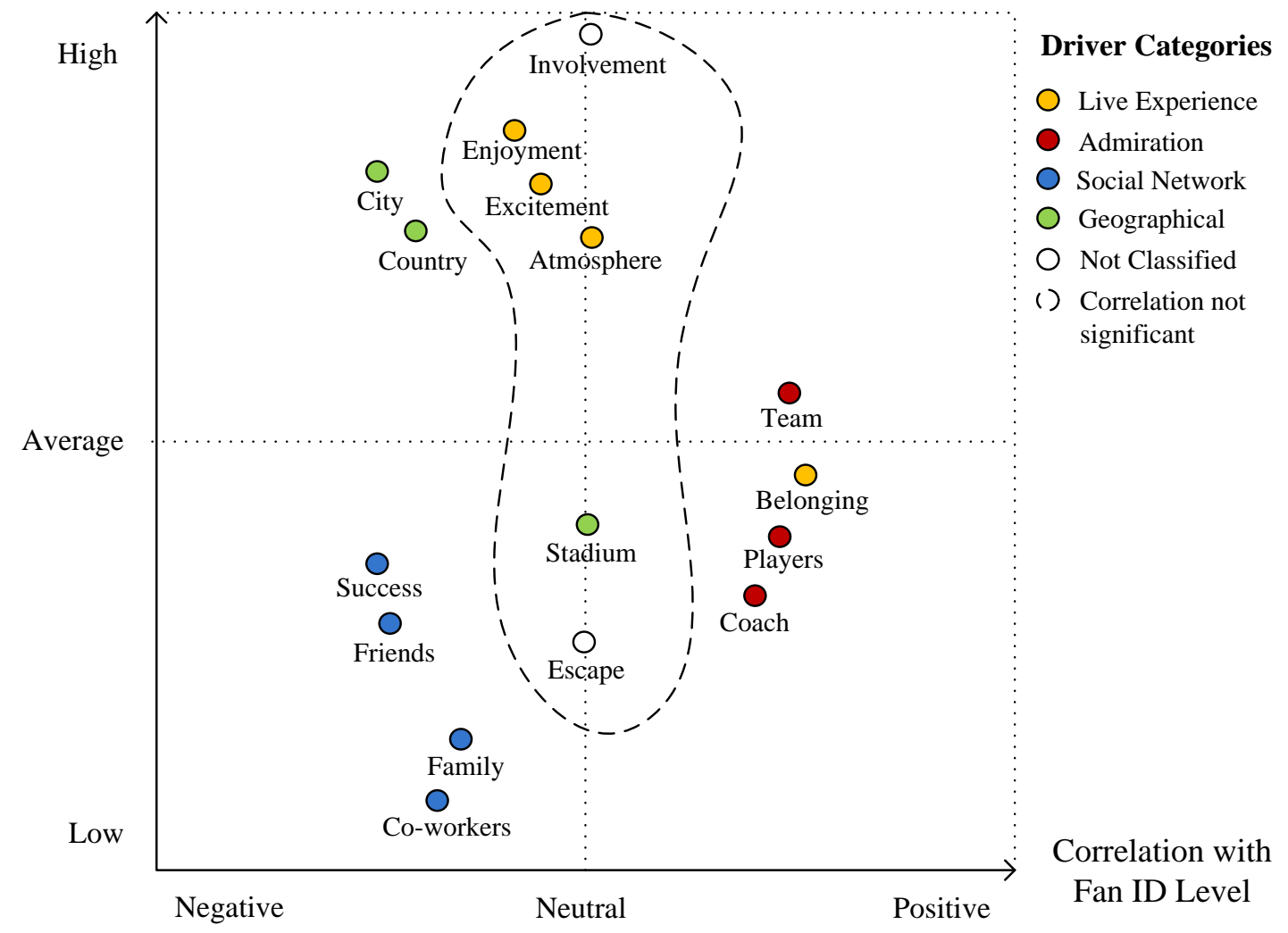

Figure 25: Conclusion: Driver - Fan ID Matrix

It should be highlighted that some drivers are important because they vary with fan ID level and show significant correlations, and that some other drivers are important because they show no significant correlations with the ID level. In the first case, insight is gained about where to target initiatives around drivers, because they may have beneficial impact; or about where not to target initiatives, because they have little or no impact. In the second case, drivers of high relative importance across all fan ID levels, even when not correlated with fan ID level, should still be involved in 
targeted initiatives. Drivers of low relative importance, and not correlated with fan ID level, can be afforded little or no priority.

It is noteworthy to mention that the driver - fan ID matrix has been first developed within this research and that it has merit by presenting multidimensional findings in an insightful 2-dimensional form. The insights provided have practical value which has not been noted in previous research. In this research, the driver - fan ID matrix was used as a basis to discuss potential marketing implications.

\subsection{Implications}

Subsequent to answering the research question, a preliminary attempt to profile fans according their fan ID level was undertaken. This profiling was influenced by findings of the relationship between identification drivers and fan ID levels. Based on this profiling, marketing implications were elaborated. As discussed in previous chapters, high fan identification can lead to various financial benefits for professional football clubs. Therefore, all marketing strategies discussed in this research were those considered as having potential to fulfil the objective of increasing the level of fan identification. As the formation of fan identification can be described as a process (James, 2001), it was considered advisable to seek to develop marketing activities that aim to bring fans to the next higher fan ID level (target ID level). To achieve that, marketing needs to highlight motives that are of particular relevance to fans of this target ID level.

Marketing strategies that address non-fans should therefore be orientated to drivers that are of high importance for lowly identified fans. Lowly identified fans place a relatively high importance on social network drivers and Wellington Phoenix' representational role regarding city and country. It is suggested that marketing strategies that target non-fans therefore incorporate aspects related to social network drivers as well as the two geographical drivers city and country. With regards to social network drivers, it would be appropriate to communicate that the attendance of live games serves as an appropriate leisure activity to spend time with family, friends, or co-workers. Strategies could involve altering advertisements or offering special deals in form of ticket bundles, for example, family deals or ticket bundles for companies. Team-related activities that facilitate father-son interactions are furthermore suggested as potentially powerful means to attract the fans of tomorrow. 
With regards to geographical drivers, a pro-active creation of a link between the team and the city in which it is located (Kolbe \& James, 2000) or through community involvement (Sutton et al., 1997) is argued to be effective in turning non-fans into lowly identified fans. It is not recommended to develop marketing strategies around success as that bears the risk of losing support in unsuccessful times (Fisher \& Wakefield, 1998).

In order to target fan groups with low or moderate fan ID levels, it is suggested that marketing strategies incorporate those drivers that are positively correlated to the fan ID level, and therefore of particular importance for highly identified fans. The driver belonging as well as the admiration drivers match these characteristics. Marketing strategies that target lowly and moderately identified fans need to communicate that attending live games of Wellington Phoenix is more than just a leisure activity. For lowly identified fans, it is argued that activities that make fans feel like a part of the team (Gladden \& Funk, 2001, p.85) can serve as a successful means to increase fan identification. This could be achieved by providing fans with information brochures, showing clips prior to games, or allowing for more direct contact between fans and players. To address moderately identified fans, it is recommended to put an emphasis on the sense of belonging which can evolve out of fan commitment. It is suggested that the sense of belonging can be promoted by an active inclusion of fans in particular fan rituals or chants, a creation of an official Wellington Phoenix song or via newsletters and fan clubs (Sutton et al., 1997).

Lastly, fans across all ID levels place a high importance on their active involvement in football as well as on stadium atmosphere, entertainment, and excitement. Therefore, Wellington Phoenix is advised to strengthen the entertainment experience (Gladden \& Funk, 2001) of home games by promoting attendance numbers as a means to create a greater stadium atmosphere. Special deals for local football teams can serve as a means to address the importance of active involvement. Given that prior studies have indicated the importance of a team's home ground (Westerbeek \& Shilbury, 1999), Wellington Phoenix is furthermore advised to develop strategies that aim to create a stronger bond between its fans and Westpac Stadium. 


\subsection{Contribution of this Research}

The findings of this research are of scientific and practical value. With regards to the scientific contribution, this research provides evidence of the relationship between the level of fan identification and the underlying drivers to become a fan, and it therefore addresses a gap in literature (Wann et al., 1999). A questionnaire survey instrument was developed that allows an assessment of both the level of fan identification and the relative importance of identification drivers for becoming a fan. Furthermore, this research provides evidence on the nature of fan identification towards new sports teams, which represents an area of study where further research is needed (Lock et al., 2009).

With regards to the practical contribution, this research addresses the need of Wellington Phoenix to more precisely understand how strongly its fans identify themselves with the club and the underlying drivers that this fan identification is based upon. Furthermore, the categorization of fans into distinct fan ID levels allowed for an attempt to profile fans according their motives. Based on this profiling, ideas for various marketing strategies were provided. Hence, the practical contribution of this research is to provide a framework that enables professional sports clubs like Wellington Phoenix to enhance knowledge about their fans, which then can be used to develop specific marketing strategies to build their fan base.

\subsection{Opportunities for Further Research}

In this research, several limitations that provide opportunities for further research need to be mentioned. The first limitation arises from the lack of research on the relationship between the level of fan identification and underlying drivers. For that reason, this research is exploratory and requires further research evidence to further substantiate findings and to strengthen the propositions developed.

The second limitation refers to the sample structure of this research. For example, targets regarding demographic characteristics of participants were set prior to data collection. However, the sample may not precisely match the actual fan demographics. Furthermore, previous research indicated that different age groups are driven by different motivations (Summers et al., 2007). Therefore, further research is necessary to enhance understanding of the extent to which different sample 
characteristics may replicate, or otherwise lead to different results regarding the research question.

The geographical location of sample participants is another limitation of this research. Sample data indicates that around $98.5 \%$ of the participants can be presumed to be located in the Wellington region, within travel distance of the Westpac Stadium home ground. Furthermore, the questionnaire survey instrument relates to various drivers that address the attendance of live games (enjoyment, excitement, escape, belonging, atmosphere) or otherwise assumes the Wellington region to be home of the participants (city, stadium). However, the fan base of Wellington Phoenix is certainly not limited to the Wellington region. Therefore, research is necessary that allows for an assessment of underlying drivers of fans that are located outside travel distance of the stadium.

Lastly, limitations arise from the selection of the football club for testing the research question. This research was undertaken on the case of New Zealand based club Wellington Phoenix. The young age of the club may influence the perceived importance of individual identification drivers, as for example, history and tradition has not yet developed as much as in well-established teams and parental indoctrination (Parker \& Stuart, 1997) is limited. Furthermore, findings indicated a perceived lack of rivals within the wider league. In order to test the propositions developed, further research needs to apply a similar approach to fans of professional football teams that are operating in different settings. Factors for these settings may include the history of a football club, the value of football in society, the economic significance of the club for the region, the competitor base, and the political or cultural significance of the club.

Not surprisingly, the professionalization of football in New Zealand has not yet attained the same level as, for example, in the United Kingdom or many other European countries. Nevertheless, findings of this research may serve clubs in more established football markets to better understand the dynamics of fan identification and may facilitate the development of a framework to acquire knowledge necessary to inform fan marketing strategies. 


\subsection{Final Comments}

Findings presented in this study not only meet a research need to understand the relationship between drivers of fan identification and fan ID levels, but also provide a platform for further work examining critical elements of fan identification and their relationship with a variety of identification drivers. In addition, findings provide insights that have practical value in addressing the needs of sports organizations that wish to develop meaningful relationships with fans. 


\section{REFERENCES}

Anderson, B. (1991). Imagined communities: Reflections on the origin and spread of nationalism. (Revised ed.). New York: Verso

Beisser, A. (1967). The madness in sports. New York: Apple ton-Century Crofts

Branscombe, N.R., Wann, D.L. (1991). The positive social and self-concept consequences of sport team identification. Journal of Sport \& Social Issues, 15, 115 127

Census Data New Zealand. (2006). Retrieved 21.02.2011, from http://www.stats.govt.nz/census.aspx

Cialdini, R.B., Borden, R.J., Thorne, A., Walker, M.R., Freeman, S., Sloan, L.R. (1976). Basking in reflected glory: Three (football) field studies. Journal of Personality and Social Psychology, 34, 366-375

Coakes, S.J., Steed, L., Ong, C. (2009). SPSS: Analysis without anguish using SPSS version 17.0 for Windows. Milton: John Wiley \& Sons

Easterby-Smith, M., Thorpe, R., \& Jackson, P. R. (2008). Management Research (3rd ed.). Los Angeles: Sage

Elsbach, K.D. (1999). An expanded model of organizational identification. Research in Organizational Behavior, 21, 163-200

Elsbach, K.D., Bhattacharya, C.B. (2001). Defining who you are by what you're not: Organizational disidentification and the National Rifle Association. Organization Science, 12, 393-413

Fisher, R.J., Wakefield, K. (1998). Factors leading to group identification: A field study of winners and losers. Psychology \& Marketing, 15, 23-40

Football Federation Australia. (2008). History. Accessed on $21^{\text {st }}$ June 2010 from: http://a-league.com.au/default.aspx?s=history

Fort, R., Quirk, J. (1995). Cross-subsidization, incentives, and outcomes in professional team sports leagues. Journal of Economic Literature, 33(3), 1265-1299 
Foster, W.M., Hyatt, C. (2007). I despise them! I detest them! Franchise relocation and the Expanded Model of Organizational Identification. Journal of Sport Management, 21, 194-212

Funk, D.C., James, J.D. (2006). Consumer loyalty: The meaning of attachment in the development of sport team allegiance. Journal of Sport Management, 20, 189-217

Funk, D.C., Pastore, D.L. (2000). Equating attitudes to allegiance: The usefulness of elected attitudinal information in segmenting loyalty to professional sports teams. Sport Marketing Quarterly, 9(4), 175-84

Gantz, W. (1981). An exploration of viewing motives and behaviors associated with television sports. Journal of Broadcasting \& Electronic Media, 25(3), 263-275

Giulianotti, R. (2002). Supporters, followers, fans, and flaneurs: A taxonomy of spectator identities in football. Journal of Sport \& Social Issues, 26(1), 25-46

Gladden, J.M., Funk, D.C. (2001). Understanding brand loyalty in professional sport: Examining the link between brand associations and brand loyalty. International Journal of Sports Marketing \& Sponsorship, 3(2), 67-94

Hague, E., Mercer, J. (1998). Geographical memory and urban identity in Scotland: Raith Rovers FC and Kirkcaldy. Geography, 83(2), 105-116

Halberstadt, J., O’Shea, R.P., Forgas, J. (2006). Outgroup fanship in Australia and New Zealand. Australian Journal of Psychology, 58(3), 159-165

Hallinan, C.J., Hughson, J.E., Burke, M. (2007). Supporting the 'World Game' in Australia: A case study of fandom at national and club level. Soccer \& Society, 8(23), $283-297$

Heere, B., James, J.D. (2007). Stepping outside the lines: Developing a multidimensional team identity scale based on social identity theory. Sport Management Review, 10, 65-91

Heider, F. (1958). The psychology of interpersonal relations. New York: Wiley

Hill, B., Green, B.C. (2000). Repeat attendance as a function of involvement, loyalty, and the sportscape across three football contexts. Sport Management Review, 3, 145162 
Hirt, E.R., Zillmann, D., Erickson, G.A., Kennedy, C. (1992). Costs and benefits of allegiance: Changes in fans' self-ascribed competencies after team victory versus defeat. Journal of Personality and Social Psychology, 63(5), 724-738

Hogg, M.A. (2000). Subjective uncertainty reduction through self-categorization: A motivational theory of social identity processes. European Review of Social Psychology, 11(1), 223-255

Independent Soccer Review Committee (2003). Report of the independent soccer review committee: Into the structure, governance and management of soccer in Australia. Canberra: Australian Sports Commission

Jacobson, B. (2003). The social psychology of the creation of a sports fan identity: A theoretical review of the literature. Athletic Insight, 5(2), 1-14

James, J.D. (2001). The role of cognitive development and socialization in the initial development of team loyalty. Leisure Sciences, 23, 233-261

James, J., Kolbe, R., Trail, G. (2002). Psychological connection to a new sport team: Building or maintaining the consumer base. Sport Marketing Quarterly, 11(2), 215225

Jones, I. (2000). A model of serious leisure identification: The case of football fandom. Leisure Studies, 19, 283-298

King, A. (2000). Football fandom and post-national identity in the New Europe. British Journal of Sociology, 51(3), 419-442

Kolbe, R.H., James, J.D. (2000). An identification and examination of influences that shape the creation of a professional team fan. International Journal of Sports Marketing \& Sponsorship, 2(1), 23-38

Krohn, F.B., Clarke, M., Preston, E., McDonald, M., Preston, B. (1998). Psychological and sociological influences on attendance at small college sporting events. College Student Journal, 32(2), 277-284

Kuentzel, W.F. (2000). Self-identity, modernity, and the rational actor in leisure research. Journal of Leisure Research, 32(1), 87-92 
Lawley, D.N., Maxwell, A.E. (1962). Factor Analysis as a statistical method. Journal of the Royal Statistical Society, 12(3), 209-229

Lewis, M. (2001). Franchise relocation and fan allegiance. Journal of Sport \& Social Issues, 25, 6-19

Lock, D. (2009). Fan perspectives of change in the A-League. Soccer \& Society, 10(1), 109-123

Lock, D., Darcy, S., Taylor, T. (2009). Starting with a clean slate: An analysis of member identification with a new sports team. Sport Management Review, 12, 15-25

Madrigal, R. (1995). Cognitive and affective determinants of fan satisfaction with sporting event attendance. Journal of Leisure Research, 27(3), 205-227

Mahony, D.F., Madrigal, R., Howard, D. (1999). The effect of individual levels of self-monitoring on loyalty to professional football teams. International Journal of Sport Marketing \& Sponsorship, 1(2), 146-167

Mead, G.H. (1934). Mind, Self, and Society: From the standpoint of a social behaviorist. Chicago: University of Chicago Press

Melnick, M.J. (1993). Searching for sociability in the stands: A theory of sports spectating. Journal of Sport Management, 7, 44-60

Milne, G.R., McDonald, M.A. (1999). Sport Marketing: Managing the exchange process. Sadbury: Jones and Bartlett Publishers

O'Leary, Z. (2004). The essential guide to doing research. Los Angeles: Sage.

Owen, P.D., Ryan, M., Weatherston, C.R. (2006). Measuring competitive balance in professional team sports using the Herfindahl-Hirschman Index. Review of Industrial Organization, 31(4), 289-302

Parker, K., Stuart, T. (1997). The west ham syndrome: Comparison between loyalty to football clubs and brand loyalty. Journal of the Market Research Society, 39(3), 509-517

Pratt, J., Salter, M. (1984). A fresh look at football hooliganism. Leisure Studies, $3(3), 201-230$ 
Rapley, M., McHoul, A. (2002). Self-glorification and its others: The discursivemoral management of sports management. Journal of Sport \& Social Issues, 26, 268280

Shank, M.D., Beasley, F.M. (1998). Fan or fanatic: Refining a measure of sports involvement. Journal of Sport Behavior, 21(4), 435-440

Shobe, H. (2008a). Place, identity and football: Catalonia, Catalanisme and Football Club Barcelona, 1899-1975. National Identities, 10(3), 329-343

Shobe, H. (2008b). Football and the politics of place: Football Club Barcelona and Catalonia, 1975-2005. Journal of Cultural Geography, 25(1), 87-105

Sloan, L. (1979). The function and impact of sports for fans: A review of theory and contemporary research. In J. Goldstein (Ed.), Sports, games, and play: Social and psychological viewpoints. New Jersey: Laurence Erlbaum Associates

Snyder, C.R., Lassegard, M., Ford, C.E. (1986). Distancing after group success and failure: Basking in reflected glory and cutting off reflected failure. Journal of Personality and Social Psychology, 51(2), 382-388

Stebbins, R. (1992). Amateurs, professionals and serious leisure. Montreal: McGill Queen's University Press

Stets, J.E., Burke, P.J. (2000). Identity theory and social identity theory. Social Psychology Quarterly, 63(3), 224-237

Straub, D., Boudreau, M.C., Gefen, D. (2004). Validation Guidelines for IS Positivist Research. Communications of the Association for Information Systems, 13, 380-427

Stryker, S. (1968). Identity salience and role performance: The relevance of symbolic interaction theory for family research. Journal of Marriage and the Family, 30, 558564

Summers, J., Johnson Morgan, M., Kanoyangwa, R. (2007). Teenage motivations for sport related consumption in Australia. Sport Marketing Association's 3rd Annual Conference, 10-12 Nov 2005, Tempe, Arizona 
Sutton, W.A., McDonald, M.A., Milne, G.R., Cimperman, A.J. (1997). Creating and fostering fan identification in professional sports. Sport Marketing Quarterly, 6(1), $15-22$

Tajfel, H. (1970). Experiments in intergroup discrimination. Scientific American, 223, 96-102

Tajfel, H. (1981). Human groups and social categories. Cambridge: Cambridge University Press

Tajfel, H., Turner, J.C. (1979). An integrative theory of intergroup conflict. The Social Psychology of Intergroup Relations, 7-24

Trail, G.T., James, J.D. (2001). The motivation scale for sport consumption: Assessment of the scale's psychometric properties. Journal of Sport Behavior, 24(1), $108-127$

Turner, J.C. (1982). Towards a cognitive redefinition of the social group. In H. Tajfel (ed.), Social Identity and Intergroup Relations (pp.15-40). London: Cambridge University Press

Turner, J.C. (1985). Social categorization and the self-concept: A social cognitive theory of group behavior. In E.J. Lawler (ed.), Advances in Group Processes: Theory and Research (pp.77-122). Greenwich: JAI Press

Van Leeuwen, L., Quick, S., Daniel, K. (2002). The sport spectator satisfaction model: A conceptual framework for understanding the satisfaction of spectators. Sport Management Review, 5, 99-128

Wann, D.L. (1993). Aggression among highly identified spectators as a function of their need to maintain positive social identity. Journal of Sport \& Social Issues, 17, $134-143$

Wann, D.L. (1995). Preliminary validation of the sport fan motivation scale. Journal of Sport \& Social Issues, 19, 377-396

Wann, D.L. (2006). Examining the potential causal relationship between sport team identification and psychological well-being. Journal of Sport Behavior, 29(1), 79-95 
Wann, D.L., Branscombe, N.R. (1990). Die-hard and fair-weather fans: Effects of identification on BIRGing and CORFing tendencies. Journal of Sport \& Social Issues, $14,103-117$

Wann, D.L., Branscombe, N.R. (1993). Sports fans: Measuring degree of identification with their team. International Journal of Sports Psychology, 24, 1-17

Wann, D.L., Dolan, T.J. (1994a). Spectators' evaluations of rival and fellow fans. The Psychological Record, 44(3), 351-358

Wann, D.L., Dolan, T.J. (1994b). Attributions of highly identified sports spectators. Journal of Social Psychology, 134(6), 783-792

Wann, D.L., Royalty, J., Roberts, A. (2000). The self-presentation of sport fans: Investigating the importance of team identification and self-esteem. Journal of Sport Behavior, 23(2), 198-206

Wann, D.L., Schrader, M.P., Wilson, A.M. (1999). Sport fan motivation: Questionnaire validation, comparisons by sport, and relationship to athletics motivation. Journal of Sport Behavior, 22(1), 114-139

Wann, D.L., Tucker, K.B., Schrader, M.P. (1996). An exploratory examination of the factors influencing the origination, continuation, and cessation of identification with sports teams. Perceptual and Motor Skills, 82(3), 995-1001

Weiss, O. (2001). Identity reinforcement in sport: Revisiting the symbolic interactionist legacy. International Review for the Sociology of Sport, 36(4), 393-405

Wenner, L.A., Gantz, W. (1989). The audience experience with sports on television, media, sports, and society. Newbury Park: Sage

Westerbeek, H.M., Shilbury, D. (1999). Increasing the focus on "place" in the marketing mix for facility dependent sport services. Sport Management Review, 2, 123

Zaichkowsky, J.L. (1985). Measuring the involvement construct. Journal of Consumer Research, 12, 341-352 


\section{APPENDIX A: RESEARCH TOOLS}

\section{A1 Information Sheet}

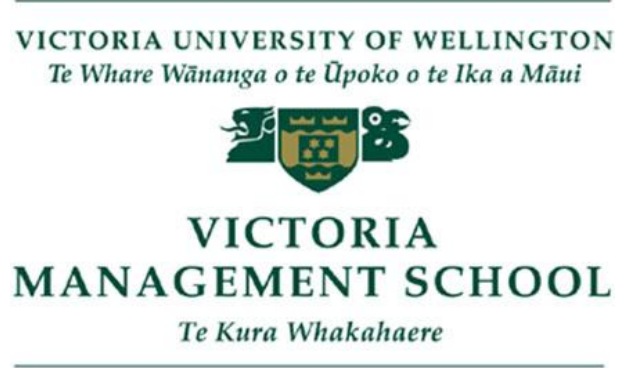

Thank you for participating in this research which has been granted ethical approval from Victoria University of Wellington. Participation is entirely voluntary and questionnaire is anonymous. By participating you give your consent to the following:

- Access to the research data will be restricted to the researcher and his supervisors. All data will be destroyed at the end of the research

- All data will be reported in aggregate form in such a way that individual persons are not identifiable

\section{Thank you for your time and effort!}

The completion of this questionnaire will take less than ten minutes

If you have questions regarding this study, please do not hesitate to contact:

Markus Ruehl Markus.Ruehl@vuw.ac.nz or Prof John Davies John.Davies@ vuw.ac.nz 


\section{A2 Questionnaire}

A. SPECTATOR CHARACTERISTICS: The following questions focus on your spectator attributes. Please only tick one option for each of the questions below.

1. What type of spectator are you?

Season ticket holder C Regular visitor (no season ticket) $\quad$ Occasional visitor

I have never attended a game of Wellington Phoenix FC so far

2. In what season did you start supporting Wellington Phoenix?
C $2007 / 2008$
C 2008/2009
C 2009/2010
C 2010/2011

3. How many of the 14 home matches did you attend last season? (if unknown, please estimate)

4. How do you most often attend Wellington Phoenix games?

$\checkmark$ By myself $\quad C$ In a group of 2-3 people $\quad C$ In a group of 4-6 people $\quad C$ ith 7 people or more

5. If you prefer going in groups, who do you mostly go with?
C Family members
C Friends
C Colleagues/Co-workers
Cother

6. What is your preferred way to follow a game of Wellington Phoenix?
C W estpac Stadium
Television
C Newspaper
C Internet
C Radio

7. How often do you wear Wellington Phoenix merchandise at home games?
C Always
C Often
Sometimes
C Rarely
C Never

8. How often do you wear Wellington Phoenix merchandise outside of games?
C Always
C Often
C Sometimes
C Rarely
C Never

B. LEVEL OF IDENTIFICATION: This section looks at how much you identify yourself with Wellington Phoenix. Please answer each of the following questions by ticking the number that most closely corresponds to you.

\begin{tabular}{|c|c|c|c|c|c|c|c|c|}
\hline & 1 & 2 & 3 & 4 & 5 & 6 & 7 & 8 \\
\hline $\begin{array}{l}\text { 1. How important to YOU is it that Wellington Phoenix wins? } \\
\text { ( } 1 \text { = Not important, } 8=\text { Very important })\end{array}$ & $r$ & $r$ & $r$ & $r$ & $r$ & $r$ & $r$ & $r$ \\
\hline $\begin{array}{l}\text { 2. How strongly do YOU see YOURSELF as a fan of Wellington } \\
\text { Phoenix? } \\
(1=\text { Not at all a fan, } 8=\text { Very much a fan })\end{array}$ & $r$ & $r$ & $r$ & $r$ & $r$ & $r$ & $r$ & $r$ \\
\hline $\begin{array}{l}\text { 3. How strongly do your FRIENDS see YOU as a fan of Wellington } \\
\text { Phoenix? } \\
(1=\text { Not at all a fan, } 8=\text { Very much a fan })\end{array}$ & $r$ & $\mathrm{C}$ & $r$ & $r$ & $r$ & $\mathrm{C}$ & $r$ & $r$ \\
\hline $\begin{array}{l}\text { 4. During the season, how closely do you follow the Phoenix via ANY } \\
\text { of the following: in person, television, radio, internet, or newspaper? } \\
(1=\text { Never, } 8 \text { = Almost everyday) }\end{array}$ & $r$ & $r$ & $r$ & $r$ & $r$ & $r$ & $r$ & $r$ \\
\hline $\begin{array}{l}\text { 5. How important is being a fan of Wellington Phoenix to YOU? } \\
\text { ( } 1 \text { = Not important, } 8 \text { = Very important) }\end{array}$ & $r$ & $r$ & $r$ & $r$ & $r$ & $r$ & $r$ & $r$ \\
\hline $\begin{array}{l}\text { 6. How much do YOU dislike the Wellington Phoenix' greatest rivals? } \\
\text { ( } 1 \text { = Do not dislike, } 8 \text { = Dislike very much) }\end{array}$ & $r$ & $r$ & $r$ & $r$ & $r$ & $r$ & $r$ & $r$ \\
\hline $\begin{array}{l}\text { 7. How often do YOU display the Wellington Phoenix name or } \\
\text { insignia at your place of work, where you live, or on your clothing? } \\
(1=\text { Never, } 8=\text { Always })\end{array}$ & $r$ & $r$ & $r$ & $r$ & 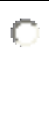 & $r$ & $r$ & $r$ \\
\hline
\end{tabular}




\section{APPENDIX B: RESEARCH RESULTS}

\section{B1 Demographic Characteristics}

B1.1 Gender, Age, and Marital Status of the Participants

\begin{tabular}{|c|c|c|c|c|c|}
\hline \multicolumn{2}{|c|}{ Gender } & Frequency & Percent & $\begin{array}{c}\text { Valid } \\
\text { Percent }\end{array}$ & $\begin{array}{c}\text { Cumulative } \\
\text { Percent }\end{array}$ \\
\hline \multirow[t]{3}{*}{ Valid } & Male & 401 & 77.6 & 77.6 & 77.6 \\
\hline & Female & 116 & 22.4 & 22.4 & 100.0 \\
\hline & Total & 517 & 100.0 & 100.0 & \\
\hline \multicolumn{2}{|c|}{ Age } & Frequency & Percent & $\begin{array}{c}\text { Valid } \\
\text { Percent }\end{array}$ & $\begin{array}{c}\text { Cumulative } \\
\text { Percent }\end{array}$ \\
\hline \multirow[t]{10}{*}{ Valid } & $\leq 20$ years & 101 & 19.5 & 19.5 & 19.5 \\
\hline & 21-25 years & 104 & 20.1 & 20.1 & 39.7 \\
\hline & $26-30$ years & 58 & 11.2 & 11.2 & 50.9 \\
\hline & $31-35$ years & 53 & 10.3 & 10.3 & 61.1 \\
\hline & $36-40$ years & 56 & 10.8 & 10.8 & 72.0 \\
\hline & 41-45 years & 42 & 8.1 & 8.1 & 80.1 \\
\hline & $46-50$ years & 48 & 9.3 & 9.3 & 89.4 \\
\hline & $51-55$ years & 33 & 6.4 & 6.4 & 95.7 \\
\hline & $\geq 56$ years & 22 & 4.3 & 4.3 & 100.0 \\
\hline & Total & 517 & 100.0 & 100.0 & \\
\hline \multicolumn{2}{|c|}{ Marital Status } & Frequency & Percent & $\begin{array}{c}\text { Valid } \\
\text { Percent }\end{array}$ & $\begin{array}{c}\text { Cumulative } \\
\text { Percent }\end{array}$ \\
\hline \multirow[t]{5}{*}{ Valid } & Single & 302 & 58.4 & 58.4 & 58.4 \\
\hline & Married & 198 & 38.3 & 38.3 & 96.7 \\
\hline & Divorced & 11 & 2.1 & 2.1 & 98.8 \\
\hline & Widowed & 6 & 1.2 & 1.2 & 100.0 \\
\hline & Total & 517 & 100.0 & 100.0 & \\
\hline
\end{tabular}

\section{B1.2 Active Engagement in Football}

\begin{tabular}{|rc|r|r|r|r|}
\hline & \multicolumn{1}{|c|}{ Frequency } & Percent & $\begin{array}{c}\text { Valid } \\
\text { Percent }\end{array}$ & $\begin{array}{c}\text { Cumulative } \\
\text { Percent }\end{array}$ \\
\hline Valid & Never played & 115 & 22.2 & 22.2 & 22.2 \\
& 82 & 15.9 & 15.9 & 38.1 \\
& 1-3 Seasons & 66 & 12.8 & 12.8 & 50.9 \\
4-6 Seasons & 50 & 9.7 & 9.7 & 60.5 \\
7-9 Seasons & 204 & 39.5 & 39.5 & 100.0 \\
10+ Seasons & 517 & 100.0 & 100.0 & \\
Total & & & & \\
\hline
\end{tabular}




\section{B1.3 Amount of Children}

\begin{tabular}{|c|c|c|c|c|c|}
\hline & & Frequency & Percent & $\begin{array}{c}\text { Valid } \\
\text { Percent }\end{array}$ & $\begin{array}{c}\text { Cumulative } \\
\text { Percent }\end{array}$ \\
\hline \multirow[t]{9}{*}{ Valid } & 0 & 333 & 64.4 & 64.4 & 64.4 \\
\hline & 1 & 47 & 9.1 & 9.1 & 73.5 \\
\hline & 2 & 85 & 16.4 & 16.4 & 89.9 \\
\hline & 3 & 37 & 7.2 & 7.2 & 97.1 \\
\hline & 4 & 10 & 1.9 & 1.9 & 99.0 \\
\hline & 5 & 3 & .6 & .6 & 99.6 \\
\hline & 6 & 1 & .2 & .2 & 99.8 \\
\hline & 7 & 1 & .2 & .2 & 100.0 \\
\hline & Total & 517 & 100.0 & 100.0 & \\
\hline
\end{tabular}

\section{B1.4 Amount of Children that play football}

\begin{tabular}{|c|c|c|c|c|c|}
\hline & & Frequency & Percent & $\begin{array}{c}\text { Valid } \\
\text { Percent }\end{array}$ & $\begin{array}{c}\text { Cumulative } \\
\text { Percent }\end{array}$ \\
\hline \multirow[t]{6}{*}{ Valid } & 0 & 413 & 79.9 & 79.9 & 79.9 \\
\hline & 1 & 54 & 10.4 & 10.4 & 90.3 \\
\hline & 2 & 38 & 7.4 & 7.4 & 97.7 \\
\hline & 3 & 11 & 2.1 & 2.1 & 99.8 \\
\hline & 5 & 1 & .2 & .2 & 100.0 \\
\hline & Total & 517 & 100.0 & 100.0 & \\
\hline
\end{tabular}


B2 Fan Identification

B2.1 Distribution of ID Scores

\begin{tabular}{|r|r|r|r|r|r|r|r|}
\hline \multicolumn{1}{|c|}{$\begin{array}{c}\text { ID } \\
\text { Score }\end{array}$} & Frequency & Percent & $\begin{array}{c}\text { Cumulative } \\
\text { Percent }\end{array}$ & $\begin{array}{c}\text { ID } \\
\text { Score }\end{array}$ & Frequency & Percent & $\begin{array}{c}\text { Cumulative } \\
\text { Percent }\end{array}$ \\
\hline 7 & 2 & .4 & .4 & 33 & 14 & 2.7 & 30.9 \\
8 & 1 & .2 & .6 & 34 & 17 & 3.3 & 34.2 \\
9 & 1 & .2 & .8 & 35 & 20 & 3.9 & 38.1 \\
11 & 1 & .2 & 1.0 & 36 & 8 & 1.5 & 39.7 \\
12 & 3 & .6 & 1.5 & 37 & 17 & 3.3 & 42.9 \\
13 & 3 & .6 & 2.1 & 38 & 12 & 2.3 & 45.3 \\
14 & 2 & .4 & 2.5 & 39 & 15 & 2.9 & 48.2 \\
15 & 3 & .6 & 3.1 & 40 & 20 & 3.9 & 52.0 \\
16 & 4 & .8 & 3.9 & 41 & 21 & 4.1 & 56.1 \\
17 & 2 & .4 & 4.3 & 42 & 12 & 2.3 & 58.4 \\
18 & 4 & .8 & 5.0 & 43 & 17 & 3.3 & 61.7 \\
19 & 7 & 1.4 & 6.4 & 44 & 16 & 3.1 & 64.8 \\
20 & 5 & 1.0 & 7.4 & 45 & 19 & 3.7 & 68.5 \\
21 & 2 & .4 & 7.7 & 46 & 24 & 4.6 & 73.1 \\
22 & 7 & 1.4 & 9.1 & 47 & 13 & 2.5 & 75.6 \\
23 & 5 & 1.0 & 10.1 & 48 & 24 & 4.6 & 80.3 \\
24 & 6 & 1.2 & 11.2 & 49 & 26 & 5.0 & 85.3 \\
25 & 4 & .8 & 12.0 & 50 & 20 & 3.9 & 89.2 \\
26 & 6 & 1.2 & 13.2 & 51 & 11 & 2.1 & 91.3 \\
27 & 17 & 3.3 & 16.4 & 52 & 20 & 3.9 & 95.2 \\
28 & 11 & 2.1 & 18.6 & 53 & 6 & 1.2 & 96.3 \\
29 & 7 & 1.4 & 19.9 & 54 & 4 & .8 & 97.1 \\
30 & 14 & 2.7 & 22.6 & 55 & 4 & .8 & 97.9 \\
31 & 16 & 3.1 & 25.7 & 56 & 11 & 2.1 & 100.0 \\
32 & 13 & 2.5 & 28.2 & Total & 517 & 100.0 & \\
\hline
\end{tabular}

B2.2 Fan ID Score Descriptives

\begin{tabular}{|c|c|c|c|}
\hline & & Statistic & Std. Error \\
\hline \multirow[t]{10}{*}{ Fan ID Score } & Mean & 38.44 & .469 \\
\hline & Median & 40.00 & \\
\hline & Variance & 113.820 & \\
\hline & Std. Deviation & 10.669 & \\
\hline & Minimum & 7 & \\
\hline & Maximum & 56 & \\
\hline & Range & 49 & \\
\hline & Interquartile Range & 16 & \\
\hline & Skewness & -.580 & .107 \\
\hline & Kurtosis & -.259 & .214 \\
\hline
\end{tabular}


B2.3 Mean ID Score by Age

\begin{tabular}{|c|c|c|c|c|c|c|c|c|c|}
\hline \multirow{2}{*}{\multicolumn{2}{|c|}{ Age }} & \multirow[t]{2}{*}{$\mathbf{N}$} & \multirow[t]{2}{*}{ Mean } & \multirow[t]{2}{*}{$\begin{array}{c}\text { Std. } \\
\text { Deviation }\end{array}$} & \multirow[t]{2}{*}{$\begin{array}{l}\text { Std. } \\
\text { Error }\end{array}$} & \multicolumn{2}{|c|}{$\begin{array}{c}\text { 95\% Confidence Interval } \\
\text { for Mean }\end{array}$} & \multirow[t]{2}{*}{ Min } & \multirow[t]{2}{*}{ Max } \\
\hline & & & & & & Lower Bound & Upper Bound & & \\
\hline \multirow[t]{10}{*}{ Valid } & $\leq 20$ years & 101 & 38.93 & 11.435 & 1.138 & 36.67 & 41.19 & 7 & 56 \\
\hline & $21-25$ years & 104 & 36.05 & 11.281 & 1.106 & 33.85 & 38.24 & 11 & 55 \\
\hline & 26-30 years & 58 & 36.14 & 11.279 & 1.481 & 33.17 & 39.10 & 7 & 56 \\
\hline & $31-35$ years & 53 & 40.25 & 10.241 & 1.407 & 37.42 & 43.07 & 17 & 54 \\
\hline & $36-40$ years & 56 & 38.98 & 9.459 & 1.264 & 36.45 & 41.52 & 18 & 54 \\
\hline & $41-45$ years & 42 & 39.64 & 9.665 & 1.491 & 36.63 & 42.65 & 16 & 56 \\
\hline & $46-50$ years & 48 & 38.77 & 10.159 & 1.466 & 35.82 & 41.72 & 15 & 56 \\
\hline & $51-55$ years & 33 & 40.45 & 10.923 & 1.902 & 36.58 & 44.33 & 12 & 56 \\
\hline & $\geq 56$ years & 22 & 41.68 & 6.462 & 1.378 & 38.82 & 44.55 & 26 & 51 \\
\hline & Total & 517 & 38.44 & 10.669 & .469 & 37.51 & 39.36 & 7 & 56 \\
\hline
\end{tabular}

One-Way ANOVA (Mean ID score - Age Groups)

\begin{tabular}{|r|r|r|r|r|r|}
\hline & Sum of Squares & \multicolumn{1}{c|}{ df } & Mean Square & F & Sig. \\
\hline Between Groups & 1547.038 & 8 & 193.380 & 1.718 & .092 \\
Within Groups & 57184.041 & 508 & 112.567 & & \\
Total & 58731.079 & 516 & & & \\
\hline
\end{tabular}

\section{B2.4 Age * Fan ID Level Cross-tabulation}

\begin{tabular}{|c|c|c|c|c|c|c|c|}
\hline & \multicolumn{6}{|c|}{ Age * Fan ID Level Cross-tabulation } \\
\hline & & $\begin{array}{c}\text { very low } \\
\text { identification }\end{array}$ & $\begin{array}{c}\text { low } \\
\text { identification }\end{array}$ & $\begin{array}{c}\text { moderate } \\
\text { identification }\end{array}$ & $\begin{array}{c}\text { high } \\
\text { identification }\end{array}$ & $\begin{array}{c}\text { very high } \\
\text { identification }\end{array}$ & Total \\
\hline $\begin{array}{l}\leq \mathbf{2 0} \\
\text { years }\end{array}$ & $\begin{array}{l}\text { Count } \\
\text { in \% }\end{array}$ & $\begin{array}{c}19 \\
18.8 \%\end{array}$ & $\begin{array}{c}19 \\
18.8 \%\end{array}$ & $\begin{array}{c}19 \\
18.8 \%\end{array}$ & $\begin{array}{c}21 \\
20.8 \%\end{array}$ & $\begin{array}{c}23 \\
22.8 \%\end{array}$ & $\begin{array}{c}101 \\
100 \%\end{array}$ \\
\hline $\begin{array}{l}21-25 \\
\text { years }\end{array}$ & $\begin{array}{l}\text { Count } \\
\text { in } \%\end{array}$ & $\begin{array}{c}25 \\
24.0 \%\end{array}$ & $\begin{array}{c}23 \\
22.1 \%\end{array}$ & $\begin{array}{c}21 \\
20.2 \%\end{array}$ & $\begin{array}{c}19 \\
18.3 \%\end{array}$ & $\begin{array}{c}16 \\
15.4 \%\end{array}$ & $\begin{array}{c}104 \\
100 \%\end{array}$ \\
\hline $\begin{array}{l}26-30 \\
\text { years }\end{array}$ & $\begin{array}{l}\text { Count } \\
\text { in \% }\end{array}$ & $\begin{array}{c}17 \\
29.3 \%\end{array}$ & $\begin{array}{c}9 \\
15.5 \%\end{array}$ & $\begin{array}{c}14 \\
24.1 \%\end{array}$ & $\begin{array}{c}9 \\
15.5 \%\end{array}$ & $\begin{array}{c}9 \\
15.5 \%\end{array}$ & $\begin{array}{c}58 \\
100 \%\end{array}$ \\
\hline $\begin{array}{l}31-35 \\
\text { years }\end{array}$ & $\begin{array}{l}\text { Count } \\
\text { in } \%\end{array}$ & $\begin{array}{c}8 \\
15.1 \%\end{array}$ & $\begin{array}{c}11 \\
20.8 \%\end{array}$ & $\begin{array}{c}7 \\
13.2 \%\end{array}$ & $\begin{array}{c}13 \\
24.5 \%\end{array}$ & $\begin{array}{c}14 \\
26.4 \%\end{array}$ & $\begin{array}{c}53 \\
100 \%\end{array}$ \\
\hline $\begin{array}{l}36-40 \\
\text { years }\end{array}$ & $\begin{array}{l}\text { Count } \\
\text { in \% }\end{array}$ & $\begin{array}{c}8 \\
14.3 \%\end{array}$ & $\begin{array}{c}12 \\
21.4 \%\end{array}$ & $\begin{array}{c}11 \\
19.6 \%\end{array}$ & $\begin{array}{c}15 \\
26.8 \%\end{array}$ & $\begin{array}{c}10 \\
17.9 \%\end{array}$ & $\begin{array}{c}56 \\
100 \%\end{array}$ \\
\hline $\begin{array}{l}41-45 \\
\text { years }\end{array}$ & $\begin{array}{l}\text { Count } \\
\text { in \% }\end{array}$ & $\begin{array}{c}6 \\
14.3 \%\end{array}$ & $\begin{array}{c}9 \\
21.4 \%\end{array}$ & $\begin{array}{c}10 \\
23.8 \%\end{array}$ & $\begin{array}{c}6 \\
14.3 \%\end{array}$ & $\begin{array}{c}11 \\
26.2 \%\end{array}$ & $\begin{array}{c}42 \\
100 \%\end{array}$ \\
\hline $\begin{array}{l}46-50 \\
\text { years }\end{array}$ & $\begin{array}{l}\text { Count } \\
\text { in } \%\end{array}$ & $\begin{array}{c}7 \\
14.6 \%\end{array}$ & $\begin{array}{c}10 \\
20.8 \%\end{array}$ & $\begin{array}{c}10 \\
20.8 \%\end{array}$ & $\begin{array}{c}11 \\
22.9 \%\end{array}$ & $\begin{array}{c}10 \\
20.8 \%\end{array}$ & $\begin{array}{c}48 \\
100 \%\end{array}$ \\
\hline $\begin{array}{l}51-55 \\
\text { years }\end{array}$ & $\begin{array}{l}\text { Count } \\
\text { in } \%\end{array}$ & $\begin{array}{c}5 \\
15.2 \%\end{array}$ & $\begin{array}{c}4 \\
12.1 \%\end{array}$ & $\begin{array}{c}6 \\
18.2 \%\end{array}$ & $\begin{array}{c}12 \\
36.4 \%\end{array}$ & $\begin{array}{c}6 \\
18.2 \%\end{array}$ & $\begin{array}{c}33 \\
100 \%\end{array}$ \\
\hline $\begin{array}{l}\geq 56 \\
\text { years }\end{array}$ & $\begin{array}{l}\text { Count } \\
\text { in } \%\end{array}$ & $\begin{array}{c}1 \\
4.5 \%\end{array}$ & $\begin{array}{c}4 \\
18.2 \%\end{array}$ & $\begin{array}{c}7 \\
31.8 \%\end{array}$ & $\begin{array}{c}7 \\
31.8 \%\end{array}$ & $\begin{array}{c}3 \\
13.6 \%\end{array}$ & $\begin{array}{c}22 \\
100 \%\end{array}$ \\
\hline Total & $\begin{array}{l}\text { Count } \\
\text { in } \%\end{array}$ & $\begin{array}{c}96 \\
18.6 \%\end{array}$ & $\begin{array}{c}101 \\
19.5 \%\end{array}$ & $\begin{array}{c}105 \\
20.3 \%\end{array}$ & $\begin{array}{c}113 \\
21.9 \%\end{array}$ & $\begin{array}{c}102 \\
19.7 \%\end{array}$ & $\begin{array}{c}517 \\
100 \%\end{array}$ \\
\hline
\end{tabular}


Chi-Square Tests (Age - Fan ID Level)

\begin{tabular}{|r|r|r|r|}
\hline & \multicolumn{1}{|c|}{ Value } & df & Asymp. Sig. (2-sided) \\
\hline Pearson Chi-Square & $27.735 \mathrm{a}$ & 32 & .682 \\
Likelihood Ratio & 27.894 & 32 & .675 \\
Linear-by-Linear Association & 3.661 & 1 & .056 \\
N of Valid Cases & 517 & & \\
\hline
\end{tabular}

a. 5 cells $(11.1 \%)$ have expected count less than 5 . The minimum expected count is 4.09 .

\section{B2.5 Gender * Fan ID Level Cross-tabulation}

\begin{tabular}{|c|c|c|c|c|c|c|c|}
\hline \multicolumn{2}{|c|}{} & \multicolumn{6}{|c|}{ Gender * Fan ID Level Cross-tabulation } \\
\cline { 2 - 8 } \multicolumn{2}{|c|}{} & $\begin{array}{c}\text { very low } \\
\text { identification }\end{array}$ & $\begin{array}{c}\text { low } \\
\text { identification }\end{array}$ & $\begin{array}{c}\text { moderate } \\
\text { identification }\end{array}$ & $\begin{array}{c}\text { high } \\
\text { identification }\end{array}$ & $\begin{array}{c}\text { very high } \\
\text { identification }\end{array}$ & Total \\
\hline \multirow{2}{*}{ Male } & Count & 56 & 76 & 82 & 97 & 90 & 401 \\
& in $\%$ & $14.0 \%$ & $19.0 \%$ & $20.4 \%$ & $24.2 \%$ & $22.4 \%$ & $100 \%$ \\
\hline \multirow{2}{*}{ Female } & Count & 40 & 25 & 23 & 16 & 12 & 116 \\
& in $\%$ & $34.5 \%$ & $21.6 \%$ & $19.8 \%$ & $13.8 \%$ & $10.3 \%$ & $100 \%$ \\
\hline \multirow{2}{*}{ Total } & Count & 96 & 101 & 105 & 113 & 102 & 517 \\
& in $\%$ & $18.6 \%$ & $19.5 \%$ & $20.3 \%$ & $21.9 \%$ & $19.7 \%$ & $100 \%$ \\
\hline
\end{tabular}

Chi-Square Tests (Gender - Fan ID Level)

\begin{tabular}{|r|r|r|r|}
\hline & \multicolumn{1}{|c|}{ Value } & df & Asymp. Sig. (2-sided) \\
\hline Pearson Chi-Square & $31.851 \mathrm{a}$ & 4 & .000 \\
Likelihood Ratio & 30.581 & 4 & .000 \\
Linear-by-Linear Association & 28.274 & 1 & .000 \\
N of Valid Cases & 517 & & \\
\hline
\end{tabular}

a. 0 cells $(.0 \%)$ have expected count less than 5 . The minimum expected count is 21.54 .

B2.6 Marital Status * Fan ID Level Cross-tabulation

\begin{tabular}{|l|c|c|c|c|c|c|c|}
\hline \multicolumn{2}{|c|}{} & \multicolumn{7}{|c|}{ Marital Status * Fan ID Level Cross-tabulation } \\
\cline { 3 - 8 } \multicolumn{2}{|c|}{} & $\begin{array}{c}\text { very low } \\
\text { identification }\end{array}$ & $\begin{array}{c}\text { low } \\
\text { identification }\end{array}$ & $\begin{array}{c}\text { moderate } \\
\text { identification }\end{array}$ & $\begin{array}{c}\text { high } \\
\text { identification }\end{array}$ & $\begin{array}{c}\text { very high } \\
\text { identification }\end{array}$ & Total \\
\hline \multirow{2}{*}{ Single } & Count & 69 & 55 & 59 & 62 & 57 & 302 \\
& in \% & $22.8 \%$ & $18.2 \%$ & $19.5 \%$ & $20.5 \%$ & $18.9 \%$ & $100 \%$ \\
\hline \multirow{2}{*}{ Married } & Count & 26 & 41 & 43 & 47 & 41 & 198 \\
& in \% & $13.1 \%$ & $20.7 \%$ & $21.7 \%$ & $23.7 \%$ & $20.7 \%$ & $100 \%$ \\
\hline \multirow{2}{*}{ Divorced } & Count & 0 & 4 & 2 & 3 & 2 & 11 \\
& in \% & $.0 \%$ & $36.4 \%$ & $18.2 \%$ & $27.3 \%$ & $18.2 \%$ & $100 \%$ \\
\hline \multirow{2}{*}{ Widowed } & Count & 1 & 1 & 1 & 1 & 2 & 6 \\
& in \% & $16.7 \%$ & $16.7 \%$ & $16.7 \%$ & $16.7 \%$ & $33.3 \%$ & $100 \%$ \\
\hline \multirow{2}{*}{ Total } & Count & 96 & 101 & 105 & 113 & 102 & 517 \\
& in \% & $100.0 \%$ & $100.0 \%$ & $100.0 \%$ & $100.0 \%$ & $100.0 \%$ & $100 \%$ \\
\hline
\end{tabular}




\section{Chi-Square Tests (Marital Status - Fan ID Level)}

\begin{tabular}{|r|r|r|r|}
\hline & \multicolumn{1}{|c|}{ Value } & df & Asymp. Sig. (2-sided) \\
\hline Pearson Chi-Square & $12.130 \mathrm{a}$ & 12 & .435 \\
Likelihood Ratio & 13.904 & 12 & .307 \\
Linear-by-Linear Association & 3.761 & 1 & .052 \\
N of Valid Cases & 517 & & \\
\hline
\end{tabular}

a. 10 cells $(50.0 \%)$ have expected count less than 5 . The minimum expected count is 1.11 .

\section{B3 Fan Analysis}

\section{B3.1 Spectator Type * Fan ID Level Cross-tabulation}

\begin{tabular}{|c|c|c|c|c|c|c|c|}
\hline & \multicolumn{6}{|c|}{ Spectator Type * Fan ID Level Cross-tabulation } \\
\hline & & $\begin{array}{c}\text { very low } \\
\text { identification }\end{array}$ & $\begin{array}{c}\text { low } \\
\text { identification }\end{array}$ & $\begin{array}{c}\text { moderate } \\
\text { identification }\end{array}$ & $\begin{array}{c}\text { high } \\
\text { identification }\end{array}$ & $\begin{array}{c}\text { very high } \\
\text { identification }\end{array}$ & Total \\
\hline \multirow{3}{*}{$\begin{array}{l}\text { Season } \\
\text { Ticket } \\
\text { Holder }\end{array}$} & Count & 6 & 11 & 27 & 64 & 67 & 175 \\
\hline & $\%(\mathrm{ST}) *$ & $3.4 \%$ & $6.3 \%$ & $15.4 \%$ & $36.6 \%$ & $38.3 \%$ & $100 \%$ \\
\hline & $\%($ ID) $* *$ & $6.2 \%$ & $10.9 \%$ & $25.7 \%$ & $56.6 \%$ & $65.7 \%$ & $33.8 \%$ \\
\hline \multirow{3}{*}{$\begin{array}{l}\text { Regular } \\
\text { Visitor }\end{array}$} & Count & 7 & 36 & 34 & 28 & 17 & 122 \\
\hline & $\%(\mathrm{ST}) *$ & $5.7 \%$ & $29.5 \%$ & $27.9 \%$ & $23.0 \%$ & $13.9 \%$ & $100 \%$ \\
\hline & $\%($ ID) $* *$ & $7.3 \%$ & $35.6 \%$ & $32.4 \%$ & $24.8 \%$ & $16.7 \%$ & $23.6 \%$ \\
\hline \multirow{3}{*}{$\begin{array}{l}\text { Occasional } \\
\text { Visitor }\end{array}$} & Count & 70 & 49 & 39 & 18 & 16 & 192 \\
\hline & $\%(\mathrm{ST}) *$ & $36.5 \%$ & $25.5 \%$ & $20.3 \%$ & $9.4 \%$ & $8.3 \%$ & $100 \%$ \\
\hline & $\%($ ID) $* *$ & $72.9 \%$ & $48.5 \%$ & $37.1 \%$ & $15.9 \%$ & $15.7 \%$ & $37.1 \%$ \\
\hline \multirow{3}{*}{$\begin{array}{l}\text { Never } \\
\text { attended a } \\
\text { game }\end{array}$} & Count & 13 & 5 & 5 & 3 & 2 & 28 \\
\hline & $\%(\mathrm{ST}) *$ & $46.4 \%$ & $17.9 \%$ & $17.9 \%$ & $10.7 \%$ & $7.1 \%$ & $100 \%$ \\
\hline & $\%($ ID) $* *$ & $13.5 \%$ & $5.0 \%$ & $4.8 \%$ & $2.7 \%$ & $2.0 \%$ & $5.4 \%$ \\
\hline \multirow{3}{*}{ Total } & Count & 96 & 101 & 105 & 113 & 102 & 517 \\
\hline & $\%(\mathrm{ST}) *$ & $18.6 \%$ & $19.5 \%$ & $20.3 \%$ & $21.9 \%$ & $19.7 \%$ & $100 \%$ \\
\hline & $\%($ ID) $* *$ & $100.0 \%$ & $100.0 \%$ & $100.0 \%$ & $100.0 \%$ & $100.0 \%$ & $100 \%$ \\
\hline
\end{tabular}

$*$ in $\%$ within Spectator Type, $* *$ in \% within Fan ID Level

\section{B3.2 Mean ID Score by Spectator Type}

\begin{tabular}{|r|r|r|r|r|r|r|}
\hline Spectator Type & Mean ID Score & \multicolumn{1}{|c|}{ N } & Std. Deviation & Std. Error & Min & Max \\
\hline Season ticket holder & 45.62 & 175 & 6.561 & .496 & 25 & 56 \\
Regular visitor & 39.60 & 122 & 7.832 & .709 & 19 & 56 \\
Occasional visitor & 32.32 & 192 & 10.731 & .774 & 7 & 55 \\
Never attended a game & 30.36 & 28 & 11.580 & 2.188 & 8 & 52 \\
Total & 38.44 & 517 & 10.669 & .469 & 7 & 56 \\
\hline
\end{tabular}


One-Way ANOVA (Mean ID score - Spectator Type)

\begin{tabular}{|r|r|r|r|r|r|}
\hline & Sum of Squares & df & Mean Square & F & Sig. \\
\hline Between Groups & 18206.243 & 3 & 6068.748 & 76.824 & .000 \\
Within Groups & 40524.836 & 513 & 78.996 & & \\
Total & 58731.079 & 516 & & & \\
\hline
\end{tabular}

\section{B3.3 Fan Duration * Fan ID Level Cross-tabulation}

\begin{tabular}{|l|c|c|c|c|c|c|c|}
\hline \multirow{2}{*}{} & \multicolumn{7}{|c|}{ Fan Duration * Fan ID Level Cross-tabulation } \\
\cline { 3 - 8 } \multicolumn{2}{|c|}{} & $\begin{array}{c}\text { very low } \\
\text { identification }\end{array}$ & $\begin{array}{c}\text { low } \\
\text { identification }\end{array}$ & $\begin{array}{c}\text { moderate } \\
\text { identification }\end{array}$ & $\begin{array}{c}\text { high } \\
\text { identification }\end{array}$ & $\begin{array}{c}\text { very high } \\
\text { identification }\end{array}$ & Total \\
\hline \multirow{2}{*}{$\mathbf{2 0 0 7 / 2 0 0 8}$} & Count & 35 & 44 & 79 & 94 & 89 & 341 \\
& in $\%$ & $36.5 \%$ & $43.6 \%$ & $75.2 \%$ & $83.2 \%$ & $87.3 \%$ & $66.0 \%$ \\
\hline \multirow{2}{*}{$\mathbf{2 0 0 8 / 2 0 0 9}$} & Count & 21 & 30 & 16 & 16 & 9 & 92 \\
& in $\%$ & $21.9 \%$ & $29.7 \%$ & $15.2 \%$ & $14.2 \%$ & $8.8 \%$ & $17.8 \%$ \\
\hline \multirow{2}{*}{$\mathbf{2 0 0 9 / 2 0 1 0}$} & Count & 31 & 26 & 10 & 2 & 4 & 73 \\
& in $\%$ & $32.3 \%$ & $25.7 \%$ & $9.5 \%$ & $1.8 \%$ & $3.9 \%$ & $14.1 \%$ \\
\hline \multirow{2}{*}{$\mathbf{2 0 1 0 / 2 0 1 1}$} & Count & 9 & 1 & 0 & 1 & 0 & 11 \\
& in $\%$ & $9.4 \%$ & $1.0 \%$ & $.0 \%$ & $.9 \%$ & $.0 \%$ & $2.1 \%$ \\
\hline \multirow{2}{*}{ Total } & Count & 96 & 101 & 105 & 113 & 102 & 517 \\
& in $\%$ & $100.0 \%$ & $100.0 \%$ & $100.0 \%$ & $100.0 \%$ & $100.0 \%$ & $100 \%$ \\
\hline
\end{tabular}

Chi-Square Tests (Fan Duration - Fan ID Level)

\begin{tabular}{|r|r|r|r|}
\hline & \multicolumn{1}{|c|}{ Value } & df & Asymp. Sig. (2-sided) \\
\hline Pearson Chi-Square & $131.541 \mathrm{a}$ & 12 & .000 \\
Likelihood Ratio & 130.241 & 12 & .000 \\
Linear-by-Linear Association & 102.265 & 1 & .000 \\
N of Valid Cases & 517 & & \\
\hline
\end{tabular}

a. 5 cells $(25.0 \%)$ have expected count less than 5 . The minimum expected count is 2.04 .

\section{B3.4a Number of Attendances by Spectator Type}

\begin{tabular}{|r|r|r|r|}
\hline Spectator Type & \multicolumn{1}{|c|}{ Mean } & \multicolumn{1}{c|}{ N } & \multicolumn{1}{c|}{$\begin{array}{c}\text { Std. } \\
\text { Deviation }\end{array}$} \\
\hline Season ticket holder & 12.14 & 175 & 2.633 \\
Regular visitor & 7.92 & 122 & 3.292 \\
Occasional visitor & 2.45 & 192 & 1.855 \\
Never attended a game & .21 & 28 & .957 \\
Total & 6.90 & 517 & 5.055 \\
\hline
\end{tabular}




\section{B3.4b Number of Attendances by Fan ID Level}

\begin{tabular}{|r|r|r|r|r|r|r|}
\hline Fan ID Level & \multicolumn{1}{|c|}{$\mathbf{N}$} & Mean & Std. Deviation & Std. Error & Min & Max \\
\hline Very Low Identification & 96 & 2.57 & 3.178 & .324 & 0 & 14 \\
Low Identification & 101 & 5.09 & 3.842 & .382 & 0 & 14 \\
Moderate Identification & 105 & 6.52 & 4.399 & .429 & 0 & 14 \\
High Identification & 113 & 9.38 & 4.706 & .443 & 0 & 14 \\
Very High Identification & 112 & 10.39 & 4.638 & .459 & 0 & 14 \\
Total & 517 & 6.90 & 5.055 & .222 & 0 & 14 \\
\hline
\end{tabular}

One-Way ANOVA (Number of Attendances - Fan ID Level)

\begin{tabular}{|r|r|r|r|r|r|}
\hline & Sum of Squares & \multicolumn{1}{c|}{ df } & Mean Square & F & Sig. \\
\hline Between Groups & 4082.738 & 4 & 1020.684 & 57.422 & .000 \\
Within Groups & 9100.829 & 512 & 17.775 & & \\
Total & 13183.567 & 516 & & & \\
\hline
\end{tabular}

\section{B3.5 Preferred Spectator Medium * Fan ID Level Cross-tabulation}

\begin{tabular}{|c|c|c|c|c|c|c|c|}
\hline & & \multicolumn{6}{|c|}{ Preferred Spectator Medium * Fan ID Level Cross-tabulation } \\
\hline & & $\begin{array}{c}\text { very low } \\
\text { identification }\end{array}$ & $\begin{array}{c}\text { low } \\
\text { identification }\end{array}$ & $\begin{array}{c}\text { moderate } \\
\text { identification }\end{array}$ & $\begin{array}{c}\text { high } \\
\text { identification }\end{array}$ & $\begin{array}{c}\text { very high } \\
\text { identification }\end{array}$ & Total \\
\hline $\begin{array}{l}\text { Westpac } \\
\text { Stadium }\end{array}$ & $\begin{array}{l}\text { Count } \\
\text { in } \%\end{array}$ & $\begin{array}{c}56 \\
58.3 \%\end{array}$ & $\begin{array}{c}72 \\
71.3 \%\end{array}$ & $\begin{array}{c}82 \\
78.1 \%\end{array}$ & $\begin{array}{c}94 \\
83.2 \%\end{array}$ & $\begin{array}{c}92 \\
90.2 \%\end{array}$ & $\begin{array}{c}396 \\
76.6 \%\end{array}$ \\
\hline Television & $\begin{array}{l}\text { Count } \\
\text { in } \%\end{array}$ & $\begin{array}{c}29 \\
30.2 \%\end{array}$ & $\begin{array}{c}24 \\
23.8 \%\end{array}$ & $\begin{array}{c}13 \\
12.4 \%\end{array}$ & $\begin{array}{c}12 \\
10.6 \%\end{array}$ & $\begin{array}{c}4 \\
3.9 \% \\
\end{array}$ & $\begin{array}{c}82 \\
15.9 \%\end{array}$ \\
\hline Newspaper & $\begin{array}{l}\text { Count } \\
\text { in } \%\end{array}$ & $\begin{array}{c}3 \\
3.1 \% \\
\end{array}$ & $\begin{array}{c}2 \\
2.0 \% \\
\end{array}$ & $\begin{array}{c}3 \\
2.9 \% \\
\end{array}$ & $\begin{array}{c}1 \\
0.9 \%\end{array}$ & $\begin{array}{c}1 \\
1.0 \%\end{array}$ & $\begin{array}{c}10 \\
1.9 \% \\
\end{array}$ \\
\hline Internet & $\begin{array}{l}\text { Count } \\
\text { in } \%\end{array}$ & $\begin{array}{c}7 \\
7.3 \% \\
\end{array}$ & $\begin{array}{c}3 \\
3.0 \% \\
\end{array}$ & $\begin{array}{c}6 \\
5.7 \% \\
\end{array}$ & $\begin{array}{c}5 \\
4.4 \% \\
\end{array}$ & $\begin{array}{c}5 \\
4.9 \% \\
\end{array}$ & $\begin{array}{c}26 \\
5.0 \% \\
\end{array}$ \\
\hline Radio & $\begin{array}{l}\text { Count } \\
\text { in } \%\end{array}$ & $\begin{array}{c}1 \\
1.0 \%\end{array}$ & $\begin{array}{c}0 \\
.0 \% \\
\end{array}$ & $\begin{array}{c}1 \\
1.0 \%\end{array}$ & $\begin{array}{c}1 \\
.9 \% \\
\end{array}$ & $\begin{array}{c}0 \\
.0 \% \\
\end{array}$ & $\begin{array}{c}3 \\
.6 \% \\
\end{array}$ \\
\hline Total & $\begin{array}{l}\text { Count } \\
\text { in } \%\end{array}$ & $\begin{array}{c}96 \\
100.0 \%\end{array}$ & $\begin{array}{c}101 \\
100.0 \%\end{array}$ & $\begin{array}{c}105 \\
100.0 \%\end{array}$ & $\begin{array}{c}113 \\
100.0 \%\end{array}$ & $\begin{array}{c}102 \\
100.0 \%\end{array}$ & $\begin{array}{c}517 \\
100 \%\end{array}$ \\
\hline
\end{tabular}

Chi-Square Tests (Preferred Spectator Medium - Fan ID Level)

\begin{tabular}{|r|r|r|r|}
\hline & \multicolumn{1}{|c|}{ Value } & df & Asymp. Sig. (2-sided) \\
\hline Pearson Chi-Square & $42.311 \mathrm{a}$ & 16 & .000 \\
Likelihood Ratio & 44.882 & 16 & .000 \\
Linear-by-Linear Association & 12.757 & 1 & .000 \\
N of Valid Cases & 517 & & \\
\hline
\end{tabular}

a. 11 cells $(44.0 \%)$ have expected count less than 5 . The minimum expected count is .56 . 


\section{B3.6 Preferred Group Size * Fan ID Level Cross-tabulation}

\begin{tabular}{|c|c|c|c|c|c|c|c|}
\hline & \multicolumn{6}{|c|}{ Preferred Group Size * Fan ID Level Cross-tabulation } \\
\hline & & $\begin{array}{c}\text { very low } \\
\text { identification }\end{array}$ & $\begin{array}{c}\text { low } \\
\text { identification }\end{array}$ & $\begin{array}{c}\text { moderate } \\
\text { identification }\end{array}$ & $\begin{array}{c}\text { high } \\
\text { identification }\end{array}$ & $\begin{array}{c}\text { very high } \\
\text { identification }\end{array}$ & Total \\
\hline By myself & $\begin{array}{c}\text { Count } \\
\text { in } \%\end{array}$ & $\begin{array}{c}7 \\
7.3 \% \\
\end{array}$ & $\begin{array}{c}4 \\
4.0 \% \\
\end{array}$ & $\begin{array}{c}5 \\
4.8 \% \\
\end{array}$ & $\begin{array}{c}12 \\
10.6 \% \\
\end{array}$ & $\begin{array}{c}7 \\
6.9 \% \\
\end{array}$ & $\begin{array}{c}35 \\
6.8 \% \\
\end{array}$ \\
\hline $\begin{array}{l}\text { Group of } \\
2-3 \text { people }\end{array}$ & $\begin{array}{l}\text { Count } \\
\text { in } \%\end{array}$ & $\begin{array}{c}48 \\
50.0 \%\end{array}$ & $\begin{array}{c}45 \\
45.0 \%\end{array}$ & $\begin{array}{c}52 \\
49.5 \%\end{array}$ & $\begin{array}{c}49 \\
43.4 \%\end{array}$ & $\begin{array}{c}49 \\
48.0 \%\end{array}$ & $\begin{array}{c}243 \\
47.1 \%\end{array}$ \\
\hline $\begin{array}{l}\text { Group of } \\
\text { 4-6 people }\end{array}$ & $\begin{array}{c}\text { Count } \\
\text { in } \%\end{array}$ & $\begin{array}{c}32 \\
33.3 \% \\
\end{array}$ & $\begin{array}{c}42 \\
42.0 \% \\
\end{array}$ & $\begin{array}{c}41 \\
39.0 \% \\
\end{array}$ & $\begin{array}{c}41 \\
36.3 \% \\
\end{array}$ & $\begin{array}{c}34 \\
33.3 \% \\
\end{array}$ & $\begin{array}{c}190 \\
36.8 \% \\
\end{array}$ \\
\hline $\begin{array}{l}7 \text { people } \\
\text { or more }\end{array}$ & $\begin{array}{c}\text { Count } \\
\text { in } \%\end{array}$ & $\begin{array}{c}9 \\
9.4 \% \\
\end{array}$ & $\begin{array}{c}9 \\
9.0 \% \\
\end{array}$ & $\begin{array}{c}7 \\
6.7 \% \\
\end{array}$ & $\begin{array}{c}11 \\
9.7 \% \\
\end{array}$ & $\begin{array}{c}12 \\
11.8 \% \\
\end{array}$ & $\begin{array}{c}48 \\
9.3 \% \\
\end{array}$ \\
\hline Total & $\begin{array}{l}\text { Count } \\
\text { in } \%\end{array}$ & $\begin{array}{c}96 \\
100.0 \%\end{array}$ & $\begin{array}{c}100 \\
100.0 \%\end{array}$ & $\begin{array}{c}105 \\
100.0 \%\end{array}$ & $\begin{array}{c}113 \\
100.0 \%\end{array}$ & $\begin{array}{c}102 \\
100.0 \%\end{array}$ & $\begin{array}{c}516 \\
100 \%\end{array}$ \\
\hline
\end{tabular}

Chi-Square Tests (Preferred Group Size - Fan ID Level)

\begin{tabular}{|r|r|r|r|}
\hline & \multicolumn{1}{|c|}{ Value } & df & Asymp. Sig. (2-sided) \\
\hline Pearson Chi-Square & $8.029 \mathrm{a}$ & 12 & .783 \\
Likelihood Ratio & 7.964 & 12 & .788 \\
Linear-by-Linear Association & .002 & 1 & .961 \\
N of Valid Cases & 516 & & \\
\hline
\end{tabular}

a. 0 cells $(.0 \%)$ have expected count less than 5 . The minimum expected count is 6.51 .

\section{B3.7 Preferred Group Type * Fan ID Level Cross-tabulation}

\begin{tabular}{|l|c|c|c|c|c|c|c|}
\hline \multicolumn{2}{|c|}{} & \multicolumn{6}{|c|}{ Preferred Group Type * Fan ID Level Cross-tabulation } \\
\cline { 3 - 8 } \multicolumn{2}{|c|}{} & $\begin{array}{c}\text { very low } \\
\text { identification }\end{array}$ & $\begin{array}{c}\text { low } \\
\text { identification }\end{array}$ & $\begin{array}{c}\text { moderate } \\
\text { identification }\end{array}$ & $\begin{array}{c}\text { high } \\
\text { identification }\end{array}$ & $\begin{array}{c}\text { very high } \\
\text { identification }\end{array}$ & Total \\
\hline $\begin{array}{l}\text { Family } \\
\text { members }\end{array}$ & Count & 25 & 28 & 30 & 34 & 27 & 144 \\
\hline Friends & $27.8 \%$ & $28.3 \%$ & $29.7 \%$ & $33.0 \%$ & $28.4 \%$ & $29.5 \%$ \\
\hline $\begin{array}{l}\text { Colleagues / } \\
\text { co-workers }\end{array}$ & Count & 63 & 64 & 65 & 64 & 68 & 324 \\
\hline \multirow{2}{*}{ in $\%$} & $70.0 \%$ & $64.6 \%$ & $64.4 \%$ & $62.1 \%$ & $71.6 \%$ & $66.4 \%$ \\
\hline \multirow{2}{*}{ Tother } & Count & 1 & 5 & 5 & 3 & 0 & 14 \\
& in & $1.1 \%$ & $5.1 \%$ & $5.0 \%$ & $2.9 \%$ & $.0 \%$ & $2.9 \%$ \\
\hline
\end{tabular}

Chi-Square Tests (Preferred Group Type - Fan ID Level)

\begin{tabular}{|r|r|r|r|}
\hline & \multicolumn{1}{|c|}{ Value } & df & Asymp. Sig. (2-sided) \\
\hline Pearson Chi-Square & $10.577 \mathrm{a}$ & 12 & .565 \\
Likelihood Ratio & 14.025 & 12 & .299 \\
Linear-by-Linear Association & .720 & 1 & .396 \\
N of Valid Cases & 488 & & \\
\hline
\end{tabular}

a. 10 cells $(50.0 \%)$ have expected count less than 5 . The minimum expected count is 1.11 . 


\section{B3.8 Merchandise at Games * Fan ID Level Cross-tabulation}

\begin{tabular}{|l|c|c|c|c|c|c|c|}
\hline \multicolumn{2}{|c|}{} & \multicolumn{6}{|c|}{ Merchandise at Games * Fan ID Level Cross-tabulation } \\
\cline { 3 - 8 } \multicolumn{2}{|c|}{} & $\begin{array}{c}\text { very low } \\
\text { identification }\end{array}$ & $\begin{array}{c}\text { low } \\
\text { identification }\end{array}$ & $\begin{array}{c}\text { moderate } \\
\text { identification }\end{array}$ & $\begin{array}{c}\text { high } \\
\text { identification }\end{array}$ & $\begin{array}{c}\text { very high } \\
\text { identification }\end{array}$ & Total \\
\hline \multirow{2}{*}{ Always } & Count & 4 & 18 & 41 & 79 & 89 & 231 \\
& in \% & $4.2 \%$ & $17.8 \%$ & $39.0 \%$ & $69.9 \%$ & $87.3 \%$ & $44.7 \%$ \\
\hline \multirow{2}{*}{ Often } & Count & 6 & 15 & 9 & 10 & 5 & 45 \\
& in \% & $6.2 \%$ & $14.9 \%$ & $8.6 \%$ & $8.8 \%$ & $4.9 \%$ & $8.7 \%$ \\
\hline \multirow{2}{*}{ Sometimes } & Count & 5 & 13 & 13 & 15 & 6 & 52 \\
& in \% & $5.2 \%$ & $12.9 \%$ & $12.4 \%$ & $13.3 \%$ & $5.9 \%$ & $10.1 \%$ \\
\hline \multirow{2}{*}{ Rarely } & Count & 7 & 17 & 16 & 2 & 0 & 42 \\
& in \% & $7.3 \%$ & $16.8 \%$ & $15.2 \%$ & $1.8 \%$ & $.0 \%$ & $8.1 \%$ \\
\hline \multirow{2}{*}{ Never } & Count & 74 & 38 & 26 & 7 & 2 & 147 \\
& in \% & $77.1 \%$ & $37.6 \%$ & $24.8 \%$ & $6.2 \%$ & $2.0 \%$ & $28.4 \%$ \\
\hline \multirow{2}{*}{ Total } & Count & 96 & 101 & 105 & 113 & 102 & 517 \\
& in \% & $100.0 \%$ & $100.0 \%$ & $100.0 \%$ & $100.0 \%$ & $100.0 \%$ & $100 \%$ \\
\hline
\end{tabular}

Chi-Square Tests (Merchandise at Games - Fan ID Level)

\begin{tabular}{|r|r|r|r|}
\hline & \multicolumn{1}{|c|}{ Value } & df & Asymp. Sig. (2-sided) \\
\hline Pearson Chi-Square & $281.236 \mathrm{a}$ & 16 & .000 \\
Likelihood Ratio & 307.196 & 16 & .000 \\
Linear-by-Linear Association & 227.169 & 1 & .000 \\
N of Valid Cases & 517 & & \\
\hline
\end{tabular}

a. 0 cells $(.0 \%)$ have expected count less than 5 . The minimum expected count is 7.80 .

\section{B3.9 Merchandise outside of Games * Fan ID Level Cross-tabulation}

\begin{tabular}{|c|c|c|c|c|c|c|c|}
\hline & \multicolumn{6}{|c|}{ Merchandise outside of Games * Fan ID Level Cross-tabulation } \\
\hline & & $\begin{array}{c}\text { very low } \\
\text { identification }\end{array}$ & $\stackrel{\text { low }}{\text { identification }}$ & $\begin{array}{c}\text { moderate } \\
\text { identification }\end{array}$ & $\begin{array}{c}\text { high } \\
\text { identification }\end{array}$ & $\begin{array}{c}\text { very high } \\
\text { identification }\end{array}$ & Total \\
\hline Always & $\begin{array}{c}\text { Count } \\
\text { in } \%\end{array}$ & $\begin{array}{c}0 \\
.0 \%\end{array}$ & $\begin{array}{c}0 \\
.0 \%\end{array}$ & $\begin{array}{c}1 \\
1.0 \%\end{array}$ & $\begin{array}{c}3 \\
2.7 \%\end{array}$ & $\begin{array}{c}8 \\
7.8 \%\end{array}$ & $\begin{array}{c}12 \\
2.3 \%\end{array}$ \\
\hline Often & $\begin{array}{l}\text { Count } \\
\text { in } \%\end{array}$ & $\begin{array}{c}0 \\
.0 \%\end{array}$ & $\begin{array}{c}3 \\
3.0 \%\end{array}$ & $\begin{array}{c}18 \\
17.1 \%\end{array}$ & $\begin{array}{c}37 \\
32.7 \%\end{array}$ & $\begin{array}{c}52 \\
51.0 \%\end{array}$ & $\begin{array}{c}110 \\
21.3 \%\end{array}$ \\
\hline Sometimes & $\begin{array}{l}\text { Count } \\
\text { in } \%\end{array}$ & $\begin{array}{c}5 \\
5.2 \%\end{array}$ & $\begin{array}{c}15 \\
14.9 \%\end{array}$ & $\begin{array}{c}35 \\
33.3 \%\end{array}$ & $\begin{array}{c}40 \\
35.4 \%\end{array}$ & $\begin{array}{c}33 \\
32.4 \%\end{array}$ & $\begin{array}{c}128 \\
24.8 \%\end{array}$ \\
\hline Rarely & $\begin{array}{c}\text { Count } \\
\text { in } \%\end{array}$ & $\begin{array}{c}13 \\
13.5 \%\end{array}$ & $\begin{array}{c}26 \\
25.7 \%\end{array}$ & $\begin{array}{c}23 \\
21.9 \%\end{array}$ & $\begin{array}{c}22 \\
19.5 \%\end{array}$ & $\begin{array}{c}7 \\
6.9 \%\end{array}$ & $\begin{array}{c}91 \\
17.6 \%\end{array}$ \\
\hline Never & $\begin{array}{l}\text { Count } \\
\text { in } \%\end{array}$ & $\begin{array}{c}78 \\
81.2 \%\end{array}$ & $\begin{array}{c}57 \\
56.4 \%\end{array}$ & $\begin{array}{c}28 \\
26.7 \%\end{array}$ & $\begin{array}{c}11 \\
9.7 \%\end{array}$ & $\begin{array}{c}2 \\
2.0 \%\end{array}$ & $\begin{array}{c}176 \\
34.0 \%\end{array}$ \\
\hline Total & $\begin{array}{l}\text { Count } \\
\text { in } \%\end{array}$ & $\begin{array}{c}96 \\
100.0 \%\end{array}$ & $\begin{array}{c}101 \\
100.0 \%\end{array}$ & $\begin{array}{c}105 \\
100.0 \%\end{array}$ & $\begin{array}{c}113 \\
100.0 \%\end{array}$ & $\begin{array}{c}102 \\
100.0 \%\end{array}$ & $\begin{array}{c}517 \\
100 \%\end{array}$ \\
\hline
\end{tabular}


Chi-Square Tests (Merchandise at Games - Fan ID Level)

\begin{tabular}{|r|r|r|r|}
\hline & \multicolumn{1}{|c|}{ Value } & df & Asymp. Sig. (2-sided) \\
\hline Pearson Chi-Square & $277.384 \mathrm{a}$ & 16 & .000 \\
Likelihood Ratio & 312.812 & 16 & .000 \\
Linear-by-Linear Association & 242.483 & 1 & .000 \\
N of Valid Cases & 517 & & \\
\hline
\end{tabular}

a. 5 cells $(20.0 \%)$ have expected count less than 5 . The minimum expected count is 2.23 .

\section{B4 Identification Drivers}

\section{B4.1 Factor Analysis - Communalities}

\begin{tabular}{|l|r|r|l|l|r|r|}
\hline & Initial & Extraction & & & Initial & Extraction \\
\hline Involvement & .233 & .330 & & Coach & .526 & .618 \\
City & .217 & .413 & & Country & .223 & .201 \\
Success & .328 & .403 & & Enjoyment & .423 & .541 \\
Family & .305 & .367 & & Belonging & .458 & .513 \\
Team & .553 & .620 & & Players & .578 & .651 \\
Atmosphere & .451 & .493 & & Excitement & .454 & .468 \\
Escape & .331 & .391 & & Co-workers & .350 & .408 \\
Friends & .368 & .451 & & Stadium & .416 & .424 \\
\hline
\end{tabular}

Extraction Method: Principal Axis Factoring 
B4.2 Factor Analysis - Rotated Factor Matrix

\begin{tabular}{|c|c|c|c|}
\hline Variables & $\begin{array}{c}\text { D_FAC1 } \\
\text { Live Experience }\end{array}$ & $\begin{array}{c}\text { D_FAC2 } \\
\text { Admiration }\end{array}$ & $\begin{array}{c}\text { D_FAC3 } \\
\text { Social Network }\end{array}$ \\
\hline D11: Enjoyment & .678 & .206 & -.036 \\
\hline D12: Belonging & .628 & .291 & .211 \\
\hline D6: Atmosphere & .599 & .278 & .198 \\
\hline D14: Excitement & .502 & .446 & .095 \\
\hline D5: Team & .228 & .795 & .129 \\
\hline D13: Players & .347 & .666 & .251 \\
\hline D9: Coach & .243 & .656 & .253 \\
\hline D15: Co-workers & .090 & .162 & .613 \\
\hline D3: Success & .065 & .180 & .612 \\
\hline D4: Family & -.010 & .189 & .598 \\
\hline D8: Friends & .303 & -.014 & .561 \\
\hline D7: Escape & .497 & .099 & .290 \\
\hline D16: Stadium & .393 & .246 & .407 \\
\hline D2: City & .198 & .046 & .313 \\
\hline
\end{tabular}

(Extraction Method: Principal Axis Factoring, Rotation Method: Varimax with Kaiser Normalization, Rotation converged in 4 iterations)

\section{B4.3 Factor Analysis - Total Variance Explained}

\begin{tabular}{|c|c|c|c|c|c|c|c|c|c|}
\hline \multirow[t]{2}{*}{ Factor } & \multicolumn{3}{|c|}{ Initial Eigenvalues } & \multicolumn{3}{|c|}{$\begin{array}{l}\text { Extraction Sums of Squared } \\
\text { Loadings }\end{array}$} & \multicolumn{3}{|c|}{$\begin{array}{c}\text { Rotation Sums of Squared } \\
\text { Loadings }\end{array}$} \\
\hline & Total & $\begin{array}{c}\% \text { of } \\
\text { Variance }\end{array}$ & $\underset{\%}{\text { Cumulative }}$ & Total & $\begin{array}{c}\% \text { of } \\
\text { Variance }\end{array}$ & $\underset{\%}{\text { Cumulative }}$ & Total & $\begin{array}{c}\% \text { of } \\
\text { Variance }\end{array}$ & $\underset{\%}{\text { Cumulative }}$ \\
\hline 1 & 5.029 & 35.918 & 35.918 & 4.519 & 32.281 & 32.281 & 2.241 & 16.009 & 16.009 \\
\hline 2 & 1.677 & 11.980 & 47.898 & 1.111 & 7.938 & 40.219 & 2.077 & 14.837 & 30.847 \\
\hline 3 & 1.176 & 8.397 & 56.295 & .696 & 4.970 & 45.189 & 2.008 & 14.342 & 45.189 \\
\hline 4 & .996 & 7.118 & 63.413 & & & & & & \\
\hline 5 & .750 & 5.360 & 68.772 & & & & & & \\
\hline 6 & .700 & 4.997 & 73.769 & & & & & & \\
\hline 7 & .628 & 4.487 & 78.256 & & & & & & \\
\hline 8 & .594 & 4.246 & 82.501 & & & & & & \\
\hline 9 & .552 & 3.941 & 86.443 & & & & & & \\
\hline 10 & .466 & 3.332 & 89.774 & & & & & & \\
\hline 11 & .422 & 3.018 & 92.792 & & & & & & \\
\hline
\end{tabular}




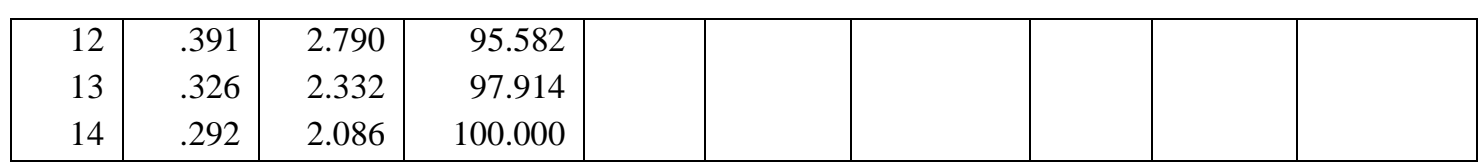

Extraction Method: Principal Axis Factoring

\section{B5 Relationship between Drivers and Fan ID}

\section{B5.1 Mean Relative Driver Scores by Fan ID Level}

\begin{tabular}{|c|c|c|c|c|c|c|}
\hline & & Mean & $\begin{array}{c}\text { Std. } \\
\text { Deviation }\end{array}$ & Std. Error & Min & Max \\
\hline \multirow[t]{6}{*}{ Involvement } & Very Low Identification & 1.42851 & .700710 & .071516 & .258 & 3.333 \\
\hline & Low Identification & 1.41760 & .449680 & .044745 & .229 & 2.743 \\
\hline & Moderate Identification & 1.47148 & .452256 & .044136 & .348 & 2.909 \\
\hline & High Identification & 1.42673 & .395433 & .037199 & .372 & 2.510 \\
\hline & Very High Identification & 1.50906 & .414382 & .041030 & .552 & 2.909 \\
\hline & Total & 1.45061 & .489441 & .021526 & .229 & 3.333 \\
\hline \multirow[t]{6}{*}{ City } & Very Low Identification & 1.47032 & 645949 & .065927 & .232 & 3.556 \\
\hline & Low Identification & 1.34750 & .394450 & .039249 & .291 & 2.246 \\
\hline & Moderate Identification & 1.27596 & .393764 & .038427 & .302 & 2.207 \\
\hline & High Identification & 1.15669 & .413165 & .038867 & .203 & 2.510 \\
\hline & Very High Identification & 1.19925 & .495885 & .049100 & .203 & 2.844 \\
\hline & Total & 1.28483 & .485425 & .021349 & .203 & 3.556 \\
\hline \multirow[t]{6}{*}{ Success } & Very Low Identification & 1.01016 & .514699 & .052531 & .246 & 2.759 \\
\hline & Low Identification & .97581 & .379512 & .037763 & .176 & 2.286 \\
\hline & Moderate Identification & .87971 & .344223 & .033593 & .219 & 1.818 \\
\hline & High Identification & .76957 & .369984 & .034805 & .180 & 1.600 \\
\hline & Very High Identification & .65154 & .387362 & .038355 & .163 & 1.939 \\
\hline & Total & .85362 & .420582 & .018497 & .163 & 2.759 \\
\hline \multirow[t]{6}{*}{ Family } & Very Low Identification & .61474 & .443941 & .045310 & .182 & 1.898 \\
\hline & Low Identification & .61788 & .398871 & .039689 & .176 & 1.818 \\
\hline & Moderate Identification & .58253 & .382701 & .037348 & .160 & 1.647 \\
\hline & High Identification & .44681 & .349006 & .032832 & .144 & 1.371 \\
\hline & Very High Identification & .46873 & .322920 & .031974 & .142 & 1.347 \\
\hline & Total & .54330 & .385974 & .016975 & .142 & 1.898 \\
\hline \multirow[t]{6}{*}{ Team } & Very Low Identification & .86516 & .440029 & .044910 & .222 & 2.545 \\
\hline & Low Identification & .95005 & .336513 & .033484 & .195 & 2.043 \\
\hline & Moderate Identification & 1.08456 & .358169 & .034954 & .203 & 2.510 \\
\hline & High Identification & 1.16957 & .326281 & .030694 & .276 & 2.286 \\
\hline & Very High Identification & 1.19961 & .411834 & .040778 & .205 & 2.909 \\
\hline & Total & 1.05882 & .394700 & .017359 & .195 & 2.909 \\
\hline
\end{tabular}




\begin{tabular}{|c|c|c|c|c|c|c|}
\hline \multirow[t]{6}{*}{ Atmosphere } & Very Low Identification & 1.26035 & .663054 & .067673 & .250 & 3.459 \\
\hline & Low Identification & 1.23643 & .324860 & .032325 & .281 & 2.000 \\
\hline & Moderate Identification & 1.18879 & .341083 & .033286 & .250 & 1.931 \\
\hline & High Identification & 1.25518 & .307036 & .028884 & .271 & 2.036 \\
\hline & Very High Identification & 1.29430 & .378169 & .037444 & .291 & 2.909 \\
\hline & Total & 1.24671 & .417729 & .018372 & .250 & 3.459 \\
\hline \multirow[t]{6}{*}{ Escape } & Very Low Identification & .81032 & .522857 & .053364 & .211 & 3.282 \\
\hline & Low Identification & .70338 & .369692 & .036786 & .193 & 1.829 \\
\hline & Moderate Identification & .72850 & .415272 & .040526 & .170 & 1.882 \\
\hline & High Identification & .85774 & .433080 & .040741 & .160 & 2.246 \\
\hline & Very High Identification & .77343 & .458026 & .045351 & .139 & 2.098 \\
\hline & Total & .77590 & .443311 & .019497 & .139 & 3.282 \\
\hline \multirow[t]{6}{*}{ Friends } & Very Low Identification & .92389 & .534633 & .054566 & .225 & 2.844 \\
\hline & Low Identification & .92180 & .402891 & .040089 & .208 & 2.036 \\
\hline & Moderate Identification & .78670 & .354168 & .034563 & .186 & 1.600 \\
\hline & High Identification & .70776 & .387574 & .036460 & .167 & 1.506 \\
\hline & Very High Identification & .65155 & .349591 & .034615 & .150 & 1.306 \\
\hline & Total & .79465 & .421753 & .018549 & .150 & 2.844 \\
\hline \multirow[t]{6}{*}{ Coach } & Very Low Identification & .61519 & .387032 & .039501 & .186 & 1.882 \\
\hline & Low Identification & .79664 & .347511 & .034579 & .195 & 2.043 \\
\hline & Moderate Identification & .84990 & .409299 & .039944 & .163 & 2.510 \\
\hline & High Identification & .94365 & .323742 & .030455 & .163 & 1.684 \\
\hline & Very High Identification & .91791 & .361811 & .035825 & .190 & 1.910 \\
\hline & Total & .82982 & .382569 & .016825 & .163 & 2.510 \\
\hline \multirow[t]{6}{*}{ Country } & Very Low Identification & 1.37105 & .659345 & .067294 & .195 & 3.556 \\
\hline & Low Identification & 1.26986 & .396584 & .039462 & .258 & 2.043 \\
\hline & Moderate Identification & 1.25454 & .448290 & .043749 & .225 & 2.510 \\
\hline & High Identification & 1.13104 & .460622 & .043332 & .155 & 2.510 \\
\hline & Very High Identification & 1.18332 & .521886 & .051674 & .203 & 2.909 \\
\hline & Total & 1.23813 & .506983 & .022297 & .155 & 3.556 \\
\hline \multirow[t]{6}{*}{ Enjoyment } & Very Low Identification & 1.47393 & .481646 & .049158 & .444 & 3.282 \\
\hline & Low Identification & 1.31475 & .319134 & .031755 & .281 & 2.286 \\
\hline & Moderate Identification & 1.30692 & .320000 & .031229 & .314 & 2.415 \\
\hline & High Identification & 1.34817 & .317084 & .029829 & .522 & 2.510 \\
\hline & Very High Identification & 1.37594 & .415009 & .041092 & .168 & 2.844 \\
\hline & Total & 1.36209 & .376945 & .016578 & .168 & 3.282 \\
\hline
\end{tabular}




\begin{tabular}{|c|c|c|c|c|c|c|}
\hline \multirow[t]{6}{*}{ Belonging } & Very Low Identification & .77176 & .427606 & .043642 & .222 & 2.196 \\
\hline & Low Identification & .85132 & .346906 & .034518 & .176 & 1.730 \\
\hline & Moderate Identification & .91722 & .326464 & .031860 & .225 & 1.778 \\
\hline & High Identification & 1.11255 & .359463 & .033815 & .176 & 2.000 \\
\hline & Very High Identification & 1.17197 & .426853 & .042265 & .172 & 2.327 \\
\hline & Total & .97029 & .406603 & .017882 & .172 & 2.327 \\
\hline \multirow[t]{6}{*}{ Players } & Very Low Identification & .68780 & .412512 & .042102 & .188 & 1.882 \\
\hline & Low Identification & .81848 & .310350 & .030881 & .195 & 1.684 \\
\hline & Moderate Identification & .89961 & .301283 & .029402 & .225 & 1.600 \\
\hline & High Identification & 1.03283 & .295090 & .027760 & .222 & 1.750 \\
\hline & Very High Identification & .98587 & .352448 & .034898 & .205 & 2.327 \\
\hline & Total & .89057 & .355550 & .015637 & .188 & 2.327 \\
\hline \multirow[t]{6}{*}{ Excitement } & Very Low Identification & 1.26316 & .455362 & .046475 & .271 & 2.612 \\
\hline & Low Identification & 1.29936 & .281642 & .028024 & .738 & 2.246 \\
\hline & Moderate Identification & 1.33235 & .345592 & .033726 & .471 & 2.510 \\
\hline & High Identification & 1.32027 & .283189 & .026640 & .271 & 2.510 \\
\hline & Very High Identification & 1.28498 & .362900 & .035932 & .211 & 2.246 \\
\hline & Total & 1.30107 & .348430 & .015324 & .211 & 2.612 \\
\hline \multirow[t]{6}{*}{ Co-workers } & Very Low Identification & .53183 & .341669 & .034871 & .195 & 1.702 \\
\hline & Low Identification & .55366 & .341461 & .033977 & .176 & 1.684 \\
\hline & Moderate Identification & .51241 & .309647 & .030218 & .147 & 1.352 \\
\hline & High Identification & .39190 & .257830 & .024255 & .148 & 1.273 \\
\hline & Very High Identification & .44379 & .283853 & .028106 & .148 & 1.196 \\
\hline & Total & .48420 & .311978 & .013721 & .147 & 1.702 \\
\hline \multirow[t]{6}{*}{ Stadium } & Very Low Identification & .90194 & .502889 & .051326 & .216 & 2.169 \\
\hline & Low Identification & .92583 & .422458 & .042036 & .198 & 2.000 \\
\hline & Moderate Identification & .92884 & .397811 & .038822 & .200 & 2.074 \\
\hline & High Identification & .92942 & .407588 & .038343 & .163 & 1.778 \\
\hline & Very High Identification & .88879 & .459677 & .045515 & .168 & 2.000 \\
\hline & Total & .91548 & .436735 & .019208 & .163 & 2.169 \\
\hline
\end{tabular}

\section{B5.2 Hypothesis Testing}

One-Way ANOVA (Relative Driver Score - Fan ID Level)

\begin{tabular}{|rr|r|r|r|r|r|}
\hline & & Sum of Squares & df & Mean Square & F & Sig. \\
\hline Involvement & Between Groups & .616 & 4 & .154 & .641 & .634 \\
& Within Groups & 122.993 & 512 & .240 & & \\
Total & 123.609 & 516 & & & \\
\hline \multirow{2}{*}{ City } & 6.311 & 4 & 1.578 & 7.007 & .000 \\
& Between Groups & 115.278 & 512 & .225 & & \\
Within Groups & 121.589 & 516 & & & \\
\hline
\end{tabular}


APPENDIX B: RESEARCH RESULTS

\begin{tabular}{|c|c|c|c|c|c|c|}
\hline Success & $\begin{array}{r}\text { Between Groups } \\
\text { Within Groups } \\
\text { Total }\end{array}$ & $\begin{array}{r}8.896 \\
82.379 \\
91.275 \\
\end{array}$ & $\begin{array}{r}4 \\
512 \\
516 \\
\end{array}$ & $\begin{array}{r}2.224 \\
.161\end{array}$ & 13.822 & .000 \\
\hline Family & $\begin{array}{r}\text { Between Groups } \\
\text { Within Groups } \\
\text { Total }\end{array}$ & $\begin{array}{r}2.833 \\
74.039 \\
76.871 \\
\end{array}$ & $\begin{array}{r}4 \\
512 \\
516 \\
\end{array}$ & $\begin{array}{l}.708 \\
.145\end{array}$ & 4.897 & .001 \\
\hline Team & $\begin{array}{r}\text { Between Groups } \\
\text { Within Groups } \\
\text { Total }\end{array}$ & $\begin{array}{r}8.273 \\
72.114 \\
80.387 \\
\end{array}$ & $\begin{array}{r}4 \\
512 \\
516 \\
\end{array}$ & $\begin{array}{r}2.068 \\
.141\end{array}$ & 14.684 & .000 \\
\hline Atmosphere & $\begin{array}{r}\text { Between Groups } \\
\text { Within Groups } \\
\text { Total }\end{array}$ & $\begin{array}{r}.620 \\
89.421 \\
90.041 \\
\end{array}$ & $\begin{array}{r}4 \\
512 \\
516 \\
\end{array}$ & $\begin{array}{l}.155 \\
.175\end{array}$ & .887 & .471 \\
\hline Escape & $\begin{array}{r}\text { Between Groups } \\
\text { Within Groups } \\
\text { Total } \\
\end{array}$ & $\begin{array}{r}1.638 \\
99.768 \\
101.407 \\
\end{array}$ & $\begin{array}{r}4 \\
512 \\
516 \\
\end{array}$ & $\begin{array}{l}.410 \\
.195\end{array}$ & 2.102 & .079 \\
\hline Friends & $\begin{array}{r}\text { Between Groups } \\
\text { Within Groups } \\
\text { Total } \\
\end{array}$ & $\begin{array}{r}6.185 \\
85.599 \\
91.784 \\
\end{array}$ & $\begin{array}{r}4 \\
512 \\
516 \\
\end{array}$ & $\begin{array}{r}1.546 \\
.167\end{array}$ & 9.248 & .000 \\
\hline Coach & $\begin{array}{r}\text { Between Groups } \\
\text { Within Groups } \\
\text { Total }\end{array}$ & $\begin{array}{r}6.832 \\
68.690 \\
75.521 \\
\end{array}$ & $\begin{array}{r}4 \\
512 \\
516 \\
\end{array}$ & $\begin{array}{r}1.708 \\
.134\end{array}$ & 12.730 & .000 \\
\hline Country & $\begin{array}{r}\text { Between Groups } \\
\text { Within Groups } \\
\text { Total }\end{array}$ & $\begin{array}{r}3.428 \\
129.200 \\
132.629 \\
\end{array}$ & $\begin{array}{r}4 \\
512 \\
516 \\
\end{array}$ & $\begin{array}{l}.857 \\
.252\end{array}$ & 3.396 & .009 \\
\hline Enjoyment & $\begin{array}{r}\text { Between Groups } \\
\text { Within Groups } \\
\text { Total }\end{array}$ & $\begin{array}{r}1.788 \\
71.529 \\
73.317 \\
\end{array}$ & $\begin{array}{r}4 \\
512 \\
516 \\
\end{array}$ & $\begin{array}{l}.447 \\
.140\end{array}$ & 3.200 & .013 \\
\hline Belonging & $\begin{array}{r}\text { Between Groups } \\
\text { Within Groups } \\
\text { Total }\end{array}$ & $\begin{array}{l}11.945 \\
73.363 \\
85.308 \\
\end{array}$ & $\begin{array}{r}4 \\
512 \\
516 \\
\end{array}$ & $\begin{array}{r}2.986 \\
.143\end{array}$ & 20.841 & .000 \\
\hline Players & $\begin{array}{r}\text { Between Groups } \\
\text { Within Groups } \\
\text { Total }\end{array}$ & $\begin{array}{r}7.694 \\
57.537 \\
65.231 \\
\end{array}$ & $\begin{array}{r}4 \\
512 \\
516 \\
\end{array}$ & $\begin{array}{r}1.923 \\
.112\end{array}$ & 17.116 & .000 \\
\hline Excitement & $\begin{array}{r}\text { Between Groups } \\
\text { Within Groups } \\
\text { Total }\end{array}$ & $\begin{array}{r}.309 \\
62.335 \\
62.644 \\
\end{array}$ & $\begin{array}{r}4 \\
512 \\
516 \\
\end{array}$ & $\begin{array}{l}.077 \\
.122\end{array}$ & .635 & .638 \\
\hline Co-workers & $\begin{array}{r}\text { Between Groups } \\
\text { Within Groups } \\
\text { Total }\end{array}$ & $\begin{array}{r}1.918 \\
48.304 \\
50.222\end{array}$ & $\begin{array}{r}4 \\
512 \\
516\end{array}$ & $\begin{array}{l}.479 \\
.094\end{array}$ & 5.082 & .001 \\
\hline
\end{tabular}




\begin{tabular}{|rr|r|r|r|r|r|}
\hline Stadium & Between Groups & .142 & 4 & .035 & .185 & .946 \\
Within Groups & 98.279 & 512 & .192 & \\
Total & 98.420 & 516 & & & \\
\hline
\end{tabular}

\section{B5.3 Pearson Correlation Analyses}

Correlations for Factor Live Experience

\begin{tabular}{|c|c|c|c|c|c|c|}
\hline & & $\begin{array}{c}\text { Fan ID } \\
\text { Score }\end{array}$ & Atmosphere & Belonging & Enjoyment & Excitement \\
\hline $\begin{array}{l}\text { Fan ID } \\
\text { Score }\end{array}$ & $\begin{array}{l}\text { Pearson Correlation } \\
\text { Sig. (2-tailed) } \\
\text { N }\end{array}$ & $\begin{array}{r}1 \\
517 \\
\end{array}$ & & & & \\
\hline Atmosphere & $\begin{array}{l}\text { Pearson Correlation } \\
\text { Sig. (2-tailed) } \\
\mathrm{N}\end{array}$ & $\begin{array}{r}.014 \\
.758 \\
517 \\
\end{array}$ & $\begin{array}{r}1 \\
517 \\
\end{array}$ & & & \\
\hline Belonging & $\begin{array}{l}\text { Pearson Correlation } \\
\text { Sig. (2-tailed) } \\
\mathrm{N}\end{array}$ & $\begin{array}{r}.364 * * \\
.000 \\
517 \\
\end{array}$ & $\begin{array}{r}.147 * * \\
.001 \\
517 \\
\end{array}$ & $\begin{array}{r}1 \\
517 \\
\end{array}$ & & \\
\hline Enjoyment & $\begin{array}{l}\text { Pearson Correlation } \\
\text { Sig. (2-tailed) } \\
\mathrm{N}\end{array}$ & $\begin{array}{r}-.111^{*} \\
.011 \\
517 \\
\end{array}$ & $\begin{array}{r}.076 \\
.084 \\
517 \\
\end{array}$ & $\begin{array}{r}.020 \\
.655 \\
517 \\
\end{array}$ & $\begin{array}{r}1 \\
517 \\
\end{array}$ & \\
\hline Excitement & $\begin{array}{l}\text { Pearson Correlation } \\
\text { Sig. (2-tailed) } \\
\mathrm{N}\end{array}$ & $\begin{array}{r}.060 \\
.176 \\
517\end{array}$ & $\begin{array}{l}.050 \\
.260 \\
517\end{array}$ & $\begin{array}{r}.012 \\
.788 \\
517\end{array}$ & $\begin{array}{r}.302 * * \\
.000 \\
517\end{array}$ & $\begin{array}{r}1 \\
517\end{array}$ \\
\hline
\end{tabular}

**. Correlation is significant at the .01 level (2-tailed).

*. Correlation is significant at the .05 level (2-tailed). 
Correlations for Factor Admiration

\begin{tabular}{|c|c|c|c|c|c|}
\hline & & $\begin{array}{c}\text { Fan ID } \\
\text { Score }\end{array}$ & Team & Coach & Players \\
\hline $\begin{array}{l}\text { Fan ID } \\
\text { Score }\end{array}$ & $\begin{array}{l}\text { Pearson Correlation } \\
\text { Sig. (2-tailed) } \\
\mathrm{N}\end{array}$ & $\begin{array}{r}1 \\
517 \\
\end{array}$ & & & \\
\hline Team & $\begin{array}{l}\text { Pearson Correlation } \\
\text { Sig. (2-tailed) } \\
\mathrm{N}\end{array}$ & $\begin{array}{r}.338 * * \\
.000 \\
517\end{array}$ & 517 & & \\
\hline Coach & $\begin{array}{l}\text { Pearson Correlation } \\
\text { Sig. (2-tailed) } \\
\mathrm{N}\end{array}$ & $\begin{array}{r}.277 * * \\
.000 \\
517 \\
\end{array}$ & $\begin{array}{r}.308 * * \\
.000 \\
517 \\
\end{array}$ & 517 & \\
\hline Players & $\begin{array}{l}\text { Pearson Correlation } \\
\text { Sig. (2-tailed) } \\
\mathrm{N}\end{array}$ & $\begin{array}{r}.325^{* *} \\
.000 \\
517\end{array}$ & $\begin{array}{r}.212 * * \\
.000 \\
517\end{array}$ & $\begin{array}{r}.340 * * \\
.000 \\
517\end{array}$ & $\begin{array}{r}1 \\
517\end{array}$ \\
\hline
\end{tabular}

**. Correlation is significant at the .01 level (2-tailed).

Correlations for Factor Social Network

\begin{tabular}{|c|c|c|c|c|c|c|}
\hline & & $\begin{array}{c}\text { Fan ID } \\
\text { Score }\end{array}$ & Success & Family & Friends & Co-workers \\
\hline $\begin{array}{l}\text { Fan ID } \\
\text { Score }\end{array}$ & $\begin{array}{l}\text { Pearson Correlation } \\
\text { Sig. (2-tailed) } \\
\mathrm{N}\end{array}$ & $\begin{array}{r}1 \\
517 \\
\end{array}$ & & & & \\
\hline Success & $\begin{array}{l}\text { Pearson Correlation } \\
\text { Sig. (2-tailed) } \\
\mathrm{N}\end{array}$ & $\begin{array}{r}-.290 * * \\
.000 \\
517 \\
\end{array}$ & $\begin{array}{r}1 \\
517 \\
\end{array}$ & & & \\
\hline Family & $\begin{array}{l}\text { Pearson Correlation } \\
\text { Sig. (2-tailed) } \\
\mathrm{N}\end{array}$ & $\begin{array}{r}-.133 * * \\
.002 \\
517 \\
\end{array}$ & $\begin{array}{r}.282 * * \\
.000 \\
517 \\
\end{array}$ & 517 & & \\
\hline Friends & $\begin{array}{l}\text { Pearson Correlation } \\
\text { Sig. (2-tailed) } \\
\mathrm{N}\end{array}$ & $\begin{array}{r}-.273 * * \\
.000 \\
517 \\
\end{array}$ & $\begin{array}{r}.112 * \\
.011 \\
517 \\
\end{array}$ & $\begin{array}{r}.067 \\
.125 \\
517 \\
\end{array}$ & $\begin{array}{r}1 \\
517 \\
\end{array}$ & \\
\hline Co-workers & $\begin{array}{l}\text { Pearson Correlation } \\
\text { Sig. (2-tailed) } \\
\mathrm{N}\end{array}$ & $\begin{array}{r}-.145^{* *} \\
.001 \\
517\end{array}$ & $\begin{array}{r}.108 * \\
.014 \\
517\end{array}$ & $\begin{array}{r}.202 * * \\
.000 \\
517\end{array}$ & $\begin{array}{r}.235^{* *} \\
.000 \\
517\end{array}$ & $\begin{array}{r}1 \\
517\end{array}$ \\
\hline
\end{tabular}

**. Correlation is significant at the .01 level (2-tailed).

*. Correlation is significant at the .05 level (2-tailed). 
Correlations for Geographical Drivers

\begin{tabular}{|c|c|c|c|c|c|}
\hline & & $\begin{array}{c}\text { Fan ID } \\
\text { Score }\end{array}$ & Country & City & Stadium \\
\hline $\begin{array}{l}\text { Fan ID } \\
\text { Score }\end{array}$ & $\begin{array}{l}\text { Pearson Correlation } \\
\text { Sig. (2-tailed) } \\
\mathrm{N}\end{array}$ & $\begin{array}{r}1 \\
517 \\
\end{array}$ & & & \\
\hline Country & $\begin{array}{l}\text { Pearson Correlation } \\
\text { Sig. (2-tailed) } \\
\mathrm{N}\end{array}$ & $\begin{array}{r}-.160 * * \\
.000 \\
517 \\
\end{array}$ & $\begin{array}{r}1 \\
517 \\
\end{array}$ & & \\
\hline City & $\begin{array}{l}\text { Pearson Correlation } \\
\text { Sig. (2-tailed) } \\
\mathrm{N}\end{array}$ & $\begin{array}{r}-.211^{* *} \\
.000 \\
517\end{array}$ & $\begin{array}{r}-.026 \\
.556 \\
517\end{array}$ & $\begin{array}{r}1 \\
517\end{array}$ & \\
\hline Stadium & $\begin{array}{l}\text { Pearson Correlation } \\
\text { Sig. (2-tailed) } \\
\mathrm{N}\end{array}$ & $\begin{array}{r}.008 \\
.861 \\
517\end{array}$ & $\begin{array}{r}-.073 \\
.099 \\
517\end{array}$ & $\begin{array}{r}.070 \\
.111 \\
517\end{array}$ & 517 \\
\hline
\end{tabular}

**. Correlation is significant at the .01 level (2-tailed).

Correlations for Driver Involvement

\begin{tabular}{|l|l|r|r|}
\hline \multicolumn{2}{|l|}{} & $\begin{array}{r}\text { Fan ID } \\
\text { Score }\end{array}$ & Involvement \\
\hline $\begin{array}{l}\text { Fan ID } \\
\text { Score }\end{array}$ & Pearson Correlation & 1 & \\
& Sig. (2-tailed) & & \\
& $\mathrm{N}$ & 517 & \\
\hline Involvement & Pearson Correlation & .057 & 1 \\
& Sig. (2-tailed) & .193 & \\
& $\mathrm{~N}$ & 517 & 517 \\
\hline
\end{tabular}

Correlations for Driver Escape

\begin{tabular}{|l|l|r|r|}
\hline \multicolumn{2}{|l|}{} & $\begin{array}{r}\text { Fan ID } \\
\text { Score }\end{array}$ & Involvement \\
\hline Fan ID & Peare & 1 & \\
& Sig. (2-tailed) & & \\
& $\mathrm{N}$ & 517 & \\
\hline Involvement & Pearson Correlation & -.004 & \\
& Sig. (2-tailed) & .933 & \\
& $\mathrm{~N}$ & 517 & 517 \\
\hline
\end{tabular}




\section{B5.4 Spearman's Rank Correlation Analyses}

Rank Correlations for Factor Live Experience

\begin{tabular}{|c|c|c|c|c|c|c|}
\hline & & $\begin{array}{c}\text { Fan ID } \\
\text { Level }\end{array}$ & Atmosphere & Belonging & Enjoyment & Excitement \\
\hline $\begin{array}{l}\text { Fan ID } \\
\text { Level }\end{array}$ & $\begin{array}{l}\text { Correlation Coefficient } \\
\text { Sig. (2-tailed) } \\
\mathrm{N}\end{array}$ & $\begin{array}{r}1 \\
517 \\
\end{array}$ & & & & \\
\hline Atmosphere & $\begin{array}{l}\text { Correlation Coefficient } \\
\text { Sig. (2-tailed) } \\
\mathrm{N}\end{array}$ & $\begin{array}{r}.045 \\
.305 \\
517 \\
\end{array}$ & $\begin{array}{r}1 \\
517 \\
\end{array}$ & & & \\
\hline Belonging & $\begin{array}{l}\text { Correlation Coefficient } \\
\text { Sig. (2-tailed) } \\
\mathrm{N}\end{array}$ & $\begin{array}{r}.373 * * \\
.000 \\
517 \\
\end{array}$ & $\begin{array}{r}.172 * * \\
.000 \\
517 \\
\end{array}$ & $\begin{array}{r}1 \\
517 \\
\end{array}$ & & \\
\hline Enjoyment & $\begin{array}{l}\text { Correlation Coefficient } \\
\text { Sig. (2-tailed) } \\
\mathrm{N}\end{array}$ & $\begin{array}{r}-.037 \\
.401 \\
517 \\
\end{array}$ & $\begin{array}{r}.142 * * \\
.001 \\
517 \\
\end{array}$ & $\begin{array}{r}.017 \\
.695 \\
517 \\
\end{array}$ & $\begin{array}{r}1 \\
517 \\
\end{array}$ & \\
\hline Excitement & $\begin{array}{l}\text { Correlation Coefficient } \\
\text { Sig. (2-tailed) } \\
\mathrm{N}\end{array}$ & $\begin{array}{l}.012 \\
.778 \\
517\end{array}$ & $\begin{array}{r}.191 * * \\
.000 \\
517\end{array}$ & $\begin{array}{l}.014 \\
.744 \\
517\end{array}$ & $\begin{array}{r}.358 * * \\
.000 \\
517\end{array}$ & $\begin{array}{r}1 \\
517\end{array}$ \\
\hline
\end{tabular}

**. Correlation is significant at the .01 level (2-tailed).

Rank Correlations for Factor Admiration

\begin{tabular}{|c|c|c|c|c|c|}
\hline & & Fan ID Level & Team & Coach & Players \\
\hline $\begin{array}{l}\text { Fan ID } \\
\text { Level }\end{array}$ & $\begin{array}{l}\text { Correlation Coefficient } \\
\text { Sig. (2-tailed) } \\
\mathrm{N}\end{array}$ & 517 & & & \\
\hline Team & $\begin{array}{l}\text { Correlation Coefficient } \\
\text { Sig. (2-tailed) } \\
\mathrm{N}\end{array}$ & $\begin{array}{r}.329 * * \\
.000 \\
517 \\
\end{array}$ & 517 & & \\
\hline Coach & $\begin{array}{l}\text { Correlation Coefficient } \\
\text { Sig. (2-tailed) } \\
\mathrm{N}\end{array}$ & $\begin{array}{r}.288 * * \\
.000 \\
517 \\
\end{array}$ & $\begin{array}{r}.287 * * \\
.000 \\
517 \\
\end{array}$ & 517 & \\
\hline Players & $\begin{array}{l}\text { Correlation Coefficient } \\
\text { Sig. (2-tailed) } \\
\mathrm{N}\end{array}$ & $\begin{array}{r}.335^{* *} \\
.000 \\
517\end{array}$ & $\begin{array}{r}.262 * * \\
.000 \\
517\end{array}$ & $\begin{array}{r}.365 * * \\
.000 \\
517\end{array}$ & $\begin{array}{r}1 \\
517\end{array}$ \\
\hline
\end{tabular}

**. Correlation is significant at the .01 level (2-tailed). 
Rank Correlations for Factor Social Network

\begin{tabular}{|c|c|c|c|c|c|c|}
\hline & & Fan ID Level & Success & Family & Friends & Co-workers \\
\hline $\begin{array}{l}\text { Fan ID } \\
\text { Level }\end{array}$ & $\begin{array}{l}\text { Correlation Coefficient } \\
\text { Sig. (2-tailed) } \\
\text { N }\end{array}$ & 517 & & & & \\
\hline Success & $\begin{array}{l}\text { Correlation Coefficient } \\
\text { Sig. (2-tailed) } \\
\mathrm{N}\end{array}$ & $\begin{array}{r}-.286 * * \\
.000 \\
517 \\
\end{array}$ & $\begin{array}{r}1 \\
517 \\
\end{array}$ & & & \\
\hline Family & $\begin{array}{l}\text { Correlation Coefficient } \\
\text { Sig. (2-tailed) } \\
\mathrm{N}\end{array}$ & $\begin{array}{r}-.200 * * \\
.000 \\
517\end{array}$ & $\begin{array}{r}.266 * * \\
.000 \\
517\end{array}$ & 517 & & \\
\hline Friends & $\begin{array}{l}\text { Correlation Coefficient } \\
\text { Sig. (2-tailed) } \\
\mathrm{N}\end{array}$ & $\begin{array}{r}-.225 * * \\
.000 \\
517 \\
\end{array}$ & $\begin{array}{r}.149 * * \\
.001 \\
517 \\
\end{array}$ & $\begin{array}{r}.061 \\
.163 \\
517 \\
\end{array}$ & $\begin{array}{r}1 \\
517 \\
\end{array}$ & \\
\hline Co-workers & $\begin{array}{l}\text { Correlation Coefficient } \\
\text { Sig. (2-tailed) } \\
\mathrm{N}\end{array}$ & $\begin{array}{r}-.189 * * \\
.000 \\
517\end{array}$ & $\begin{array}{r}.131 * * \\
.003 \\
517\end{array}$ & $\begin{array}{r}.305^{* *} \\
.000 \\
517\end{array}$ & $\begin{array}{r}.210 * * \\
.000 \\
517\end{array}$ & $\begin{array}{r}1 \\
517\end{array}$ \\
\hline
\end{tabular}

**. Correlation is significant at the .01 level (2-tailed).

\section{Rank Correlations for Geographical Drivers}

\begin{tabular}{|c|c|c|c|c|c|}
\hline & & Fan ID Level & Country & City & Stadium \\
\hline $\begin{array}{l}\text { Fan ID } \\
\text { Level }\end{array}$ & $\begin{array}{l}\text { Correlation Coefficient } \\
\text { Sig. (2-tailed) } \\
\mathrm{N}\end{array}$ & $\begin{array}{r}1 \\
517 \\
\end{array}$ & & & \\
\hline Country & $\begin{array}{l}\text { Correlation Coefficient } \\
\text { Sig. (2-tailed) } \\
\text { N }\end{array}$ & $\begin{array}{r}-.155^{* *} \\
.000 \\
517 \\
\end{array}$ & 517 & & \\
\hline City & $\begin{array}{l}\text { Correlation Coefficient } \\
\text { Sig. (2-tailed) } \\
\mathrm{N}\end{array}$ & $\begin{array}{r}-.197 * * \\
.000 \\
517 \\
\end{array}$ & $\begin{array}{r}.010 \\
.825 \\
517 \\
\end{array}$ & 517 & \\
\hline Stadium & $\begin{array}{l}\text { Correlation Coefficient } \\
\text { Sig. (2-tailed) } \\
\mathrm{N}\end{array}$ & $\begin{array}{r}.008 \\
.857 \\
517\end{array}$ & $\begin{array}{r}-.078 \\
.075 \\
517\end{array}$ & $\begin{array}{r}.068 \\
.121 \\
517\end{array}$ & $\begin{array}{r}1 \\
517\end{array}$ \\
\hline
\end{tabular}

**. Correlation is significant at the .01 level (2-tailed). 
Rank Correlations for Driver Involvement

\begin{tabular}{|l|l|r|r|}
\hline \multicolumn{2}{|l|}{} & Fan ID Level & Involvement \\
\hline Fan ID & Correlation Coefficient & 1 & \\
& Sig. (2-tailed) & & \\
& $\mathrm{N}$ & 517 & \\
\hline \multirow{2}{*}{ Involvement } & Correlation Coefficient & .043 & 1 \\
& Sig. (2-tailed) & .329 & \\
& $\mathrm{~N}$ & 517 & 517 \\
\hline
\end{tabular}

Rank Correlations for Driver Escape

\begin{tabular}{|l|l|r|r|}
\hline \multicolumn{2}{|l|}{} & Fan ID Level & Escape \\
\hline $\begin{array}{l}\text { Fan ID } \\
\text { Level }\end{array}$ & Correlation Coefficient & 1 & \\
& Sig. (2-tailed) & & \\
& $\mathrm{N}$ & 517 & \\
\hline \multirow{2}{*}{ Escape } & Correlation Coefficient & .040 & 1 \\
& Sig. (2-tailed) & .362 & \\
& $\mathrm{~N}$ & 517 & 517 \\
\hline
\end{tabular}

\section{B5.5 Regression Analysis}

Model Summary for Driver Atmosphere

\begin{tabular}{|l|r|r|l|}
\hline $\mathrm{R}$ & R square & Adjusted R square & Std. Error of the Estimate \\
\hline $.014^{\mathrm{a}}$ & .000 & -.002 & 10.678 \\
\hline
\end{tabular}

a. Predictors: (Constant), Atmosphere

Coefficients $^{\mathrm{a}}$ for Driver Atmosphere

\begin{tabular}{|c|c|c|c|c|c|c|}
\hline & \multirow[b]{2}{*}{ Model } & \multicolumn{2}{|c|}{ Unstandardized Coefficients } & \multirow{2}{*}{$\begin{array}{c}\begin{array}{l}\text { Standardized } \\
\text { Coefficients }\end{array} \\
\text { Beta }\end{array}$} & \multirow[b]{2}{*}{$\mathrm{t}$} & \multirow[b]{2}{*}{ Sig. } \\
\hline & & B & Std. Error & & & \\
\hline \multirow[t]{2}{*}{1} & (Constant) & 38.003 & 1.479 & & 25.687 & .000 \\
\hline & Atmosphere & .347 & 1.125 & .014 & .308 & .758 \\
\hline
\end{tabular}

a. Dependent Variable: Fan ID Score

Model Summary for Driver Enjoyment

\begin{tabular}{|l|r|r|r|}
\hline R & R square & Adjusted R square & Std. Error of the Estimate \\
\hline $.111^{\mathrm{a}}$ & .012 & .010 & 10.613 \\
\hline
\end{tabular}

a. Predictors: (Constant), Enjoyment 
Coefficients $^{\text {a }}$ for Driver Enjoyment

\begin{tabular}{|c|c|c|c|c|c|c|}
\hline \multirow{2}{*}{\multicolumn{2}{|c|}{ Model }} & \multicolumn{2}{|c|}{ Unstandardized Coefficients } & \multirow{2}{*}{$\begin{array}{c}\begin{array}{l}\text { Standardized } \\
\text { Coefficients }\end{array} \\
\text { Beta }\end{array}$} & \multirow[b]{2}{*}{$t$} & \multirow[b]{2}{*}{ Sig. } \\
\hline & & $\mathrm{B}$ & Std. Error & & & \\
\hline \multirow[t]{2}{*}{1} & (Constant) & 42.722 & 1.752 & & 24.391 & .000 \\
\hline & Enjoyment & -3.147 & 1.239 & -.111 & -2.539 & .011 \\
\hline
\end{tabular}

a. Dependent Variable: Fan ID Score

Model Summary for Driver Excitement

\begin{tabular}{|l|l|r|l|}
\hline $\mathrm{R}$ & R square & Adjusted R square & Std. Error of the Estimate \\
\hline $.060^{\mathrm{a}}$ & .004 & .002 & 10.660 \\
\hline
\end{tabular}

a. Predictors: (Constant), Excitement

Coefficients $^{\text {a }}$ for Driver Excitement

\begin{tabular}{|c|c|c|c|c|c|c|}
\hline & \multirow[b]{2}{*}{ Model } & \multicolumn{2}{|c|}{ Unstandardized Coefficients } & \multirow{2}{*}{$\begin{array}{c}\text { Standardized } \\
\text { Coefficients }\end{array}$} & \multirow[b]{2}{*}{$\mathrm{t}$} & \multirow[b]{2}{*}{ Sig. } \\
\hline & & B & Std. Error & & & \\
\hline \multirow[t]{2}{*}{1} & (Constant) & 36.063 & 1.814 & & 19.880 & .000 \\
\hline & Excitement & 1.824 & 1.347 & .060 & 1.354 & .176 \\
\hline
\end{tabular}

a. Dependent Variable: Fan ID Score

Model Summary for Driver Belonging

\begin{tabular}{|l|r|r|l|}
\hline $\mathrm{R}$ & R square & Adjusted R square & Std. Error of the Estimate \\
\hline $.364^{\mathrm{a}}$ & .132 & .131 & 9.947 \\
\hline
\end{tabular}

a. Predictors: (Constant), Belonging

Coefficients ${ }^{\text {a }}$ for Driver Belonging

\begin{tabular}{|c|c|c|c|c|c|c|}
\hline & \multirow[b]{2}{*}{ Model } & \multicolumn{2}{|c|}{ Unstandardized Coefficients } & \multirow{2}{*}{$\begin{array}{c}\begin{array}{l}\text { Standardized } \\
\text { Coefficients }\end{array} \\
\text { Beta }\end{array}$} & \multirow[b]{2}{*}{$\mathrm{t}$} & \multirow[b]{2}{*}{ Sig. } \\
\hline & & B & Std. Error & & & \\
\hline \multirow[t]{2}{*}{1} & (Constant) & 29.172 & 1.133 & & 25.751 & .000 \\
\hline & Belonging & 9.547 & 1.077 & .364 & 8.865 & .000 \\
\hline
\end{tabular}

a. Dependent Variable: Fan ID Score 


\begin{tabular}{|l|r|r|r|}
\hline R & R square & Adjusted R square & Std. Error of the Estimate \\
\hline $.396^{\mathrm{a}}$ & .157 & .150 & 9.835 \\
\hline
\end{tabular}

a. Predictors: (Constant), Excitement, Belonging, Atmosphere, Enjoyment

Coefficients $^{\text {a }}$ for Factor Live Experience

\begin{tabular}{|c|c|c|c|c|c|c|}
\hline & & Unstandardize & Coefficients & Standardized & & \\
\hline & Model & B & Std. Error & Beta & $\mathrm{t}$ & Sig. \\
\hline 1 & (Constant) & 31.724 & 2.467 & & 12.860 & .000 \\
\hline & Belonging & 9.726 & 1.077 & .371 & 9.033 & .000 \\
\hline & Atmosphere & -.890 & 1.051 & -.035 & -.847 & .397 \\
\hline & Enjoyment & -4.142 & 1.207 & -.146 & -3.430 & .001 \\
\hline & Excitement & 3.094 & 1.304 & .101 & 2.373 & .018 \\
\hline
\end{tabular}

a. Dependent Variable: Fan ID Score

\section{Model Summary for Driver Team}

\begin{tabular}{|l|r|r|r|}
\hline $\mathrm{R}$ & R square & Adjusted R square & Std. Error of the Estimate \\
\hline $.338^{\mathrm{a}}$ & .114 & .112 & 10.052 \\
\hline
\end{tabular}

a. Predictors: (Constant), Team

Coefficients $^{\text {a }}$ for Driver Team

\begin{tabular}{|c|c|c|c|c|c|c|}
\hline & \multirow[b]{2}{*}{ Model } & \multicolumn{2}{|c|}{ Unstandardized Coefficients } & \multirow{2}{*}{$\begin{array}{c}\begin{array}{l}\text { Standardized } \\
\text { Coefficients }\end{array} \\
\text { Beta }\end{array}$} & \multirow[b]{2}{*}{$\mathrm{t}$} & \multirow[b]{2}{*}{ Sig. } \\
\hline & & B & Std. Error & & & \\
\hline \multirow[t]{2}{*}{1} & (Constant) & 28.774 & 1.267 & & 22.715 & .000 \\
\hline & Team & 9.125 & 1.121 & .338 & 8.139 & .000 \\
\hline
\end{tabular}

a. Dependent Variable: Fan ID Score

Model Summary for Driver Coach

\begin{tabular}{|l|r|r|r|}
\hline $\mathrm{R}$ & R square & Adjusted R square & Std. Error of the Estimate \\
\hline $.277^{\mathrm{a}}$ & .077 & .075 & 10.260 \\
\hline
\end{tabular}

a. Predictors: (Constant), Coach 


\begin{tabular}{|c|c|c|c|c|c|c|}
\hline & \multirow[b]{2}{*}{ Model } & \multicolumn{2}{|c|}{ Unstandardized Coefficients } & \multirow{2}{*}{$\begin{array}{c}\begin{array}{l}\text { Standardized } \\
\text { Coefficients }\end{array} \\
\text { Beta }\end{array}$} & \multirow[b]{2}{*}{$\mathrm{t}$} & \multirow[b]{2}{*}{ Sig. } \\
\hline & & B & Std. Error & & & \\
\hline \multirow[t]{2}{*}{1} & (Constant) & 32.020 & 1.079 & & 29.685 & .000 \\
\hline & Coach & 7.730 & 1.181 & .277 & 6.547 & .000 \\
\hline
\end{tabular}

a. Dependent Variable: Fan ID Score

\section{Model Summary for Driver Players}

\begin{tabular}{|l|r|r|r|}
\hline $\mathrm{R}$ & R square & Adjusted R square & Std. Error of the Estimate \\
\hline $.325^{\mathrm{a}}$ & .106 & .104 & 10.098 \\
\hline
\end{tabular}

a. Predictors: (Constant), Players

Coefficients $^{\text {a }}$ for Driver Players

\begin{tabular}{|c|c|c|c|c|c|c|}
\hline & & Unstandardize & Coefficients & Standardized & & \\
\hline & Model & B & Std. Error & Beta & $\mathrm{t}$ & Sig. \\
\hline 1 & (Constant) & 29.744 & 1.199 & & 24.811 & .000 \\
\hline & Players & 9.759 & 1.250 & .325 & 7.805 & .000 \\
\hline
\end{tabular}

a. Dependent Variable: Fan ID Score

Model Summary for Factor Admiration

\begin{tabular}{|l|r|r|r|}
\hline R & R square & Adjusted R square & Std. Error of the Estimate \\
\hline $.440^{\mathrm{a}}$ & .193 & .189 & 9.609 \\
\hline
\end{tabular}

a. Predictors: (Constant), Players, Team, Coach

Coefficients $^{\text {a }}$ for Factor Admiration

\begin{tabular}{|c|c|c|c|c|c|c|}
\hline & \multirow[b]{2}{*}{ Model } & \multicolumn{2}{|c|}{ Unstandardized Coefficients } & \multirow{2}{*}{$\begin{array}{c}\text { Standardized } \\
\text { Coefficients } \\
\text { Beta }\end{array}$} & \multirow[b]{2}{*}{$\mathrm{t}$} & \multirow[b]{2}{*}{ Sig. } \\
\hline & & $\mathrm{B}$ & Std. Error & & & \\
\hline \multirow[t]{4}{*}{1} & (Constant) & 22.276 & 1.517 & & 14.683 & .000 \\
\hline & Team & 6.789 & 1.135 & .251 & 5.982 & .000 \\
\hline & Coach & 3.383 & 1.217 & .121 & 2.781 & .006 \\
\hline & Players & 6.920 & 1.274 & .231 & 5.430 & .000 \\
\hline
\end{tabular}

a. Dependent Variable: Fan ID Score

\section{Model Summary for Driver Success}




\begin{tabular}{|l|r|r|l|}
\hline $\mathrm{R}$ & R square & Adjusted R square & Std. Error of the Estimate \\
\hline $.290^{\mathrm{a}}$ & .084 & .082 & 10.221 \\
\hline
\end{tabular}

a. Predictors: (Constant), Success

\section{Coefficients ${ }^{\mathrm{a}}$ for Driver Success}

\begin{tabular}{|c|c|c|c|c|c|c|}
\hline & \multirow[b]{2}{*}{ Model } & \multicolumn{2}{|c|}{ Unstandardized Coefficients } & \multirow{2}{*}{$\begin{array}{c}\begin{array}{l}\text { Standardized } \\
\text { Coefficients }\end{array} \\
\text { Beta }\end{array}$} & \multirow[b]{2}{*}{$\mathrm{t}$} & \multirow[b]{2}{*}{ Sig. } \\
\hline & & $\mathrm{B}$ & Std. Error & & & \\
\hline \multirow[t]{2}{*}{1} & (Constant) & 44.707 & 1.018 & & 43.921 & .000 \\
\hline & Success & -7.347 & 1.070 & -.290 & -6.867 & .000 \\
\hline
\end{tabular}

a. Dependent Variable: Fan ID Score

\section{Model Summary for Driver Family}

\begin{tabular}{|l|r|r|r|}
\hline $\mathrm{R}$ & R square & Adjusted R square & Std. Error of the Estimate \\
\hline $.133^{\mathrm{a}}$ & .018 & .016 & 10.584 \\
\hline
\end{tabular}

a. Predictors: (Constant), Family

Coefficients $^{\text {a }}$ for Driver Family

\begin{tabular}{|c|c|c|c|c|c|c|}
\hline & \multirow[b]{2}{*}{ Model } & \multicolumn{2}{|c|}{ Unstandardized Coefficients } & \multirow{2}{*}{$\begin{array}{c}\text { Standardized } \\
\text { Coefficients } \\
\text { Beta }\end{array}$} & \multirow[b]{2}{*}{$\mathrm{t}$} & \multirow[b]{2}{*}{ Sig. } \\
\hline & & B & Std. Error & & & \\
\hline \multirow[t]{2}{*}{1} & (Constant) & 40.429 & .804 & & 50.267 & .000 \\
\hline & Family & -3.670 & 1.207 & -.133 & -3.040 & .002 \\
\hline
\end{tabular}

a. Dependent Variable: Fan ID Score

Model Summary for Driver Friends

\begin{tabular}{|l|r|r|r|}
\hline $\mathrm{R}$ & \multicolumn{1}{|c|}{ R square } & Adjusted R square & Std. Error of the Estimate \\
\hline $.273^{\mathrm{a}}$ & .075 & .073 & 10.272 \\
\hline
\end{tabular}

a. Predictors: (Constant), Friends 


\begin{tabular}{|c|c|c|c|c|c|c|}
\hline & \multirow[b]{2}{*}{ Model } & \multicolumn{2}{|c|}{ Unstandardized Coefficients } & \multirow{2}{*}{$\begin{array}{c}\text { Standardized } \\
\text { Coefficients }\end{array}$} & \multirow[b]{2}{*}{$\mathrm{t}$} & \multirow[b]{2}{*}{ Sig. } \\
\hline & & B & Std. Error & & & \\
\hline \multirow[t]{2}{*}{1} & (Constant) & 43.932 & .964 & & 45.555 & .000 \\
\hline & Friends & -6.917 & 1.072 & -.273 & -6.451 & .000 \\
\hline
\end{tabular}

a. Dependent Variable: Fan ID Score

Model Summary for Driver Co-workers

\begin{tabular}{|l|r|r|r|}
\hline $\mathrm{R}$ & R square & Adjusted R square & Std. Error of the Estimate \\
\hline $.145^{\mathrm{a}}$ & .021 & .019 & 10.566 \\
\hline
\end{tabular}

a. Predictors: (Constant), Co-workers

Coefficients ${ }^{\text {a }}$ for Driver Co-workers

\begin{tabular}{|c|c|c|c|c|c|c|}
\hline & \multirow[b]{2}{*}{ Model } & \multicolumn{2}{|c|}{ Unstandardized Coefficients } & \multirow{2}{*}{$\begin{array}{l}\text { Standardized } \\
\text { Coefficients } \\
\text { Beta }\end{array}$} & \multirow[b]{2}{*}{$\mathrm{t}$} & \multirow[b]{2}{*}{ Sig. } \\
\hline & & B & Std. Error & & & \\
\hline \multirow[t]{2}{*}{1} & (Constant) & 40.840 & .859 & & 47.570 & .000 \\
\hline & Co-workers & -4.967 & 1.491 & -.145 & -3.331 & .001 \\
\hline
\end{tabular}

a. Dependent Variable: Fan ID Score

Model Summary for Factor Social Network

\begin{tabular}{|l|r|r|r|}
\hline R & R square & Adjusted R square & Std. Error of the Estimate \\
\hline $.384^{\mathrm{a}}$ & .148 & .141 & 9.888 \\
\hline
\end{tabular}

a. Predictors: (Constant), Co-workers, Success, Friends, Family

Coefficients $^{\text {a }}$ for Factor Social Network

\begin{tabular}{|c|c|c|c|c|c|c|}
\hline & \multirow[b]{2}{*}{ Model } & \multicolumn{2}{|c|}{ Unstandardized Coefficients } & \multirow{2}{*}{$\begin{array}{c}\begin{array}{l}\text { Standardized } \\
\text { Coefficients }\end{array} \\
\text { Beta }\end{array}$} & \multirow[b]{2}{*}{$\mathrm{t}$} & \multirow[b]{2}{*}{ Sig. } \\
\hline & & B & Std. Error & & & \\
\hline \multirow[t]{5}{*}{1} & (Constant) & 49.900 & 1.327 & & 37.608 & .000 \\
\hline & Success & -6.280 & 1.085 & -.248 & -5.789 & .000 \\
\hline & Family & -.989 & 1.195 & -.036 & -.827 & .408 \\
\hline & Friends & -5.812 & 1.066 & -.230 & -5.451 & .000 \\
\hline & Co-workers & -1.959 & 1.463 & -.057 & -1.339 & .181 \\
\hline
\end{tabular}

a. Dependent Variable: Fan ID Score 


\section{Model Summary for Driver Country}

\begin{tabular}{|l|r|r|l|}
\hline $\mathrm{R}$ & \multicolumn{1}{|l|}{ R square } & Adjusted R square & Std. Error of the Estimate \\
\hline $.160^{\mathrm{a}}$ & .026 & .024 & 10.542 \\
\hline
\end{tabular}

a. Predictors: (Constant), Country

\section{Coefficients $^{\mathrm{a}}$ for Driver Country}

\begin{tabular}{|c|c|c|c|c|c|c|}
\hline \multirow{2}{*}{\multicolumn{2}{|c|}{ Model }} & \multicolumn{2}{|c|}{ Unstandardized Coefficients } & \multirow{2}{*}{$\begin{array}{c}\begin{array}{l}\text { Standardized } \\
\text { Coefficients }\end{array} \\
\text { Beta }\end{array}$} & \multirow[b]{2}{*}{$\mathrm{t}$} & \multirow[b]{2}{*}{ Sig. } \\
\hline & & B & Std. Error & & & \\
\hline \multirow[t]{2}{*}{1} & (Constant) & 42.602 & 1.224 & & 34.792 & .000 \\
\hline & Country & -3.365 & .915 & -.160 & -3.677 & .000 \\
\hline
\end{tabular}

a. Dependent Variable: Fan ID Score

Model Summary for Driver City

\begin{tabular}{|l|r|r|r|}
\hline $\mathrm{R}$ & R square & Adjusted R square & Std. Error of the Estimate \\
\hline $.211^{\mathrm{a}}$ & .045 & .043 & 10.438 \\
\hline
\end{tabular}

a. Predictors: (Constant), City

\section{Coefficients $^{\mathrm{a}}$ for Driver City}

\begin{tabular}{|c|c|c|c|c|c|c|}
\hline & \multirow[b]{2}{*}{ Model } & \multicolumn{2}{|c|}{ Unstandardized Coefficients } & \multirow{2}{*}{$\begin{array}{c}\begin{array}{l}\text { Standardized } \\
\text { Coefficients }\end{array} \\
\text { Beta }\end{array}$} & \multirow[b]{2}{*}{$\mathrm{t}$} & \multirow[b]{2}{*}{ Sig. } \\
\hline & & B & Std. Error & & & \\
\hline \multirow[t]{2}{*}{1} & (Constant) & 44.400 & 1.300 & & 34.154 & .000 \\
\hline & City & -4.642 & .947 & -.211 & -4.904 & .000 \\
\hline
\end{tabular}

a. Dependent Variable: Fan ID Score

\section{Model Summary for Driver Stadium}

\begin{tabular}{|l|r|r|l|}
\hline $\mathrm{R}$ & R square & Adjusted R square & Std. Error of the Estimate \\
\hline $.008^{\mathrm{a}}$ & .000 & -.002 & 10.679 \\
\hline
\end{tabular}

a. Predictors: (Constant), Stadium

\section{Coefficients $^{\mathrm{a}}$ for Driver Stadium}




\begin{tabular}{|c|c|c|c|c|c|c|}
\hline & \multirow[b]{2}{*}{ Model } & \multicolumn{2}{|c|}{ Unstandardized Coefficients } & \multirow{2}{*}{$\begin{array}{c}\begin{array}{l}\text { Standardized } \\
\text { Coefficients }\end{array} \\
\text { Beta }\end{array}$} & \multirow[b]{2}{*}{$\mathrm{t}$} & \multirow[b]{2}{*}{ Sig. } \\
\hline & & B & Std. Error & & & \\
\hline \multirow[t]{2}{*}{1} & (Constant) & 38.262 & 1.092 & & 35.051 & .000 \\
\hline & Stadium & .189 & 1.076 & .008 & .175 & .861 \\
\hline
\end{tabular}

a. Dependent Variable: Fan ID Score

Model Summary for Geographical Drivers

\begin{tabular}{|l|r|r|r|}
\hline $\mathrm{R}$ & R square & Adjusted R square & Std. Error of the Estimate \\
\hline $.269^{\mathrm{a}}$ & .072 & .067 & 10.307 \\
\hline
\end{tabular}

a. Predictors: (Constant), Stadium, City, Country

\section{Coefficients $^{\mathrm{a}}$ for Geographical Drivers}

\begin{tabular}{|c|c|c|c|c|c|c|}
\hline & \multirow[b]{2}{*}{ Model } & \multicolumn{2}{|c|}{ Unstandardized Coefficients } & \multirow{2}{*}{$\begin{array}{c}\begin{array}{l}\text { Standardized } \\
\text { Coefficients }\end{array} \\
\text { Beta }\end{array}$} & \multirow[b]{2}{*}{$\mathrm{t}$} & \multirow[b]{2}{*}{ Sig. } \\
\hline & & B & Std. Error & & & \\
\hline \multirow[t]{4}{*}{1} & (Constant) & 48.589 & 1.963 & & 24.753 & .000 \\
\hline & Country & -3.467 & .898 & -.165 & -3.863 & .000 \\
\hline & City & -4.753 & .937 & -.216 & -5.071 & .000 \\
\hline & Stadium & .268 & 1.044 & .011 & .256 & .798 \\
\hline
\end{tabular}

a. Dependent Variable: Fan ID Score 